\title{
Cell-based therapy for hypoxic-ischemic injury in the preterm brain
}

Citation for published version (APA):

Jellema, R. K. (2014). Cell-based therapy for hypoxic-ischemic injury in the preterm brain. [Doctoral Thesis, Maastricht University]. Datawyse / Universitaire Pers Maastricht.

https://doi.org/10.26481/dis.20140923rj

Document status and date:

Published: 01/01/2014

DOI:

10.26481/dis.20140923rj

Document Version:

Publisher's PDF, also known as Version of record

\section{Please check the document version of this publication:}

- A submitted manuscript is the version of the article upon submission and before peer-review. There can be important differences between the submitted version and the official published version of record.

People interested in the research are advised to contact the author for the final version of the publication, or visit the DOI to the publisher's website.

- The final author version and the galley proof are versions of the publication after peer review.

- The final published version features the final layout of the paper including the volume, issue and page numbers.

Link to publication

\footnotetext{
General rights rights.

- You may freely distribute the URL identifying the publication in the public portal. please follow below link for the End User Agreement:

www.umlib.nl/taverne-license

Take down policy

If you believe that this document breaches copyright please contact us at:

repository@maastrichtuniversity.nl

providing details and we will investigate your claim.
}

Copyright and moral rights for the publications made accessible in the public portal are retained by the authors and/or other copyright owners and it is a condition of accessing publications that users recognise and abide by the legal requirements associated with these

- Users may download and print one copy of any publication from the public portal for the purpose of private study or research.

- You may not further distribute the material or use it for any profit-making activity or commercial gain

If the publication is distributed under the terms of Article $25 \mathrm{fa}$ of the Dutch Copyright Act, indicated by the "Taverne" license above, 

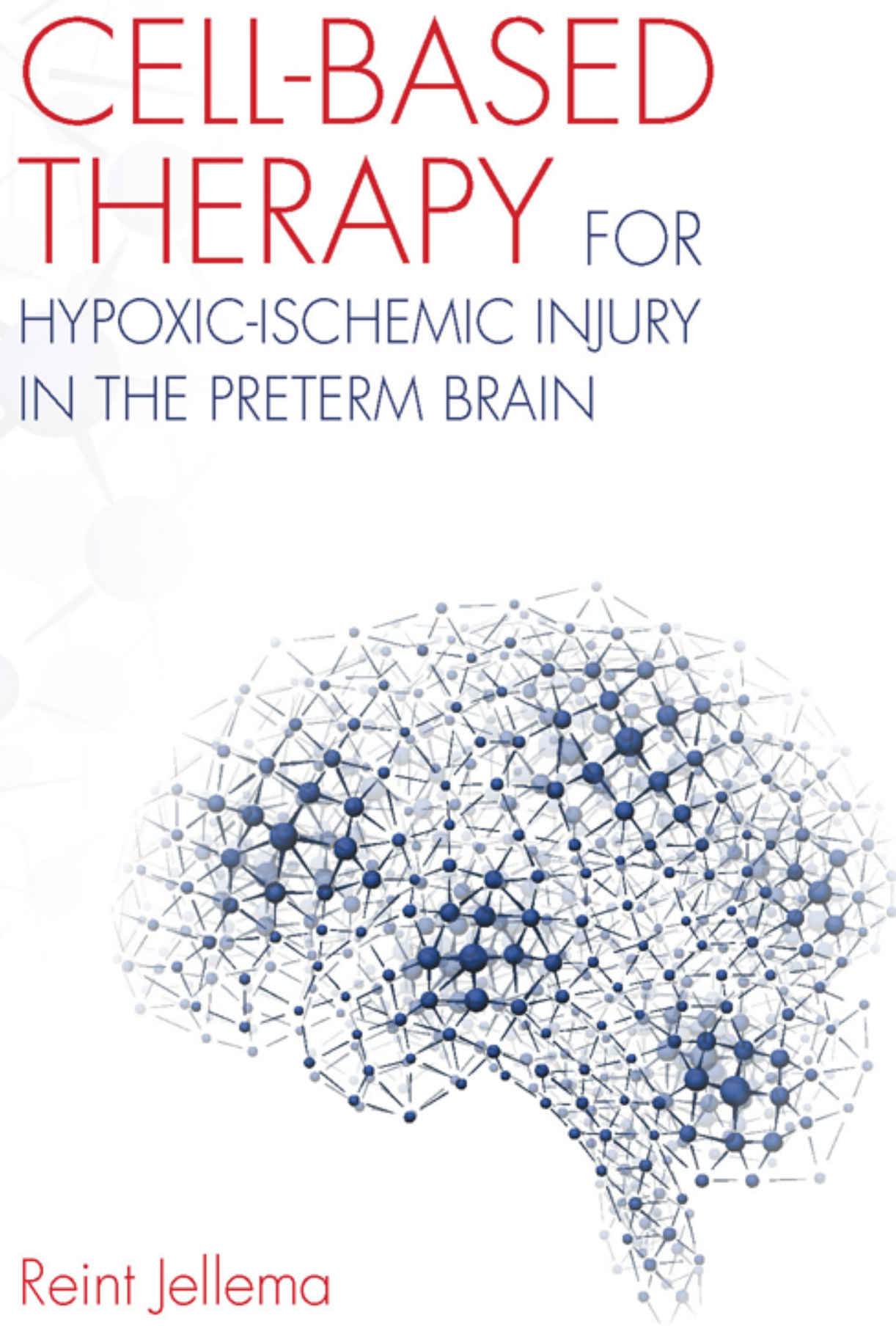
Copyright Reint K Jellema, Maastricht 2014

Production: Datawyse | Universitaire Pers Maastricht

ISBN 9789461593528 


\title{
Cell-based therapy for hypoxic-ischemic injury in the preterm brain
}

\author{
PROEFSCHRIFT \\ ter verkrijging van de graad van doctor aan de Universiteit Maastricht, \\ op gezag van de Rector Magnificus, Prof. dr. L.L.G. Soete \\ volgens het besluit van het College van Decanen, \\ in het openbaar te verdedigen \\ op dinsdag 23 september 2014 om 16.00 uur \\ door \\ Reint K Jellema \\ geboren op 4 mei 1981 te Boornbergum
}

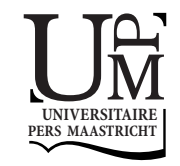




\section{Promotores}

Prof. dr. B.W.W. Kramer

Prof. dr. H.W. Steinbusch

\section{Copromotores}

Dr. W.T.V. Germeraad

Dr. P. Andriessen

\section{Beoordelingscommissie}

Prof. dr. L. J. Zimmermann (voorzitter)

Prof. dr. M. H. de Baets

Prof. dr. A. Franx, UMC Utrecht

Prof. dr. P. Gressens, Université Paris Diderot; King's College London

Prof. dr. F.C.S. Ramaekers 


\section{Contents}

$\begin{array}{lc}\text { Abbreviations } & 6\end{array}$

$\begin{array}{lll}\text { Chapter } 1 & \text { General introduction and aims } & 9\end{array}$

Chapter 2 Heart rate mediated blood pressure control in preterm fetal sheep $\quad 45$ under normal and hypoxic-ischemic conditions

Chapter 3 Cerebral inflammation and mobilization of the peripheral immune $\quad 61$ system following global hypoxic-ischemia in preterm sheep

Chapter 4 Mesenchymal stem cells induce T-cell tolerance and protect the preterm brain after global hypoxia-ischemia

Chapter 5 Systemic G-CSF attenuates cerebral inflammation and hypomyelination but does not reduce seizure burden in preterm sheep exposed to global hypoxia-ischemia

Chapter 6 General discussion

Chapter 7 Summary

Chapter 8 Nederlandse samenvatting (Summary in Dutch)

Valorization 173

Dankwoord (Acknowledgements)

Publications

Curriculum vitae 


\section{Abbreviations}

\begin{tabular}{|c|c|}
\hline 7-AAD & 7-Aminoactinomycin D \\
\hline aEEG & amplitude-integrated electroencephalogram \\
\hline AMPA/KA & a-Amino-3-hydroxy-5-methyl-4-isoxazolepropionic acid/ kainate \\
\hline ANOVA & analysis of variance \\
\hline BSA & bovine serum albumin \\
\hline$C D$ & cluster of differentiation \\
\hline CFSE & carboxyfluorescein succinimidyl ester \\
\hline $\mathrm{Cl}$ & confidence interval \\
\hline DAMPs & danger-associated molecular patterns \\
\hline DAPI & 4',6-diamidino-2-phenylindole \\
\hline DCs & dendritic cells \\
\hline DMSO & dimethylsulfoxide \\
\hline DNA & deoxyribonucleic acid \\
\hline DTI & diffusion tensor imaging \\
\hline ECG & electrocardiogram \\
\hline EEG & electroencephalogram \\
\hline EPCs & endothelial progenitor cells \\
\hline FA & fractional anisotropy \\
\hline FCS & fetal calf serum \\
\hline FDR & false discovery rate \\
\hline FHR & feta heart rate \\
\hline FIRS & fetal inflammatory response syndrome \\
\hline FISH & fluorescent in situ hybridization \\
\hline FITC & fluorescein isothiocyanate \\
\hline FOV & field of view \\
\hline FSC & forward scatter \\
\hline GA & gestational age \\
\hline G-CSF & granulocyte-colony stimulating factor \\
\hline $\mathrm{H} 2 \mathrm{O} 2$ & hydrogen peroxide \\
\hline HELLP & hemolysis, elevated liver enzymes, low platelets \\
\hline $\mathrm{HI}$ & hypoxia-ischemia \\
\hline HIE & hypoxic-ischemic encephalopathy \\
\hline HSCs & hematopoietic stem cells \\
\hline IBA-1 & ionized calcium binding adaptor molecule 1 \\
\hline$|\mathrm{B}|$ & interburst interval \\
\hline IL & interleukin \\
\hline IMDM & Iscove's modified Dulbecco's medium \\
\hline IQR & interquartile range \\
\hline IR & immunoreactivity \\
\hline
\end{tabular}




$\begin{array}{ll}\text { IUGR } & \text { intrauterine growth retardation } \\ \text { LF } & \text { low frequency } \\ \text { LMA } & \text { lower margin amplitude } \\ \text { log } & \text { natural logarithm } \\ \text { MABP } & \text { mean arterial blood pressure } \\ \text { MBP } & \text { myelin basic protein } \\ \text { MDSC } & \text { myeloid suppressor cells } \\ \text { MPAQ } & \text { Maastricht-programmable acquisition system } \\ \text { MPO } & \text { myeloperoxidase } \\ \text { MRI } & \text { magnetic resonance imaging } \\ \text { MSCs } & \text { mesenchymal stem cells } \\ \text { NEC } & \text { necrotizing enterocolitis } \\ \text { NICU } & \text { neonatal intensive care unit } \\ \text { NiDAB } & \text { nickel sulfate-diaminobenzidine } \\ \text { NK cells } & \text { natural killer cells } \\ \text { NMDA } & \text { n-methyl-d-aspartate } \\ \text { NPCs } & \text { neural progenitor cells } \\ \text { OL } & \text { oligodendrocyte } \\ \text { PAMPs } & \text { pathogen-associated molecular patterns } \\ \text { PBS } & \text { phosphate buffered saline } \\ \text { PCR } & \text { polymerase chain reaction } \\ \text { PE } & \text { r-phycoerythrin } \\ \text { PerCP } & \text { peridinin chlorophyll protein } \\ \text { PHA } & \text { phytohemagglutinin } \\ \text { PPROM } & \text { preterm premature rupture of membranes } \\ \text { pre-OL } & \text { pre-oligodendrocytes } \\ \text { PVE } & \text { periventricular echogenicity } \\ \text { PVL } & \text { periventricular leukomalacia } \\ \text { PVWM } & \text { periventricular white matter } \\ \text { RNA } & \text { ribonucleic acid } \\ \text { RNS } & \text { reactive nitrogen species } \\ \text { ROS } & \text { reactive oxygen species } \\ \text { RT } & \text { room temperature } \\ \text { SAL } & \text { saline } \\ \text { SBP } & \text { systolic blood pressure } \\ \text { SCF } & \text { stem cell factor } \\ \text { SCWM } & \text { subcortical white matter } \\ \text { standard deviation } \\ \text { tideward scatter } \\ \text { tris buffered saline } \\ \text { THe receptor }\end{array}$


regulatory $T$ cell

Tris tris(hydroxymethyl)aminomethane

UCO umbilical cord occlusion

UMA upper margin amplitude

VSI virtual slide imaging 
Chapter 1

General introduction and aims

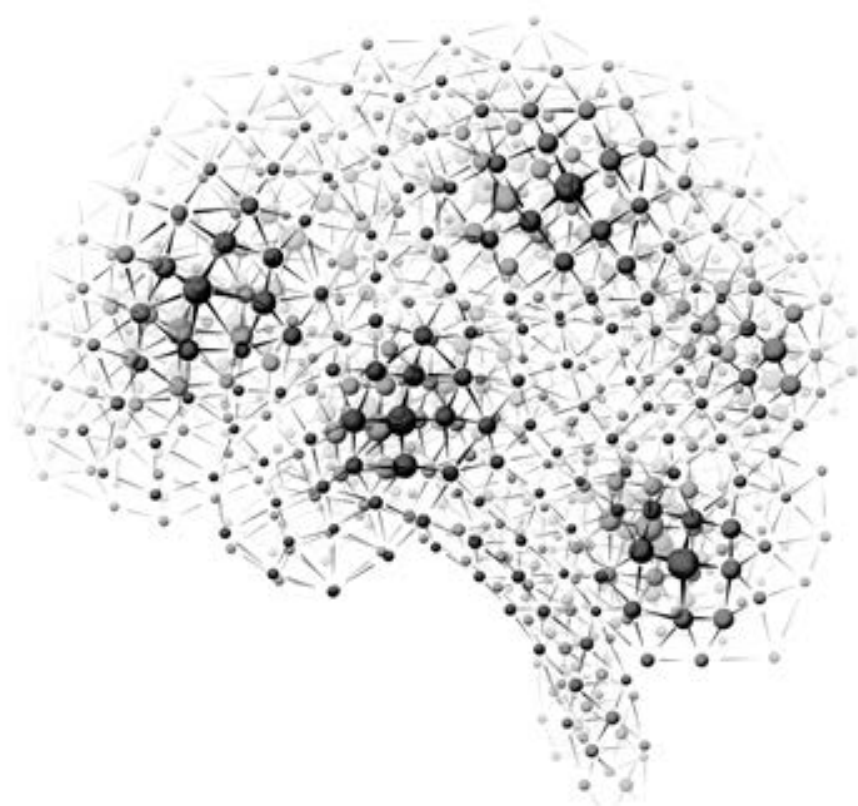




\section{Preterm birth}

\section{The magnitude of the problem}

Preterm birth, defined as birth before 37 weeks of gestation, is the leading cause of perinatal morbidity and mortality in developed countries [1]. Prematurity is the $10^{\text {th }}$ leading causes of death worldwide (Figure 1) [2]. Most deaths due to prematurity occur in low and lower-middle income countries [2]. In developed countries most preterm infants survive due to advancing clinical support, but preterm babies are at high risk of neurodevelopmental $[3,4]$, respiratory [5] and gastro-intestinal [6, 7] complications [8].

The second Peristat study, which reported perinatal data of 25 European countries in 2004 , showed that in the Netherlands $7,4 \%$ of all live born infants were born before 37 weeks of gestation and 1,1\% were born before 32 weeks of gestation [9-11]. These numbers were in accordance with the European average [10]. In 2004 approximately 182.000 infants were born in the Netherlands, meaning that a total of 13.500 preterm infants were born before 37 weeks of gestation and 2000 infants were born before 32 weeks of gestation. In the U.S. the number of preterm birth is higher; $12-13 \%$ of all live born infants in the U.S. are born prematurely [1]. Worldwide the number of preterm births is gradually increasing due to an increasing number of medically indicated preterm births and artificially conceived multiple pregnancies, which by itself is an important risk factor for preterm birth [1]. In contrast, in the Netherlands preterm birth rate has decreased from $8,0 \%$ in 2000 to $7.4 \%$ in 2007 [12]. This trend is largely explained by a reduction in multiple pregnancies [12].

Survival after preterm birth has sharply increased in the last decades [8]. This positive trend can be largely contributed to reduction of early pulmonary complications, which has been established by widespread use of antepartum corticosteroids, postpartum surfactant administration and the development of improved ventilation strategies $[5,8]$. Unfortunately, preterm birth is still associated with mortality and long-term morbidity, despite the mentioned improvements in perinatal care [8]. Obviously, mortality and morbidity are inversely related with gestational age. Survival rate at 24 weeks is less than $10 \%$, at 26 weeks survival rate increases to $45 \%$ and preterms born at 28 weeks of gestation have a chance to survive of $70 \%$ [9]. Congenital malformation, asphyxia, sepsis and necrotizing enterocolitis (NEC) are the most important causes of death associated with preterm birth $[8,9,13]$. Among survivors preterm birth is associated with long term morbidity and disability, which have a tremendous impact on patients and their families [8].

Given the magnitude of the problem of preterm birth, obviously such a large scale health care challenge also forms a tremendous economic burden on society. Recently, mean health care costs of initial hospitalization were calculated to be around $€ 55.000$ for preterm birth compared to $€ 1.500$ for term birth [14]. This would indicate that annual costs of preterm birth are around 700 million Euros in the Netherlands. In this 
estimation, the long term costs of increased morbidity are not taken into account. Preterm birth is thus a significant cause for mortality and morbidity on a societal scale [15].

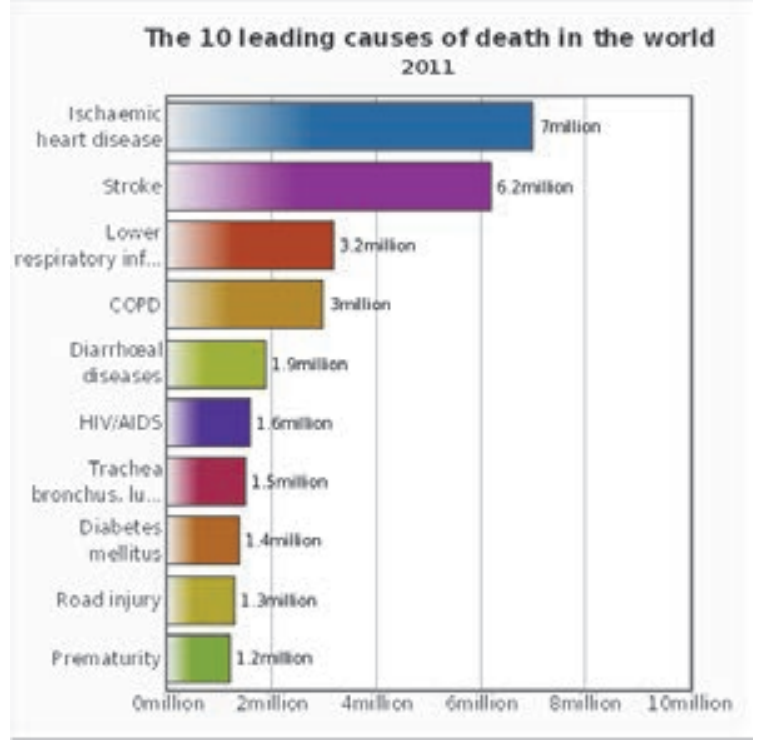

Figure 1. The 10 leading causes of death in the world in 2011. Prematurity is the 10th cause of death worldwide (data WHO, 2011).

\section{Causes of preterm birth}

The most important causes leading to preterm birth can be roughly divided in two major groups; fetal hypoxia-ischemia and intrauterine infection. Fetal hypoxia-ischemia can result from placental insufficiency caused by pre-eclampsia or HELLP (hemolysis, elevated liver enzymes, low platelets) syndrome, compromised umbilical cord flow caused by umbilical cord prolapse or compression or disturbed placental perfusion caused by abruptio placentae (placenta detachment) or twin-to-twin perfusion syndrome. These conditions result in compromised delivery of oxygen and nutrients to the fetus leading to intrauterine growth retardation (IUGR), chronic fetal compromise or acute fetal distress [1]. In this category preterm birth is usually the result from cesarean section on fetal and/or maternal indication [1].

Intrauterine infection is a frequent cause of preterm birth and can present as clinical chorioamnionitis with general maternal symptoms (fever, leukocytosis and raised Creactive protein) and local symptoms (uterine tenderness and vaginal discharge) $[1,13]$. Intrauterine infection, however, frequently occurs clinically silent and is diagnosed after birth as histological chorioamnionitis $[1,13]$. Chorioamnionitis initiates an inflammatory cascade characterized by secretion of pro-inflammatory cytokines, prostaglandins and 
extracellular matrix degrading proteins [16]. Prostaglandins can activate preterm uterine contractions, which often results in spontaneous preterm delivery [16]. Extracellular matrix degrading proteins damage the membranes leading to preterm premature rupture of membranes (PPROM), which may advance to spontaneous preterm delivery or overt clinical symptoms of infection and subsequent medically indicated cesarean section $[1,16,17]$.

\section{The immune system}

In this thesis the interplay between the hypoxic-ischemic brain and the developing peripheral immune system plays a prominent role. Therefore the function and development of the immune system in the perinatal period will be introduced here. The basics of the innate and the adaptive immune system will be introduced based on references: [18-21].

\section{The innate immune system}

The immune system is classically divided into the innate immune system and the adaptive immune system. The innate immune system is the first response mechanism in the face of danger. The most important effector cells of the innate immune system are NK cells, monocytes, tissue macrophages and granulocytes (e.g. neutrophils) [18-21]. Pathogen-associated molecular patterns (PAMPs) expressed by invading microorganisms are recognized by pattern recognition receptors (PPRs), such as Toll-like receptors (TLRs), which are expressed on the effector cells of the innate immune system, as well as on dendritic cells (DC). TLR signaling in DC and macrophages leads to activation of these cells. Activated DC and macrophages phagocytize invading microorganisms and initiate an inflammatory response characterized by secretion of pro-inflammatory cytokines. These cytokines activate expression of adhesion molecules on the vascular endothelium around the site of inflammation. The adhesion molecules facilitate diapedesis of neutrophils into the tissue. Neutrophils transmigrate towards the site of inflammation attracted by the concentration gradient of chemokines (chemotaxis). At the site of inflammation, neutrophils start cleaning up debris and micro-organisms by phagocytosis, thus further controlling tissue damage. Natural killer (NK) cells form another cell type of the innate immune system, which are predominantly involved in the recognition and killing of tumor cells and cells infected by viruses. The complement system consists of many proteins that enhance phagocytosis by opsonization. In addition, complement proteins are able to directly kill micro-organisms by lysis and act as chemo attractants to attract granulocytes. Dendritic cells form the bridge between the innate and adaptive immune system, by presenting antigen originating from the site of inflammation to T-lymphocytes, which reside in the peripheral lymphoid organs. 


\section{The adaptive immune system}

The adaptive immune system's effector cells are T and B lymphocytes. The response of the adaptive immune system is relatively slow (days to weeks), but very accurately targeted against a specific antigen (e.g. PAMPs associated with microorganisms). The specificity of the response is established after proliferation and differentiation of lymphocytes recognizing one antigen. Lymphocytes can be divided into B-lymphocytes and T-lymphocytes based on their antigen receptor.

The antigen receptors of B-lymphocytes consist of membrane-bound antibodies (immunoglobulins) which are capable of recognizing a variety of antigens (i.e. protein, lipid, carbohydrate, DNA). Upon recognition of a specific antigen, B-lymphocytes are activated and differentiate into immunoglobulin producing plasma cells that secrete large amounts of immunoglobulins with the same specificity for the antigen which was originally recognized. The immunoglobulins bind to their antigen (for example on a microorganism) thereby enhancing phagocytosis by granulocytes (opsonization). This type of B-lymphocyte immunity is called humoral (humoris; Latin for liquid) immunity, since the protective effect is mainly established by the immunoglobulins present in the serum. Humoral immunity is particularly involved in the recognition of extracellular micro-organisms.

Protection against intracellular pathogens (e.g. viruses) requires a different strategy, since antibodies do not penetrate the cell membrane. T-lymphocytes recognize their antigen with the T-cell receptor (TCR). However, the TCR does not directly recognize the intracellular antigen. Instead the TCR binds to small peptide fragments of antigen proteins which are presented on the cell membrane by the major histocompatibility complex (MHC), in humans called human leukocyte antigen (HLA). The HLA I molecule presents cytoplasmic peptides (e.g. derived from viruses) and can only be recognized by CD8 expressing cytotoxic T-lymphocytes. HLA II molecules present peptides derived from phagocytized proteins and can only be recognized by CD4 expressing helper T-lymphocytes. HLA I is expressed on all somatic cells except for erythrocytes and the gametes. HLA II is exclusively expressed by immune cells with antigen presenting function, such as dendritic cells, B-lymphocytes, macrophages and monocytes. Upon activation T-lymphocytes produce IL-2, which stimulates further proliferation of Tlymphocytes and differentiation into helper T-lymphocytes and cytotoxic Tlymphocytes.

Cytotoxic T-lymphocytes are capable of killing tumor cells or cells infected with viruses by secreting apoptosis-inducing proteins. Helper T-lymphocytes play a central role in orchestrating the immune response by the secretion of regulatory cytokines. Based on their cytokine profile, helper T-lymphocytes cells are further divided into Th1, Th2, Th17 and Treg cells. Th1 cells mainly produce IFN- $\gamma$, IL-2 and TNF- $\alpha$. Th1 cells are predominantly involved in activation of macrophages by IFN- - , stimulation of inflammatory processes by TNF- $\alpha$ and differentiation of cytotoxic T-lymphocytes. Th2 cells mainly produce IL-4, IL-5 and IL-13. IL-4 and IL-5 are important for humoral immunity by 
supporting plasma cells. During an inflammatory response to an antigen both Th1 and Th2 cytokines are produced. In the face of infection however, the balance is often disturbed (temporarily) towards a Th1 response. Persistent disturbance of the balance towards Th2 is seen in allergy. The Th1/Th2 balance is maintained by regulatory Tlymphocytes (Tregs), which play a pivotal role in determining the intensity and length of the inflammatory response. Th17 cells are a recently established suppopulation of Th cells, which mainly secrete IL-17 and IL-22 and are important for clearance of fungi and extracellular bacteria by attracting neutrophils and macrophages to the site of infection.

\section{Danger-associated molecular patterns}

Classically the immune system is activated after recognition of PAMPs by TLR signaling. This response is aimed at recognizing and neutralizing exogenous threats. Ratzinger and Seong first described the possibility of endogenous danger-associated molecular patterns (DAMPs) eliciting an immune response in a similar fashion [22]. Evidence has shown that endogenous molecules (i.e. self-antigens, such as intracellular proteins, DNA, RNA, nucleotides, heat shock proteins and extracellular matrix proteins) which are released during cell injury indeed activate APCs through TLR signaling. In other words, an inflammatory response is evoked without the presence of microorganisms. Hence this type of response is referred to as sterile inflammation. This concept adequately explains the marked activation of the immune system as observed after clinical and experimental stroke [23-31]. In this scenario local cerebral hypoxia-ischemia causes cell death and tissue injury, which elicits an immune response after the release of selfantigens (DAMPs) that are hidden to the immune system under normal conditions [26, 27].

\section{Peripheral immune organs}

During human fetal development, hematopoiesis starts at gestational week 3 when the first hematopoietic myeloid cells develop in the yolk sac [32]. Around gestational week 12 these hematopoietic cells migrate to the liver and spleen [32]. Until shortly before term birth, the liver is the predominant site of myeloid and lymphoid hematopoiesis [32]. Around gestational week, 16 hematopoietic cells start migrating to the bone marrow, which becomes the chief site of hematopoiesis at term birth [32]. Therefore, in preterm infants hematopoietic foci can still be seen in the liver and to a lesser extent in the spleen, lymph nodes and thymus [32]. At term birth and later in life all immune cells originate in the bone marrow. Here, pluripotent hematopoietic stem cells differentiate into lymphoid stem cells and myeloid stem cells. Lymphoid stem cells further differentiate into B-lymphocytes, NK cells and prothymocytes. The latter migrate to the thymus where they differentiate into T-lymphocytes. Myeloid stem cells further differentiate into granulocytes, monocytes/ macrophages, erythrocytes and thrombocytes. 


\section{The neonatal immune system - immature or competent?}

The fetal and neonatal immune system has long been perceived as defenseless and naïve. In the last two decennia however, mounting evidence has demonstrated that the developing immune system may be more competent as previously thought. Moreover, it has become more evident that the fetal and neonatal immune system is very well adapted to its task. The fetal immune system faces a challenge which is unique in life; avoiding an auto-immune response between mother and fetus, protecting the fetus from invading pathogens, and facilitating the transition of intra-uterine sterility to extra-uterine colonization by microorganisms [33]. The fetus has adapted to these challenges in various ways; evidence shows that the fetal immune system is markedly skewed towards production of Th2 polarizing cytokines, protecting the fetus against a harmful pro-inflammatory Th1 polarizing response, which is associated with alloimmune reactions and premature labor and preterm delivery [33]. Th2 polarization could be disadvantageous in the face of an infection and therefore the fetal environment (i.e. uterus, placenta, skin and amniotic fluid) is equipped with a range of antimicrobial substances, which protect the fetus against intra-uterine invasion of pathogens [33]. The (IL-6 mediated) acute phase response observed immediately after birth in addition plays a pivotal role in the clearance of invading pathogens during birth or initial colonization of the skin and the gut [33].

The fetal cellular immune system is immature in the sense that the number of immune cells gradually rises during gestation up to the first weeks to months in postnatal life $[33,34]$. Considering the innate immune system, the concentration of complement in the neonatal serum is much lower when compared to adult levels [33]. A relative lack of complement limits effective opsonization and instruction of the adaptive immune system [33]. Neonates, and especially preterm infants, have lower numbers of quiescent neutrophils, which in addition show functional impairment of adhesion, migration and microbicidal mechanisms when compared to adult neutrophils [33]. These functional defects may be enhanced by the tendency of APCs to predominantly produce IL-6, which inhibits neutrophil migration to sites of inflammation [33]. Fetal and neonatal monocytes and APCs express lower levels of MHC II molecules, which impairs their antigen-presenting function. Although TLR expression on monocytes in preterm infants is not substantially lower compared with adults, the functional consequence of TLR signaling in monocytes derived from preterm infants is reduced [33].

The adaptive immune system has long thought to be functionally immature [34]. This dogma changed in the mid 90's when multiple research groups showed that under certain circumstances the developing immune system is capable of mounting an adultlevel $\mathrm{T}$ cell response despite reduced numbers of T-lymphocytes and their functional immaturity [34]. As mentioned previously, the neonatal T-cell response is biased to the Th2-cell lineage, but evidence has shown that adult-level Th1 responses can be achieved in neonates depending on antigen load, distribution of fetal versus adult precursor cell derived T-lymphocytes and the local environment [34]. Similarly neonatal 
cytotoxic T-lymphocytes can develop mature function under specific circumstances [34]. On the other hand, neonatal B-lymphocyte antibody responses are impaired in terms of peak levels, time of onset, affinity and heterogeneity [34]. These impairments in fetal and neonatal humoral immunity are covered by maternal immunoglobulins which cross the placenta. Neonatal DC function however, as for neonatal Tlymphocytes, can reach adult levels depending on the appropriate environmental signals [34].

In conclusion, the fetal and neonatal immune system can be considered as being 'under construction' and will become more effective when time passes and maturation occurs. Still, the developing immune system has been very well adapted to the challenges it faces in the intra-uterine environment and during transition to the outside life. The fetus has found a way to deal with the exposure to a great number of exogenous and endogenous antigens during growth and development. In order to do so the fetal immune system is biased to an anti-inflammatory non-responsive state under normal conditions [33, 34] while supported by numerous microbicidal substances [33]. At the same time the fetal and neonatal immune system has the flexibility to mount an effective pro-inflammatory response when faced with high levels of danger [34] such as invasion of pathogens or tissue injury and cell death after hypoxia-ischemia.

\section{Hypoxic-ischemic encephalopathy}

Brain injury, or encephalopathy, is the biggest contributor to mortality and morbidity in preterm infants $[8,35]$. The magnitude of the problem of encephalopathy in preterm infants is illustrated by the fact that $25-50 \%$ of preterm infants suffer from cognitive, socialization, attentional and/or behavioral disorders [8, 35, 36]. Spastic motor deficits (i.e. cerebral palsy), which creates disability with a tremendous burden for patients and their environment, occur in $5-10 \%$ of preterm infants $[3,8,35,37,38]$.

\section{Causes of hypoxic-ischemic encephalopathy}

Encephalopathy of prematurity is caused by fetal, perinatal or postnatal cerebral hypoxia-ischemia and is therefore often referred to as hypoxic-ischemic encephalopathy (HIE) [35]. As discussed above, fetal hypoxia-ischemia with subsequent chronic fetal compromise or acute fetal distress can be caused by placental insufficiency or infection, which is often an indication for preterm delivery by cesarean section [1]. Perinatal hypoxia-ischemia here refers to hypoxic-ischemic insults that occur during delivery, usually referred to as perinatal asphyxia. Although perinatal asphyxia more frequently occurs in term infants (due to larger size of the baby with inherent risk of difficult passage through the birth canal), perinatal hypoxic-ischemic events do occur in preterm infants, but are frequently the result of pre-existing fetal compromise [39]. In addition, preterm infants are especially prone to postnatal cerebral hypoxia-ischemia due to the immature cerebral vasculature and cerebrovascular regulatory system which impede ade- 
quate adaptation to fluctuation in cerebral perfusion [36, 39]. Postnatal cerebral hypoxia-ischemia due to diminished cerebral perfusion can be additionally caused by infection, systemic hypotension, hypocapnia (hyperventilation) or steal of cerebral perfusion by a persistent ductus Botalli [39]. Furthermore, apneas that disturb oxygenation and cause subsequent cerebral hypoxia frequently occur in preterm infants [39]. The immature cerebral vasculature of the preterm brain is more prone to bleeding leading to germinal matrix hemorrhage and intraventricular hemorrhage, which is often associated with secondary periventricular hemorrhagic infarction and local cerebral ischemia [35].

\section{Normal myelination of the preterm brain}

During fetal development the immature brain starts to produce myelin, which serves as electric insulation of neurons thereby enhancing neuronal conductivity. Myelinated brain regions appear white in a fresh cut brain and are therefore referred to as white matter. Myelin is produced by oligodendrocytes. During gestation, oligodendrocytes develop from oligodendrocyte progenitors towards mature myelinating oligodendrocytes [40]. Each developmental stage of oligodendrocyte maturation is characterized by specific cellular morphology and antigen expression (Figure 2) [40], allowing histopathological estimation of normal and disturbed development according to gestational age [41-46].

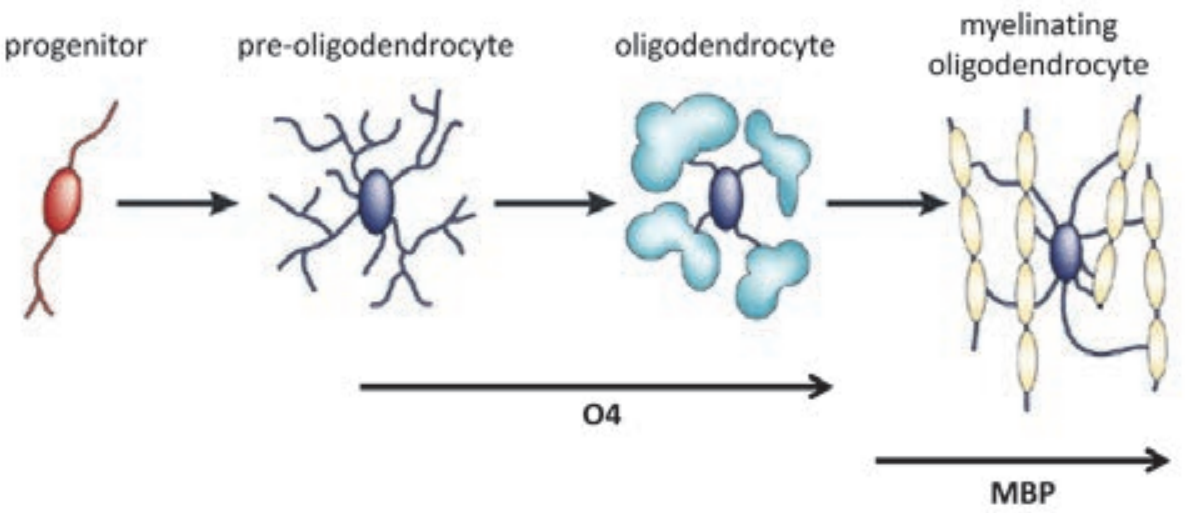

Figure 2. Phenotype and antigen (O4 and MBP) expression during different developmental stages of oligodendrocyte maturation. $M B P=$ myelin basic protein. (adapted from Zhang et al., Nature Reviews Neuroscience 2001 [40])

\section{White matter injury}

White matter injury is the clinical and histopathological hallmark of HIE in preterm infants [35, 36, 39]. However, recent work has shown that grey matter (i.e. neuronal/ 
axonal networks) is also importantly affected in the hypoxic-ischemic preterm brain $[35,47-52]$. Damage to subplate neurons after hypoxia-ischemia has been shown to play an important role in the etiology of neuronal injury in the preterm brain [53-56]. These subplate neurons are crucial for development and maturation of thalamocortical connectivity $[53,56]$. Therefore, injury to these regulatory neurons results in axonal and neuronal dysfunction $[35,54]$. White matter injury in the preterm brain is mainly characterized by periventricular leukomalacia (PVL), which occurs in $50 \%$ of preterm infants $[35,39]$. PVL is clinically diagnosed by routine ultrasound and is subdivided in non-cystic PVL (PVL grade 1) with diffuse periventricular echogenicity (PVE) persisting more than one week after birth and focal cystic PVL (PVL grade 2-4) with development of small (PVL grade 2) up to extensive (PVL grade 4) periventricular cysts. Focal cyst formation occurs when periventricular hypoxia-ischemia results in irreversible cell death forming necrotic lesions, which resolve over a period of several weeks into fluidfilled cavities [35, 36]. Diffuse non-cystic PVL is caused by injury to immature oligodendrocytes and astrogliosis after hypoxia-ischemia and is discussed in more detail below $[35,36]$ Timing of detection of PVL provides an indication of when the hypoxic-ischemic insult occurred. For example, cyst formation on ultrasound in the first week of life, suggests that cerebral hypoxia-ischemia already occurred during fetal life [39]. Germinal matrix hemorrhage or intraventricular hemorrhage with secondary venous periventricular hemorrhagic infarction occurs in $5 \%$ of preterm infants, with increasing incidence up to $20-30 \%$ in extreme preterm infants [35].

\section{Seizures}

Besides abnormalities on ultrasound, preterm infants with HIE may show early clinical symptoms ranging from hyperexcitability to hypotonia, stupor and absent primitive reflexes [39]. HIE in preterm infants often presents with clinical and electrophysiological seizures [39], which have been associated with adverse neurodevelopmental outcome [57-59]. Electroencephalogram (EEG) and camera registration are routinely used to detect seizure activity in preterm infants in the Neonatal Intensive Care Unit (NICU). However, continuous recording of a full EEG with 16 or 32 leads is troublesome in preterm infants, since the application of the electrodes and interpretation of the signals require expertise. Therefore, most NICU's are equipped with amplitude-integrated EEG (aEEG), which is recorded using only 4 leads. The amplitudes of the EEG signal are displayed in a time-compressed fashion, allowing easy detection of electrophysiological seizures. Electrographic seizure activity is usually seen in the aEEG as an abrupt rise in the lower margin amplitude (LMA) and a simultaneous rise in the upper margin amplitude (UMA), often followed by a short period of decreased amplitude [60]. The raw EEG simultaneously shows gradual build-up and decline in amplitude of repetitive sharpwaves [61]. Experimental evidence shows that EEG is a valuable tool to detect brain injury caused by cerebral inflammation [62]. 


\section{Pathophysiology of HIE}

Diffuse non-cystic PVL is predominantly caused by damage to oligodendrocytes. Oligodendrocyte progenitors are particularly vulnerable to hypoxic-ischemia and mediators of inflammation [36, 42]. Damage to oligodendrocyte progenitors causes degeneration and arrested maturation of these cells, which precludes differentiation into mature myelinating cells leading to hypomyelination of the developing brain $[43,46,63]$. Oligodendrocyte progenitors are the predominant oligodendrocyte lineage between 23 and 32 weeks of gestation in the preterm brain [42]. The abundant presence of vulnerable oligodendrocyte progenitors in the developing brain explains why the preterm brain is particularly prone to white matter injury when exposed to hypoxia-ischemia or inflammation [36]. The concept of oligodendrocyte progenitors as the key target of hypoxic-ischemic injury is underlined by data showing that the localization of white matter injury in the preterm brain coincides with the distribution of oligodendrocytes progenitors [45]. The principal mechanisms underlying oligodendrocyte injury after cerebral hypoxia-ischemia are (1) glutamate excitotoxicity, (2) free radical attack and (3) activation of microglia (Figure 3) [41, 64-70].

Glutamate excitotoxicity occurs when cerebral hypoxia-ischemia compromises delivery of oxygen and nutrients to the preterm brain leading to energy failure [36, 39, 71]. Depletion of energy sources causes failure of the sodium/potassium pump and subsequent failure, or even reversed function, of sodium-dependent glutamate transporters leading to increased extracellular glutamate concentrations [36]. High concentrations of extracellular glutamate activate $\mathrm{N}$-methyl-D-aspartate (NMDA) and $\alpha$ Amino-3-hydroxy-5-methyl-4-isoxazolepropionic acid/ kainate (AMPA/KA) receptors which are abundantly expressed in the preterm brain on oligodendrocyte progenitor cell processes and cell somata, respectively. Glutamate-mediated activation of NDMA and AMPA/KA receptors leads to $\mathrm{Ca} 2+$ influx with subsequent activation of proteolytic enzymes, apoptotic pathways and generation of reactive oxygen species (ROS) and reactive nitrogen species (RNS) [36, 49]. Excessive activation of AMPA/KA receptors on the somata of oligodendrocyte progenitors leads to cell death, whereas activation of NMDA receptors on the processes of oligodendrocytes progenitors may lead to loss of processes on viable cells with subsequent failure to differentiate into mature myelinating oligodendrocytes $[36,46,63]$. 


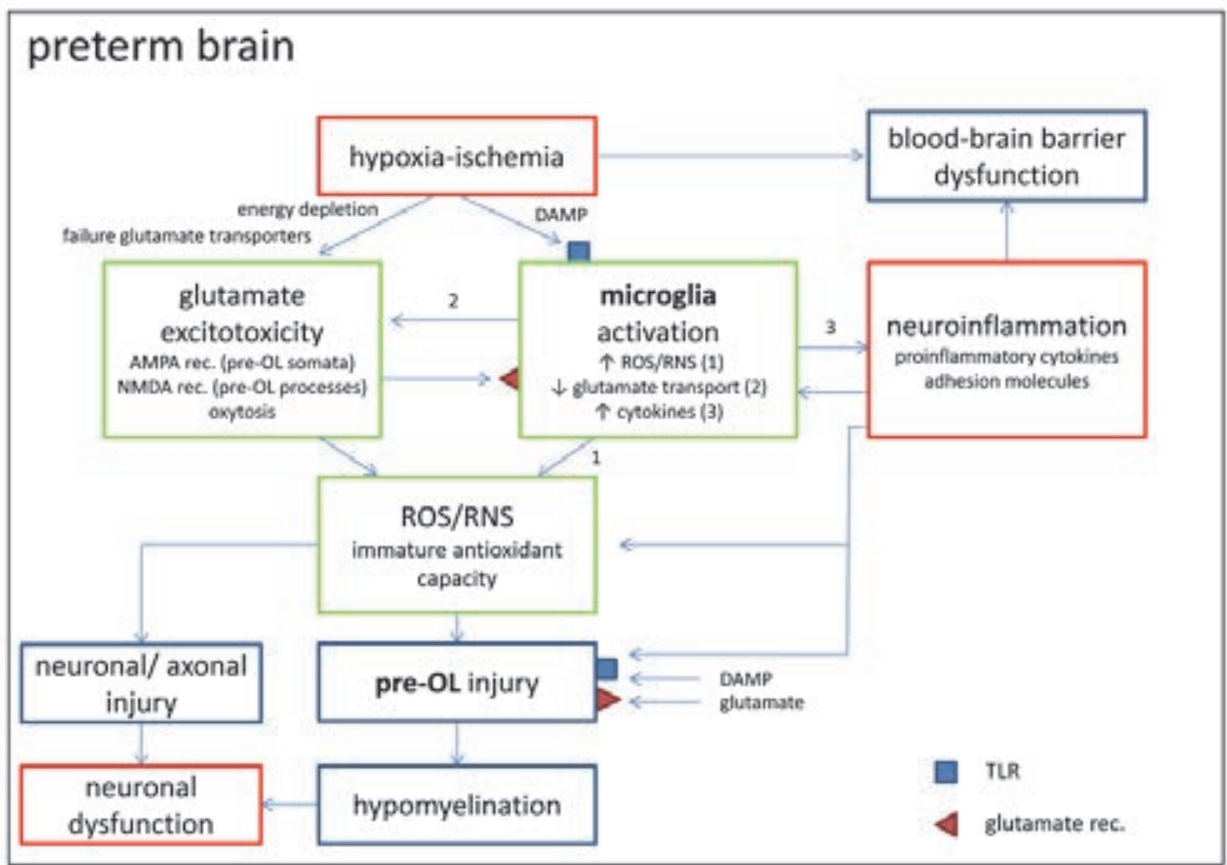

Figure 3. Schematic overview of the pathophysiology of hypoxic-ischemic encephalopathy in the preterm brain. Global hypoxia-ischemia in the preterm brain causes energy depletion and failure of glutamate transporters with subsequent glutamate excitotoxicity. Microglia are activated by excessive extracellular glutamate and TLR-mediated recognition of DAMPs. Upon activation, microglia produce ROS/RNS (1), enhance glutamate excitotoxicity (2) and release pro-inflammatory cytokines (3). Pre-oligodendrocytes are prone to injury by excessive ROS/RNS production, since antioxidant systems in the preterm brain are immature. Furthermore, pre-oligodendrocytes are injured by glutamate-mediated activation of AMPA and NMDA receptors on the somata and cell processes and oxytosis. Excessive microglial activation induces cerebral inflammation, characterized by expression of adhesion molecules on the cerebral vasculature and prolonged release of pro-inflammatory cytokines. The state of inflammation causes dysfunction of the bloodbrain barrier and further enhances activation of microglia. Release of pro-inflammatory cytokines and TLRmediated recognition of DAMPs form an additional injurious hit to pre-oligodendrocytes. The multiple injurious triggers to pre-oligodendrocytes cause immediate cell death or arrested maturation leading to hypomyelination of the brain. Hypomyelination and ischemic injury to neurons and axons causes dysfunction of the preterm brain, characterized by suppressed electrophysiological brain activity and clinical and electrophysiological seizure activity. $D A M P=$ danger associated molecular pattern, pre-OL $=$ preoligodendrocytes, AMPA rec. $=\alpha$-Amino-3-hydroxy-5-methyl-4-isoxazolepropionic acid receptor, NMDA rec. = $N$-methyl-D-aspartate receptor, ROS/RNS = reactive oxygen species and reactive nitrogen species, TLR $=T$ Tolllike receptor. 
Cerebral hypoxia-ischemia and subsequent reperfusion causes oxidative stress, which is characterized by excessive formation of detrimental ROS and RNS [36, 39]. Experimental data have shown that oligodendrocyte progenitors are particularly vulnerable to oxidative stress, whereas mature oligodendrocytes are more resistant to this type of injury $[66,69]$. The vulnerability of oligodendrocyte progenitors to free radical attack is explained by deficiency of free radical scavenging enzymes, making the preterm brain prone to oxidative stress after a hypoxic-ischemic event $[66,69]$.

Microglia play a key role in the pathophysiology of HIE in the preterm brain [36, 72]. Microglia are the innate immune cells of the brain, which are involved in the surveillance of the brain detecting possible threats such as infection and injury [72-75]. Under normal conditions microglia are in their resting state with long thin processes sensing their environment for signs of danger [72]. Following hypoxia-ischemia, activation of microglia can occur through detection of excessive extracellular glutamate by the glutamate receptor on the microglial membrane or by recognition DAMPs (intracellular proteins, DNA, RNA, nucleotides, heat shock proteins and extracellular matrix protein such as hyaluronic acid), which are released after neuronal injury and detected by Toll-like receptors (TLR) expressed on the microglial membrane [72, 76]. Activated microglia initiate a cerebral inflammatory response characterized by enhanced glutamate excitotoxicity, production of ROS, release of pro-inflammatory cytokines (i.g. IL-1 $\beta$ and TNF $\alpha$ ) and expression of adhesion molecules [36, 74-76]. The cerebral inflammatory response initiated by microglia triggers the peripheral innate and adaptive immune system as indicated by brain invasion of neutrophils and T-cell activation [31]. The inflammatory response mediated by microglia is aimed at fighting off pathogens, clearing debris and repairing injury [74]. However, prolonged and excessive activation of microglia, which may occur in the event of severe cerebral hypoxia-ischemia, initiates an exaggerated cerebral inflammatory response causing more harm than benefit for the brain $[72-75,77,78]$. Remarkably, microglia are abundantly present in the cerebral white matter during the period that coincides with high vulnerability for white matter injury in the preterm brain [79]. Taken together, this implies that the preterm brain is prone to injury following hypoxia-ischemia due to multiple factors; the presence of highly vulnerable oligodendrocyte progenitors, deficient antioxidant capacity and the abundant presence of microglia which may trigger injurious cerebral inflammation.

\section{New cellular treatment strategies for HIE in preterm infants}

Despite the high prevalence of neurological sequelae, therapeutic options to improve the neurodevelopmental outcome in preterm infants after HIE are unavailable. In mild cases of HIE in term infants whole body cooling therapy has been shown to improve neurodevelopmental outcome [80-82]. Cooling therapy is an independent risk factor for adverse neurological outcomes in preterm infants and therefore is not standard clinical care for this vulnerable patient group [80-82]. In the last decade, stem cell therapy has 
emerged as a putative treatment for neonatal ischemic brain damage [83-91]. The approach of regenerative medicine in treating the injured brain may be especially suitable for preterm infants considering the growth-promoting preterm environment, which may maximize regenerative effects of stem cells. Here, mesenchymal stem cells (MSCs) and hematopoietic stem cells (HSCs) will be described as candidates for cell-based therapy in perinatal medicine.

MSCs possess self-renewal capacity and pluripotency defined by their ability to differentiate into osteoblasts, chondrocytes, adipocytes and muscle cells of mesodermal lineage [92-95]. MSCs have great therapeutic potential in the field of neonatal regenerative medicine due to their immunomodulatory and neuroprotective properties $[88,89,94]$. MSCs can be harvested from various tissues such as bone-marrow [92, 93, 96-98], adipose tissue [97, 99] and perinatal tissues such as placenta [100], umbilical cord blood [101-106] and umbilical cord stroma (Wharton jelly) [104, 107, 108]. Therefore, mesenchymal stromal cells (instead of mesenchymal stem cells) may be a more accurate description of MSCs [109].

The immunomodulatory effects of MSCs consist of modulation of both innate and adaptive immunity $[94,95]$. Innate immunomodulation by MSCs entails inhibition of monocyte maturation into dendritic cells (DCs) and impairing antigen presentation by DCs preventing clonal expansion of T-cells [94, 95, 110]. MSCs further modulate innate immunity by inhibiting activation and proliferation of natural killer (NK) cells and dampening the respiratory burst of neutrophils $[94,95,110]$. MSCs have the ability to suppress the antigen specific proliferation of T-cells, which keeps these effector cells in a quiescent state $[94,95,110]$. Furthermore, MSCs modulate the adaptive immune system by promoting a shift of helper $\mathrm{T}$ cells from a pro-inflammatory to an antiinflammatory state, by downregulating cytotoxicity of cytotoxic T cells and by inhibiting proliferation of B-cells [94, 95, 110-113]. MSCs have been shown to induce proliferation of regulatory T cells, which are involved in maintaining immune homeostasis [94, 95, $110,113]$. In short, MSCs modulate innate and adaptive immunity towards an antiinflammatory state $[94,95,110]$. Because of their anti-inflammatory properties, MSCs have been studied as therapeutic intervention in many diseases, such as graft versus host disease [114], autoimmune encephalomyelitis [115] and bronchopulmonary dysplasia [116-118], in which inflammation or a pathogenic immune response play a key role in pathophysiology. Although the exact mechanisms remain largely unknown, general consensus is that MSC-mediated immunomodulation is predominantly caused by the paracrine effect of soluble factors secreted by MSCs $[94,95,110]$. 


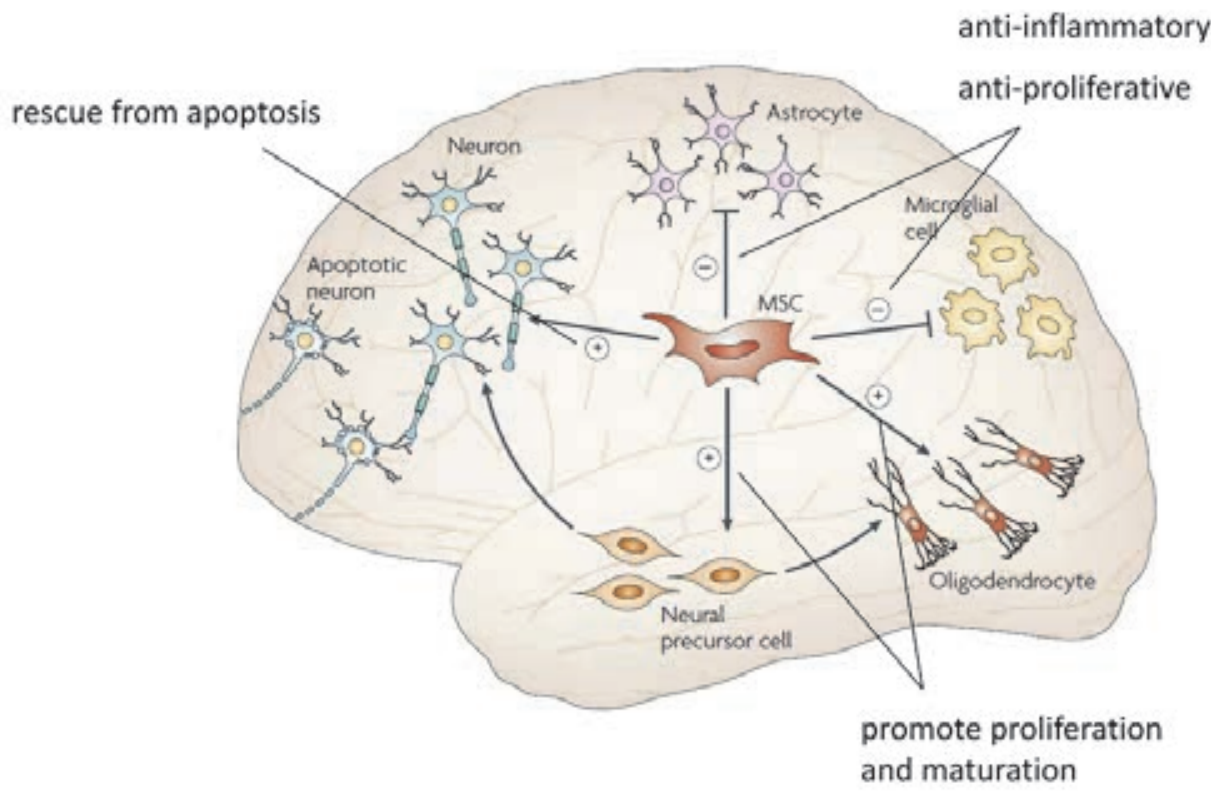

Figure 4. Potential neuroprotective effects of mesenchymal stem cells (MSCs). MSCs secrete soluble factors which promote proliferation and maturation of neural precursor cells and oligodendrocytes. MSCs release anti-inflammatory factors that inhibit proliferation of microglia and astrocytes. Neurotrophic factors excreted by MSCs may rescue neurons in the ischemic brain from going into apoptosis (Adapted from Ucelli, Nature Reviews Immunology 2008 [94]).

The neuroprotective properties of MSCs have been attributed to several mechanisms (Figure 4) [85, 94, 119, 120]. MSCs have been shown to stimulate proliferation of endogenous neural progenitor cells (NPCs) and promote differentiation of NPCs towards neurons $[88,94,119,121,122]$ and the oligodendrocyte lineage $[88,94,119,123,124]$. By replenishing the oligodendrocyte population, MSCs promote remyelination of the ischemic brain [88, 94, 119, 122]. Furthermore, secretion of neurotrophic factors by MSCs may rescue newly formed neurons and oligodendrocytes from apoptosis in the ischemic environment [88, 94, 119]. Importantly, MSCs have been shown to induce a switch of microglia from a pro-inflammatory M1 state towards a regenerative M2 state, thereby reducing pro-inflammatory cytokine release in the brain [88, 119, 125]. Moreover, MSCs inhibit proliferation of reactive astrocytes [88, 94, 119]. In vitro studies have demonstrated that MSCs are able to transdifferentiate into neurons [126-128], but this has not been reliably reproduced in vivo $[94,119]$. In most reports only a minor fraction of transplanted MSCs are recovered in the brain [129, 130], therefore the contribution of neural transdifferentiation to neural repair is most likely negligible [88, 94, 119]. Thus, MSCs most likely exert their neuroprotective effect by secreting soluble factors with anti-inflammatory, anti-apoptotic and neurotrophic effects [88, 93-95, 110, 119]. 
Hematopoietic stem cells (HSCs) form a second interesting stem cell population with therapeutic potential in perinatal medicine. HSCs are defined by their capacity to selfrenew and to differentiate into cells of all blood lineages [93, 131-134]. HSCs are dormant stem cells that can be activated by inflammatory stimuli and act as part of the inflammatory response by giving rise to immune cells [132]. Hence, transplanted HSCS can replace or regenerate the diseased blood system, including the immune system [93, 131-134]. HSCs can be readily isolated from bone marrow and peripheral blood and umbilical cord blood also offer a rich source of HSCs [135]. Granulocyte-colony stimulating factor (G-CSF) is routinely used in the clinical setting to mobilize HSCs into the peripheral blood resulting in easy isolation of enough HSCs for clinical applications [133, 136, 137].

HSCs may not only give rise to cells of the blood and immune system. Microglia and perivascular cells (astrocytes) have been reported to originate from HSCs as well [138141]. HSC differentiation into microglia probably reflects HSC-derived myeloid cells (monocytes) becoming microglia once invading the brain [139, 140]. Furthermore, mobilized HSCs were shown to migrate towards the brain [142] and adapt a neuronal phenotype $[143,144]$. Neuronal differentiation from mobilized HSCs, however, may reflect simultaneous mobilization of neural progenitor cells (NPCs) [143-145] or transdifferentiation of concomitantly mobilized MSCs into a neural phenotype [127, 141, 146]. Moreover, HSCs have been shown to differentiate into endothelial progenitor cells (EPCs) [147]. EPCs are involved in neovascularization [147-151] and may therefore be of high therapeutic value to re-establish adequate cerebral perfusion after ischemic brain injury.

\section{Translational animal model}

The aim of this thesis is to explore the neuroprotective potential of cell-based therapy in the hypoxic-ischemic preterm brain. Effectiveness, safety and feasibility of such an innovative therapeutic strategy should first be tested in an animal model before clinical application. It is essential that the animal model is chosen with care, since there are many examples in literature of therapeutic interventions that showed promising results in animal models but failed in the human situation [152-155]. The discordance between human and animal studies is often attributed to failure of the animal model to accurately mimic the human disease [152-155]. The optimal translational animal model should therefore adequately mimic the biology of the human situation and the etiology of the human disease [152-155].

In this thesis, neuroprotective potential of cell-based therapy in the hypoxicischemic preterm brain was studied in fetal sheep, since the developmental biology of the ovine fetus closely resembles the human situation of prematurity [156-160]. Development and maturation of several key organs follow the same time course in sheep as in humans [159]. For example, the alveolarization of the lung [12], myelination of the 
brain [13] and formation of the intestinal crypts and villus [14] occur before birth in humans and sheep. This is in contrast with widely used rodent models, in which these aspects of organ development follow a different time course and predominantly occur after birth (Figure 5).
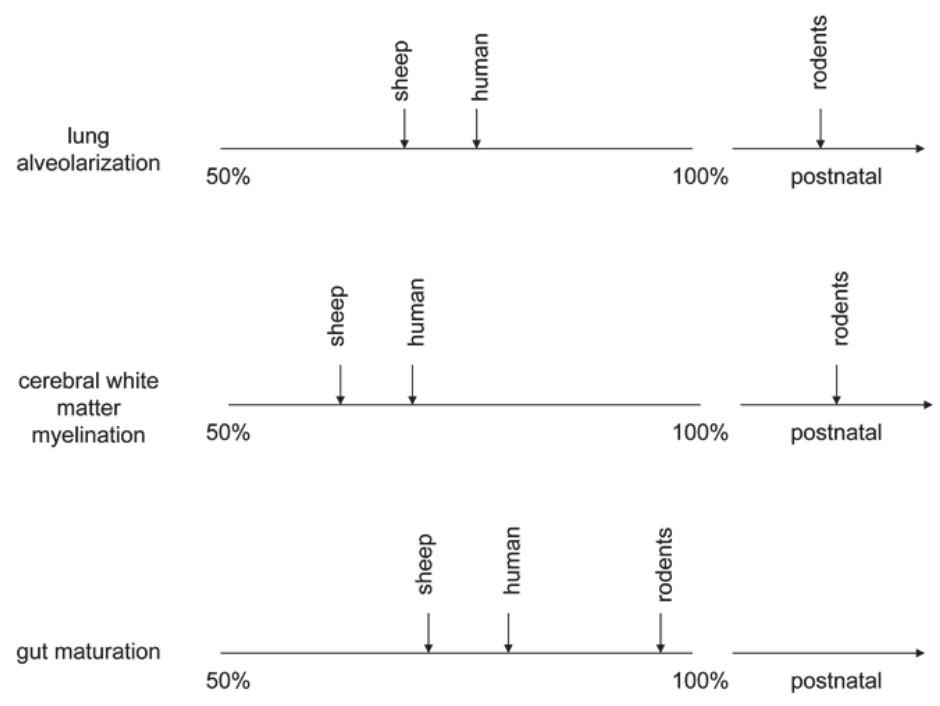

percent of completed gestation

Figure 5. Important hallmarks of fetal organ development. Maturation of the fetal lung, brain and gut follow a similar time course in humans and sheep, this in contrast to rodents.

Moreover, sheep brain anatomy is closely similar to human brain anatomy. Sheep, like humans, are gyrencephalic (a brain with gyri and sulci) whereas rodents are lissenchephalic (a smooth-surfaced brain) [160]. Furthermore, vascular anatomy as well as white to grey matter ratio are similar in humans and sheep [160]. The oligodendrocyte is the key cellular target in the hypoxic-ischemic preterm brain [36, 39]. Importantly, oligodendrocyte maturation in fetal sheep follows a similar time course as in human development (Figure 6) [158]. As in humans, sheep oligodendrocyte density is highest in periventricular white matter, and therefore this region is most vulnerable to HI-injury $[36,45]$.

As previously described, the etiology of HIE in the preterm brain can be roughly divided in two groups, namely fetal hypoxia-ischemia and infection. In our studies, we focused on hypoxia-ischemia as the cause of preterm brain injury. In the human situation, fetal hypoxia-ischemia is generally caused by chronic or acute compromise of blood flow to the fetus, which induces systemic hypoxia-ischemia involving all organs. To adequately mimic the acute clinical scenario, we induced systemic hypoxia-ischemia 
in the fetal sheep by transient umbilical cord occlusion in utero. In contrast, in the commonly used Rice-Vannucci model rat pups are postnatally exposed to focal cerebral ischemia by unilateral permanent occlusion of the middle cerebral artery followed by a period of generalized hypoxia $[161,162]$. Although this model has definitely contributed to our knowledge of the mechanisms involved in hypoxic-ischemic brain injury [162], the developmental biology of the animal and the etiology of injury may not optimally mimic the human situation in which the preterm brain is exposed to systemic hypoxiaischemia.

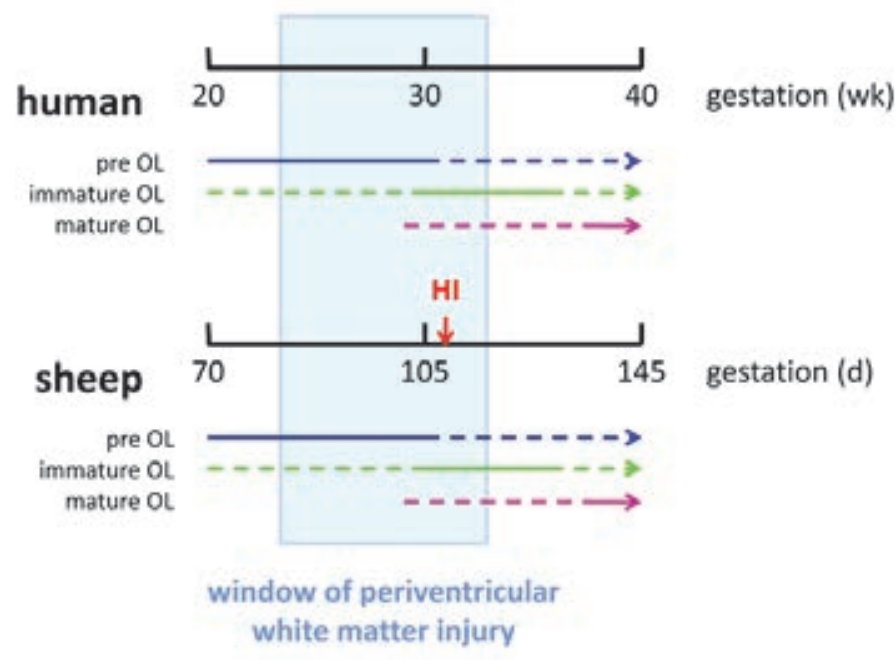

Figure 6. Timing of appearance of oligodendrocyte lineage in human and sheep. Oligodendrocyte maturation follows a similar time course in human and in sheep brain. Solid lines indicate the period in which the oligodendrocyte lineages predominate. During the period of pre-oligodendrocytes predominance the preterm brain is highly prone to periventricular white matter injury (adapted from Back et al. J Child Neurol 2006 [158]). In our studies hypoxia-ischemia was induced by transient umbilical cord occlusion at 106 days of gestation, which roughly corresponds to a human preterm brain between 30-34 weeks. $\mathrm{OL}=$ oligodendrocyte, $\mathrm{HI}=$ hypoxia-ischemia.

In the fetal sheep model transient umbilical cord occlusion is performed after in utero instrumentation of the fetus, as described below. The instrumented fetal sheep model allows delivering insults in utero while physiological outcome can be monitored in utero and the insult can be delivered at an equivalent developmental stage that coincides with the window of vulnerability in human preterm infants $[42,45,158]$. In our studies of the preterm brain, we included sheep fetuses at 100 days (term is 145 days) of gestation, which in terms of neurodevelopment and oligodendrocyte maturation is equivalent to a late preterm human newborn of 30 to 34 weeks [156]. Previous studies have 
shown that the pattern of white matter injury closely resembles the hypoxic-ischemic injury seen in human preterm infants [158, 160, 163-166].

\section{The instrumented fetal sheep model}

In all studies described in this thesis fetal instrumentations was performed as follows (Figure 7) [167-170]. Fetuses of time-mated Texel ewes were instrumented around 101 \pm 1 (mean \pm SD) days of gestation. Before surgery, ewes received intravenous prophylactic antibiotics. After intubation and induction of anesthesia, general anesthesia was maintained with 1-2\% isoflurane guided by depth of sedation and supplemented by intravenous analgesia. Vital parameters and depth of sedation were continuously monitored by certified personnel. A catheter was placed in the maternal long saphenous vein to provide access for a peri-operative saline drip and post-operative blood sampling and administration of the prophylactic antibiotics during four days.

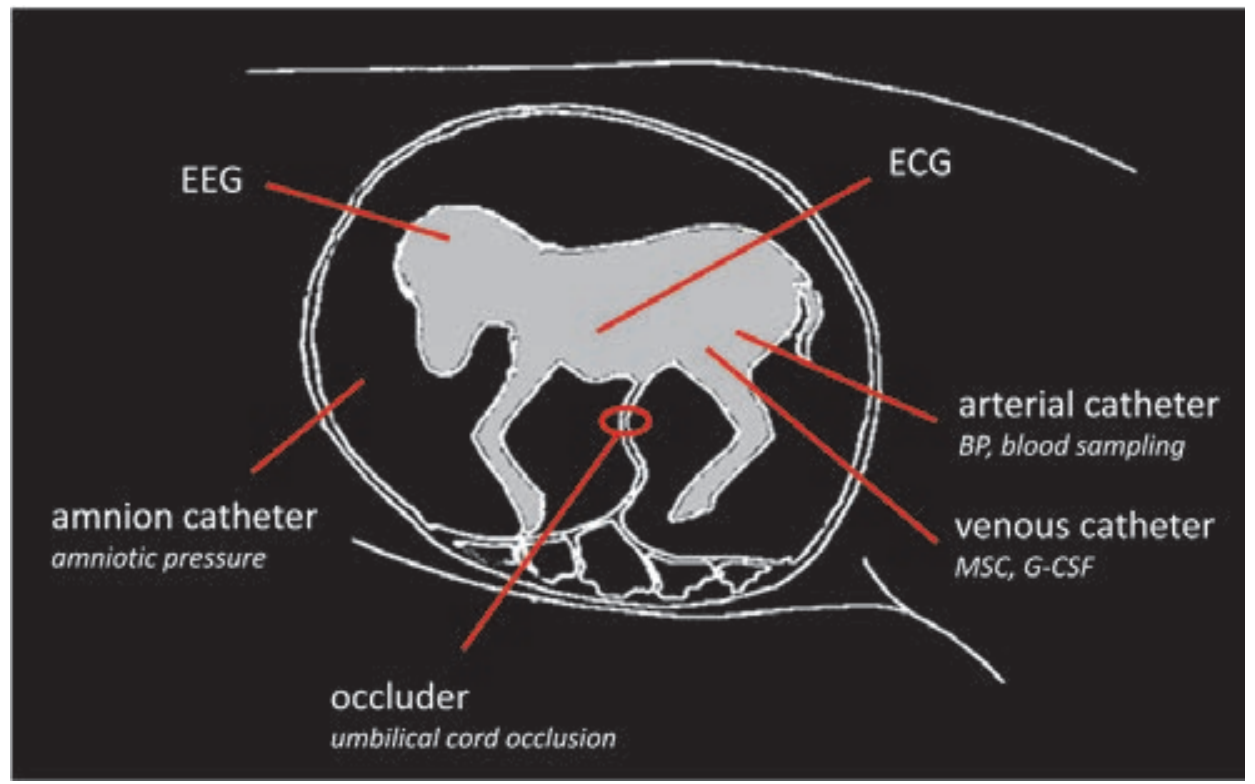

Figure 7. Fetal instrumentation. Electroencephalogram (EEG) electrodes are placed on the head. Electrocardiogram (ECG) electrodes are placed on the chest. An inflatable vascular occluder is placed around the umbilical cord. An arterial catheter is placed for blood pressure measurements and sampling of blood and blood gases. A venous catheter is placed for the administration of stem cells, G-CSF or other interventions. An amniotic catheter is placed to measure pressure inside the uterus. This pressure was subtracted from the fetal arterial pressure to obtain the real arterial pressure in the fetus.

After laparotomy, the uterus was opened and fetuses were catheterized with umbilical vessel catheters placed in the femoral artery and the brachial or femoral vein. Three custom-made electrocardiogram (ECG) shielded with silver plates were sewn on the 
chest according to Einthoven for fetal heart rate recordings. Two pairs of custom-made electroencephalogram (EEG) shielded electrodes with silver tips were placed bilaterally on the dura over the parasagittal parietal cortex, with a sub-cutaneous silver reference electrode placed in the neck. Both sham animals and animals assigned to global hypoxia-ischemia were instrumented with an inflatable vascular occluder placed around the umbilical cord. A catheter for amniotic pressure recording was placed in the amniotic sac. Before closure of the uterus antibiotics were administered into the amniotic sac to prevent infection related to surgery. All fetal catheters and leads were exteriorized through a trocar hole in the flank of the ewe. After surgery, ewes were housed in a confined space to allow handling and continuous perfusion of the catheters. Surgical wounds were inspected daily and treated with antibiotic spray to prevent infection. Animals had ad libitum access to water and food. The welfare of the animals was monitored daily by certified personnel.

\section{Experimental design}

In all studies described in this thesis, the experimental design was as follows [167-170]. After surgery, the ewe and her fetus were allowed to recover for four days. This recovery period was to minimize effects of surgery and anesthesia on the experiment. In all studies, fetuses were randomly allocated to the sham (no umbilical cord occlusion, with or without treatment) and global hypoxia-ischemia (umbilical cord occlusion with or without treatment) study groups. In the global hypoxia-ischemia groups, the occluder was rapidly inflated with sterile saline and complete occlusion was confirmed with a sudden drop in heart rate and subsequent arterial blood gas analysis indicating acidemia, hypoxia and hypercapnia. Such an insult has been previously shown to result in global hypoxic-ischemia and subsequent cerebral hypoperfusion [156, 163]. After (sham) umbilical cord occlusion a reperfusion period of 7 days followed. At the end of the experiment (experimental day 7), the animals were sacrificed and all tissues including brain were collected.

\section{Fetal monitoring}

In utero instrumentation of the ovine fetus allows for continuous monitoring of electrophysiological brain activity by EEG, electrophysiological cardiac function by ECG, hemodynamics by heart rate and blood pressure measurement and blood gas analyses (Figure 8). In the model, physiological changes of these parameters can be accurately measured during umbilical cord occlusion.

In all studies described in this thesis data were acquired as follows [167-170]. Blood pressure, amniotic pressure EEG and ECG data were acquired and digitized by a custom-made MPAQ unit (Maastricht-Programmable AcQuisition system, Maastricht Instruments BV, Maastricht, the Netherlands) with IDEEQ software (Maastricht Instruments BV). Heart rate (beats per minute) was extracted from the ECG by R-top identifi- 
cation. Fetal mean arterial blood pressure $(\mathrm{mmHg})$ was calculated by online subtraction of the amniotic fluid pressure from the femoral artery pressure. In this thesis, we used two different approaches to analyze electrophysiological brain function. In the first approach, burst activity was determined and length of interburst intervals was used as a surrogate for functional brain suppression. Burst activity was defined as an epoch with an amplitude $>30 \mu \mathrm{V}$ and a duration $>1 \mathrm{~s}$ in both channels. Interburst intervals (IBI) were defined as epochs with an amplitude $<30 \mu \mathrm{V}$ and a duration $>3 \mathrm{~s}$ in both channels. In the second approach the raw EEG signals were converted into amplitudeintegrated EEG (aEEG) traces, using a Matlab (R2011b; The Mathworks Inc., Natick, MA, USA) algorithm similar to the clinical EEG NicoletOne ${ }^{\mathrm{TM}}$ device (Viasys Healthcare, Conshohocken, PA, USA) [171]. The (a)EEG traces were used to detect electrographic seizure activity.

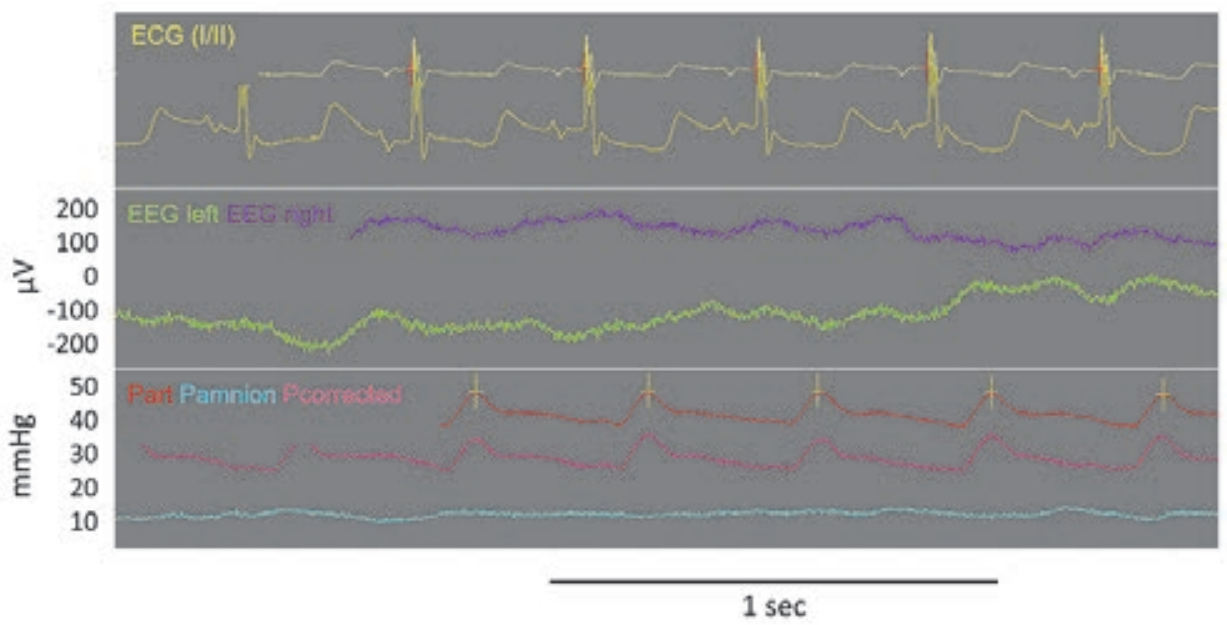

Figure 8. Continuous monitoring of fetal vital parameters. Upper panel: electrocardiogram (ECG), Einthoven's derivation I and II (yellow). Middle panel: electroencephalogram (EEG), left (green) and right (purple). Lower panel: blood pressure, fetal arterial blood pressure ( $P$ art; red), amniotic pressure ( $P$ amnion, blue) and fetal blood pressure corrected for amniotic pressure (P corrected, pink).

\section{Imaging the preterm brain}

In all studies, the effect of systemic hypoxia-ischemia and the cell-based interventions were assessed by immunohistochemistry of the preterm brain [167-170]. These analyses primarily focused on the cells playing a predominant role in the pathophysiology of white matter injury in the brain. First of all, activation and proliferation of microglia was assessed as a measure of cerebral inflammation. White matter injury was assessed by analyzing density of oligodendrocyte and myelin binding protein. Furthermore, white matter injury was assessed by measuring fractional anisotropy (FA) with diffusion 
tensor imaging (DTI) [169], which is a reliable method to assess white matter organization [172-174].

\section{Research questions and hypotheses}

From the adult field of local cerebral ischemia (i.e. stroke) it became evident that the cross-talk between brain and the immune system is essential in health and disease (Figure 9) [175]. Clinical and experimental evidence showed that transient or permanent local cerebral ischemia not only caused acute infarction and neurodegeneration, but in addition induced massive activation of the peripheral immune system as characterized by the production of pro-inflammatory cytokines in peripheral lymphoid organs and rapid mobilization of immune effector cells from the spleen [23, 27]. Mobilized effector cells (i.e. T-cells, monocytes, NK-cells) were shown to invade the affected brain, where these inflammatory cells aggravated cerebral inflammation and injury [27]. The rapid mobilization of the peripheral immune system in the acute phase resulted in splenic atrophy and was followed by a period of immunosuppression, making patients more susceptible to opportunistic infections [23, 25-29, 31, 176]. Several studies showed in adult rodent models of local cerebral ischemia that stem cell therapy (i.e. mesenchymal stem cells, hematopoietic stem cells or cord blood cells) reduced infarction volume and the protective mechanism was particularly attributed to modulation of the cerebral and peripheral inflammatory response [177-184]. Similarly, stem cell therapy (i.e. mesenchymal stem cells, hematopoietic stem cells or cord blood cells) reduced infarction volume after local cerebral ischemia in experimental models of newborn rodents by modulating inflammation and promoting regeneration [121, 122, 130, 185194]. 


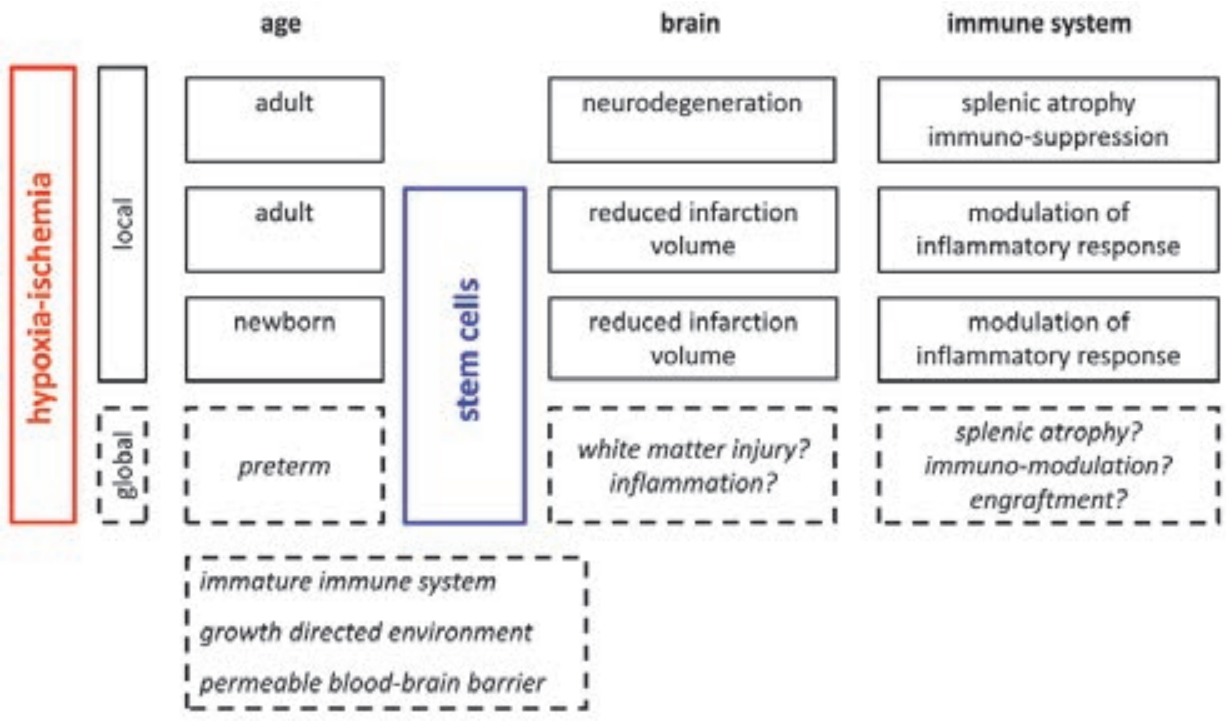

Figure 9. Outline of findings leading to the basic research questions of this thesis.

The previous findings have formed the basis on which the mechanistic and therapeutic research questions of this thesis have been formulated (Figure 9). All previously described studies assessed brain injury and involvement of the peripheral immune system after local hypoxia-ischemia. As stated before, the clinical scenario in hypoxic-ischemic encephalopathy in preterm infants predominantly involves global hypoxia-ischemia involving all organs and not solely the brain. Therefore the mechanistic research questions were:

1. Does experimental global hypoxia-ischemia induce a similar pattern of injury as seen in preterm infants?

2. Does global hypoxia-ischemia induce inflammation in the preterm brain?

3. Does global hypoxia-ischemia activate and mobilize the immature peripheral immune system?

To answer these mechanistic research questions we have established a translational animal model of global hypoxia-ischemia in preterm sheep in which the developmental biology and the etiology of the disease closely resemble the human situation. The therapeutic research question was directly derived from the mechanistic ones:

Can stem cell therapy prevent cerebral inflammation, activation of the peripheral immune system and white matter injury in the preterm brain after global hypoxiaischemia? 
We hypothesized that preterm infants would be excellent candidates for stem cell therapy since (1) their immature immune system would be likely to tolerate allogeneic stem cells, (2) stem cells would support regeneration after injury in the growth-directed preterm environment and (3) the immature blood-brain barrier in the preterm brain would make it more likely for stem cells to reach the site of injury. These general hypotheses lead to the following outline of the thesis:

\section{Chapter 2. Immature cerebrovascular regulatory system}

In chapter 2, we validated the translational instrumented sheep model by assessing longitudinal function of the baroreceptor reflex in fetal sheep after umbilical cord occlusion. This primitive reflex is part of an essential cerebrovascular regulatory system, which ensures rapid adaptation to fluctuation in systemic blood pressure thereby maintaining adequate cerebral perfusion [39]. Preterm infants are especially prone to cerebral ischemia and blood pressure fluctuation due to their immature cerebral vasculature and cerebrovascular auto-regulatory system [39]. Therefore, we hypothesized that adequate baroreflex function would be persistently disturbed by transient umbilical cord occlusion in fetal sheep.

\section{Chapter 3. Cerebral inflammation and recruitment of the peripheral immune system}

In chapter 3, we studied the pattern of injury in further detail by assessing cerebral inflammation, white matter injury and electrophysiological brain activity after global hypoxia-ischemia in fetal sheep. We hypothesized that global hypoxia-ischemia by transient umbilical cord occlusion would induce a cerebral and peripheral inflammatory response similar to the one seen after local cerebral ischemia. In addition, we hypothesized that cerebral inflammation would result in white matter injury and suppression of brain function.

\section{Chapter 4. Exogenous stem cells}

In chapter 4, we studied the neuroprotective potential of exogenous administration of MSCs after global hypoxia-ischemia in fetal sheep. We chose to study MSCs for their potent anti-inflammatory and regenerative capacities [13-16]. MSCs were infused intravenously, to test effectiveness of MSC therapy using a clinically feasible administration route. We hypothesized that intravenously administered human bone-marrow derived MSCs would be neuroprotective and dampen the cerebral and peripheral inflammatory response in a translational animal model of hypoxic-ischemic preterm brain injury.

\section{Chapter 5. Endogenous stem cells}

In chapter 5, we studied the neuroprotective potential of mobilization of endogenous HSCs by granulocyte-colony stimulating factor (G-CSF) after global hypoxia-ischemia in 
fetal sheep. We hypothesized that systemic G-CSF treatment would be neuroprotective in a translational animal model of hypoxic-ischemic preterm brain injury.

\section{Chapter 6. General discussion}

The overall results of this thesis and future implications are discussed in chapter 6. 


\section{Chapter 1}

\section{References}

1. Goldenberg RL, Culhane JF, lams JD, Romero R: Epidemiology and causes of preterm birth. Lancet 2008, 371:75-84.

2. World Health Organization: The top 10 causes of death [http://who.int/mediacentre/factsheets/fs310/en/index.html]

3. Farooqi A, Hagglof B, Sedin G, Gothefors L, Serenius F: Chronic conditions, functional limitations, and special health care needs in 10- to 12-year-old children born at 23 to 25 weeks' gestation in the 1990s: a Swedish national prospective follow-up study. Pediatrics 2006, 118:e1466-1477.

4. Hagberg B, Hagberg G, Beckung E, Uvebrant P: Changing panorama of cerebral palsy in Sweden. VIII. Prevalence and origin in the birth year period 1991-94. Acta Paediatr 2001, 90:271-277.

5. Doyle LW, Faber B, Callanan C, Freezer N, Ford GW, Davis NM: Bronchopulmonary dysplasia in very low birth weight subjects and lung function in late adolescence. Pediatrics 2006, 118:108-113.

6. Fitzgibbons SC, Ching Y, Yu D, Carpenter J, Kenny M, Weldon C, Lillehei C, Valim C, Horbar JD, Jaksic T: Mortality of necrotizing enterocolitis expressed by birth weight categories. J Pediatr Surg 2009, 44:1072-1075; discussion 1075-1076.

7. Uauy RD, Fanaroff AA, Korones SB, Phillips EA, Phillips JB, Wright LL: Necrotizing enterocolitis in very low birth weight infants: biodemographic and clinical correlates. National Institute of Child Health and Human Development Neonatal Research Network. J Pediatr 1991, 119:630-638.

8. Saigal S, Doyle LW: An overview of mortality and sequelae of preterm birth from infancy to adulthood. Lancet 2008, 371:261-269.

9. Nationaal Kompas Volksgezondheid Vroeggeboorten. 4.12 edition. Bilthoven, the Netherlands: Rijksinstituut voor Volksgezondheid en Milieu, Ministerie van Volksgezondheid, Welzijn en Sport; 2013.

10. Mohangoo AD, Buitendijk SE, Hukkelhoven CW, Ravelli AC, Rijninks-van Driel GC, Tamminga P, Nijhuis JG: [Higher perinatal mortality in The Netherlands than in other European countries: the Peristat-II study]. Ned Tijdschr Geneeskd 2008, 152:2718-2727.

11. Tamminga P, Rijninks-van Driel GC, Mohangoo AD, Hukkelhoven CW, Nijhuis JG, Buitendijk S, Ravelli AC: Neonatale Uitkomsten. Ned Tijdschr Obst Gyn 2009, 12:83-88.

12. Schaaf JM, Mol BW, Abu-Hanna A, Ravelli AC: Trends in preterm birth: singleton and multiple pregnancies in the Netherlands, 2000-2007. BJOG 2011, 118:1196-1204.

13. Gantert M, Been JV, Gavilanes AW, Garnier Y, Zimmermann LJ, Kramer BW: Chorioamnionitis: a multiorgan disease of the fetus? J Perinatol 2010, 30 Suppl:S21-30.

14. Korvenranta E, Linna M, Rautava L, Andersson S, Gissler M, Hallman M, Hakkinen U, Leipala J, Peltola M, Tammela O, Lehtonen L: Hospital costs and quality of life during 4 years after very preterm birth. Arch Pediatr Adolesc Med 2010, 164:657-663.

15. Institute of Medicine (Ed.). Preterm birth: Causes, Consequences and Prevention. Washington: The National Academies Press; 2007.

16. Goldenberg RL, Hauth JC, Andrews WW: Intrauterine infection and preterm delivery. N Engl J Med 2000, 342:1500-1507.

17. Romero R, Espinoza J, Kusanovic JP, Gotsch F, Hassan S, Erez O, Chaiworapongsa T, Mazor M: The preterm parturition syndrome. BJOG 2006, 113 Suppl 3:17-42

18. Abbas AK, Lichtman AH, Pillai S: Cellular and molecular immunology. 7th edn. Philadelphia: Elsevier/Saunders; 2012.

19. Delves PJ, Roitt IM: Roitt's essential immunology. 12th edn. Chichester, West Sussex ; Hoboken, NJ: Wiley-Blackwell; 2011.

20. Murphy K, Travers P, Walport M, Janeway C: Janeway's immunobiology. 8th edn. New York: Garland Science; 2012.

21. Rijkers GT, Kroese FGM, Kallenberg CGM, Derksen RHWM: Immunologie. 1st edn. Houten: Bohn Stafleu van Loghum; 2009.

22. Seong SY, Matzinger P: Hydrophobicity: an ancient damage-associated molecular pattern that initiates innate immune responses. Nat Rev Immunol 2004, 4:469-478. 
23. Ajmo CT, Jr., Vernon DO, Collier L, Hall AA, Garbuzova-Davis S, Willing A, Pennypacker KR: The spleen contributes to stroke-induced neurodegeneration. J Neurosci Res 2008, 86:2227-2234.

24. Brea D, Sobrino T, Ramos-Cabrer P, Castillo J: Inflammatory and neuroimmunomodulatory changes in acute cerebral ischemia. Cerebrovasc Dis 2009, 27 Suppl 1:48-64.

25. Dirnagl U, Klehmet J, Braun JS, Harms H, Meisel C, Ziemssen T, Prass K, Meisel A: Stroke-induced immunodepression: experimental evidence and clinical relevance. Stroke 2007, 38:770-773.

26. Meisel C, Schwab JM, Prass K, Meisel A, Dirnagl U: Central nervous system injury-induced immune deficiency syndrome. Nat Rev Neurosci 2005, 6:775-786.

27. Offner H, Subramanian S, Parker SM, Afentoulis ME, Vandenbark AA, Hurn PD: Experimental stroke induces massive, rapid activation of the peripheral immune system. J Cereb Blood Flow Metab 2006, 26:654-665.

28. Offner H, Subramanian S, Parker SM, Wang C, Afentoulis ME, Lewis A, Vandenbark AA, Hurn PD: Splenic atrophy in experimental stroke is accompanied by increased regulatory $T$ cells and circulating macrophages. J Immunol 2006, 176:6523-6531.

29. Schwartz M, Shechter R: Systemic inflammatory cells fight off neurodegenerative disease. Nat Rev Neurol 2010, 6:405-410.

30. Winerdal M, Winerdal ME, Kinn J, Urmaliya V, Winqvist O, Aden U: Long lasting local and systemic inflammation after cerebral hypoxic ischemia in newborn mice. PLoS One 2012, 7:e36422.

31. Gelderblom M, Leypoldt F, Steinbach K, Behrens D, Choe CU, Siler DA, Arumugam TV, Orthey E, Gerloff C, Tolosa E, Magnus T: Temporal and spatial dynamics of cerebral immune cell accumulation in stroke. Stroke 2009, 40:1849-1857.

32. Robbins SL, Kumar V: Robbins and Cotran pathologic basis of disease. 8th edn. Philadelphia, PA: Saunders/Elsevier; 2010.

33. Levy O: Innate immunity of the newborn: basic mechanisms and clinical correlates. Nat Rev Immunol 2007, 7:379-390.

34. Adkins B, Leclerc C, Marshall-Clarke S: Neonatal adaptive immunity comes of age. Nat Rev Immunol 2004, 4:553-564.

35. Volpe JJ: Brain injury in premature infants: a complex amalgam of destructive and developmental disturbances. Lancet Neurol 2009, 8:110-124.

36. Volpe JJ, Kinney HC, Jensen FE, Rosenberg PA: The developing oligodendrocyte: key cellular target in brain injury in the premature infant. Int J Dev Neurosci 2011, 29:423-440.

37. Larroque B, Ancel PY, Marret S, Marchand L, Andre M, Arnaud C, Pierrat V, Roze JC, Messer J, Thiriez G, Burguet A, Picaud JC, Breart G, Kaminski M: Neurodevelopmental disabilities and special care of 5-yearold children born before 33 weeks of gestation (the EPIPAGE study): a longitudinal cohort study. Lancet 2008, 371:813-820.

38. Mwaniki MK, Atieno M, Lawn JE, Newton CR: Long-term neurodevelopmental outcomes after intrauterine and neonatal insults: a systematic review. Lancet 2012, 379:445-452.

39. Volpe JJ: Neurology of the Newborn. 5th edn. Philadelphia: Elsevier-Saunders 2008.

40. Zhang SC: Defining glial cells during CNS development. Nat Rev Neurosci 2001, 2:840-843.

41. Back SA, Han BH, Luo NL, Chricton CA, Xanthoudakis S, Tam J, Arvin KL, Holtzman DM: Selective vulnerability of late oligodendrocyte progenitors to hypoxia-ischemia. J Neurosci 2002, 22:455-463.

42. Back SA, Luo NL, Borenstein NS, Levine JM, Volpe JJ, Kinney HC: Late oligodendrocyte progenitors coincide with the developmental window of vulnerability for human perinatal white matter injury. $J$ Neurosci 2001, 21:1302-1312.

43. Buser JR, Maire J, Riddle A, Gong X, Nguyen T, Nelson K, Luo NL, Ren J, Struve J, Sherman LS, Miller SP, Chau V, Hendson G, Ballabh P, Grafe MR, Back SA: Arrested preoligodendrocyte maturation contributes to myelination failure in premature infants. Ann Neurol 2012, 71:93-109.

44. Dean JM, Riddle A, Maire J, Hansen KD, Preston M, Barnes AP, Sherman LS, Back SA: An organotypic slice culture model of chronic white matter injury with maturation arrest of oligodendrocyte progenitors. Mol Neurodegener 2011, 6:46. 


\section{Chapter 1}

45. Riddle A, Luo NL, Manese M, Beardsley DJ, Green L, Rorvik DA, Kelly KA, Barlow CH, Kelly JJ, Hohimer $A R$, Back SA: Spatial heterogeneity in oligodendrocyte lineage maturation and not cerebral blood flow predicts fetal ovine periventricular white matter injury. J Neurosci 2006, 26:3045-3055.

46. Segovia KN, McClure M, Moravec M, Luo NL, Wan Y, Gong X, Riddle A, Craig A, Struve J, Sherman LS, Back SA: Arrested oligodendrocyte lineage maturation in chronic perinatal white matter injury. Ann Neurol 2008, 63:520-530.

47. Dean JM, McClendon E, Hansen K, Azimi-Zonooz A, Chen K, Riddle A, Gong X, Sharifnia E, Hagen M, Ahmad T, Leigland LA, Hohimer AR, Kroenke CD, Back SA: Prenatal Cerebral Ischemia Disrupts MRIDefined Cortical Microstructure Through Disturbances in Neuronal Arborization. Sci Transl Med 2013, 5:168ra167.

48. Inder TE, Huppi PS, Warfield S, Kikinis R, Zientara GP, Barnes PD, Jolesz F, Volpe JJ: Periventricular white matter injury in the premature infant is followed by reduced cerebral cortical gray matter volume at term. Ann Neurol 1999, 46:755-760.

49. Northington FJ, Chavez-Valdez R, Martin LJ: Neuronal cell death in neonatal hypoxia-ischemia. Ann Neurol 2011, 69:743-758.

50. Vinall J, Grunau RE, Brant R, Chau V, Poskitt KJ, Synnes AR, Miller SP: Slower postnatal growth is associated with delayed cerebral cortical maturation in preterm newborns. Sci Transl Med 2013, 5:168ra168.

51. Volpe JJ: Encephalopathy of prematurity includes neuronal abnormalities. Pediatrics 2005, 116:221-225.

52. Riddle A, Maire J, Gong X, Chen KX, Kroenke CD, Hohimer AR, Back SA: Differential susceptibility to axonopathy in necrotic and non-necrotic perinatal white matter injury. Stroke 2012, 43:178-184.

53. Kanold PO, Luhmann HJ: The subplate and early cortical circuits. Annu Rev Neurosci 2010, 33:23-48.

54. McQuillen PS, Ferriero DM: Perinatal subplate neuron injury: implications for cortical development and plasticity. Brain Pathol 2005, 15:250-260.

55. McQuillen PS, Sheldon RA, Shatz CJ, Ferriero DM: Selective vulnerability of subplate neurons after early neonatal hypoxia-ischemia. J Neurosci 2003, 23:3308-3315.

56. Wang WZ, Hoerder-Suabedissen A, Oeschger FM, Bayatti N, Ip BK, Lindsay S, Supramaniam V, Srinivasan L, Rutherford M, Mollgard K, Clowry GJ, Molnar Z: Subplate in the developing cortex of mouse and human. J Anat 2010, 217:368-380.

57. Glass HC, Glidden D, Jeremy RJ, Barkovich AJ, Ferriero DM, Miller SP: Clinical Neonatal Seizures are Independently Associated with Outcome in Infants at Risk for Hypoxic-Ischemic Brain Injury. J Pediatr 2009, 155:318-323.

58. Gluckman PD, Wyatt JS, Azzopardi D, Ballard R, Edwards AD, Ferriero DM, Polin RA, Robertson CM, Thoresen M, Whitelaw A, Gunn AJ: Selective head cooling with mild systemic hypothermia after neonatal encephalopathy: multicentre randomised trial. Lancet 2005, 365:663-670.

59. Miller SP, Weiss J, Barnwell A, Ferriero DM, Latal-Hajnal B, Ferrer-Rogers A, Newton N, Partridge JC, Glidden DV, Vigneron DB, Barkovich AJ: Seizure-associated brain injury in term newborns with perinatal asphyxia. Neurology 2002, 58:542-548.

60. Rosen I: The physiological basis for continuous electroencephalogram monitoring in the neonate. Clin Perinatol 2006, 33:593-611, v.

61. Davidson JO, Quaedackers JS, George SA, Gunn AJ, Bennet L: Maternal dexamethasone and EEG hyperactivity in preterm fetal sheep. J Physiol 2011, 589:3823-3835.

62. Gavilanes AW, Gantert M, Strackx E, Zimmermann LJ, Seeldrayers S, Vles JS, Kramer BW: Increased EEG delta frequency corresponds to chorioamnionitis-related brain injury. Front Biosci (Schol Ed) 2010, 2:432-438.

63. Billiards SS, Haynes RL, Folkerth RD, Borenstein NS, Trachtenberg FL, Rowitch DH, Ligon KL, Volpe JJ, Kinney HC: Myelin abnormalities without oligodendrocyte loss in periventricular leukomalacia. Brain Pathol 2008, 18:153-163.

64. Haynes RL, Folkerth RD, Trachtenberg FL, Volpe JJ, Kinney HC: Nitrosative stress and inducible nitric oxide synthase expression in periventricular leukomalacia. Acta Neuropathol 2009, 118:391-399. 
65. Back SA, Luo NL, Mallinson RA, O'Malley JP, Wallen LD, Frei B, Morrow JD, Petito CK, Roberts CT, Jr., Murdoch GH, Montine TJ: Selective vulnerability of preterm white matter to oxidative damage defined by F2-isoprostanes. Ann Neurol 2005, 58:108-120.

66. Back SA, Gan X, Li Y, Rosenberg PA, Volpe JJ: Maturation-dependent vulnerability of oligodendrocytes to oxidative stress-induced death caused by glutathione depletion. J Neurosci 1998, 18:6241-6253.

67. Li J, Ramenaden ER, Peng J, Koito H, Volpe JJ, Rosenberg PA: Tumor necrosis factor alpha mediates lipopolysaccharide-induced microglial toxicity to developing oligodendrocytes when astrocytes are present. J Neurosci 2008, 28:5321-5330.

68. Cai Z, Lin S, Fan LW, Pang Y, Rhodes PG: Minocycline alleviates hypoxic-ischemic injury to developing oligodendrocytes in the neonatal rat brain. Neuroscience 2006, 137:425-435.

69. Li J, Baud O, Vartanian T, Volpe JJ, Rosenberg PA: Peroxynitrite generated by inducible nitric oxide synthase and NADPH oxidase mediates microglial toxicity to oligodendrocytes. Proc Natl Acad Sci USA 2005, 102:9936-9941.

70. Kaindl AM, Favrais G, Gressens P: Molecular mechanisms involved in injury to the preterm brain. J Child Neurol 2009, 24:1112-1118.

71. Ferriero DM: Neonatal brain injury. N Engl J Med 2004, 351:1985-1995.

72. Czeh M, Gressens P, Kaindl AM: The yin and yang of microglia. Dev Neurosci 2011, 33:199-209.

73. Block ML, Zecca L, Hong JS: Microglia-mediated neurotoxicity: uncovering the molecular mechanisms. Nat Rev Neurosci 2007, 8:57-69.

74. Hanisch UK, Kettenmann H: Microglia: active sensor and versatile effector cells in the normal and pathologic brain. Nat Neurosci 2007, 10:1387-1394.

75. Saijo K, Glass CK: Microglial cell origin and phenotypes in health and disease. Nat Rev Immunol 2011, 11:775-787.

76. Vontell R, Supramaniam V, Thornton C, Wyatt-Ashmead J, Mallard C, Gressens P, Rutherford M, Hagberg $\mathrm{H}$ : Toll-like receptor 3 expression in glia and neurons alters in response to white matter injury in preterm infants. Dev Neurosci 2013, 35:130-139.

77. Ekdahl CT, Kokaia Z, Lindvall O: Brain inflammation and adult neurogenesis: the dual role of microglia. Neuroscience 2009, 158:1021-1029.

78. Kaindl AM, Degos V, Peineau S, Gouadon E, Chhor V, Loron G, Le Charpentier T, Josserand J, Ali C, Vivien D, Collingridge GL, Lombet A, Issa L, Rene F, Loeffler JP, Kavelaars A, Verney C, Mantz J, Gressens P: Activation of microglial $\mathrm{N}$-methyl-D-aspartate receptors triggers inflammation and neuronal cell death in the developing and mature brain. Ann Neurol 2012, 72:536-549.

79. Billiards SS, Haynes RL, Folkerth RD, Trachtenberg FL, Liu LG, Volpe JJ, Kinney HC: Development of microglia in the cerebral white matter of the human fetus and infant. J Comp Neurol 2006, 497:199208.

80. Edwards AD, Brocklehurst P, Gunn AJ, Halliday H, Juszczak E, Levene $M$, Strohm B, Thoresen $M$, Whitelaw A, Azzopardi D: Neurological outcomes at 18 months of age after moderate hypothermia for perinatal hypoxic ischaemic encephalopathy: synthesis and meta-analysis of trial data. BMJ 2010, 340:c363.

81. Jacobs S, Hunt R, Tarnow-Mordi W, Inder T, Davis P: Cooling for newborns with hypoxic ischaemic encephalopathy. Cochrane Database Syst Rev 2007, 4:CD003311.

82. Azzopardi DV, Strohm B, Edwards AD, Dyet L, Halliday HL, Juszczak E, Kapellou O, Levene M, Marlow N, Porter E, Thoresen M, Whitelaw A, Brocklehurst P: Moderate hypothermia to treat perinatal asphyxial encephalopathy. N Engl J Med 2009, 361:1349-1358.

83. Bennet L, Tan S, Van den Heuij L, Derrick M, Groenendaal F, van Bel F, Juul S, Back SA, Northington F, Robertson NJ, Mallard C, Gunn AJ: Cell therapy for neonatal hypoxia-ischemia and cerebral palsy. Ann Neurol 2012, 71:589-600.

84. Titomanlio L, Kavelaars A, Dalous J, Mani S, El Ghouzzi V, Heijnen C, Baud O, Gressens P: Stem cell therapy for neonatal brain injury: Perspectives and Challenges. Ann Neurol 2011, 70:698-712.

85. van Velthoven CTJ, Kavelaars A, van Bel F, Heijnen CJ: Regeneration of the ischemic brain by engineered stem cells: Fuelling endogenous repair processes. Brain Res Rev 2009, 61:1-13. 


\section{Chapter 1}

86. Gortner L, Felderhoff-Muser U, Monz D, Bieback K, Kluter H, Jellema R, Kramer BW, Keller M, Reiss I, Horn PA, Giebel B: Regenerative Therapies in Neonatology: Clinical Perspectives. Klin Padiatr 2012, 224:233-240.

87. Borlongan CV, Weiss MD: Baby STEPS: a giant leap for cell therapy in neonatal brain injury. Pediatr Res 2011, 70:3-9.

88. van Velthoven CT, Kavelaars A, Heijnen CJ: Mesenchymal stem cells as a treatment for neonatal ischemic brain damage. Pediatr Res 2012, 71:474-481.

89. Donega V, van Velthoven $\mathrm{CT}$, Nijboer $\mathrm{CH}$, Kavelaars A, Heijnen $\mathrm{CJ}$ : The endogenous regenerative capacity of the damaged newborn brain: boosting neurogenesis with mesenchymal stem cell treatment. J Cereb Blood Flow Metab 2013.

90. Dalous J, Pansiot J, Pham H, Chatel P, Nadaradja C, D'Agostino I, Vottier G, Schwendimann L, Vanneaux V, Charriaut-Marlangue C, Titomanlio L, Gressens P, Larghero J, Baud O: Use of human umbilical cord blood mononuclear cells to prevent perinatal brain injury: a preclinical study. Stem Cells Dev 2013, 22:169-179.

91. Fleiss B, Guillot PV, Titomanlio L, Baud O, Hagberg H, Gressens P: Stem cell therapy for neonatal brain injury. Clin Perinatol 2014, 41:133-148.

92. Jiang $Y$, Jahagirdar BN, Reinhardt RL, Schwartz RE, Keene CD, Ortiz-Gonzalez XR, Reyes M, Lenvik T, Lund T, Blackstad M, Du J, Aldrich S, Lisberg A, Low WC, Largaespada DA, Verfaillie CM: Pluripotency of mesenchymal stem cells derived from adult marrow. Nature 2002, 418:41-49.

93. Mendez-Ferrer S, Michurina TV, Ferraro F, Mazloom AR, Macarthur BD, Lira SA, Scadden DT, Ma'ayan A, Enikolopov GN, Frenette PS: Mesenchymal and haematopoietic stem cells form a unique bone marrow niche. Nature 2010, 466:829-834.

94. Uccelli A, Moretta L, Pistoia V: Mesenchymal stem cells in health and disease. Nat Rev Immunol 2008, 8:726-736.

95. Le Blanc K, Mougiakakos D: Multipotent mesenchymal stromal cells and the innate immune system. Nat Rev Immunol 2012, 12:383-396.

96. Gentry T, Foster S, Winstead L, Deibert E, Fiordalisi M, Balber A: Simultaneous isolation of human BM hematopoietic, endothelial and mesenchymal progenitor cells by flow sorting based on aldehyde dehydrogenase activity: implications for cell therapy. Cytotherapy 2007, 9:259-274.

97. Wagner W, Wein F, Seckinger A, Frankhauser M, Wirkner U, Krause U, Blake J, Schwager C, Eckstein V, Ansorge W, Ho AD: Comparative characteristics of mesenchymal stem cells from human bone marrow, adipose tissue, and umbilical cord blood. Exp Hematol 2005, 33:1402-1416.

98. Bieback K, Schallmoser K, Kluter H, Strunk D: Clinical Protocols for the Isolation and Expansion of Mesenchymal Stromal Cells. Transfus Med Hemother 2008, 35:286-294.

99. Dicker A, Le Blanc K, Astrom G, van Harmelen V, Gotherstrom C, Blomqvist L, Arner P, Ryden M: Functional studies of mesenchymal stem cells derived from adult human adipose tissue. Exp Cell Res 2005, 308:283-290.

100. Portmann-Lanz CB, Schoeberlein A, Huber A, Sager R, Malek A, Holzgreve W, Surbek DV: Placental mesenchymal stem cells as potential autologous graft for pre- and perinatal neuroregeneration. AJOG 2006, 194:664-673.

101. Lee OK, Kuo TK, Chen WM, Lee KD, Hsieh SL, Chen TH: Isolation of multipotent mesenchymal stem cells from umbilical cord blood. Blood 2004, 103:1669-1675.

102. Wang $M$, Yang Y, Yang D, Luo F, Liang W, Guo S, Xu J: The immunomodulatory activity of human umbilical cord blood-derived mesenchymal stem cells in vitro. Immunology 2009, 126:220-232.

103. Bieback K, Kern S, Kluter H, Eichler H: Critical parameters for the isolation of mesenchymal stem cells from umbilical cord blood. Stem cells 2004, 22:625-634.

104. Secco M, Zucconi E, Vieira NM, Fogaca LLQ, Cerqueira A, Carvalho MDF, Jazedje T, Okamoto OK, Muotri AR, Zatz M: Multipotent stem cells from umbilical cord: cord is richer than blood! Stem Cells 2008, 26:146-150.

105. Lu X, Alshemali S, de Wynter EA, Dickinson AM: Mesenchymal stem cells from CD34 human umbilical cord blood. Transfus Med 2010, 20:178-184. 
106. Tondreau T, Meuleman N, Delforge A, Dejeneffe M, Leroy R, Massy M, Mortier C, Bron D, Lagneaux L: Mesenchymal stem cells derived from CD133-positive cells in mobilized peripheral blood and cord blood: proliferation, Oct4 expression, and plasticity. Stem Cells 2005, 23:1105-1112.

107. Pereira WC, Khushnooma I, Madkaikar M, Ghosh K: Reproducible methodology for the isolation of mesenchymal stem cells from human umbilical cord and its potential for cardiomyocyte generation. $J$ Tissue Eng Regen Med 2008, 2.

108. Sarugaser R, Lickorish D, Baksh D, Hosseini MM, Davies JE: Human umbilical cord perivascular (HUCPV) cells: a source of mesenchymal progenitors. Stem cells 2005, 23:220-229.

109. Dominici M, Le Blanc K, Mueller I, Slaper-Cortenbach I, Marini FC, Krause DS, Deans RJ, Keating A, Prockop DJ, Horwitz EM: Minimal criteria for defining multipotent mesenchymal stromal cells. The International Society for Cellular Therapy position statement. Cytotherapy 2006, 8:315-317.

110. Siegel G, Schafer R, Dazzi F: The immunosuppressive properties of mesenchymal stem cells. Transplantation 2009, 87:S45-49.

111. Aggarwal S, Pittenger MF: Human mesenchymal stem cells modulate allogeneic immune cell responses. Blood 2005, 105:1815-1822.

112. Di Nicola M, Carlo-Stella C, Magni M, Milanesi M, Longoni PD, Matteucci P, Grisanti S, Gianni AM: Human bone marrow stromal cells suppress T-lymphocyte proliferation induced by cellular or nonspecific mitogenic stimuli. Blood 2002, 99:3838-3843.

113. Selmani Z, Naji A, Zidi I, Favier B, Gaiffe E, Obert L, Borg C, Saas P, Tiberghien P, Rouas-Freiss N, Carosella ED, Deschaseaux F: Human leukocyte antigen-G5 secretion by human mesenchymal stem cells is required to suppress $T$ lymphocyte and natural killer function and to induce CD4+CD25highFOXP3+ regulatory T cells. Stem Cells 2008, 26:212-222.

114. Le Blanc K, Rasmusson I, Sundberg B, Gotherstrom C, Hassan M, Uzunel M, Ringden O: Treatment of severe acute graft-versus-host disease with third party haploidentical mesenchymal stem cells. Lancet 2004, 363:1439-1441.

115. Gerdoni E, Gallo B, Casazza S, Musio S, Bonanni I, Pedemonte E, Mantegazza R, Frassoni F, Mancardi G, Pedotti R, Uccelli A: Mesenchymal stem cells effectively modulate pathogenic immune response in experimental autoimmune encephalomyelitis. Ann Neurol 2007, 61:219-227.

116. Aslam M, Baveja R, Liang OD, Fernandez-Gonzalez A, Lee C, Mitsialis SA, Kourembanas S: Bone marrow stromal cells attenuate lung injury in a murine model of neonatal chronic lung disease. Am J Respir Crit Care Med 2009, 180:1122-1130.

117. van Haaften T, Byrne R, Bonnet S, Rochefort GY, Akabutu J, Bouchentouf M, Rey-Parra GJ, Galipeau J, Haromy A, Eaton F, Chen M, Hashimoto K, Abley D, Korbutt G, Archer SL, Thebaud B: Airway delivery of mesenchymal stem cells prevents arrested alveolar growth in neonatal lung injury in rats. Am J Respir Crit Care Med 2009, 180:1131-1142.

118. Zhang X, Wang H, Shi Y, Peng W, Zhang S, Zhang W, Xu J, Mei Y, Feng Z: Role of bone marrow-derived mesenchymal stem cells in the prevention of hyperoxia-induced lung injury in newborn mice. Cell Biol Int 2012, 36:589-594.

119. Uccelli A, Benvenuto F, Laroni A, Giunti D: Neuroprotective features of mesenchymal stem cells. Best Pract Res Clin Haematol 2011, 24:59-64.

120. Zhang ZG, Chopp M: Neurorestorative therapies for stroke: underlying mechanisms and translation to the clinic. Lancet Neurol 2009, 8:491-500.

121. van Velthoven CT, Kavelaars A, van Bel F, Heijnen CJ: Mesenchymal stem cell treatment after neonatal hypoxic-ischemic brain injury improves behavioral outcome and induces neuronal and oligodendrocyte regeneration. Brain Behav Immun 2010, 24:387-393.

122. van Velthoven CT, Kavelaars A, van Bel F, Heijnen CJ: Repeated mesenchymal stem cell treatment after neonatal hypoxia-ischemia has distinct effects on formation and maturation of new neurons and oligodendrocytes leading to restoration of damage, corticospinal motor tract activity, and sensorimotor function. J Neurosci 2010, 30:9603-9611. 


\section{Chapter 1}

123. Steffenhagen C, Dechant FX, Oberbauer E, Furtner T, Weidner N, Kury P, Aigner L, Rivera FJ: Mesenchymal stem cells prime proliferating adult neural progenitors toward an oligodendrocyte fate. Stem Cells Dev 2012, 21:1838-1851.

124. Rivera FJ, Couillard-Despres S, Pedre X, Ploetz S, Caioni M, Lois C, Bogdahn U, Aigner L: Mesenchymal stem cells instruct oligodendrogenic fate decision on adult neural stem cells. Stem Cells 2006, 24:22092219.

125. Busch SA, Hamilton JA, Horn KP, Cuascut FX, Cutrone R, Lehman N, Deans RJ, Ting AE, Mays RW, Silver J: Multipotent adult progenitor cells prevent macrophage-mediated axonal dieback and promote regrowth after spinal cord injury. J Neurosci 2011, 31:944-953.

126. Kopen GC, Prockop DJ, Phinney DG: Marrow stromal cells migrate throughout forebrain and cerebellum, and they differentiate into astrocytes after injection into neonatal mouse brains. Proc Natl Acad Sci U S A 1999, 96:10711-10716.

127. Brazelton TR, Rossi FM, Keshet GI, Blau HM: From marrow to brain: expression of neuronal phenotypes in adult mice. Science 2000, 290:1775-1779.

128. Pittenger MF, Mackay AM, Beck SC, Jaiswal RK, Douglas R, Mosca JD, Moorman MA, Simonetti DW, Craig S, Marshak DR: Multilineage potential of adult human mesenchymal stem cells. Science 1999, 284:143-147.

129. Lee RH, Pulin AA, Seo MJ, Kota DJ, Ylostalo J, Larson BL, Semprun-Prieto L, Delafontaine P, Prockop DJ: Intravenous hMSCs improve myocardial infarction in mice because cells embolized in lung are activated to secrete the anti-inflammatory protein TSG-6. Cell Stem Cell 2009, 5:54-63.

130. van Velthoven CT, Kavelaars A, van Bel F, Heijnen CJ: Mesenchymal stem cell transplantation changes the gene expression profile of the neonatal ischemic brain. Brain Behav Immun 2011.

131. Giebel B, Punzel M: Lineage development of hematopoietic stem and progenitor cells. Biol Chem 2008, 389:813-824.

132. King KY, Goodell MA: Inflammatory modulation of HSCs: viewing the HSC as a foundation for the immune response. Nat Rev Immunol 2011, 11:685-692.

133. Trumpp A, Essers M, Wilson A: Awakening dormant haematopoietic stem cells. Nat Rev Immunol 2010, 10:201-209.

134. Yoshimoto M, Yoder MC: Developmental biology: Birth of the blood cell. Nature 2009, 457:801-803.

135. Gluckman E, Wagner J, Hows J, Kernan N, Bradley B, Broxmeyer HE: Cord blood banking for hematopoietic stem cell transplantation: an international cord blood transplant registry. Bone Marrow Transplant 1993, 11:199-200.

136. Liu F, Poursine-Laurent J, Link DC: The granulocyte colony-stimulating factor receptor is required for the mobilization of murine hematopoietic progenitors into peripheral blood by cyclophosphamide or interleukin-8 but not flt-3 ligand. Blood 1997, 90:2522-2528.

137. Petit I, Szyper-Kravitz M, Nagler A, Lahav M, Peled A, Habler L, Ponomaryov T, Taichman RS, ArenzanaSeisdedos F, Fujii N, Sandbank J, Zipori D, Lapidot T: G-CSF induces stem cell mobilization by decreasing bone marrow SDF-1 and up-regulating CXCR4. Nat Immunol 2002, 3:687-694.

138. Cogle CR, Yachnis AT, Laywell ED, Zander DS, Wingard JR, Steindler DA, Scott EW: Bone marrow transdifferentiation in brain after transplantation: a retrospective study. Lancet 2004, 363:1432-1437.

139. Eglitis MA, Mezey E: Hematopoietic cells differentiate into both microglia and macroglia in the brains of adult mice. Proc Natl Acad Sci U S A 1997, 94:4080-4085.

140. Hess DC, Abe T, Hill WD, Studdard AM, Carothers J, Masuya M, Fleming PA, Drake CJ, Ogawa M: Hematopoietic origin of microglial and perivascular cells in brain. Exp Neurol 2004, 186:134-144.

141. Mezey E, Chandross KJ, Harta G, Maki RA, McKercher SR: Turning blood into brain: cells bearing neuronal antigens generated in vivo from bone marrow. Science 2000, 290:1779-1782.

142. England TJ, Abaei M, Auer DP, Lowe J, Jones DR, Sare G, Walker M, Bath PM: Granulocyte-colony stimulating factor for mobilizing bone marrow stem cells in subacute stroke: the stem cell trial of recovery enhancement after stroke 2 randomized controlled trial. Stroke 2012, 43:405-411. 
143. Kawada H, Takizawa S, Takanashi T, Morita Y, Fujita J, Fukuda K, Takagi S, Okano H, Ando K, Hotta T: Administration of hematopoietic cytokines in the subacute phase after cerebral infarction is effective for functional recovery facilitating proliferation of intrinsic neural stem/progenitor cells and transition of bone marrow-derived neuronal cells. Circulation 2006, 113:701-710.

144. Corti S, Locatelli F, Strazzer S, Salani S, Del Bo R, Soligo D, Bossolasco P, Bresolin N, Scarlato G, Comi GP: Modulated generation of neuronal cells from bone marrow by expansion and mobilization of circulating stem cells with in vivo cytokine treatment. Exp Neurol 2002, 177:443-452.

145. Hess DC, Hill WD, Martin-Studdard A, Carroll J, Brailer J, Carothers J: Bone marrow as a source of endothelial cells and NeuN-expressing cells After stroke. Stroke 2002, 33:1362-1368.

146. Tondreau T, Lagneaux L, Dejeneffe M, Massy M, Mortier C, Delforge A, Bron D: Bone marrow-derived mesenchymal stem cells already express specific neural proteins before any differentiation. Differentiation 2004, 72:319-326.

147. Urbich C, Dimmeler S: Endothelial progenitor cells: characterization and role in vascular biology. Circ Res 2004, 95:343-353.

148. Yoon CH, Hur J, Park KW, Kim JH, Lee CS, Oh IY, Kim TY, Cho HJ, Kang HJ, Chae IH, Yang HK, Oh BH, Park YB, Kim HS: Synergistic neovascularization by mixed transplantation of early endothelial progenitor cells and late outgrowth endothelial cells: the role of angiogenic cytokines and matrix metalloproteinases. Circulation 2005, 112:1618-1627.

149. Murohara T, Ikeda H, Duan J, Shintani S, Sasaki K, Eguchi H, Onitsuka I, Matsui K, Imaizumi T: Transplanted cord blood-derived endothelial precursor cells augment postnatal neovascularization. J Clin Invest 2000, 105:1527-1536.

150. Asahara T, Murohara T, Sullivan A, Silver M, van der Zee R, Li T, Witzenbichler B, Schatteman G, Isner JM: Isolation of putative progenitor endothelial cells for angiogenesis. Science 1997, 275:964-967.

151. Tillman BW, Yazdani SK, Geary RL, Corriere MA, Atala A, Yoo JJ: Efficient recovery of endothelial progenitors for clinical translation. Tissue Eng Part C Methods 2009, 15:213-221.

152. Hackam DG: Translating animal research into clinical benefit. BMJ 2007, 334:163-164.

153. Perel P, Roberts I, Sena E, Wheble P, Briscoe C, Sandercock P, Macleod M, Mignini LE, Jayaram P, Khan KS: Comparison of treatment effects between animal experiments and clinical trials: systematic review. BMJ 2007, 334:197.

154. Hackam DG, Redelmeier DA: Translation of research evidence from animals to humans. JAMA 2006, 296:1731-1732.

155. van der Worp HB, Howells DW, Sena ES, Porritt MJ, Rewell S, O'Collins V, Macleod MR: Can animal models of disease reliably inform human studies? PLoS Med 2010, 7:e1000245.

156. Gunn AJ, Bennet L: Fetal hypoxia insults and patterns of brain injury: insights from animal models. Clin Perinatol 2009, 36:579-593.

157. Rees S, Harding R, Walker D: The biological basis of injury and neuroprotection in the fetal and neonatal brain. Int J Dev Neurosci 2011, 29:551-563.

158. Back SA, Riddle A, Hohimer AR: Role of instrumented fetal sheep preparations in defining the pathogenesis of human periventricular white-matter injury. J Child Neurol 2006, 21:582-589.

159. Wolfs TG, Jellema RK, Turrisi G, Becucci E, Buonocore G, Kramer BW: Inflammation-induced immune suppression of the fetus: a potential link between chorioamnionitis and postnatal early onset sepsis. $J$ Matern Fetal Neonatal Med 2012, 25 Suppl 1:8-11.

160. Hagberg H, Peebles D, Mallard C: Models of white matter injury: comparison of infectious, hypoxicischemic, and excitotoxic insults. Ment Retard Dev Disabil Res Rev 2002, 8:30-38.

161. Rice JE, 3rd, Vannucci RC, Brierley JB: The influence of immaturity on hypoxic-ischemic brain damage in the rat. Ann Neurol 1981, 9:131-141.

162. Vannucci RC, Vannucci SJ: Perinatal hypoxic-ischemic brain damage: evolution of an animal model. Dev Neurosci 2005, 27:81-86.

163. Bennet L, Roelfsema V, George S, Dean JM, Emerald BS, Gunn AJ: The effect of cerebral hypothermia on white and grey matter injury induced by severe hypoxia in preterm fetal sheep. J Physiol 2007, 578:491506. 


\section{Chapter 1}

164. Roelfsema V, Bennet L, George S, Wu D, Guan J, Veerman M, Gunn AJ: Window of opportunity of cerebral hypothermia for postischemic white matter injury in the near-term fetal sheep. J Cereb Blood Flow Metab 2004, 24:877-886.

165. Welin AK, Sandberg M, Lindblom A, Arvidsson P, Nilsson UA, Kjellmer I, Mallard C: White matter injury following prolonged free radical formation in the 0.65 gestation fetal sheep brain. Pediatr Res 2005, 58:100-105.

166. Volpe JJ: Neurobiology of periventricular leukomalacia in the premature infant. Pediatr Res 2001, 50:553-562.

167. Jellema RK, Lima Passos V, Ophelders DR, Wolfs TG, Zwanenburg A, De Munter S, Nikiforou M, Collins JJ, Kuypers E, Bos GM, Steinbusch HW, Vanderlocht J, Andriessen P, Germeraad WT, Kramer BW: Systemic G-CSF attenuates cerebral inflammation and hypomyelination but does not reduce seizure burden in preterm sheep exposed to global hypoxia-ischemia. Exp Neurol 2013, 250C:293-303.

168. Jellema RK, Lima Passos V, Zwanenburg A, Ophelders DR, De Munter S, Vanderlocht J, Germeraad WT, Kuypers E, Collins JJ, Cleutjens JP, Jennekens W, Gavilanes AW, Seehase M, Vles HJ, Steinbusch H, Andriessen P, Wolfs TG, Kramer BW: Cerebral inflammation and mobilization of the peripheral immune system following global hypoxia-ischemia in preterm sheep. J Neuroinflammation 2013, 10:13.

169. Jellema RK, Wolfs TG, Lima Passos V, Zwanenburg A, Ophelders DR, Kuypers E, Hopman AH, Dudink J, Steinbusch HW, Andriessen P, Germeraad WT, Vanderlocht J, Kramer BW: Mesenchymal stem cells induce T-cell tolerance and protect the preterm brain after global hypoxia-ischemia. PLoS One 2013, 8:e73031.

170. Zwanenburg A, Jellema RK, Jennekens W, Ophelders D, Vullings R, van Hunnik A, van Pul C, Bennet $L$, Delhaas T, Kramer BW, Andriessen P: Heart rate-mediated blood pressure control in preterm fetal sheep under normal and hypoxic-ischemic conditions. Pediatr Res 2013, 73:420-426.

171. Niemarkt HJ, Jennekens W, Maartens IA, Wassenberg T, van Aken M, Katgert T, Kramer BW, Gavilanes AW, Zimmermann $\amalg$, Bambang Oetomo S, Andriessen P: Multi-channel amplitude-integrated EEG characteristics in preterm infants with a normal neurodevelopment at two years of corrected age. Early Hum Dev 2012, 88:209-216.

172. Ward P, Counsell S, Allsop J, Cowan F, Shen Y, Edwards D, Rutherford M: Reduced fractional anisotropy on diffusion tensor magnetic resonance imaging after hypoxic-ischemic encephalopathy. Pediatrics 2006, 117:e619-630.

173. Dudink J, Kerr JL, Paterson K, Counsell SJ: Connecting the developing preterm brain. Early Hum Dev 2008, 84:777-782.

174. Dudink J, Lequin M, van Pul C, Buijs J, Conneman N, van Goudoever J, Govaert P: Fractional anisotropy in white matter tracts of very-low-birth-weight infants. Pediatr Radiol 2007, 37:1216-1223.

175. Schwartz M: The emergence of a new science of the mind: immunology benefits the mind. Mol Psychiatry 2010, 15:337-338.

176. Offner $H$, Vandenbark AA, Hurn PD: Effect of experimental stroke on peripheral immunity: CNS ischemia induces profound immunosuppression. Neurosci 2009, 158:1098-1111.

177. Koh SH, Kim KS, Choi MR, Jung KH, Park KS, Chai YG, Roh W, Hwang SJ, Ko HJ, Huh YM, Kim HT, Kim SH: Implantation of human umbilical cord-derived mesenchymal stem cells as a neuroprotective therapy for ischemic stroke in rats. Brain Res 2008, 1229:233-248.

178. Schwarting S, Litwak S, Hao W, Bahr M, Weise J, Neumann H: Hematopoietic stem cells reduce postischemic inflammation and ameliorate ischemic brain injury. Stroke 2008, 39:2867-2875.

179. Taguchi A, Soma T, Tanaka H, Kanda T, Nishimura H, Yoshikawa H, Tsukamoto Y, Iso H, Fujimori Y, Stern DM, Naritomi H, Matsuyama T: Administration of CD34+ cells after stroke enhances neurogenesis via angiogenesis in a mouse model. J Clin Invest 2004, 114:330-338.

180. Vendrame M, Cassady J, Newcomb J, Butler T, Pennypacker KR, Zigova T, Sanberg CD, Sanberg PR, Willing AE: Infusion of human umbilical cord blood cells in a rat model of stroke dose-dependently rescues behavioral deficits and reduces infarct volume. Stroke 2004, 35:2390-2395. 
181. Vendrame M, Gemma C, de Mesquita D, Collier L, Bickford PC, Sanberg CD, Sanberg PR, Pennypacker KR, Willing AE: Anti-inflammatory effects of human cord blood cells in a rat model of stroke. Stem Cells Dev 2005, 14:595-604.

182. Vendrame M, Gemma C, Pennypacker KR, Bickford PC, Davis Sanberg C, Sanberg PR, Willing AE: Cord blood rescues stroke-induced changes in splenocyte phenotype and function. Exp Neurol 2006, 199:191-200.

183. Borlongan CV, Hadman M, Sanberg CD, Sanberg PR: Central nervous system entry of peripherally injected umbilical cord blood cells is not required for neuroprotection in stroke. Stroke 2004, 35:23852389.

184. Riegelsberger UM, Deten A, Posel C, Zille M, Kranz A, Boltze J, Wagner DC: Intravenous human umbilical cord blood transplantation for stroke: impact on infarct volume and caspase-3-dependent cell death in spontaneously hypertensive rats. Exp Neurol 2011, 227:218-223.

185. Donega V, van Velthoven CT, Nijboer CH, van Bel F, Kas MJ, Kavelaars A, Heijnen CJ: Intranasal mesenchymal stem cell treatment for neonatal brain damage: long-term cognitive and sensorimotor improvement. PLoS One 2013, 8:e51253.

186. van Velthoven CT, van de Looij Y, Kavelaars A, Zijlstra J, van Bel F, Huppi PS, Sizonenko S, Heijnen CJ: Mesenchymal stem cells restore cortical rewiring after neonatal ischemia in mice. Ann Neurol 2012, 71:785-796.

187. Xia G, Hong X, Chen X, Lan F, Zhang G, Liao L: Intracerebral transplantation of mesenchymal stem cells derived from human umbilical cord blood alleviates hypoxic ischemic brain injury in rat neonates. $J$ Perinat Med 2010, 38:215-221.

188. Yasuhara T, Matsukawa N, Yu G, Xu L, Mays RW, Kovach J, Deans R, Hess DC, Carroll JE, Borlongan CV: Transplantation of cryopreserved human bone marrow-derived multipotent adult progenitor cells for neonatal hypoxic-ischemic injury: targeting the hippocampus. Rev Neurosci 2006, 17:215-225.

189. Yasuhara T, Matsukawa N, Yu G, Xu L, Mays RW, Kovach J, Deans RJ, Hess DC, Carroll JE, Borlongan CV: Behavioral and histological characterization of intrahippocampal grafts of human bone marrow-derived multipotent progenitor cells in neonatal rats with hypoxic-ischemic injury. Cell Transplant 2006, 15:231238.

190. Chung DJ, Choi CB, Lee SH, Kang EH, Lee JH, Hwang SH, Han H, Choe BY, Lee SY, Kim HY: Intraarterially delivered human umbilical cord blood-derived mesenchymal stem cells in canine cerebral ischemia. $J$ Neurosci Res 2009, 87:3554-3567.

191. Lee JA, Kim BI, Jo CH, Choi CW, Kim EK, Kim HS, Yoon KS, Choi JH: Mesenchymal stem-cell transplantation for hypoxic-ischemic brain injury in neonatal rat model. Pediatr Res 2010, 67:42-46.

192. Perasso L, Cogo CE, Giunti D, Gandolfo C, Ruggeri P, Uccelli A, Balestrino M: Systemic administration of mesenchymal stem cells increases neuron survival after global cerebral ischemia in vivo (2VO). Neural Plast 2010, 2010:534925.

193. Pimentel-Coelho PM, Magalhães ES, Lopes LM, deAzevedo LC, Santiago MF, Mendez-Otero R: Human cord blood transplantation in a neonatal rat model of hypoxic-ischemic brain damage: functional outcome related to neuroprotection in the striatum. Stem Cells Dev 2010, 19:351-358.

194. Yasuhara T, Hara K, Maki M, Mays RW, Deans RJ, Hess DC, Carroll JE, Borlongan CV: Intravenous grafts recapitulate the neurorestoration afforded by intracerebrally delivered multipotent adult progenitor cells in neonatal hypoxic-ischemic rats. J Cereb Blood Flow Metab 2008, 28:1804-1810. 



\section{Chapter 2}

\section{Heart rate mediated blood pressure control in preterm fetal sheep under normal and hypoxic-ischemic conditions}

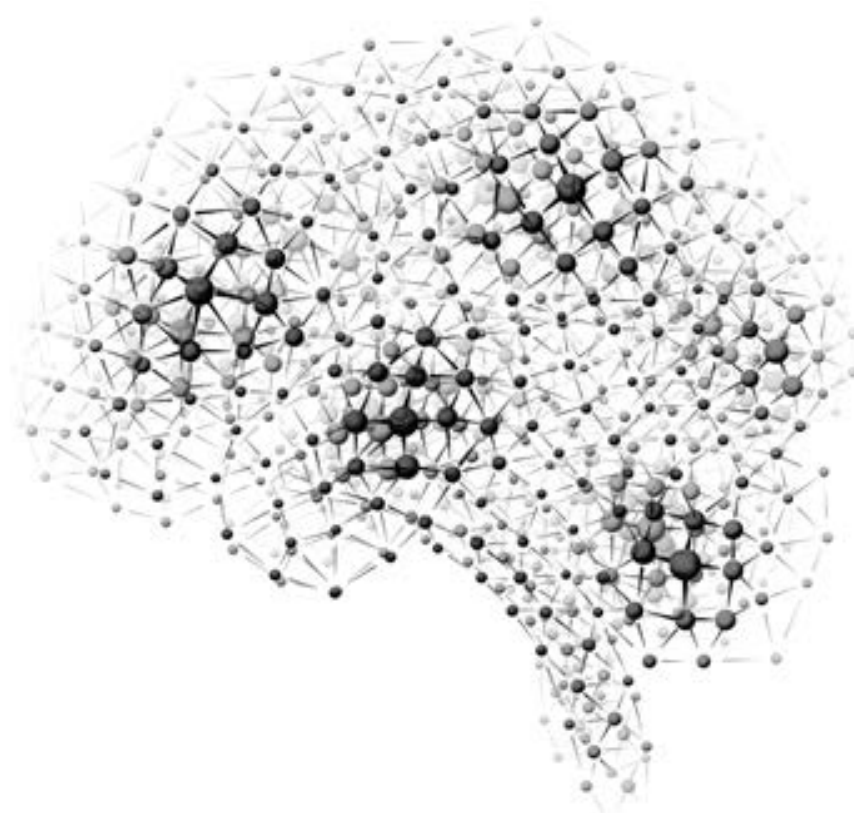

Published as: *Zwanenburg A, *Jellema RK, Jennekens W, Ophelders D, Vullings R, van Hunnik A, van Pul C, Bennet L, Delhaas T, Kramer BW, Andriessen P: Heart rate-mediated blood pressure control in preterm fetal sheep under normal and hypoxic-ischemic conditions. Pediatr Res 2013, 73:420-426. * both authors contributed equally 


\section{Abstract}

The understanding of hypoxemia-induced changes in baroreflex function is limited and may be studied in a fetal sheep experiment before, during, and after standardized hypoxic conditions.

Preterm fetal lambs were instrumented at 102 days gestation (term: 146 days). At 106 days intra-uterine hypoxic-ischemia was induced by 25 -min of umbilical cord occlusion (UCO). Baroreflex related fluctuations were calculated at 30-min intervals during the first week after UCO by transfer function (cross-spectral) analysis between systolic blood pressure and R-R interval fluctuations, estimated in the low frequency (LF, 0.04$0.15 \mathrm{~Hz}$ ) band. LF transfer gain (baroreflex sensitivity) and delay (s) reflect the baroreflex function.

Baseline showed no differences in LF transfer gain and delay between controls and UCO. In controls, LF gain showed postnatal increase. In contrast, LF gain gradually decreased in the UCO group, resulting in significantly lower values 4-7 days after UCO. In the UCO group, LF delay increased and differed significantly from controls.

Our results show that intra-uterine hypoxic-ischemia results in reduced baroreflex sensitivity over a period of 7 days, indicating limited efficacy to buffer blood pressure changes by adapting heart rate. Cardiovascular dysregulation may augment already present cerebral damage after systemic hypoxic-ischemia in the reperfusion period. 


\section{Introduction}

Preterm infants have a higher incidence of neurological morbidity and mortality compared to term infants [1]. Neurological sequelae in preterm infants may be the consequence of hypoxic-ischemia during fetal and early postnatal life [2]. Hemodynamic factors during hypoxic-ischemia and the post-hypoxic-ischemia reperfusion phase contribute considerably to these neurological disorders [3]. To ensure adequate blood flow to organs throughout the body, including the brain, blood pressure is controlled by baro- and chemoreflex mechanisms. Under normoxaemia, the baroreflex stabilizes perfusion pressure in the face of disturbances of circulatory homeostasis by adapting heart rate, myocardial contraction and vascular resistance. A poorly developed baroreflex function could contribute to blood pressure instabilities, which may lead to impaired cerebral perfusion or hemorrhage [4]. A better understanding of the dynamics underlying the control mechanisms regulating blood pressure may be useful to improve diagnosis of these disorders.

Low-frequency (LF) fluctuations in arterial blood pressure with a wave length of approximate $10 \mathrm{~s}$ (also called Mayer waves) have historically been attributed to baroreflex activity [5]. The oscillations are assumed to be caused by a feedback control and mediated through the sympathetic and parasympathetic innervations of the baroreflex [6]. Assessment of the baroreflex function (i.e. heart rate mediated blood pressure control) can be obtained through quantification of baroreceptor sensitivity. Baroreceptor sensitivity ( $\mathrm{ms} / \mathrm{mmHg}$ ) may simply be defined as the change in heart rate (or R-R interval) in response to changes in arterial blood pressure, and may be estimated from LF cross spectral analysis of spontaneous fluctuations in R-R intervals and blood pressure [7-10].

Our understanding of the cardiovascular response of the human preterm infant is limited [11, 12] and knowledge of fetal baroreflex is mostly based on animal (sheep) models $[13,14]$. There is, however, conflicting evidence on the fetal and postnatal development of baroreceptor reflex function. While some studies show increasing baroreflex sensitivity with age, other studies show no significant maturational change [15-18]. The cardiovascular system responds to hypoxic-ischemia by changing heart rate and redistributing cardiac output to preserve the limited energy resources and maintain adequate supply to the brain. Current knowledge about how the preterm fetus, hampered by an immature blood pressure regulation, responds to hypoxia is limited. Experiments have shown that the immature sheep fetus can survive prolonged periods of hypoxic-ischemia, but resulting hypotension and hypoperfusion may contribute to cerebral injury as seen in human preterm fetuses $[13,19,20]$. These studies mainly focus on cerebrovascular and fetal heart rate response following hypoxic-ischemia for $72 \mathrm{~h}$. Heart rate mediated blood pressure control has not been examined for longer than several days after the initial period of hypoxic-ischemia. 
The aim of this study was (a) to quantify baroreflex mediated heart rate response (baroreflex sensitivity) by transfer function analysis between low-frequency R-R and systolic blood pressure fluctuations in an instrumented preterm fetal sheep model and (b) to evaluate longitudinal changes of baroreflex mediated heart rate response during the first week following umbilical cord occlusion (UCO) induced hypoxic-ischemia.

\section{Materials \& methods}

\section{Animals}

Texel ewes were date-mated and the fetuses were randomized for UCO or control. The study group consisted of 14 fetal sheep ( 9 controls and 5 UCO). Fetal instrumentation was performed at 0.7 GA (102 days, term 146 days). The study was conducted at Maastricht University Medical Center, Maastricht, The Netherlands, and was approved by the local Animal Ethics Research Committee.

\section{Experimental preparations}

The pregnant ewes were deprived of food, but not water, $24 \mathrm{~h}$ before surgery. They were anesthetized using $1-2 \%$ isoflurane, guided by depth of sedation. After a lower midline incision, the fetus was carefully extracted through a small incision of the uterus. The fetus was instrumented with a 3.5 French Argyle umbilical vessel catheter (Tyco Health Care Group, Mansfield, MA) in the femoral artery. The arterial catheter was utilized for continuous monitoring of fetal arterial pressure. A vascular occluder (OC16HD, in vivo Metric, Healdsburg, CA ) was placed around the umbilical cord. Three custom-made silver electrodes with fixed leads (Cooner, Chatsworth, CA) were inserted in the subdermis and fixed with sutures. These electrodes were used for electrocardiography and formed an Einthoven triangle. The fetus was then repositioned in the uterus. A catheter was inserted into the amniotic sac to monitor the amniotic fluid pressure. Before closure the amniotic cavity was filled with warm sterile saline ( $\mathrm{NaCl} 0.9 \%)$. All fetal catheters and electrode leads were exteriorized through the flank of the ewe. The lower midline incision was securely sutured. After surgery, the ewe was allowed to recover and housed in a confined space to allow continuous perfusion of catheters with heparinized saline. Post-surgery ewes received five days of intravenous amoxicillin (1000 mg) / clavulanic-acid (200 mg). During the complete course of the experiment (11 days) the animals had ad libitum access to water and food.

\section{Experimental design}

Experiments were conducted at 102 (operation) to 113 (sacrifice) days of gestation. After a recovery period of four days (GA, 106 days) the umbilical cord of the fetuses in the UCO group was occluded by rapidly inflating the occluder with sterile saline of a defined volume known to completely inflate the occluder. Verification of the occlusion 
was obtained by observation of a sudden drop in heart rate. The occlusion was discontinued after $25 \mathrm{~min}$, or earlier when mean arterial blood pressure dropped below 8 $\mathrm{mmHg}$ or asystole occurred. At the end of the occlusion, the lambs always suffered from severe bradycardia (heart rate $<90 \mathrm{bpm}$, normal approximately $180 \mathrm{bpm}$ ) or even complete cardiac arrest. If there was no increase in heart rate within $20 \mathrm{~s}$ after the end of occlusion, resuscitation was started using an injection of adrenalin $(0.1 \mathrm{mg} / \mathrm{kg})$. Arterial blood gas analysis (pO2, $\mathrm{pCO} 2, \mathrm{pH}$ ) was performed before, during and after umbilical cord occlusion to monitor the metabolic state during hypoxic-ischemia and recovery. Fetuses were studied for 7 days post-occlusion. At the end of the experiment, both ewe and fetus were euthanized by administration of pentobarbital ( $200 \mathrm{mg} / \mathrm{kg})$.

Table 1. Baseline values and long-term monitoring of blood gas, cardiovascular and transfer function parameters. Blood gas analyses, cardiovascular parameters and transfer function parameters during the baseline period and on the seventh day ( $T=144-168$ h) after UCO, respectively. Time domain and transfer function measures were determined from 30-min segments during 24 hours before and 144-168 h after occlusion, respectively. Values are expressed as mean \pm SEM or median (IQR). ${ }^{*} p<0.01,+p<0.05$ (comparison between UCO and control at corresponding time). Assessment of change between baseline and following days within group is performed by multilevel analysis (see Table 2).

\begin{tabular}{|c|c|c|c|c|}
\hline & \multicolumn{2}{|l|}{ Control group } & \multicolumn{2}{|l|}{ UCO } \\
\hline & Baseline & $T=144-168 \mathrm{~h}$ & Baseline & $T=144-168 \mathrm{~h}$ \\
\hline \multicolumn{5}{|l|}{ Blood gas analysis } \\
\hline $\mathrm{pH}$ & $7.41 \pm 0.04$ & $7.38 \pm 0.05$ & $7.41 \pm 0.03$ & $7.40 \pm 0.07$ \\
\hline Arterial $\mathrm{pCO}_{2}(\mathrm{mmHg})$ & $42 \pm 6$ & $31 \pm 10$ & $41 \pm 9$ & $41 \pm 10$ \\
\hline Arterial $\mathrm{pO}_{2}(\mathrm{mmHg})$ & $17 \pm 2$ & $17 \pm 3$ & $15 \pm 4$ & $19 \pm 6$ \\
\hline \multicolumn{5}{|l|}{$\mathbf{R}-\mathbf{R}$ interval series } \\
\hline R-R interval (ms) & $328(315-341)$ & $345(327-363)$ & $332(322-341)$ & $347(332-357)$ \\
\hline SD-RR (ms) & $21(15-25)$ & $21(18-27)$ & $21(17-24)$ & $11(9-16) *$ \\
\hline Total power $\left(\mathrm{ms}^{2}\right)$ & $184(54-451)$ & $271(149-463)$ & $258(46-406)$ & $13(2-71) *$ \\
\hline LF power $\left(\mathrm{ms}^{2}\right)$ & $138(44-144)$ & $214(144-335)$ & $116(37-359)$ & $13(1-62)^{*}$ \\
\hline \multicolumn{5}{|l|}{ SBP series } \\
\hline $\mathrm{SBP}(\mathrm{mmHg})$ & $46(43-48)$ & $49(45-50)$ & $47(39-55)$ & $52(45-57)$ \\
\hline SD-SBP (mmHg) & $1.8(1.7-2.1)$ & $2.2(2.0-2.3)$ & $1.8(1.7-1.9)$ & $1.9(1.7-2.4)$ \\
\hline Total power $\left(10^{-2} \mathrm{mmHg}^{2}\right)$ & $1.7(1.2-2.7)$ & $3.2(2.1-4.1)$ & $1.7(1.0-2.0)$ & $1.3(0.7-2.2)+$ \\
\hline LF power $\left(10^{-2} \mathrm{mmHg}^{2}\right)$ & $1.5(1.1-2.5)$ & $2.4(1.9-3.5)$ & $1.6(0.9-1.8)$ & $1.3(0.6-2.2)+$ \\
\hline SD-RR/SD-SBP (ms/mmHg) & $10.4(8.6-11.9)$ & $10.5(8.7-12.0)$ & $12.2(8.6-13.2)$ & $6.2(3.4-8.0) *$ \\
\hline \multicolumn{5}{|l|}{ Transfer function } \\
\hline Frequency $(\mathrm{Hz})$ & $0.09(0.09-0.10)$ & $0.09(0.09-0.11)$ & $0.09(0.09-0.11)$ & $0.09(0.08-0.09)$ \\
\hline Coherence & $0.62(0.61-0.65)$ & $0.65(0.63-0.68)$ & $0.64(0.63-0.67)+$ & $0.63(0.61-0.65)$ \\
\hline Gain (ms/mmHg) & $6.2(5.6-8.4)$ & $7.7(6.7-10.6)$ & $7.8(5.6-11.4)$ & $4.8(3.1-6.7)^{*}$ \\
\hline Delay (s) & $5.5(3.3-6.8)$ & $4.3(3.2-5.9)$ & $4.0(3.3-5.6)$ & $6.6(3.7-7.6)+$ \\
\hline
\end{tabular}




\section{Data acquisition}

Blood pressure, amniotic pressure and ECG data were acquired and digitized by an MPAQ unit (Maastricht-Programmable AcQuisition system, Maastricht Instruments BV, Maastricht, The Netherlands). Analog filtering was applied to the ECG data, with a 1$200 \mathrm{~Hz}$ band-pass filter. Arterial blood pressure and amniotic pressure data were not filtered. All data were sampled at $1000 \mathrm{~Hz}$. Finally, data were stored on a hard drive for off-line analysis.

\section{Data analysis}

Data were processed off-line using MATLAB R2009a (The MathWorks, Inc., Natick, MA). Recordings were divided into 30-min segments for analysis. ECG data were filtered using a $50 \mathrm{~Hz}$ infinite impulse response notch filter and $20-80 \mathrm{~Hz} 4^{\text {th }}$-order Butterworth band-pass filter, empirically found to be optimal for the R-peak detection algorithm used. Fetal blood pressure signals were filtered using a $50 \mathrm{~Hz}$ infinite impulse response notch filter and 2-16 Hz $4^{\text {th }}$-order Butterworth band-pass filter to facilitate detection by the waveform analysis algorithm. Fetal blood pressure was corrected for offset by subtraction of the low-pass filtered amniotic fluid pressure.

In each 30-min segment, R-peaks of the QRS-complex and systolic blood pressure were detected by adaptive filtering of the ECG and blood pressure waveforms, respectively. Segments containing artifacts were excluded ( $<5 \%$ of the data). The unevenly time-spaced R-R interval and SBP series were convolved with a boxcar function and subsequently resampled at $4 \mathrm{~Hz}$ using nearest-neighbor interpolation to obtain equidistant sample points [21].

\section{Spectral analysis and transfer-function analysis}

Spectral analysis offers the opportunity to decompose spontaneously occurring fluctuations in SBP and R-R interval time series into a power spectrum, and to relate the character of the fluctuations to physiological processes. Transfer function analysis (crossspectral analysis) between SBP and R-R interval series in the low-frequency band (0.04$0.15 \mathrm{~Hz}$ ) is a useful estimate of baroreflex sensitivity $[7,22,23]$. This methodology was adapted for preterm infants and we refer to previous papers for further details [11, 21]. As R-R interval and blood pressure values obtained from fetal sheep are comparable with values found in preterm infants, the same spectral analysis methodology was followed. Each 30-min segment of R-R interval and SBP series was divided into nine 192-s segments. In the 192-s segments total spectral power $(0.04-2 \mathrm{~Hz})$ and LF $(0.04-0.15 \mathrm{~Hz})$ spectral power were calculated from the auto spectra of $R-R$ interval and SBP series. From the cross spectra of R-R interval and SBP series, the coherence, transfer gain and transfer phase were calculated for the LF band. As the reliability of transfer function depends on coherence between the signals, transfer function parameters were only assessed if coherence $>0.50$. In $41 \%$ of all 192-s segments coherence was $>0.50$ and 
these segments were included for transfer function analysis. Baroreflex sensitivity was calculated as the LF transfer gain and assessed at the frequency with the highest coherence within the LF band. Baroreflex delay was calculated by dividing the transfer phase at the corresponding frequency bin by $2 \pi$-times this frequency. Time domain cross correlation of the R-R interval and SBP series was used to correct for $n \cdot 2 \pi$ phase shifts.

\section{Time domain estimates of variability}

Heart rate variability was assessed for each 192-s segment by calculating the mean R-R interval and standard deviation (SD-RR) [23]. Likewise, blood pressure variability was assessed by calculating the mean SBP and standard deviation (SD-SBP). To verify results obtained by spectral analysis, baroreceptor sensitivity was also analyzed in the time domain. To obtain a time domain estimate for baroreceptor sensitivity, SD-RR was divided by SD-SBP [21].

\section{Data processing}

Median values per 30-min segment were calculated from the underlying 192-s segments. For further analysis, 30-min segments were pooled as $6 \mathrm{~h}$ or $24 \mathrm{~h}$ values (median; (QR), depending on the mode of presentation in graph or table, respectively. The median was used because normality was not a priori assumed and to reduce the effect of outliers. Baseline values were assessed in the $24 \mathrm{~h}$ before UCO and median values for the long-term follow-up were assessed between 0-24, 24-48, 48-72, 72-96, 96-120, 120-144 and 144-168 $\mathrm{h}$ after UCO.

\section{Statistics}

Blood gas data were expressed as mean \pm SEM. Group comparisons for blood gas analysis were performed using the two-sided unpaired student t-test. Time and frequency domain estimates were expressed as median and IQR and group comparisons were analyzed using the Mann-Whitney $U$ test. As the 6-h values were normal distributed, the maturational effects on time domain and frequency domain spectral measures were evaluated using a multilevel analysis. In this analysis linear regression is estimated using the random effects model (SPSS 19.0.0, Inc., Chicago, IL), which extends the generalized linear model to allow for analysis of repeated 6-h values between and within subjects. Regression analysis results are shown with the a- and b-coefficient ( $a$, intercept; $b$, slope of regression line). A p-value $<0.05$ was considered significant. 
Table 2. Maturation of cardiovascular and transfer function parameters. Results of multi-level regression analysis using a generalized linear model to correct for repeated measurements. Regression analysis is performed according to: $f(t)=a+b \bullet x$, with a the offset, $b$ the slope and the time (days) with $t=0$ corresponding to the time of occlusion for the UCO group. Values are expressed as mean \pm SD. ${ }^{*} p<0.01,+p<0.05$.

\begin{tabular}{lll}
\hline & $\begin{array}{l}\text { Control; b } \\
\text { (change/day) }\end{array}$ & $\begin{array}{l}\text { UCO; b } \\
\text { (change/day) }\end{array}$ \\
\hline R-R interval series & & NS \\
R-R interval (ms) & $2.8 \pm 0.6^{*}$ & $\mathrm{NS}$ \\
SD-RR (ms) & $0.8 \pm 0.2^{*}$ & \\
SBP series & & $\mathrm{NS}$ \\
SBP (mmHg) & $0.4 \pm 0.1^{*}$ & $0.10 \pm 0.02^{*}$ \\
SD-SBP (mmHg) & $0.04 \pm 0.02+$ & $-0.7 \pm 0.1^{*}$ \\
SD-RR/SD-SBP (ms/mmHg) & $\mathrm{NS}$ & \\
Transfer function & & $\mathrm{NS}$ \\
Frequency (Hz) & $\mathrm{NS}$ & $\mathrm{NS}$ \\
Coherence & $\mathrm{NS}$ & $-0.7 \pm 0.1 *$ \\
LF gain (ms/mmHg) & $0.4 \pm 0.1^{*}$ & $0.5 \pm 0.1 *$ \\
LF delay (s) & $\mathrm{NS}$ &
\end{tabular}

\section{Results}

\section{Cardiovascular and transfer function parameters at baseline}

Baseline values for both the UCO and the control group were derived in the $24 \mathrm{~h}$ before the UCO (Table 1). Time domain estimates of variability were comparable in both groups. A slight but significant difference in coherence values was noted between both groups. The baseline values for LF transfer gain, delay and frequency were comparable in both groups.

\section{Cardiovascular and transfer function parameters at 144-168 $\mathrm{h}$}

At the end of the experiment, mean R-R interval, mean systolic blood pressure (SBP) and SBP standard deviation (SD-SBP) showed no differences between the intervention group and controls (Table 1 ). In contrast, the R-R interval standard deviation (SD-RR) was significantly reduced after UCO at comparable endpoint. Spectral power analysis showed significant differences in LF and total power for the R-R interval and SBP series between UCO and controls. In the UCO group, LF and total power for the R-R interval showed a 15 to 20-times reduction, compared to controls. For the SBP series, LF and total power were reduced by a factor of 2 . Transfer function analysis showed no difference in coherence or LF frequency. A slight increase in LF delay after UCO was observed 
compared to controls. Following UCO, both time domain estimate for baroreflex sensitivity (SD-RR/SD-SBP) and transfer gain were reduced by approximately $40 \%$.

\section{Maturation of cardiovascular and transfer function parameters}

Figure 1 shows the changes in short-term variability of R-R interval time series (SD-RR) and SBP (SD-SBP) time series, respectively. After UCO the decrease in SD-RR is reflected by decrease from 72-168 $\mathrm{h}$ in SD-RR/SD-SBP, time domain estimate for baroreflex sensitivity. Figure 2 shows the changes in coherence, LF transfer gain and delay. From $96 \mathrm{~h}$, LF transfer gain is decreased versus controls.

In addition, the maturational effects on time and frequency domain spectral measures were evaluated by multilevel regression analysis for both the control and UCO group using pooled 6-hr values during the first week after UCO. This model corrects for the repeated measurements within and between subjects. The results of the multilevel analysis are shown in Table 2. The control group showed a significant increase in R-R interval, SD-RR, SBP and SD-SBP. The UCO group showed a significant increase in SD-SBP, approximately 2.5-fold the magnitude of the SD-SBP increase in the control group. The multilevel analysis supported the finding that baroreflex sensitivity increases in controls, but decreases gradually after UCO induced asphyxia. Both time domain estimate for baroreflex sensitivity (SD-RR/SD-SBP) and LF transfer gain decreased by the same amount following UCO, $-0.7 \mathrm{~ms} / \mathrm{mmHg} /$ day. 
Chapter 2

a

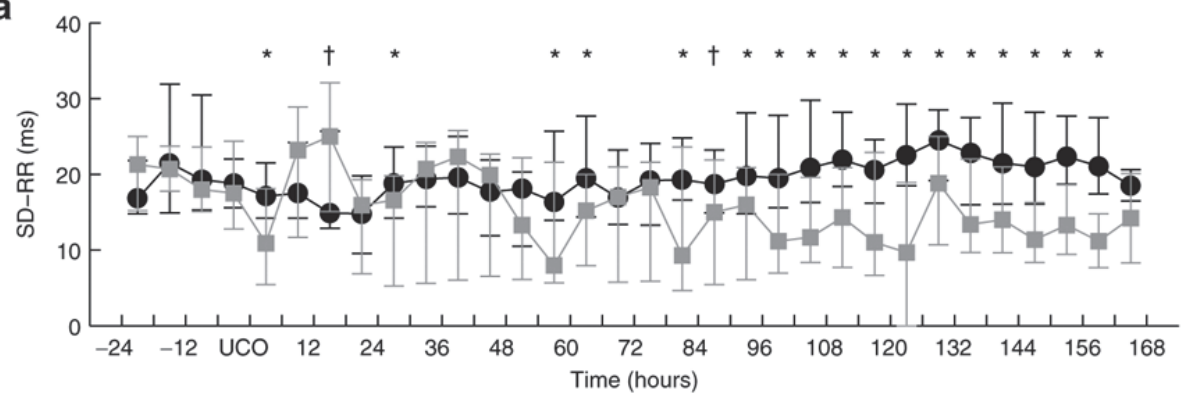

b

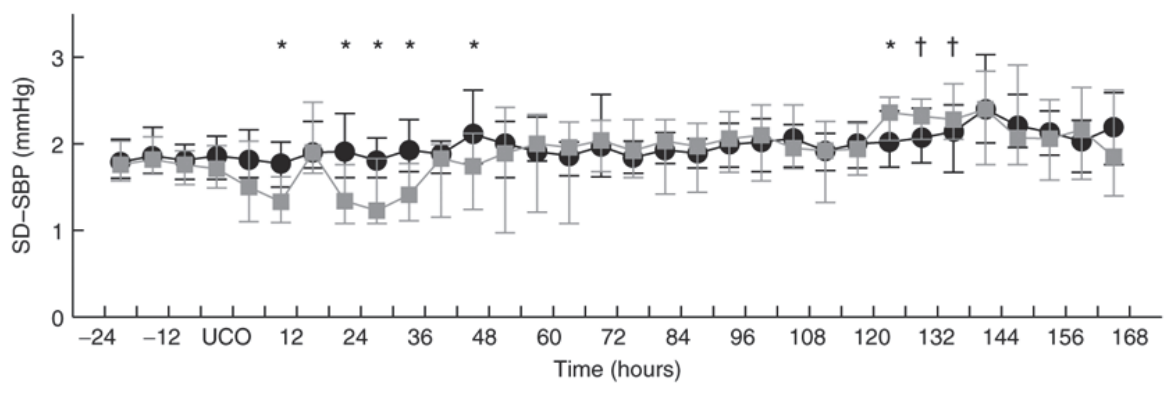

C

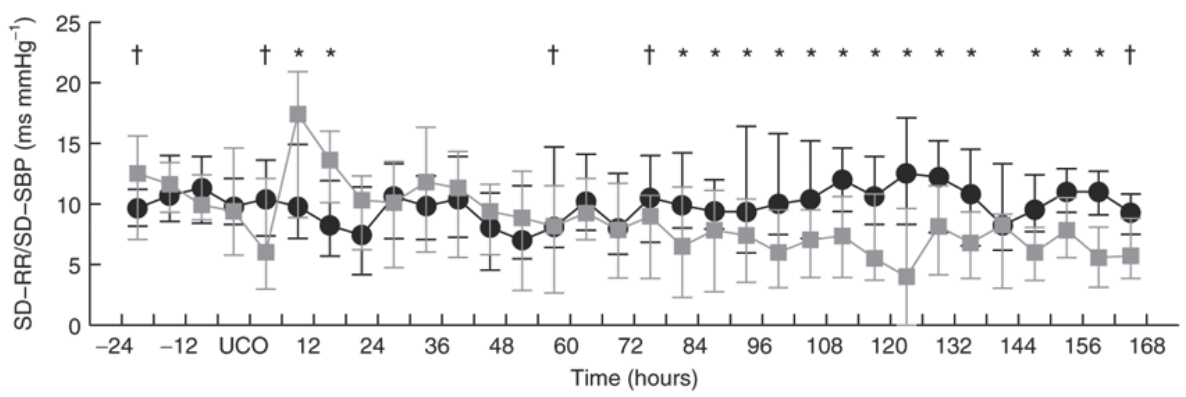

Figure 1: Longitudinal changes in $S D-R R, S D-S B P$ and $S D-R R / S D-S B P$. Legend: Plots of the longitudinal development of heart rate variability $(S D-R R, A)$, blood pressure variability $(S D-S B P, B)$ and time domain measure of baroreflex sensitivity (SD-RR/SD-SBP, C). The $x$-axis represents time in $h$. The black and gray symbols indicate the control and UCO group, respectively. The first $24 \mathrm{~h}$ after UCO significant differences are observed between UCO and control group, inherent to the experimental occlusion. After $72 \mathrm{~h}$ a consistent decrease in SD-RR and SD-RR/SD-SBP is noted. Data are shown as median and IQR for each 6-h period. * indicate $p<0.01 ; t<0.05$. 

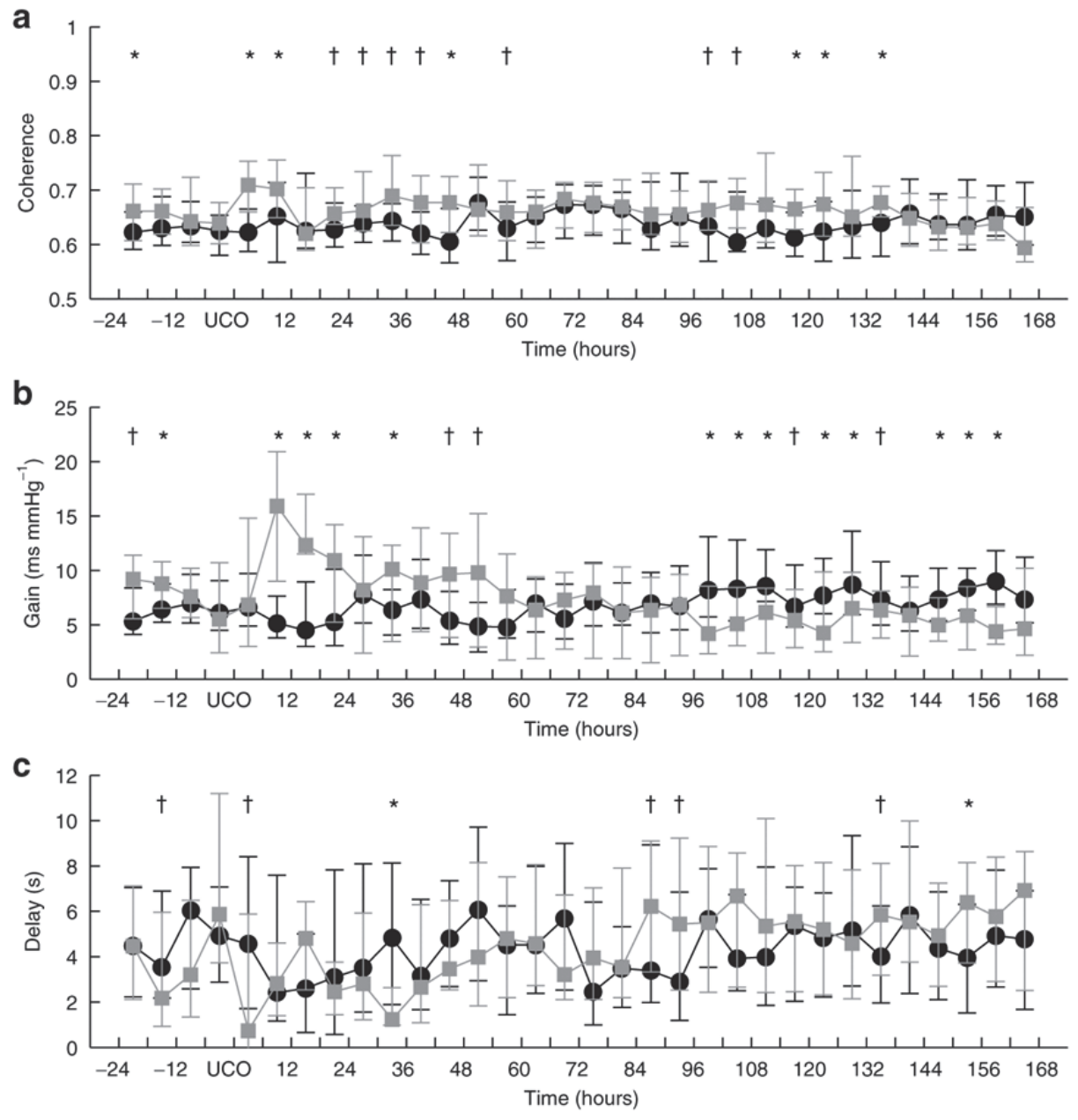

Figure 2: Longitudinal changes in coherence, LF transfer gain and delay. Legend: Plots of the longitudinal development of coherence (A), transfer gain (B) and delay (C). The $x$-axis represents time in $h$. The black and gray symbols indicate the control and UCO group, respectively. The first 24 h after UCO significant differences are observed between UCO and control group, inherent to the experimental occlusion. After $96 \mathrm{~h}$ a consistent decrease in LF transfer gain is noted. Data are shown as median and IQR for each 6-h period. * indicate $p<$ $0.01 ;+<0.05$. 


\section{Discussion}

The present study demonstrates that intra-uterine induced hypoxic-ischemia in preterm fetal sheep has long-term effects on baroreflex function. During the first week following prolonged umbilical cord occlusion, heart rate variability decreases dramatically and baroreflex sensitivity decreases gradually to show lower values than controls at 4-7 days after UCO. These results suggest that intra-uterine hypoxic-ischemia limits the baroreflex activity to buffer changes in SBP by adapting fetal R-R interval. The dysregulation of the baroreflex may augment already present cerebral damage after systemic hypoxic-ischemia in the reperfusion period. As a consequence of this cardiovascular instability the preterm brain may be prone to blood pressure fluctuations, leading to disruption of the immature vascular architecture and neonatal encephalopathy [24].

\section{Transfer function analysis and baroreflex function}

In the present study we focused on the baroreflex-mediated interactions between LF fluctuations of SBP and R-R intervals during the normoxaemic recovery state, hence after the immediate cardiovascular effects of acute hypoxia and hypoxic-ischemia. Under normoxaemic condition, baroreflex rather than chemoreflex is involved in the interactions between arterial blood pressure and fetal heart rate [25]. We were interested in the long-term effect of induced fetal hypoxic-ischemia on baroreflex function, i.e. baroreflex sensitivity and delay of the reflex arc. The evaluation of baroreflex function is useful for the assessment of fetal autonomic cardiovascular control [26]. Evaluation of baroreflex function by spectral methods is based on the concept that each spontaneous oscillation in blood pressure elicits an oscillation at the same frequency in R-R interval by the effect of arterial baroreflex activity [7]. As found in other fetal sheep experiments, we observed an oscillation frequency associated with fetal baroreflex activity centered around $0.1 \mathrm{~Hz}$ [27]. According to the transfer function method, baroreflex sensitivity was calculated as the value of the transfer function modulus and phase (i.e. gain and delay) between SBP and R-R interval in the LF frequency, considering a coherence $\geq 0.5$ [22]. The transfer function methodology has been used in several studies of human preterm infants $[11,21]$. As the values of SBP and R-R intervals obtained from the fetal sheep are comparable with values found in preterm infants, the same spectral analysis methodology was followed. Transfer function analysis in this study showed relatively high coherence values in the LF band, suggesting reliable estimates of transfer gain and delay.

\section{Long-term effects of hypoxic-ischemia}

During longitudinal monitoring of the UCO group, the LF transfer gain gradually decreased over time, leading to a significantly lower LF transfer gain post-UCO compared 
to the control group. Consistent with this finding is the time-domain observation of a decreased SD-RR, while SD-SBP remains unchanged. In contrast, the LF delay between blood pressure variations and subsequent heart rate variations increased compared to the control group. The gradual decrease of baroreflex sensitivity and increase in delay between variations in heart rate and systolic blood pressure suggest that hypoxicischemia results in a deregulation of the baroreceptor reflex arc. A decreased LF transfer gain and increased delay may result from changes in the dynamics of the sympathetic and parasympathetic pathways and/or from changes in the balance between these pathways $[6,17,18,26]$. As the parasympathetic effect on heart rate changes is fast compared to sympathetic effect, increased delay may indicate a greater relative contribution of sympathetic regulation. This is supported by the finding that normalized LF power (LF/total power) increased to nearly $100 \%$ following UCO, while remained stable in controls (approximately 75\%).

The afferent signals from the baroreceptor output are projected on the nucleus of the solitary tract, which is located in the medulla region, to be processed and transferred to the blood pressure regulation effectors [28]. Previous findings in 0.6 gestation fetal sheep showed that suppressed fetal heart rate variability following 30 minute UCO was associated with severe neuronal loss in the brain stem 3 days after the insult [20]. This neuronal loss may affect the processing of afferent nerve signals and therefore the baroreflex function, thereby decreasing regulation efficacy. Although we did not study brain stem histology, our findings showed that deregulation of baroreflex function gradually increases over the course of seven days suggesting evolving neuronal loss in the brain stem. This finding also highlights the importance of study length. At 3 days after UCO, the end-point for most other longitudinal studies [19, 20], baroreflex transfer function parameters of our UCO group were not significantly different from the control group, potentially obscuring long-term hypoxic-ischemia-induced functional loss. We speculate that gradual functional loss may be related to the evolvement of hypoxic-ischemic associated cytotoxic edema during the first week as seen by MRI studies in human infants [29]. Fetal heart rate variability (SD-RR) was already significantly decreased at 3 days post-UCO, and gradually decreased further during the remainder of the study. This observation is in agreement with Ikeda et al., who showed that decreased long-term fetal heart rate variability at 24-72 h of recovery after UCO showed to be an indicator of the severity of histological damage in the term fetal brain [30]. To our knowledge, our study is the first to describe this change in fetal heart rate variability in preterm asphyxiated fetal lambs.

\section{Maturational effects of baroreflex activity}

Results of our study indicate that the baroreflex function matures during fetal life, as shown by the increase in LF transfer gain for the control group between 0.75 and 0.80 $\mathrm{GA}$. These results confirm findings by other experiments, which noted that the baroreflex function was active from approximately 85 days of gestation ( $0.6 \mathrm{GA})$, and the 
magnitude of fetal heart rate response to blood pressure changes increased towards term [15]. Other studies found a decrease in baroreflex sensitivity during development [31-33]. Several studies showed no significant maturation of the baroreflex sensitivity $[16,17]$. There may be several explanations for these conflicting findings. First, it is known that the different pathways of the baroreflex feedback system mature at different rates. In preterm sheep of $0.7 \mathrm{GA}$ there is probably no significant control by the renal sympathetic nerve, which regulates vascular resistance $[18,34]$, whereas in the term sheep vascular resistance control is present [32]. In our study, fetal sheep were instrumented at $0.7 \mathrm{GA}$, and maturational changes were studied between 0.75 and 0.80 $\mathrm{GA}$. Other studies have little to no variation in GA, or their results lack the temporal resolution required to compare results to our findings directly [16, 17, 31, 32]. Second, the discrepancies may be due to methodological differences. Quantification of spontaneous baroreflex sensitivity by spectral methods and quantification by injection of drugs or aortic compression do not necessarily produce comparable results [35]. Spontaneous variations in blood pressure are normally in the order of several $\mathrm{mmHg}$, whereas experiments using invasive quantification methods generally study heart rate responses to larger blood pressure changes. Third, heart rate response to blood pressure changes is non-linear, and can be characterized by a sigmoidal input-output relation with maximum responses around the (normal) operating point and decreased regulation capacity at the extremes [8].

\section{Pathophysiological implications}

Reduction in fetal heart rate variability is associated with fetal hypoxia and acidemia in human preterm [36] and term fetus [37]. However, despite the highly adverse outcomes of moderate to severe encephalopathy around birth the predictive value of abnormal fetal heart rate patterns for cerebral palsy is consistently weak [38]. This study demonstrates an association between fetal hypoxic-ischemia and reduced baroreflex sensitivity. For obvious reasons, direct measurement of fetal blood pressure in humans is not possible. Future studies may explore the use of non-invasive (Doppler) estimation of fetal blood pressure and spectral-derived variability in assessing hypoxemia-induced changes in brain stem mechanisms for cardiovascular control [39].

In conclusion, this is the first study to quantify baroreflex mediated heart rate response in a preterm fetal sheep model by transfer function analysis of R-R interval and SBP fluctuations, and to show long-term effects on baroreflex function after intrauterine umbilical cord occlusion induced hypoxic-ischemia. Our results show that intrauterine hypoxic-ischemia limits baroreflex efficacy to buffer changes in SBP by adapting fetal R-R interval following umbilical cord occlusion. As a consequence, the preterm brain may be prone to blood pressure fluctuations, possibly leading to disruption of the immature vascular architecture and augmenting already present cerebral damage after systemic hypoxic-ischemia in the reperfusion period. 


\section{References}

1. Volpe JJ: Brain injury in the premature infant. Neuropathology, clinical aspects, pathogenesis, and prevention. Clin Perinatol 1997, 24:567-587.

2. Nelson KB, Leviton A: How much of neonatal encephalopathy is due to birth asphyxia? Am J Dis Child 1991, 145:1325-1331.

3. Liem KD, Greisen G: Monitoring of cerebral haemodynamics in newborn infants. Early Hum Dev 2010, 86:155-158.

4. Pryds O, Edwards AD: Cerebral blood flow in the newborn infant. Arch Dis Child Fetal Neonatal Ed 1996, 74:F63-69.

5. Penaz J, Honzikova N, Fiser B: Spectral analysis of resting variability of some circulatory parameters in man. Physiol Bohemoslov 1978, 27:349-357.

6. Akselrod S, Gordon D, Madwed JB, Snidman NC, Shannon DC, Cohen RJ: Hemodynamic regulation: investigation by spectral analysis. Am J Physiol 1985, 249:H867-875.

7. deBoer RW, Karemaker JM, Strackee J: Hemodynamic fluctuations and baroreflex sensitivity in humans: a beat-to-beat model. Am J Physiol 1987, 253:H680-689.

8. Ursino $M$, Magosso $E$ : Role of short-term cardiovascular regulation in heart period variability: a modeling study. Am J Physiol Heart Circ Physiol 2003, 284:H1479-1493.

9. Laude D, Elghozi JL, Girard A, Bellard E, Bouhaddi M, Castiglioni P, Cerutti C, Cividjian A, Di Rienzo M, Fortrat JO, Janssen B, Karemaker JM, Leftheriotis G, Parati G, Persson PB, Porta A, Quintin L, Regnard J, Rudiger $\mathrm{H}$, Stauss HM: Comparison of various techniques used to estimate spontaneous baroreflex sensitivity (the EuroBaVar study). Am J Physiol Regul Integr Comp Physiol 2004, 286:R226-231.

10. La Rovere MT, Pinna GD, Raczak G: Baroreflex sensitivity: measurement and clinical implications. Ann Noninvasive Electrocardiol 2008, 13:191-207.

11. Andriessen P, Oetomo SB, Peters C, Vermeulen B, Wijn PF, Blanco CE: Baroreceptor reflex sensitivity in human neonates: the effect of postmenstrual age. J Physiol 2005, 568:333-341.

12. Jennekens $\mathrm{W}$, Dat M, Bovendeerd PH, Wijn PF, Andriessen P: Validation of a preterm infant cardiovascular system model under baroreflex control with heart rate and blood pressure data. Conf Proc IEEE Eng Med Biol Soc 2011, 2011:896-899.

13. Bennet L, Gunn AJ: The fetal heart rate response to hypoxia: insights from animal models. Clin Perinatol 2009, 36:655-672.

14. Gunn AJ, Bennet L: Fetal hypoxia insults and patterns of brain injury: insights from animal models. Clin Perinatol 2009, 36:579-593.

15. Shinebourne EA, Vapaavuori EK, Williams RL, Heymann MA, Rudolph AM: Development of baroreflex activity in unanesthetized fetal and neonatal lambs. Circ Res 1972, 31:710-718.

16. Frasch MG, Muller T, Wicher C, Weiss C, Lohle M, Schwab K, Schubert H, Nathanielsz PW, Witte OW, Schwab M: Fetal body weight and the development of the control of the cardiovascular system in fetal sheep. J Physiol 2007, 579:893-907.

17. Maloney JE, Cannata J, Dowling MH, Else W, Ritchie B: Baroreflex activity in conscious fetal and newborn lambs. Biol Neonate 1977, 31:340-350.

18. Booth LC, Malpas SC, Barrett CJ, Guild SJ, Gunn AJ, Bennet L: Is baroreflex control of sympathetic activity and heart rate active in the preterm fetal sheep? Am J Physiol Regul Integr Comp Physiol 2009, 296:R603-609.

19. Bennet L, Rossenrode S, Gunning MI, Gluckman PD, Gunn AJ: The cardiovascular and cerebrovascular responses of the immature fetal sheep to acute umbilical cord occlusion. J Physiol 1999, 517 ( Pt 1):247257.

20. George S, Gunn AJ, Westgate JA, Brabyn C, Guan J, Bennet L: Fetal heart rate variability and brain stem injury after asphyxia in preterm fetal sheep. Am J Physiol Regul Integr Comp Physiol 2004, 287:R925933.

21. Andriessen P, Koolen AM, Berendsen RC, Wijn PF, ten Broeke ED, Oei SG, Blanco CE: Cardiovascular fluctuations and transfer function analysis in stable preterm infants. Pediatr Res 2003, 53:89-97. 


\section{Chapter 2}

22. Robbe HW, Mulder LJ, Ruddel H, Langewitz WA, Veldman JB, Mulder G: Assessment of baroreceptor reflex sensitivity by means of spectral analysis. Hypertension 1987, 10:538-543.

23. Heart rate variability. Standards of measurement, physiological interpretation, and clinical use. Task Force of the European Society of Cardiology and the North American Society of Pacing and Electrophysiology. Eur Heart J 1996, 17:354-381.

24. Perlman JM: The relationship between systemic hemodynamic perturbations and periventricularintraventricular hemorrhage--a historical perspective. Semin Pediatr Neurol 2009, 16:191-199.

25. Jensen A, Hanson MA: Circulatory responses to acute asphyxia in intact and chemodenervated fetal sheep near term. Reprod Fertil Dev 1995, 7:1351-1359.

26. Frasch MG, Muller T, Szynkaruk M, Schwab M: Validation of spontaneous assessment of baroreceptor reflex sensitivity and its relation to heart rate variability in the ovine fetus pre- and near-term. Can J Physiol Pharmacol 2009, 87:736-742.

27. Suzuki H, Sugawara J, Kimura Y, Murakami T, Okamura K: Contribution of the fetal baroreceptor reflex to the low frequency component of fetal heart rate fluctuations. Gynecol Obstet Invest 2003, 55:156161.

28. Sagawa K: Baroreflex control of systemic arterial pressure and vascular bed. In Comprehensive Physiology. Edited by Terjung RL. Hoboken, NJ: John Wiley \& Sons, Inc.; 2011: 453-496

29. Roelants-van Rijn AM, Nikkels PG, Groenendaal F, van Der Grond J, Barth PG, Snoeck I, Beek FJ, de Vries LS: Neonatal diffusion-weighted MR imaging: relation with histopathology or follow-up MR examination. Neuropediatrics 2001, 32:286-294.

30. Ikeda T, Murata Y, Quilligan EJ, Parer JT, Theunissen IM, Cifuentes P, Doi S, Park SD: Fetal heart rate patterns in postasphyxiated fetal lambs with brain damage. Am J Obstet Gynecol 1998, 179:1329-1337.

31. Blanco CE, Dawes GS, Hanson MA, McCooke HB: Carotid baroreceptors in fetal and newborn sheep. Pediatr Res 1988, 24:342-346.

32. Segar JL, Hajduczok G, Smith BA, Merrill DC, Robillard JE: Ontogeny of baroreflex control of renal sympathetic nerve activity and heart rate. Am J Physiol 1992, 263:H1819-1826.

33. Segar JL: Ontogeny of the arterial and cardiopulmonary baroreflex during fetal and postnatal life. Am J Physiol 1997, 273:R457-471.

34. Booth LC, Gunn AJ, Malpas SC, Barrett CJ, Davidson JO, Guild SJ, Bennet L: Baroreflex control of renal sympathetic nerve activity and heart rate in near-term fetal sheep. Exp Physiol 2011, 96:736-744.

35. Persson PB, DiRienzo M, Castiglioni P, Cerutti C, Pagani M, Honzikova N, Akselrod S, Parati G: Time versus frequency domain techniques for assessing baroreflex sensitivity. J Hypertens 2001, 19:16991705.

36. Matsuda $\mathrm{Y}, \mathrm{Maeda} \mathrm{T}$, Kouno S: The critical period of non-reassuring fetal heart rate patterns in preterm gestation. Eur J Obstet Gynecol Reprod Biol 2003, 106:36-39.

37. Williams KP, Galerneau F: Intrapartum fetal heart rate patterns in the prediction of neonatal acidemia. Am J Obstet Gynecol 2003, 188:820-823.

38. Nelson KB, Dambrosia JM, Ting TY, Grether JK: Uncertain value of electronic fetal monitoring in predicting cerebral palsy. N Engl J Med 1996, 334:613-618.

39. Struijk PC, Mathews VJ, Loupas T, Stewart PA, Clark EB, Steegers EA, Wladimiroff JW: Blood pressure estimation in the human fetal descending aorta. Ultrasound Obstet Gynecol 2008, 32:673-681. 


\section{Chapter 3}

\section{Cerebral inflammation and mobilization of the peripheral immune system following global hypoxia-ischemia in preterm sheep}

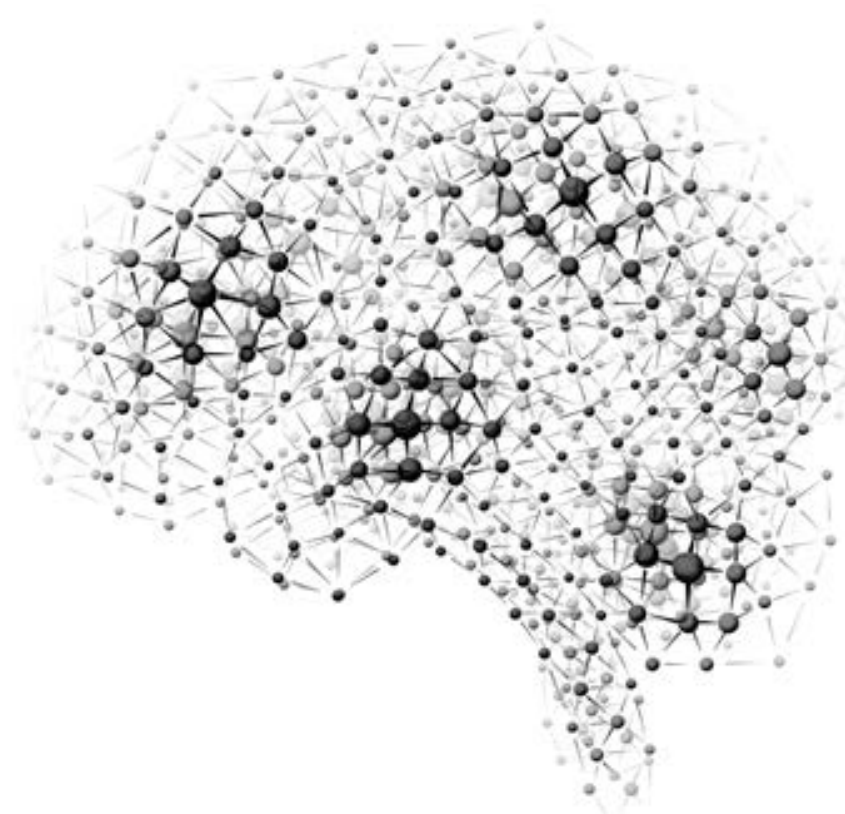

Published as: Jellema RK, Lima Passos V, Zwanenburg A, Ophelders DR, De Munter S, Vanderlocht J, Germeraad WT, Kuypers E, Collins JJ, Cleutjens JP, Jennekens W, Gavilanes AW, Seehase M, Vles HJ, Steinbusch H, Andriessen P, Wolfs TG, Kramer BW: Cerebral inflammation and mobilization of the peripheral immune system following global hypoxia-ischemia in preterm sheep. J Neuroinflammation 2013, 10:13. 


\section{Abstract}

Hypoxic-ischemic encephalopathy (HIE) is one of the most important causes of brain injury in preterm infants. Preterm HIE is predominantly caused by global hypoxicischemia (HI). In contrast, focal ischemia is most common in the adult brain and known to result in cerebral inflammation and activation of the peripheral immune system. These inflammatory responses are considered to play an important role in the adverse outcomes following brain ischemia. In this study, we hypothesized that cerebral and peripheral immune activation was also involved in preterm brain injury after global $\mathrm{HI}$.

Preterm instrumented fetal sheep were exposed to 25 minutes of umbilical cord occlusion (UCO) $(n=8)$ at 0.7 gestation. Sham-treated animals $(n=8)$ were used as a control group. Brain sections were stained for ionized calcium binding adaptor molecule 1 (IBA-1) to investigate microglial proliferation and activation. The peripheral immune system was studied by assessment of circulating white blood cell counts, cellular changes of the spleen and influx of peripheral immune cells (MPO-positive neutrophils) into the brain. Pre-oligodendrocytes (O4) and myelin basic protein (MBP) were detected to determine white matter injury. Electro-encephalography (EEG) was recorded to assess functional impairment by interburst interval (IBI) length analysis.

Global $\mathrm{HI}$ resulted in profound activation and proliferation of microglia in the hippocampus, periventricular and subcortical white matter. In addition, non-preferential mobilization of white blood cells into the circulation was observed within 1 day after global $\mathrm{HI}$ and a significant influx of neutrophils into the brain was detected 7 days after the global $\mathrm{HI}$ insult. Furthermore, global $\mathrm{HI}$ resulted in marked involution of the spleen, which could not be explained by increased splenic apoptosis. In concordance with cerebral inflammation, global $\mathrm{HI}$ induced severe brain atrophy, region-specific preOL vulnerability, hypomyelination and persistent suppressed brain function.

Our data provided evidence that global $\mathrm{HI}$ in preterm ovine fetuses resulted in profound cerebral inflammation and mobilization of the peripheral innate immune system. These inflammatory responses were paralleled by marked injury and functional loss of the preterm brain. Further understanding of the interplay between preterm brain inflammation and activation of the peripheral immune system following global $\mathrm{HI}$ will contribute to the development of future therapeutic interventions in preterm HIE. 


\section{Introduction}

Hypoxic-ischemic encephalopathy (HIE) is one of the most important causes of brain injury in preterm infants [1]. Preterm infants suffering from HIE develop cognitive disorders in $25-50 \%$ of all cases and $5-10 \%$ suffer from severe motor deficits (i.e. cerebral palsy) [2]. The hippocampus plays a key role in cognition and several studies suggest that $\mathrm{HI}$-induced injury to the hippocampus may predispose to cognitive disorders later in life [3-7]. Motor deficits in preterm HIE are mainly attributable to injury of white matter in the immature brain [1]. Despite the high prevalence of neurological sequelae, no therapeutic interventions are available to treat HIE in preterm infants. Cooling therapy, which has been shown to improve neurodevelopmental outcome in mild cases of HIE in term infants, is associated with adverse outcomes in preterm infants and has therefore not yet been established as standard clinical care for this vulnerable patient group [8-10].

White matter injury, the clinical hallmark of preterm hypoxic-ischemic encephalopathy, is caused by injury to the highly vulnerable immature oligo-dendrocytes in the preterm brain. HI-induced damage to immature oligodendrocytes impedes effective differentiation into mature myelinating oligodendrocytes leading to hypomyelination of the preterm brain [11-13]. Microglial activation is considered to be involved in the injury to immature oligodendrocytes [13]. Microglia are the resident innate immune cells in the brain and play a central role in the initiation of an inflammatory response aimed at resolving injury caused by $\mathrm{HI}$ [14-16]. Excessive activation of microglia, however, results in a detrimental cerebral inflammatory response with neurotoxic consequences [15, 16].

In addition to cerebral inflammation, experimental data from adult rodent models of focal HI (i.e. stroke) suggest a role for the peripheral immune system in the etiology of cerebral HI. More precisely, several studies showed that acute brain injury after focal ischemia is followed by a massive activation of the peripheral immune system with rapid mobilization of immune effector cells from the spleen $[17,18]$. These mobilized effector cells can invade the brain and aggravate the existing injury [17].

Given the importance of cerebral inflammation and peripheral immune system activation in focal $\mathrm{HI}$ of the adult brain, we hypothesized that similar inflammatory responses are involved in the etiology of preterm brain injury following global HI.

To test this hypothesis, preterm instrumented sheep were exposed to 25 minutes of umbilical cord occlusion (UCO) at 0.7 gestation. At this time of gestation, neurodevelopment of fetal sheep is equivalent to that of a preterm human infant of 28-32 weeks [19-21]. During this neurodevelopmental stage of the human and ovine fetus, the preterm brain is highly prone to develop white matter injury following global HI [1113]. 


\section{Materials \& methods}

\section{Animal experiments}

The study was approved by the Animal Ethics Research Committee of Maastricht University, The Netherlands. Fetuses of time-mated Texel ewes were instrumented at 101 \pm 1.1 (mean \pm SD) days gestation. Before surgery, ewes received i.v. prophylactic antibiotics (1000 mg amoxicillin and $200 \mathrm{mg}$ clavulanic acid). Anesthesia was induced by i.v. thiopenthal (15 mg/kg). After intubation, general anesthesia was maintained with 1-2\% isoflurane guided by depth of sedation and supplemented by remifentanyl i.v. 0.75 $\mu \mathrm{g} / \mathrm{kg} / \mathrm{min}$ ) for analgesia. Vital parameters and depth of sedation were continuously monitored by certified personnel. A catheter was placed in the maternal long saphenous vein to provide access for a peri-operative saline drip ( $250 \mathrm{~mL} /$ hour) and postoperative blood sampling and administration of the prophylactic antibiotics during four days.

Fetuses were catheterized with 3.5 French polyurethane umbilical vessel catheters (Tyco Healthcare Group, Mansfield, Massachusetts, USA) placed in the femoral artery and the brachial vein. Three custom-made electrocardiogram (ECG) shielded electrodes (Cooner wire Co., Chatsworth, CA, USA) with silver plates $(5 \mathrm{~mm}$ ) were sewn on the chest for fetal heart rate recordings. Two pairs of custom-made EEG shielded electrodes (Cooner wire Co., Chatsworth, CA, USA) with silver tips were placed bilaterally on the dura over the parasagittal parietal cortex $(5 \mathrm{~mm}$ and $15 \mathrm{~mm}$ anterior to point bregma and $10 \mathrm{~mm}$ lateral), with a subcutaneous silver reference electrode $(10 \mathrm{~mm})$ placed in the neck. The EEG electrodes were secured with cyanoacrylate glue and covered with fetal skin. All animals were instrumented with an inflatable vascular occluder (OC16HD, 16 mm, In Vivo Metric, Healdsburg, California, USA) placed around the umbilical cord. A catheter for amniotic pressure recording was placed in the amniotic sac. Before closure of the uterus $80 \mathrm{mg}$ of Gentamycin was administered into the amniotic sac. All fetal catheters and leads were exteriorized through a trocar hole in the flank of the ewe.

After surgery, ewes were housed in a confined space to allow handling and continuous perfusion of the catheters with heparinized saline ( $25 \mathrm{IU} / \mathrm{mL}, 0.2 \mathrm{~mL} / \mathrm{hr}$ ). Surgical wounds were inspected daily and treated with chlortetracycline spray to prevent infection. Animals had ad libitum access to water and food. The welfare of the animals was monitored daily by certified personnel.

\section{Experimental design}

Fetuses were instrumented at $101 \pm 1$ (mean \pm SD) days of gestation (experimental day -4). After surgery, the ewe and her fetus were allowed to recover for four days. On experimental day 0 , fetuses were randomly allocated to either be subjected to 25 minutes of umbilical cord occlusion ( $\mathrm{HI}$ group; $\mathrm{n}=8$ ) or sham occlusion (sham group; 
$\mathrm{n}=8)$. In the HI group, the occluder was rapidly inflated with sterile saline and complete occlusion was confirmed with a sudden drop in heart rate and subsequent arterial blood gas analysis indicating acidemia, hypoxia and hypercapnia (see figure 1). Such an insult has been previously shown to result in global hypoxic-ischemia and subsequent cerebral hypoperfusion [19, 22]. After (sham) umbilical cord occlusion a reperfusion period of 7 days followed. At the end of the experiment (experimental day 7), both ewe and fetus were euthanized by administration of pentobarbital $(200 \mathrm{mg} / \mathrm{kg}$ ).
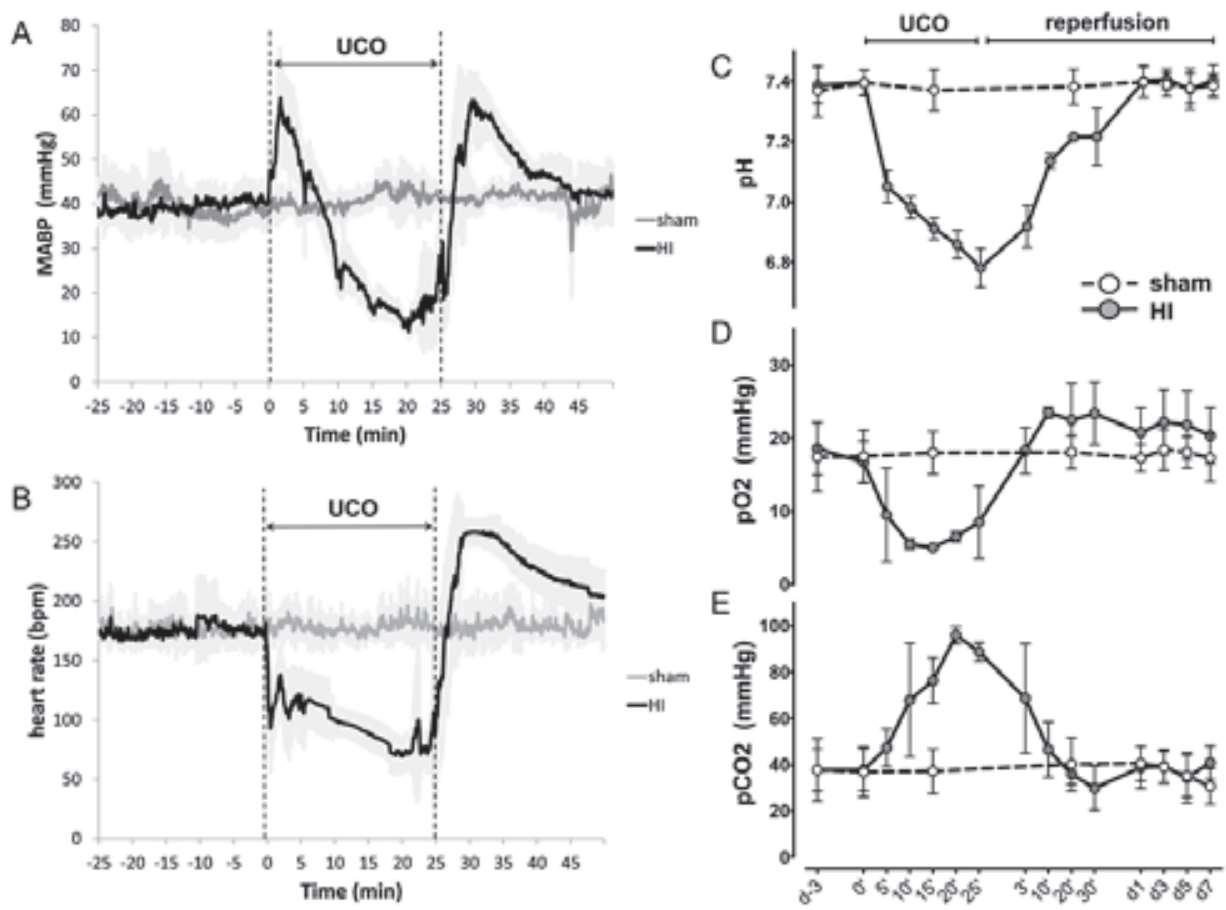

Figure 1. Vital parameters and blood gases of sham and hypoxic-ischemia (HI) animals during umbilical cord occlusion (UCO). (A) fetal mean arterial blood pressure (MABP), the small deflections (every five minutes) in the MABP curve are caused by arterial blood gas sampling (B) fetal heart rate (HR) in beats per minute (bpm) (C) blood gas; arterial $\mathrm{pH}(D)$ blood gas; arterial partial oxygen pressure (pO2) (E) blood gas; arterial partial carbon dioxide pressure ( $p C O 2)$. Shaded areas (MABP and HR) and error bars (blood gases) depict standard deviation (SD). Min/ ' = minutes, $d=$ day

\section{Data acquisition}

Blood pressure, amniotic pressure EEG and ECG data were acquired and digitized by a custom-made MPAQ unit (Maastricht-Programmable AcQuisition system, Maastricht Instruments BV, Maastricht, the Netherlands) with IDEEQ software (Maastricht Instruments BV, Maastricht, the Netherlands). All data were sampled at $1000 \mathrm{~Hz}$ and stored 
on hard-disk for off-line analysis. Analog filtering was applied to the ECG data, with a 1 $\mathrm{Hz}$ high-pass filter and a $200 \mathrm{~Hz}$ low-pass filter. Heart rate (beats per minute) was extracted from the ECG by R-top identification. Blood pressure and amniotic pressure data were not filtered. Fetal mean arterial blood pressure was calculated by online subtraction of the amniotic fluid pressure from the femoral artery pressure.

The EEG data were filtered using a $0.5-30 \mathrm{~Hz} 4^{\text {th }}$ order Butterworth band-pass filter. EEG signal with an amplitude $>1000 \mu \mathrm{V}$ was considered an artifact and removed from analysis ( $<1 \%$ of data). After filtering, EEG background analysis was performed using an amplitude- and time-threshold based algorithm [23]. Burst activity was defined as an epoch with an amplitude $>30 \mu \mathrm{V}$ and a duration $>1 \mathrm{~s}$ in both channels. Interburst intervals (IBI) were defined as epochs with an amplitude $<30 \mu \mathrm{V}$ and a duration $>3 \mathrm{~s}$ in both channels. Segments not meeting above criteria were classified as undefined. Using these criteria, mean IBI length per 30 minutes and per 24 hours segments was calculated and used as a surrogate for functional brain suppression for all animals during the period starting two days before UCO (day -2) until the end of the experiment (day 7).
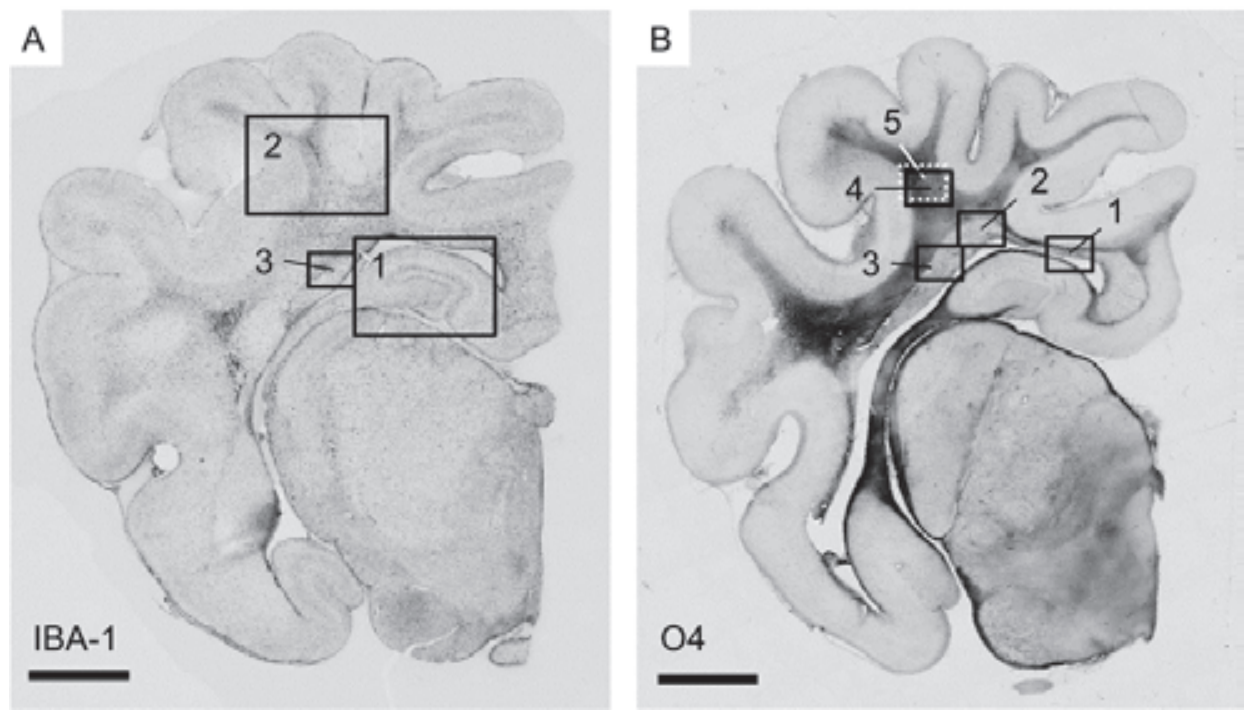

Figure 2. Overview of regions of interest in the right hemisphere at the posterior hippocampus/mid-thalamus level. (A) Regions of interest for the detection of IBA-1 immunoreactivity; 1 = hippocampus, 2 = subcortical white matter and 3 = periventricular white matter. (B) Regions of interest for the detection of O4-positive cell density; 1 = medial periventricular white matter, 2 = intermediate periventricular white matter, $3=$ lateral periventricular white matter and $4=$ subcortical white matter. Scale bar $=4 \mathrm{~mm}$. The white dashed box (5) indicates in which region the myelin binding protein (MBP) images in figure 7 were obtained. 


\section{Immunohistochemistry brain}

The fetal brain was removed from the skull and weighed. The right hemisphere was submersion fixated in ice-cold $4 \%$ paraformaldehyde for 3 months. Brain tissue was embedded in gelatin and serial coronal sections $(50 \mu \mathrm{m})$ were cut on a Leica VT $1200 \mathrm{~S}$ vibrating microtome (Leica Biosystems, Nussloch, Germany). Free floating sections at the level of mid-thalamus and posterior hippocampus were stained with a rabbit antiionized calcium binding adaptor molecule 1 (IBA-1) antibody (Wako Pure Chemical Industries, Osaka, Japan), a highly specific marker for microglia, to localize resting and activated microglia [24-26]. A mouse anti-O4 antibody (Merck Millipore, Billerica, MA, USA) was used to detect late oligodendrocyte progenitors and immature oligodendrocytes (hereafter collectively referred to as pre-oligodendrocytes; preOLs) and a rat antimyelin basic protein (MBP) antibody (Merck Millipore, Billerica, MA, USA) was used to detect myelin sheaths and myelin producing (mature) oligodendrocytes. A rabbit antimyeloperoxidase (MPO) antibody (DAKO A0398, DAKO, Glostrup, Denmark) was used to detect neutrophils.

Endogenous peroxidase-activity was blocked by incubation with 0,3\% $\mathrm{H} 2 \mathrm{O} 2$ in Tris buffered saline (TBS, pH 7.4). Free floating sections were incubated overnight (anti-IBA$1, \mathrm{MBP}$ and MPO) or during three days (anti-O4) at $4{ }^{\circ} \mathrm{C}$ with the diluted primary antibody (1:1000 anti-IBA-1, 1:400 anti-O4, 1:2000 MBP and 1:1000 MPO) followed by incubation with a secondary donkey-anti-rabbit (anti-IBA-1 and MPO), donkey-anti-rat (MBP) or donkey-anti-mouse (anti-O4) biotin labeled antibody. The immunostaining was enhanced with Vectastain ABC peroxidase Elite kit (PK-6200, Vector Laboratories, Burlingame, CA, USA) followed by a nickel sulfate-diaminobenzidine (NiDAB) staining. Sections were mounted on gelatin-coated glass slides, air-dried, dehydrated in ascending ethanol concentrations and coverslipped with PerTex.

\section{Analysis immunohistochemistry brain}

For the analysis of IBA-1 immunoreactivity (IR), digital images of the hippocampus, subcortical white matter (SCWM) and periventricular white matter (PVWM) were acquired at 100x magnification using an Olympus BX51 microscope (Olympus, Tokyo, Japan). In the regions of interest (ROIs) areal fraction of IBA-1 IR was determined with a standard threshold to determine positive staining using Leica Qwin Pro V 3.5.1 software (Leica, Rijswijk, the Nettherlands). Within the hippocampus IBA-1 IR was additionally analyzed in the CA1-2, CA3 and dentate gyrus (DG) sub regions. IBA-1 IR areal fraction in the ROIs was assessed in six consecutive coronal sections (posterior hippocampus/ mid-thalamus level) per animal (sham $\mathrm{n}=6 ; \mathrm{HI} \mathrm{n}=6$ ) by an independent observer who was blinded to the experimental conditions.

Analysis of the $\mathrm{O} 4$ immunohistochemical staining clearly showed that within the periventricular white matter three sub-regions had region-specific preOL characteristics in sham animals that responded differently to global HI. Therefore $\mathrm{O} 4$ staining was 
assessed in these three different regions of interest in the PVWM. In addition, $\mathrm{O} 4$ staining was assessed in the SCWM. Regions of interest are indicated in figure 2.

To assess $\mathrm{O} 4$ immunoreactivity, we adapted the method previously reported by Back et al. [11]. A differential count was performed, discriminating between immature (ring-shaped membrane staining, no processes), mature (ring-shaped membrane staining, extensively branched processes) and degenerative (fragmented membrane staining, fragmentation of processes, signs of cell death; nuclear condensation and apoptotic bodies) phenotype of the $\mathrm{O} 4$ positive cells. The sum of the differential count resulted in the total number of $\mathrm{O} 4$ positive cells. Differential counts were performed in six consecutive coronal sections (posterior hippocampus/ mid-thalamus level) per animal (sham $\mathrm{n}=3 ; \mathrm{HI}=3$ ). The investigator who performed the differential count was blinded to the experimental conditions. In each region of interest, $\mathrm{O} 4$ positive cells were counted in eight randomly chosen fields of view with a 40x objective equipped with a counting grid $\left(0.0625 \mathrm{~mm}^{2}\right)$ using a Nikon Eclipse E400 microscope (Nikon, Amsterdam, the Netherlands).

Differential counts of MPO positive cells in the brain were performed to assess the localization of these cells in relation to the cerebral vasculature. Numbers of intravascular, perivascular and interstitial cells were counted in the hippocampus, periventricular white matter and subcortical white matter. Six coronal sections per animal (sham $n=3$; $\mathrm{HI}=3$ ) were studied at the posterior hippocampus/ mid-thalamus level. In each section, cells were counted in eight fields of view (focused on the cerebral vasculature) per region of interest (hippocampus, periventricular white matter and subcortical white matter) with a $20 x$ objective equipped with a counting grid $\left(0.25 \mathrm{~mm}^{2}\right)$ using a Nikon Eclipse E400 microscope (Nikon, Amsterdam, the Netherlands).

Since in the MPO analysis the fields of view were not randomly chosen, but focused on the cerebral vasculature, the numbers of cells were expressed as cells per field of view (FOV). All images of immunohistochemical staining in the brain (IBA-1, 04, $\mathrm{MBP}, \mathrm{MPO}$ ) presented here were obtained with an Olympus AX-70 microscope (Olympus, Tokyo, Japan) equipped with a digital camera.

\section{White blood cell counts}

Automated white blood cell counts were performed in heparinized arterial blood on experimental day $-3,0,1,3,5$ and 7 using a Sysmex XE-5000 hematology analyzer (Sysmex, Etten-Leur, the Netherlands).

\section{Immunohistochemistry spleen}

Spleens were removed immediately following sacrifice and subsequently weighed. Tissue blocks $\left(5 \times 5 \mathrm{~mm}^{2}\right)$ were snap frozen in liquid nitrogen. Frozen spleen sections (4 $\mu \mathrm{m})$ were stained for cleaved caspase-3 (Asp175, \#9661S, Cell Signaling Technology, Boston, MA, USA) for detection of apoptosis, CD3 (DAKO A0452, DAKO Denmark) for 
detection of T-cells and MPO (DAKO A0398, DAKO, Glostrup, Denmark) for detection of neutrophils.

Endogenous peroxidase was inactivated by incubation with $0,3 \% \mathrm{H} 2 \mathrm{O} 2$ that was dissolved in methanol. Antigen aspecific binding was prevented by incubating the slides for 30 minutes with $5 \%$ bovine serum albumin (BSA). Slides were incubated overnight at $4^{\circ} \mathrm{C}$ with the diluted primary antibody (cleaved caspase-3 1:200, CD3 1:200, MPO 1:500) followed by incubation with the appropriate secondary biotin labeled antibody. Immunostaining was enhanced with Vectastain ABC peroxidase Elite kit (PK-6200, Vector Laboratories) followed by a NiDAB staining. Sections were counterstained with $0.1 \%$ Nuclear Fast Red washed, dehydrated and coverslipped.

The number of caspase- 3 positive cells in the spleen were counted in twenty (to accommodate heterogenic distribution) fields of view per animal (sham $n=6, H I n=6$ ) with a 20x objective equipped with a counting grid $\left(0.25 \mathrm{~mm}^{2}\right)$ using a Nikon Eclipse E400 microscope (Nikon, Amsterdam, the Netherlands). The number of caspase-3 positive cells was expressed in cells/ $\mathrm{mm}^{2}$.

For the analysis of CD3 and MPO immunoreactivity (IR), digital images of spleen sections were acquired at 100x magnification using a Leica DM200 microscope equipped with a Leica DFC295 digital camera (Leica Microsystems, Rijswijk, the Netherlands) and Leica Application Suite (LAS) software (Leica LAS V 3.7, Rijswijk, the Netherlands). Areal fraction of CD3 and MPO IR was determined in five sections per animal ( ham $\mathrm{n}=6, \mathrm{HI} \mathrm{n}=6$ ) with a standard threshold to determine positive staining using Leica Qwin software (Leica Qwin Pro V 3.5.1, Rijswijk, the Netherlands).

\section{Flow cytometry}

At the end of the experiment (day 7), the spleen was immediately harvested after sacrifice. Single-cell splenocyte suspensions were obtained by dissociating freshly sampled spleen tissues in gentleMACS ${ }^{\text {тм }}$ C-tubes (MiltEnyi, Leiden, the Netherlands) filled with Gibco $^{\circledR}$ Iscove's Modified Dulbecco's Medium (IMDM) (Life Technologies, Bleiswijk, the Netherlands) using the gentleMACS ${ }^{\mathrm{m}}$ Dissociator (MiltEnyi, Leiden, the Netherlands). Subsequently, the cell suspensions were passed through a $70 \mu \mathrm{m}$ cell strainer (BD Biosciences, Erembodegem-Aalst, Belgium). Splenocytes were stored in nitrogen in freezing medium containing IMDM medium with $10 \%$ heat-inactivated fetal calf serum and 10\% dimethylsulfoxide (DMSO).

To study the cellular composition of the spleen 7 days after global HI, 200.000 splenocytes per animal (sham $\mathrm{n}=8 ; \mathrm{HI} n=8$ ) were stained for detection of lymphocytes (mouse anti sheep CD45-biotin; AbDSerotec, Düsseldorf, Germany / streptavidinHorizon V450; BD Biosciences, Bleiswijk, the Netherlands), neutrophils (mouse antibovine CD11b-Fluorescein isothiocyanate (-FITC); AbDSerotec, Düsseldorf, Germany), Thelper cells (mouse anti sheep CD4-AlexaFluor ${ }^{\circledR} 647$ (-A647); AbDSerotec, Düsseldorf, Germany), cytotoxic T-cells (mouse anti sheep CD8-R-phycoerythrin (-PE); AbDSerotec, Düsseldorf, Germany) and viability (7-Aminoactinomycin D (7-AAD); BD Biosciences, 
Bleiswijk, the Netherlands) according to the manufacturer's protocol. Stained cells were acquired on a FACS Canto II flow cytometer (BD Biosciences, Bleiswijk, the Netherlands) equipped with FACS Diva software (BD Biosciencs, Bleiswijk, the Netherlands).

The number of CD11b, CD4 and CD8 positive splenocytes were determined as a percentage of living CD45-positive lymphocytes. The expression of CD11b, CD4 and CD8 on living CD45-positive lymphocytes was analyzed using the mean fluorescent intensity (MFI).

\section{Statistics}

Summary statistics of animal characteristics (gestational age at UCO, body weight) are shown as means with $95 \%$ Confidence Intervals $(\mathrm{Cl})$. For analysis of $\mathrm{O} 4$, MPO and activated caspase- 3 parameters, cell counts in each section's region of interest were first averaged per field of view ( $n=8$ for 04 and MPO; $n=20$ for activated caspase-3).

Groups' comparisons (sham vs. HI) with respect to all outcome parameters were drawn either with independent t-tests, or with random intercept models in case of repeated measurements per animal (e.g. different sections per brain). Variables, whose distributions were positively skewed, were log-transformed previous to statistical testing. To facilitate interpretation, averages on the log scale were back transformed to the original scale (antilog) and are presented as geometric means and corresponding 95\% Cls.

Average (additive) differences on log transformed data become 'multiplicative' on the original scale. Thus, the displayed geometric means for the sham and $\mathrm{HI}$ groups should be compared in relative terms, i.e. not as difference in averages (e.g. mean sham minus mean $\mathrm{HI}$ ) but rather as a ratio of the sham geometric mean with respect to the $\mathrm{HI}$ geometric mean (mean sham divided by mean $\mathrm{HI}$ ). The interpretation of the geometric means ratio is provided for example for areal fraction (\%) IBA-1 immunoreactivity in the subcortical white matter (see Results section).

For analysis of the EEG parameter (i.e. IBI length), log transformation also preceded parametric inferences regarding groups' comparisons and temporal dynamics of mean IBI length before and after UCO (or sham). To accommodate both the interrupted nature of the experimental follow-up, with UCO happening on day 0 of the experiment, as well as the correlation among longitudinal measurements of individual fetuses, a piecewise mixed regression model was fitted [27]. This mixed model approach allowed additionally for heterogeneity of groups' variances to be accounted for. In the model, Time (pre and post UCO, measured in days), group (sham vs. $\mathrm{HI}$ ), and a dummy for pre and post UCO times, pre-post, were the fixed effects factors. Fetuses (subjects) were the random factor. The addition of random effects was meant to model individual variability relative to the group's average. Variables selection was carried out via the topdown procedure based on likelihood ratio (LR) tests for fixed effects and tests for the covariance structure. Statistical analysis was performed with PASW Statistics 18 (SPSS Inc., Chicago, IL, USA). 


\section{Results}

\section{Animal characteristics}

Fetal body weight did not differ between the sham and HI group; sham man 1782 gram (1571; 1993) versus HI mean 1742 gram $(1482 ; 2002), p=0.677$. There was no significant difference in gestational age at the time of UCO between the sham and HI group; sham mean 105.6 days $(104.6 ; 106.5)$ versus $\mathrm{HI}$ mean 105.5 days $(104.7 ; 106.3), p=0.717$.

\section{Fetal vital parameters}

Fetal vital parameters and blood gases during UCO are depicted in figure 1. After an initial compensatory rise, mean arterial blood pressure gradually declined from 40 $\mathrm{mmHg}$ to $10 \mathrm{mmHg}$ at the end of 25 minutes UCO (figure $1 \mathrm{~A}$ ). Mean fetal heart rate rapidly fell after initiation of UCO from around 200 beats per minute (bpm) at baseline to below $100 \mathrm{bpm}$ at the end of UCO (figure 1B). All vital parameters normalized within 30 minutes of reperfusion time.

Blood gas data (figure $1 \mathrm{C}-\mathrm{E}$ ) indicate that average $\mathrm{pH}$ dropped from 7.4 at baseline to 6.8 at the end of UCO. Mean partial oxygen pressure decreased from $20 \mathrm{mmHg}$ at baseline to values below $5 \mathrm{mmHg}$ at the end of UCO. Mean partial carbon dioxide pressure increased from baseline levels of $40 \mathrm{mmHg}$ to values around $90 \mathrm{mmHg}$ at the end of UCO. Upon reperfusion hypoxemia and hypercapnia resolved within minutes. Normalization of $\mathrm{pH}$ values occurred after 60-90 minutes (data not shown).

A

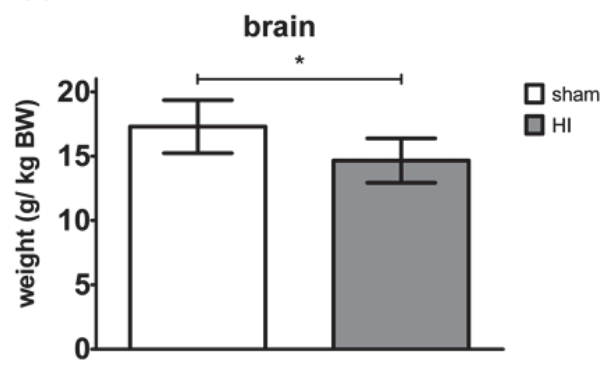

B

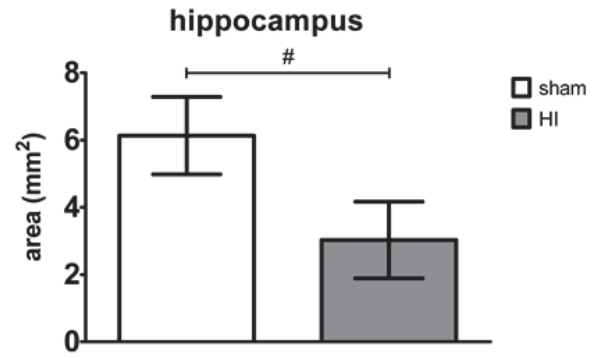

Figure 3. Global $\mathrm{HI}$ induced atrophy of the brain including the hippocampus as indicated by significant reduction of $(A)$ brain weight $(\mathrm{g} / \mathrm{kg} \mathrm{BW})(A)$ and $(B)$ hippocampus area (mm2). (A) Means $\pm 95 \% \mathrm{Cl}$ are depicted. (B) Geometric means $\pm 95 \% \mathrm{Cl}$ are depicted. ${ }^{*} P \leq 0.05, \# P \leq 0.01, \neq P \leq 0.001, N S$, non-significant. $H I=$ hypoxic-ischemia.

\section{Brain atrophy}

Brain weight, corrected for body weight (BW), and hippocampal area were determined to study $\mathrm{HI}$-induced brain atrophy. Average brain weight (gram/kg BW) was significantly decreased in animals exposed to $\mathrm{HI}$ compared with sham (figure $3 \mathrm{~A}$ ); sham mean 17.3 
gram/kg BW $(95 \%$ Cl 15.2; 19.4) versus $\mathrm{HI}$ mean 14.6 gram $/ \mathrm{kg}$ BW (95\% Cl 12.9; 16.4), $\mathrm{p}=0.037$.

Atrophy of the hippocampus was assessed since there is clinical [3-5] and experimental $[19,28]$ evidence that this brain region is affected in preterm HIE. Mean area $\left(\mathrm{mm}^{2}\right)$ of the hippocampus was significantly reduced in animals exposed to $\mathrm{HI}$ compared with sham (figure 3B); sham mean $6.1 \mathrm{~mm}^{2}$ (95\% $\mathrm{Cl} 5.0 ; 7.3$ ) versus $\mathrm{HI}$ mean 3.0 $\mathrm{mm}^{2}(95 \% \mathrm{Cl} 1.9 ; 4.2), \mathrm{p}=0.002$. In hippocampal sub-regions the analysis of the areas $\left(\mathrm{mm}^{2}\right)$ showed significant atrophy of the cornu ammonis (CA)1-2; sham mean $1.7 \mathrm{~mm}^{2}$ (95\% Cl 1.3; 2.0) versus $\mathrm{HI}$ mean $0.7 \mathrm{~mm}^{2}$ (95\% $\left.\mathrm{Cl} 0.4 ; 1.0\right), \mathrm{p}=0.001$ and $\mathrm{CA} 3$; sham mean $0.7 \mathrm{~mm}^{2}(95 \% \mathrm{Cl} 0.6 ; 0.9)$ versus $\mathrm{HI}$ mean $0.4 \mathrm{~mm}^{2}$ (95\% Cl $\left.0.2 ; 0.6\right), \mathrm{p}=0.013$. Mean area of the dentate gyrus (DG) was not significantly affected by $\mathrm{HI}$; sham mean $1.2 \mathrm{~mm}^{2}(95 \% \mathrm{Cl} 1.0 ; 1.4)$ versus $\mathrm{HI}$ mean $0.7 \mathrm{~mm}^{2}$ (95\% Cl 0.6; 1.1), $\mathrm{p}=0.060$.

\section{Microglial activation and proliferation}

Microglia (IBA-1) were studied to determine the local inflammatory response in the brain. Areal fraction (\%) of IBA-1 immunoreactivity (IR) was studied in the subcortical white matter (SCWM), periventricular white matter (PVWM) and hippocampus (figure 3A). IBA-1 IR was significantly increased in the SCWM of animals exposed to HI compared with sham (figure 4D-F); sham geometric mean $25.6 \%$ (95\% Cl 17.0; 38.4) versus $\mathrm{HI}$ geometric mean $70.0 \%(95 \% \mathrm{Cl} 46.6 ; 105.1), \mathrm{p}=0.003$. Thus, the ratio of the two geometric means, $\mathrm{HI}$ with respect to sham is $70.0 / 25.6=2.73$. The corresponding interpretation is: the geometric mean of the areal fraction in the HI group is 2.73 higher (173\% increase) than the geometric mean of the sham group.

In the PVWM the areal fraction (\%) of IBA-1 IR was significantly increased in animals exposed to $\mathrm{HI}$ compared with sham (figure $4 \mathrm{~A}-\mathrm{C}$ ); sham geometric mean $1.3 \%$ $(95 \% \mathrm{Cl} 0.6 ; 3.0)$ versus $\mathrm{HI}$ geometric mean $5.2 \%$ (95\% Cl 2.9; 9.2), $\mathrm{p}=0.013$. The areal fraction (\%) of IBA-1 IR in the hippocampus was significantly increased in animals exposed to $\mathrm{HI}$ compared with sham (figure 4G-I); sham geometric mean $1.9 \%$ (95\% Cl 1.0; 3.6) versus $\mathrm{HI}$ geometric mean $22.5 \%$ (95\% Cl 12.1; 41.8), $\mathrm{p}<0.001$.

Analysis of hippocampal sub-region CA1-2 showed significantly increased IBA-1 IR in animals exposed to $\mathrm{HI}$ compared to sham (figure $5 \mathrm{~A}-\mathrm{C}$ ); sham geometric mean $1.5 \%$ (95\% Cl 0.7; 3.2) versus $\mathrm{HI}$ geometric mean $29.8 \%$ (95\% Cl 14.1; 63.1), $\mathrm{p}<0.001$. IBA-1 IR was also significantly increased in CA3 (figure 5D-F); sham geometric mean $1.4 \%$ (95\% $\mathrm{Cl} 0.7 ; 3.0)$ versus $\mathrm{HI}$ geometric mean $31.4 \%(95 \% \mathrm{Cl} 15.2 ; 64.8), \mathrm{p}<0.001$ and DG (figure 5 G-I); sham geometric mean $1.3 \%(95 \% \mathrm{Cl} 0.6$; 3.0) versus $\mathrm{HI}$ geometric mean $5.2 \%$ (95\% Cl 2.9; 9.2), $\mathrm{p}<0.001$.

Microglia in sham animals exhibited a quiescent state characterized by extensively branched thin processes (inserts figure $4 \mathrm{E}$ and $\mathrm{H}$ and figure $5 \mathrm{~B}, \mathrm{E}$, and $\mathrm{H}$ ). In contrast, in $\mathrm{HI}$-exposed animals, microglia with thick cell bodies and retracted processes were observed indicating an activated state (inserts figure $4 \mathrm{~F}$ and $\mathrm{I}$ and figure $5 \mathrm{C}, \mathrm{F}$ and $\mathrm{I}$ ). 

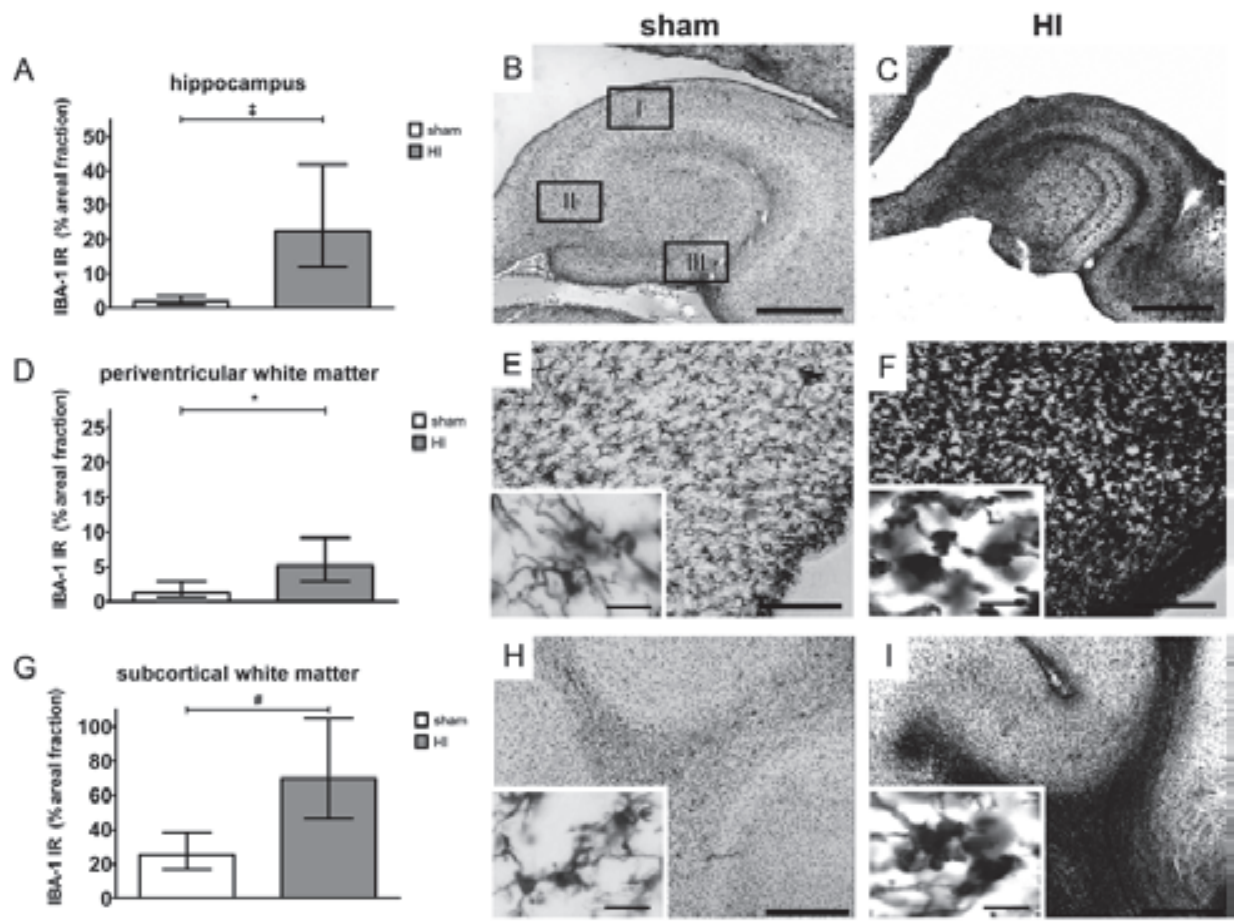

Figure 4. In the hippocampus, periventricular white matter (PVWM) and subcortical white matter (SCWM) global $\mathrm{HI}$ resulted in profound proliferation and activation of microglia, as indicated by significantly increased areal fraction (\%) of IBA-1 immunoreactivity (IR) and by loss of processes and amoeboid morphology, respectively. (A) Global HI significantly increased areal fraction (\%) of IBA-1 IR in the hippocampus. (B) Sham, hippocampus; resting microglia, also depicting the analyzed hippocampal sub-regions (see figure 5); I=cornu ammonis (CA)1-2, II = CA3, III = dentate gyrus (DG) (C) HI, hippocampus; profound microglial proliferation and activation (scale bar $=500 \mu \mathrm{m}$ ). (D) Global HI significantly increased areal fraction (\%) of IBA-1 IR in the PVWM. (E) Sham, PVWM; resting microglia (scale bar $=200 \mu \mathrm{m}$, scale bar insert $=25 \mu \mathrm{m}$ ). (F) HI, PVWM; proliferation and activation of microglia (scale bar $=200 \mu \mathrm{m}$, scale bar insert $=25 \mu \mathrm{m}$ ). (G) Global HI significantly increased areal fraction (\%) of IBA-1 IR in the SCWM (H) Sham, SCWM; resting microglia (scale bar $=200 \mu \mathrm{m}$, scale bar insert $=25 \mu \mathrm{m}$ ). (I) HI, SCWM proliferation and activation of microglia (scale bar = $200 \mu \mathrm{m}$, scale bar insert $=25 \mu \mathrm{m}) .(A, D, G)$ Geometric means $\pm 95 \% \mathrm{Cl}$ are depicted. ${ }^{*} P \leq 0.05, \# P \leq 0.01, \neq$ $P \leq 0.001, N S$, non-significant. $\mathrm{HI}=$ hypoxic-ischemia.

\section{Region-specific pre-oligodendrocyte vulnerability}

Differential counts of O4-positive pre-oligodendrocytes were performed in the medial, intermediate and lateral PVWM and in the SCWM (figure 3B). Analysis of the $\mathrm{O} 4$ staining showed that in sham animals the medial and lateral PVWM were predominantly populated by $04-$ positive cells with a mature phenotype (figure $6 A-B$ and $\mathrm{G}-\mathrm{H}$ ). In contrast, O4-positive cells in the SCWM and intermediate PVWM were predominantly of immature phenotype (figure 6D-E and J-K). Following global $\mathrm{HI}$ all regions showed an 
increase in preOLs with degenerative morphology (figure 6A, D, G and J) which reached statistical significance in the regions which were populated by mature pre-OLs in sham conditions (medial and lateral PVWM). In the medial PVWM, the areal density of O4positive cells with degenerative phenotype significantly increased in animals exposed to $\mathrm{HI}$ compared to sham (figure $6 \mathrm{~A}-\mathrm{C}$ ); sham geometric mean 4.6 cells/ $\mathrm{mm}^{2}$ ( $95 \% \mathrm{Cl} 1.9$; 11.3) versus $\mathrm{HI}$ geometric mean 44.2 cells $/ \mathrm{mm}^{2}$ (95\% $\left.\mathrm{Cl} 17.8 ; 109.4\right), \mathrm{p}=0.009$. In the lateral PVWM, the areal density of O4-positive cells with degenerative morphology similarly increased following HI (figure 6G-I); sham geometric mean 8.3 cells/ mm ${ }^{2}$ (95\% $\mathrm{Cl} 3.6 ; 18.8$ ) versus $\mathrm{HI}$ geometric mean 61.6 cells $/ \mathrm{mm}^{2}$ (95\% $\left.\mathrm{Cl} 31.9 ; 119.1\right)$.
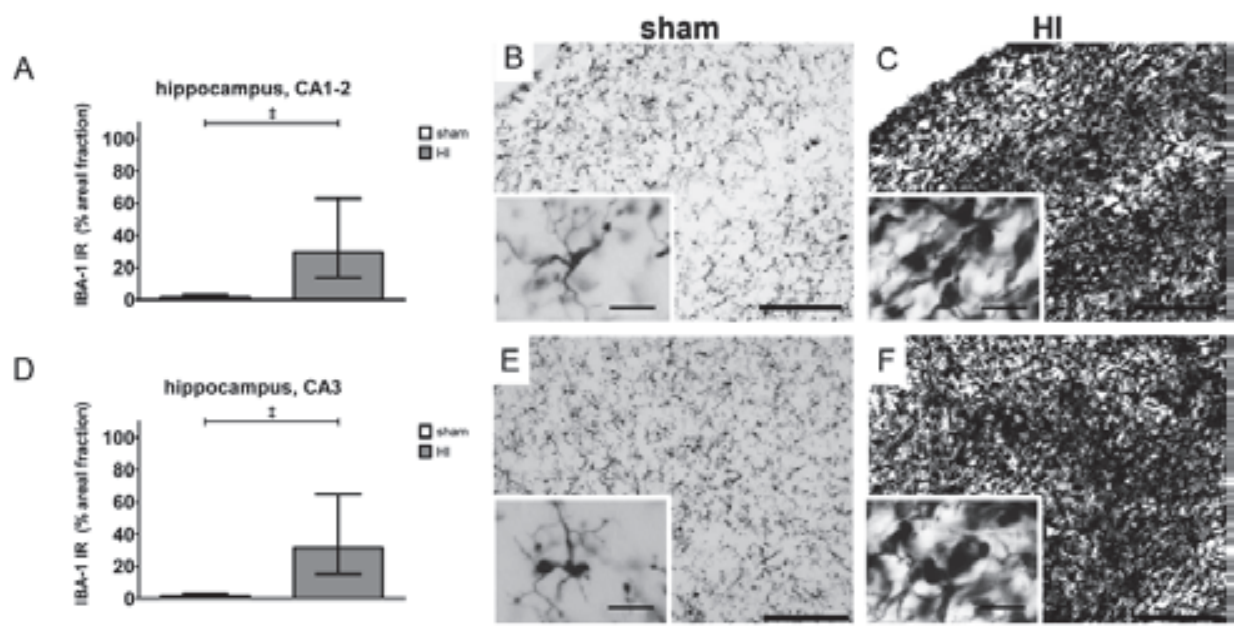

G
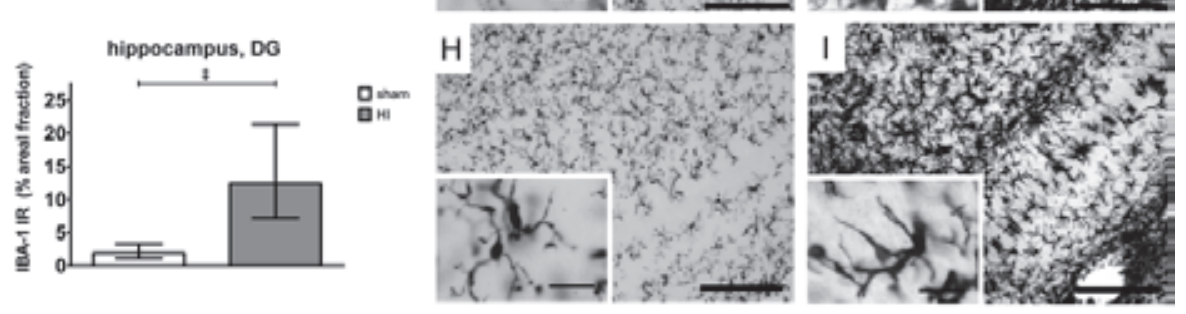

Figure 5. Global HI induced significant proliferation and activation of microglia in the cornu ammonis (CA)1-2, CA3 and dentate gyrus (DG), sub-regions of the hippocampus. (A) Global HI significantly increased areal fraction (\%) of IBA-1 immunoreactivity (IR) in CA1-2. (B) Sham, CA1-2; resting microglia (C) HI, CA1-2; profound microglial proliferation and activation. (D) Global HI significantly increased areal fraction (\%) of IBA-1 IR in CA3. (E) Sham, CA3; resting microglia (F) HI, CA3; profound proliferation and activation of microglia. (G) Global HI significantly increased areal fraction (\%) of IBA-1 IR in DG. (H) Sham DG; resting microglia. (I) HI, DG; proliferation and activation of microglia. Scale bar images $=200 \mu \mathrm{m}$, scale bar inserts = $25 \mu \mathrm{m}$. $(A, D, G)$ Geometric means $\pm 95 \% \mathrm{Cl}$ are depicted. ${ }^{*} P \leq 0.05, \# P \leq 0.01, \neq P \leq 0.001, N S$, non-significant. $H I=$ hypoxic-ischemia . 


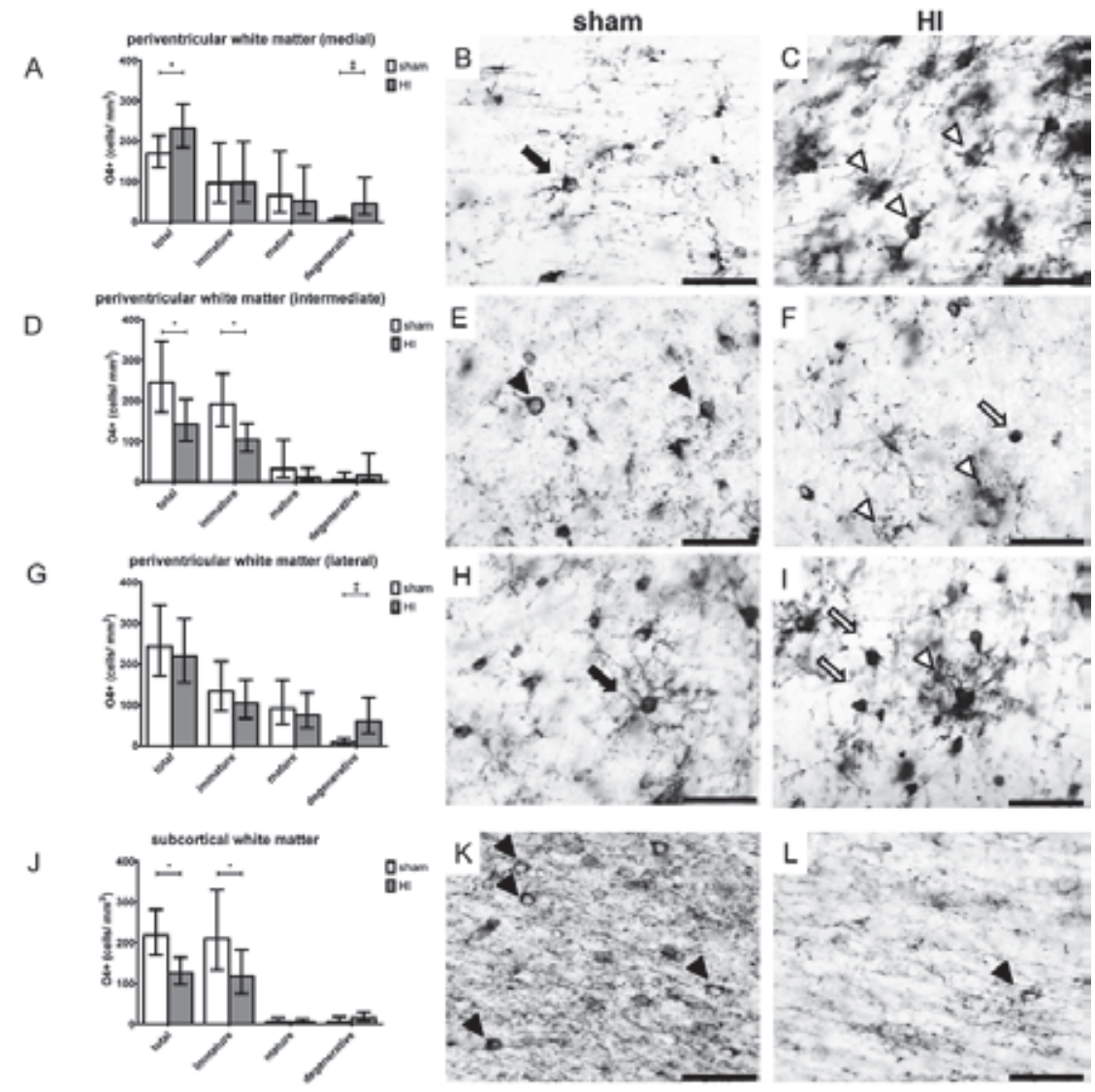

Figure 6. Global HI induced region-specific vulnerability of O4-positive pre-oligodendrocytes (preOLs; late oligodendrocyte progenitors and immature oligodendrocytes). Regions of interest are depicted in figure 3. (A) Global HI significantly increased the density of total and degenerative preOLs in the medial periventricular white matter (PVWM). (B) Sham, medial PVWM; preOL with mature phenotype (black arrow). (C) HI, medial PVWM; preOLs with degenerative phenotype (white arrowheads). (D) Global HI significantly decreased density of total and immature preOLs in the intermediate PVWM. (E) Sham, intermediate PVWM; preOLs with immature phenotype (black arrow heads). (F) HI, intermediate PVWM; preOLs with degenerative phenotype (white arrow heads) and apoptotic preOL (white arrow). (G) Global HI significantly increased the density of degenerative preOLs in the lateral PVWM, density of total preOLs was unchanged. (H) Sham, lateral PVWM; preOL with mature phenotype (black arrow). (I) HI, lateral PVWM; preOL with degenerative (white arrow head) and apoptotic (white arrow) phenotype. (J) Global HI significantly reduced the density of total and immature preOLs subcortical white matter (SCWM). (K) Sham, SCWM; preOLs with immature phenotype (black arrow heads). (L) HI, SCWM; reduced density of preOLs with immature phenotype (black arrow heads) and disturbance of O4-positive myelin sheath organization. Scale bar all images $=50 \mu \mathrm{m} .(A, D, G, J)$ Geometric means $\pm 95 \% \mathrm{Cl}$ are depicted. ${ }^{*} P \leq 0.05, \# P \leq 0.01, \neq P \leq 0.001$, NS, non-significant. $\mathrm{HI}=$ hypoxic-ischemia. 
Following global $\mathrm{HI}$, the total number of preOLs significantly decreased in those regions which were populated by immature preOLs in sham conditions (intermediate PVWM and SCWM). In the intermediate PVWM, the areal density of total O4-positive cells significantly decreased following global HI (figure 6D-F); sham geometric mean 244.2 cells/ $\mathrm{mm}^{2}$ (95\% Cl 171.7; 347.2) versus $\mathrm{HI}$ geometric mean 143.2 cells/ $\mathrm{mm}^{2}(95 \% \mathrm{Cl}$ 100.7 ; 203.6), $\mathrm{p}=0.041$. Loss of total preOLs in the intermediate PVWM was mainly attributable to loss of O4-positive cells with immature phenotype (figure 6D-F); sham geometric mean 191.9 cells/ $\mathrm{mm}^{2}$ (95\% Cl 137.7; 267.5) versus $\mathrm{HI}$ geometric mean 104.3 cells/ $\mathrm{mm}^{2}$ (95\% Cl 74.8; 145.3), $\mathrm{p}=0.023$.

The areal density of total O4-positive cells in the SCWM significantly decreased in $\mathrm{HI}$-exposed animals compared to sham (figure $6 \mathrm{~J}-\mathrm{L}$ ); sham geometric mean 218.3 cells/ $\mathrm{mm}^{2}$ (95\% Cl 169.2; 282.0) versus $\mathrm{HI}$ geometric mean 126.8 cells/ $\mathrm{mm}^{2}$ (95\% Cl 98.0; 164.0), $p=0.014$. Loss of total preOLs in the SCWM was mainly attributable to loss of O4-positive cells with immature phenotype (figure 6J-L); sham geometric mean 210.2 cells/ $\mathrm{mm}^{2}$ (95\% Cl 133.9; 330.3) versus $\mathrm{HI}$ geometric mean 117.2 cells $/ \mathrm{mm}^{2}(95 \% \mathrm{Cl}$ 75.0; 183.1), $p=0.014$. Moreover, in the SCWM a clear disturbance of O4-positive myelin sheath organization was observed following $\mathrm{HI}$ (figure $6 \mathrm{~L}$ ). Remarkably, in the medial PVWM the total number of preOLs significantly increased (figure 6A); sham geometric mean 169.4 cells/ $\mathrm{mm}^{2}$ (95\% Cl 134.4; 213.4) versus $\mathrm{HI}$ geometric mean 232.1 cells/ $\mathrm{mm}^{2}$ (95\% Cl 184.2; 292.4), $\mathrm{p}=0.038$.
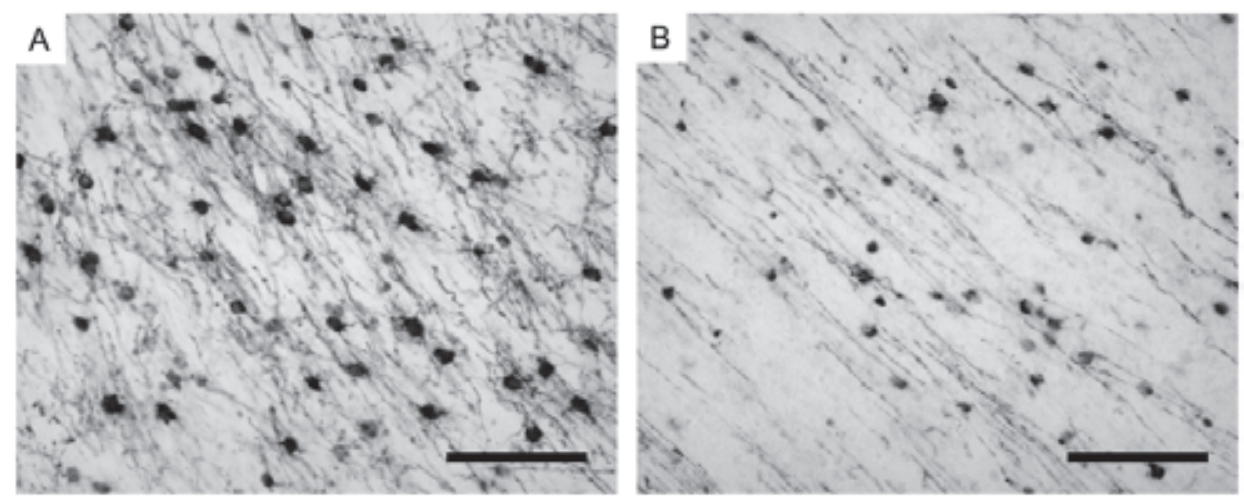

Figure 7. Global HI-induced marked loss of myelin basic protein (MBP) positive myelin sheaths and myelinproducing cells (mature oligodendrocytes) in the subcortical white matter (region of interest indicated in figure 3).

\section{MBP}

Brain sections were stained for myelin basic protein (MBP) to detect white matter injury following HI. In sham animals abundant MBP-positive myelin sheaths and myelin- 
producing cells (mature oligodendrocytes) were observed in the subcortical white matter (figure 7). Following global $\mathrm{HI}$ a marked reduction of both myelin sheaths and mature oligodendrocytes was observed (figure 7). In the PVWM (regions 1, 2 and 3 in figure 3) no MBP immunoreactivity was detected in both sham and $\mathrm{HI}$ animals (data not shown) indicating that these white matter regions were not myelinated at this developmental stage of the preterm brain.

\section{Cerebral neutrophil invasion}

Brain sections were stained for myeloperoxidase (MPO) to detect neutrophils that invaded the brain following $\mathrm{HI}$. Although microglia can also produce MPO, neutrophils and microglia can be easily distinguished by intensity of staining, localization and morphology [29-31].

Following global $\mathrm{HI}$ the total number of MPO-positive cells inside or adjacent to the cerebral vasculature significantly increased in the hippocampus (figure $8 \mathrm{~A}-\mathrm{C}$ ); sham geometric mean 2.0 cells/ field of view (FOV) $(95 \% \mathrm{Cl} 1.7 ; 2.4)$ versus $\mathrm{HI}$ geometric mean 8.5 cells/ FOV $(95 \% \mathrm{Cl} 2.7 ; 9.9), \mathrm{p}<0.001$. Similarly, the total number of MPOpositive cells significantly increased in the PVWM (figure 8D-F); sham geometric mean 2.1 cells/ FOV $(95 \% \mathrm{Cl} 1.6$; 2.9$)$ versus $\mathrm{HI}$ geometric mean 4.5 cells/ FOV $(95 \% \mathrm{Cl} 3.3$; 6.2 ), $p=0.002$ and in the SCWM (figure 7G-I); sham geometric mean 1.6 cells/ FOV (95\% $\mathrm{Cl} 0.7 ; 2.5)$ versus $\mathrm{HI}$ geometric mean 4.3 cells/ FOV (95\% Cl 2.7; 6.9), $\mathrm{p}<0.001$.

All analyzed regions showed an increase of intravascular MPO-positive cells following global $\mathrm{HI}$, which reached significance in the hippocampus (figure 8A); sham geometric mean 1.0 cells/ FOV $(95 \% \mathrm{Cl} 0.5 ; 2.3)$ versus HI geometric mean 2.1 cells/ FOV $(95 \%$ $\mathrm{Cl} 0.9 ; 4.6$ ), $\mathrm{p}=0.002$ and in the SCWM (figure $8 \mathrm{G}$ ); sham geometric mean 1.0 cells/ FOV $(95 \% \mathrm{Cl} 0.3 ; 2.9)$ versus $\mathrm{HI}$ geometric mean 1.6 cells/ FOV ( $95 \% \mathrm{Cl} 0.7 ; 4.0), \mathrm{p}=0.009$.

The number of perivascular MPO-positive cells was significantly increased in the hippocampus of $\mathrm{HI}$-exposed animals (figure 8A-C); sham geometric mean 0.4 cells/ FOV $(95 \% \mathrm{Cl} 0.3 ; 0.6)$ versus $\mathrm{HI}$ geometric mean 4.3 cells/ FOV $(95 \% \mathrm{Cl} 3.1 ; 5.9), \mathrm{p}<0.001$. Likewise, the number of perivascular MPO-positive cells was significantly increased in the PVWM of HI-exposed animals (figure 8D-F); sham geometric mean 0.4 cells/ FOV (95\% $\mathrm{Cl} 0.3 ; 0.7)$ versus $\mathrm{HI}$ geometric mean 2.1 cells/ $\mathrm{FOV}(95 \% \mathrm{Cl} 1.5 ; 3.1), \mathrm{p}<0.001$ and in the HI-exposed SCWM (figure 8G-I); sham geometric mean 0.3 cells/ FOV $(95 \% \mathrm{Cl} 0.2$; $0.5)$ versus $\mathrm{HI}$ geometric mean 1.8 cells/ FOV $(95 \% \mathrm{Cl} 1.2 ; 2.6), \mathrm{p}<0.001$.

All analyzed regions showed an increase of interstitial MPO-positive cells following global $\mathrm{HI}$, which reached significance in the hippocampus (figure $8 \mathrm{~A}$ ); sham geometric mean 0.4 cells/ FOV $(95 \% \mathrm{Cl} 0.3 ; 0.5)$ versus $\mathrm{HI}$ geometric mean 1.6 cells/ $\mathrm{FOV}(95 \% \mathrm{Cl}$ $1.3 ; 2.1$ ), $\mathrm{p}<0.001$ and in the SCWM (figure $8 \mathrm{G}$ ); sham geometric mean 0.3 cells/ FOV $(95 \% \mathrm{Cl} 0.2 ; 0.6)$ versus $\mathrm{HI}$ geometric mean 0.9 cells/ FOV $(95 \% \mathrm{Cl} 0.6 ; 1.3), \mathrm{p}=0.007$.

MPO-positive cells in the brain sections studied were large round-shaped cells with lobular intracellular structures situated in and around the cerebral vasculature (figure 8 $\mathrm{B}-\mathrm{C}, \mathrm{E}-\mathrm{F}$ and $\mathrm{H}-\mathrm{I})$. These morphological features and their localization indicate that 


\section{Chapter 3}

these MPO-positive cells were neutrophils. MPO-positive cells lacking neutrophil morphology were rarely detected (data not shown).

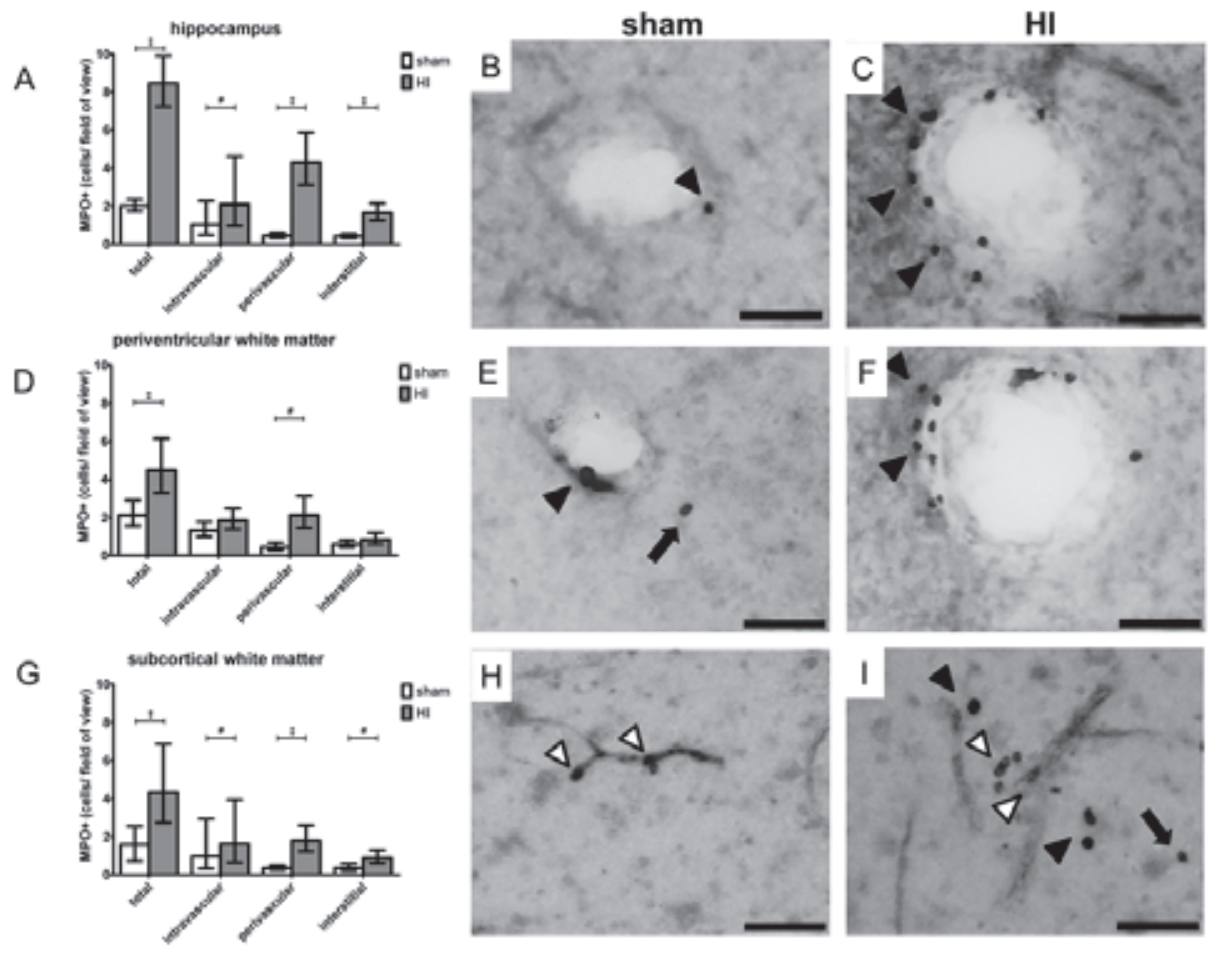

Figure 8. Global HI induced significant invasion of MPO-positive cells (neutrophils) into the hippocampus, periventricular white matter (PVWM) and subcortical white matter (SCWM). Invading neutrophils were predominantly localized in the perivascular zone. (A) Global HI caused a significant increase in the total number of MPO-positive cells in the hippocampus, mainly attributable to a profound increase in the number of perivascular MPO-positive cells. (B) Sham, hippocampus; perivascular MPO-positive cell (black arrow head). (C) HI, hippocampus; profound increase in the number of perivascular MPO-positive cells (black arrow heads). (D) Global HI caused a significant increase in the total number of MPO-positive cells in the PVWM, attributable to a significant increase in the number of perivascular MPO-positive cells. (E) Sham, PVWM; perivascular (black arrow head) and interstitial (black arrow) MPO-positive cell. (F) HI, PVWM; marked increase in perivascular MPO-positive cells (black arrow heads). (G) Global HI caused a significant increase in the total number of MPO-positive cells in the SCWM, attributable to a significant increase in the number of intravascular, perivascular and interstitial MPO-positive cells. (H) Sham, SCWM; intravascular MPO-positive cells (white arrow heads). (I) HI, SCWM; intravascular (white arrow heads), perivascular (black arrow heads) and interstitial (black arrow) MPO-positive cells. Scale bar all images $=50 \mu m .(A, D, G)$ Geometric means \pm $95 \% \mathrm{Cl}$ are depicted. ${ }^{*} P \leq 0.05, \# P \leq 0.01, \neq P \leq 0.001, N S$, non-significant. $\mathrm{HI}=$ hypoxic-ischemia. 


\section{White blood cell mobilization}

One day post-UCO a significant increase in white blood cell count was observed (figure 9); sham geometric mean $1.5 \times 10^{9}$ cells/L (95\% 0.8; 2.2) versus HI geometric mean 3.1 $10^{9}$ cells/L (95\% Cl 2.1; 4.5), $p=0.009$.

Furthermore, white blood cell counts showed a gradual increase in the number of circulating white blood cells during the study period in both sham and $\mathrm{HI}$ animals (figure 9). When geometric means were compared to sham day $-3\left(0.5 \times 10^{9}\right.$ cells $/ \mathrm{L}$ ( $95 \%$ $\mathrm{Cl} 0.3$; 0.9)), white blood cell counts of sham animals significantly increased at day 0 $\left(1.4 \times 10^{9}\right.$ cells/L $\left.(95 \% \mathrm{Cl} 1.0 ; 2.0) ; \mathrm{p}=0.027\right)$, day $1\left(1.5 \times 10^{9}\right.$ cells $/ \mathrm{L}(95 \% \mathrm{Cl} 0.8 ; 2,2)$; $\mathrm{p}=0.024)$, day $3(1.6 \times 109$ cells/ L (95\% Cl 1.1; 2.3$) ; \mathrm{p}=0.008)$, day $5\left(2.3 \times 10^{9}\right.$ cells $/ \mathrm{L}$ (95\% Cl 1.6; 3.4); $\mathrm{p}<0.001)$ and day $7\left(2.9 \times 10^{9}\right.$ cells/ L (95\% Cl 1.7; 4.8); $\left.\mathrm{p}<0.001\right)$. In HI animals geometric mean white blood cell counts were significantly elevated compared to $\mathrm{HI}$ day $-3\left(0.9 \times 10^{9}\right.$ cells/ $\left.\mathrm{L}(95 \% \mathrm{Cl} 0.5 ; 1.4)\right)$ at day $1\left(3.1 \times 10^{9}\right.$ cells/ L (95\% Cl 2.1; 4.5); $p<0.001)$ and day $7\left(2.5 \times 10^{9}\right.$ cells/ L (95\% Cl 1.3; 3.7); $\left.p=0.002\right)$.

\section{white blood cell count}

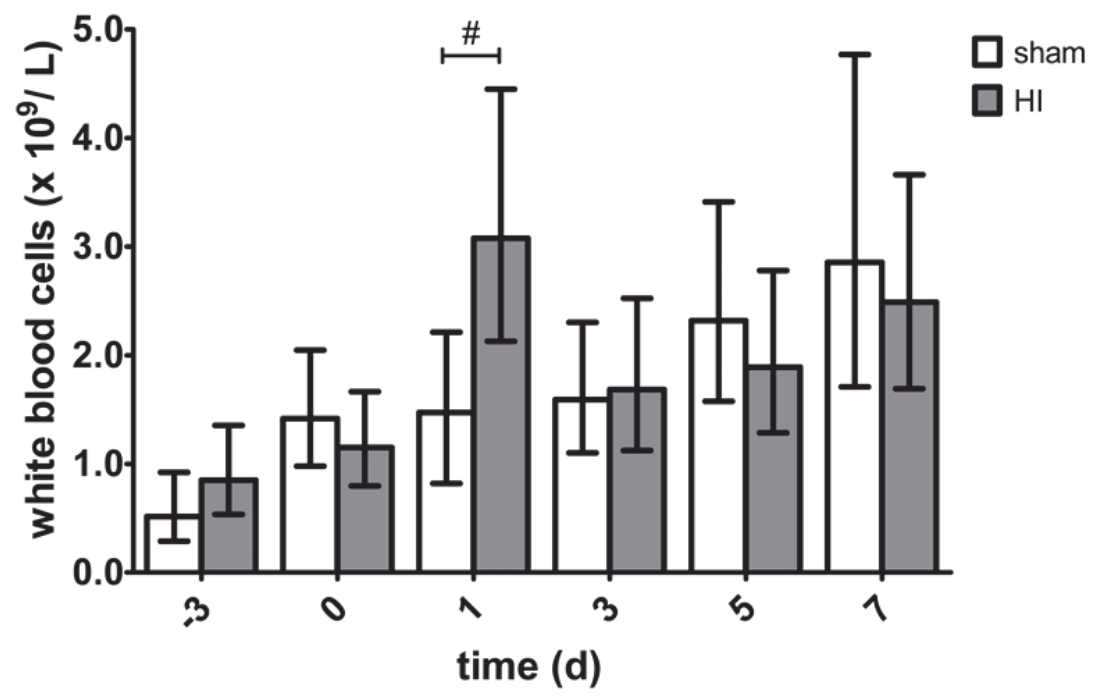

Figure 9. Global $\mathrm{HI}$ induced significant white blood cell mobilization in the first 24 hours following umbilical cord occlusion (UCO). White blood cell counts gradually increased during the study period. Geometric means $\pm 95 \% \mathrm{Cl}$ are depicted. ${ }^{*} P \leq 0.05, \# P \leq 0.01, \neq P \leq 0.001, N S$, non-significant. $H I=$ hypoxic-ischemia .

Flow cytometry analysis of whole blood showed that the percentage of living (7-AAD negative) CD45-positive lymphocytes expressing CD11b (neutrophils), CD4 (helper Tcells) or CD8 (cytotoxic T-cells) did not differ between sham and $\mathrm{HI}$ groups in the circu- 
lation on day 1 (data not shown). This indicated that global HI induced non-preferential mobilization of immune cells 24 hours following global $\mathrm{HI}$.

\section{Splenic involution}

Seven days after global HI, splenic weight was analyzed as an indication of activation of the peripheral immune system. Spleen weight, corrected for fetal BW, was significantly decreased in fetuses exposed to $\mathrm{HI}$ (figure 10A); sham geometric mean $2.5 \mathrm{gram} / \mathrm{kg}$ BW (95\% Cl 1.7; 3.6) versus $\mathrm{HI}$ geometric mean 1.7 gram/ kg BW (95\% Cl 1.5; 1.9), $\mathrm{p}=0.033$. Consistently, spleen size was markedly reduced following $\mathrm{HI}$ (figure 10B).

To assess whether splenic involution was caused by increased apoptotic cell death, spleen sections were stained for activated caspase-3. The number (cells/ $\mathrm{mm}^{2}$ ) of activated caspase- 3 positive cells in the spleen did not differ between sham and $\mathrm{HI}$ groups (figure $11 \mathrm{~A}-\mathrm{C}$ ); sham mean 12.2 cells $/ \mathrm{mm}^{2}$ (95\% Cl 4.4; 20.0) versus $\mathrm{HI}$ mean 16.4 cells/ $\mathrm{mm}^{2}$ (95\% Cl 6.4; 26.4), $\mathrm{p}=0.391$.
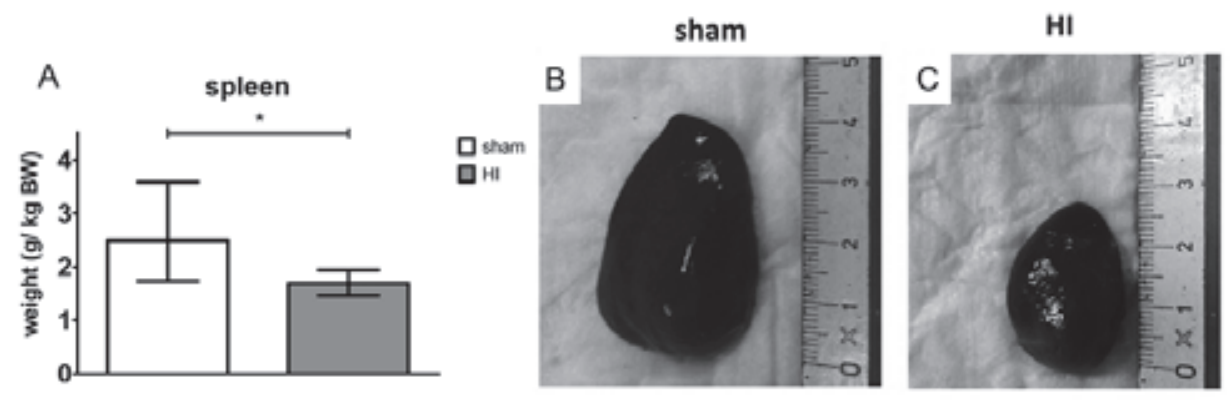

Figure 10. Global $\mathrm{HI}$ resulted in splenic involution. Global $\mathrm{HI}$ significantly reduced $(\mathrm{A})$ spleen weight $(\mathrm{g} / \mathrm{kg}$ $B W)$ and $(B, C)$ size. (B) Sham, spleen. (C) HI, spleen. (A) Geometric means $\pm 95 \% \mathrm{Cl}$ are depicted. ${ }^{*} P \leq 0.05, \#$ $P \leq 0.01, \neq P \leq 0.001, N S$, non-significant. $H I=$ hypoxic-ischemia.

\section{Splenic cellular composition}

Immunohistochemical staining of spleen sections for neutrophils showed that areal fraction (\%) of MPO immunoreactivity (IR) in the spleen did not differ between sham and $\mathrm{HI}$ animals after a reperfusion time of 7 days (figure 11D-F); sham mean $5.3 \%$ (95\% $\mathrm{Cl} 3.5$; 7.1) versus $\mathrm{HI}$ mean $4.0 \%(95 \% \mathrm{Cl} 2.4$; 5.6), $\mathrm{p}=0.254$. Immunohistochemical staining of spleen sections for T-cells showed that areal fraction (\%) of CD3 IR in the spleen did not differ between sham and $\mathrm{HI}$ animals after a reperfusion time of 7 days (figure 11D-F); sham mean $3.8 \%(95 \% \mathrm{Cl} 1.6$; 6.0) versus $\mathrm{HI}$ mean $6.3 \%(95 \% \mathrm{Cl} 4.2$; 8.3), $p=0.100$.

Similarly, no differences in splenic cell populations were found between sham and $\mathrm{HI}$ animals using flow cytometry on splenocytes. The percentage of living (7-AAD negative) CD45-positive splenocytes expressing CD11b (neutrophils) did not differ between 
sham and $\mathrm{HI}$ groups (figure 12); sham mean $45.8 \%$ (95\% $\mathrm{Cl} 28.0 ; 63.7)$ versus $\mathrm{HI}$ mean $44.9 \%(95 \% \mathrm{Cl} 27.1 ; 62.7), \mathrm{p}=0.936$. The percentage of living CD45-positive splenocytes expressing CD4 (helper T-cells) was not changed 7 days following HI (figure 12); sham mean $9.9 \%(95 \% \mathrm{Cl} 7.3 ; 12.5)$ versus $\mathrm{HI}$ mean $9.9 \%(95 \% \mathrm{Cl} 7.6 ; 12.2), \mathrm{p}=0.996$. The percentage of living splenocytes in the spleen expressing CD8 (cytotoxic T-cells) remained also unchanged 7 days following $\mathrm{HI}$ (figure 11); sham mean $4.1 \%$ (95\% Cl 2.4; 5.8) versus $\mathrm{HI}$ mean $3.9 \%(95 \% \mathrm{Cl} 2.4 ; 5.3), \mathrm{p}=0.825$. In line with these data, expression levels of CD11b, CD4 and CD8 on living CD45+ splenocytes, as measured with mean fluorescence intensity (MFI), were not changed by global $\mathrm{HI}$ after a reperfusion period of seven days (data not shown).
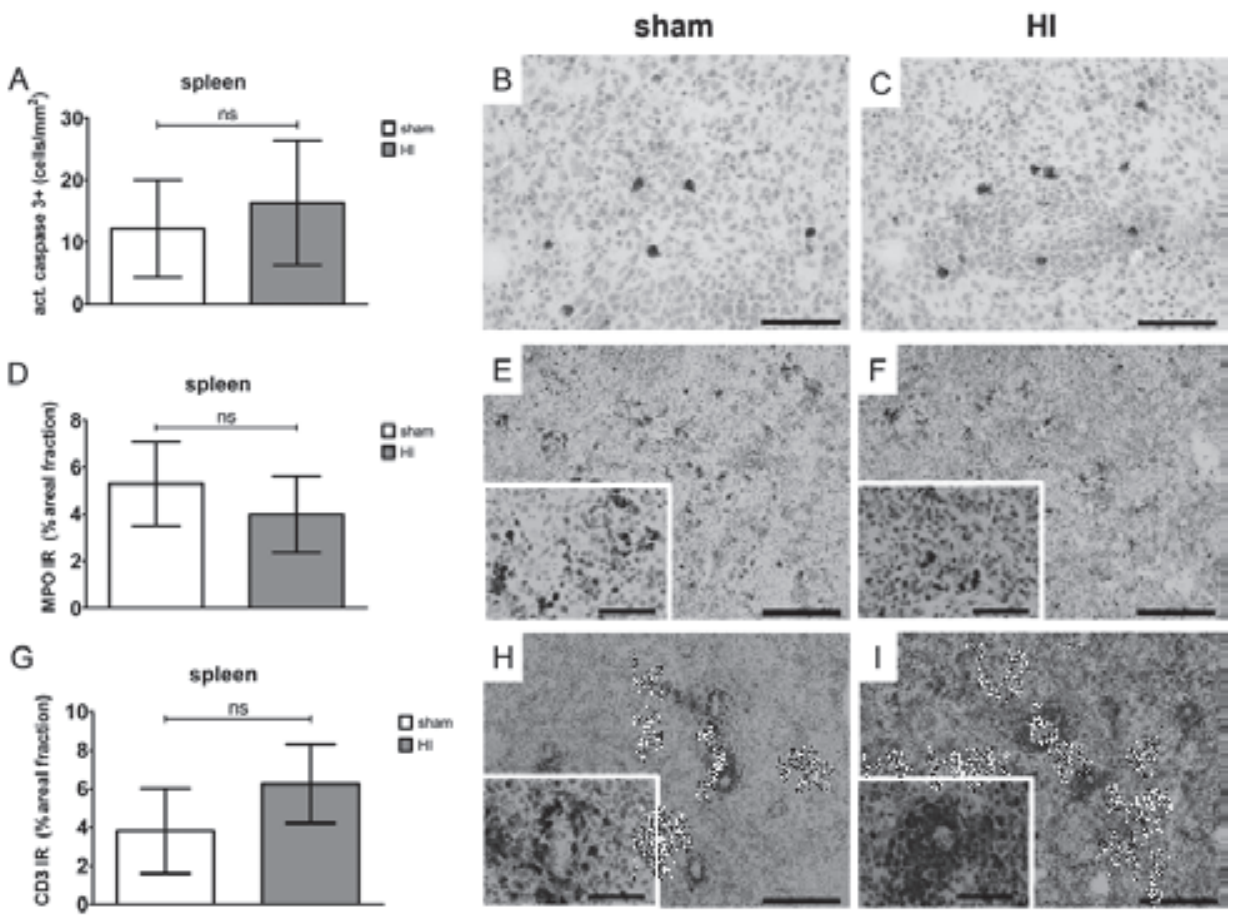

Figure 11. (A) Splenic apoptosis was not affected by global HI as indicated by unchanged numbers (cells/ $\mathrm{mm} 2$ ) of activated caspase-3 positive cells in the spleen assessed seven days after umbilical cord occlusion (UCO). (B) Sham, spleen; activated caspase-3. (C) HI, spleen; activated caspase-3. (D) Global HI did not change areal fraction (\%) of MPO immunoreactivity in the spleen seven days after UCO. (E) Sham, spleen; MPO. (F) HI, spleen; MPO. (G) Global HI did not change areal fraction (\%) of CD3 immunoreactivity in the spleen seven days after UCO. (H) Sham, spleen; CD3. (I) HI, spleen; CD3. Scale bar activated caspase-3 images $=50 \mu \mathrm{m}$. Scale bar CD3 and MPO images $=200 \mu \mathrm{m}$, scale bar inserts $=50 \mu \mathrm{m} .(A, D, G)$ Means $\pm 95 \% \mathrm{Cl}$ are depicted. ${ }^{*} P \leq 0.05, \# P \leq 0.01, \neq P \leq 0.001, N S$, non-significant. $H I=$ hypoxic-ischemia. 


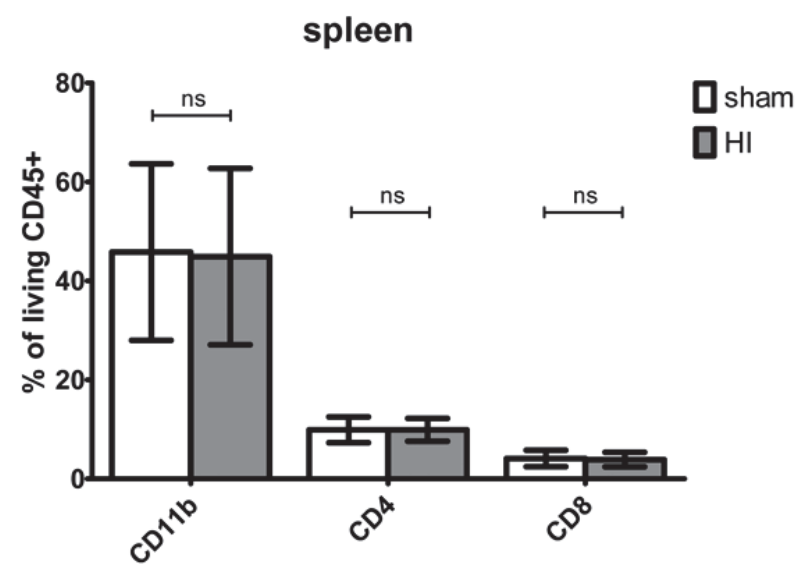

Figure 12. Global HI did not affect the number of splenocytes expressing CD11b (neutrophils), CD4 (helper T-cells) or CD8 (cytotoxic T-cells) seven days after umbilical cord occlusion (UCO). (A) Means $\pm 95 \% \mathrm{Cl}$ are depicted. ${ }^{*} P \leq 0.05, \# P \leq 0.01, \neq P \leq 0.001, N S$, non-significant. $H I=$ hypoxic-ischemia.

\section{EEG suppression}

The fetal EEG was continuously recorded in HI-exposed $(n=8)$ and sham $(n=8)$ fetuses during the complete study period. EEG analysis was performed from two days before UCO until the end of the experiment after a reperfusion period of seven days. Interburst interval (IBI) length was assessed to determine suppression of brain function following $\mathrm{HI}$. EEG suppression was indicated by prolonged IBI length. Figure 13A displays the observed IBI length values (background; grey) over time of two animals, one sham fetus and one $\mathrm{HI}$ fetus, averaged over 30 minutes. Time point ' 0 ' indicates day of UCO. Note the distinct difference in IBI length between the HI vs. sham fetuses after occlusion, with more prolonged length and larger fluctuations for the former. Superimposed on the 30 minutes data in figure $13 \mathrm{~A}$ are also the IBI length values averaged over 24 hours - the same two animals (foreground; full circles). For model simplicity, the piecewise regression model was fitted on the 24 hours data.

Figure $13 \mathrm{~B}$ displays the $\mathrm{IBI}$ length temporal dynamics as estimated by the final regression model. Its fixed and random effect parameters are displayed in Table 1 . The predicted lines (according to the model) are superimposed on observed 24 hours values (all animals). Note the greater IBI length variability in the $\mathrm{HI}$ fetuses induced by the occlusion. This more variable responsiveness was captured in the model by the significant random slope variance for in the HI group (Table 1).

There is a clear upwards shift (increase) in the average IBI length values (log scale) for the $\mathrm{HI}$ group compared to sham after UCO (significant interaction between pre-post 
dummy and group variables, capturing the average change in IBI length level for the HI group immediately after UCO). Mean IBI length after UCO remained higher throughout the measured time span (one week) for the HI group. With respect to temporal changes, it is noteworthy to mention that before UCO the averaged values remain stable over time (pre-UCO time variable did not reach statistical significance), contrary to post-UCO time. After UCO, IBI length seemed to change in a curve-linear pattern for both groups (significant quadratic and cubic post-time parameters in the model). In summary, IBI length was significantly increased following UCO and remained higher in the HI group during the seven day reperfusion time, indicating prolonged suppression of preterm brain function following global HI.
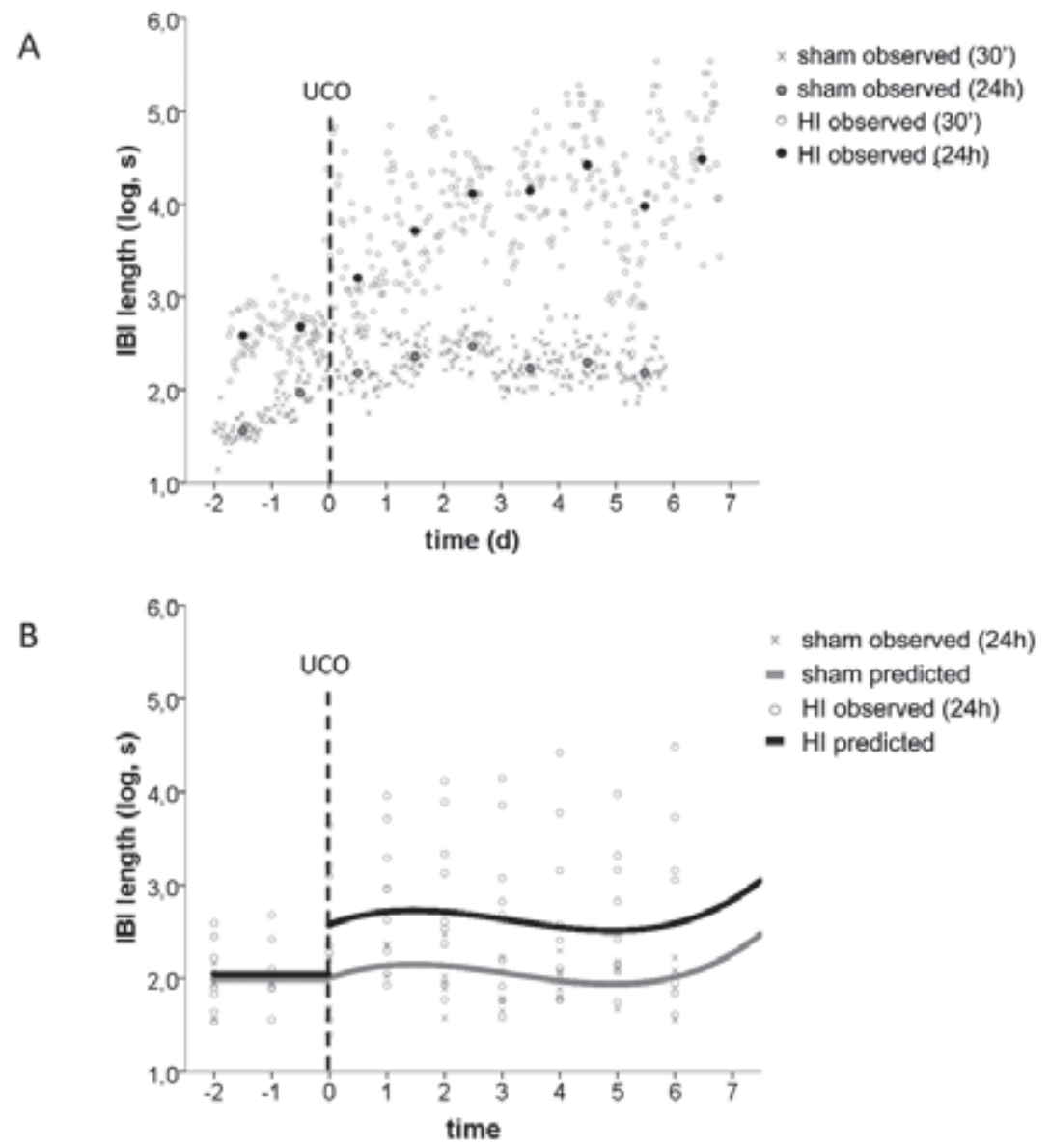

Figure 13. Global HI resulted in prolonged profound suppression of preterm brain function. (A) Observed mean IBI length (log scale) per 24 hours of two animals, one sham and one HI, superimposed on observed mean IBI length per 30 minutes. (B) Values predicted by the mixed linear model are superimposed on observed $|B|$ length per 24 hours of all animals. $|B|=$ interburst interval length, log = natural logarithm, $s=$ seconds, UCO = umbilical cord occlusion, 30' $=30$ minutes, $24 \mathrm{~h}=24$ hours, $d=$ day. 


\section{Discussion}

In this study we showed that global hypoxic-ischemia (HI) caused profound inflammation of the preterm ovine brain, which was paralleled by mobilization of the peripheral innate immune system. These inflammatory changes were associated with suppressed brain function, brain atrophy, region-specific vulnerability of pre-oligodendrocytes (preOLs) and hypomyelination, which are known to correlate with white matter disease, the clinical hallmark of preterm HIE [13].

Microglial proliferation following global $\mathrm{HI}$ was demonstrated by immunohistochemical staining of IBA-1, a specific marker for microglia under normal and neuroinflammatory conditions [24-26, 32,33]. Moreover, we showed morphological transformation of IBA-1 positive microglia from ramified into amoeboid state indicating activation of these cells following global $\mathrm{HI}$ in preterm sheep [34, 35]. These microglial changes, as seen after global ischemia in preterm lambs, are in line with the microglial response after focal ischemia of the adult brain which typically occurs within 24 hours after the insult [36-38].

Mobilization of the peripheral innate immune system in our model was demonstrated by a non-preferential recruitment of immune cells into the circulation within 24 hours following global $\mathrm{HI}$ as well as a marked influx of neutrophils into the HI-exposed preterm hippocampus and white matter seven days after the global $\mathrm{HI}$ insult. This invasion of neutrophils, which is an important histopathological finding in cerebral ischemia, was primarily localized in the perivascular zone [39-41]. The influx of neutrophils, which typically occurs as a second hit within 48-72 hours after cerebral ischemia, is considered to further aggravate acute inflammation of the brain that was initiated by immediate cell death and microglial activation by enhanced free radical attack [36-38].

A permeable blood brain barrier (BBB) is a prerequisite for the influx of neutrophils such as seen following global $\mathrm{HI}[41,42]$. Clinical [43] and experimental [44-46] evidence showed disruption of the BBB in perinatal hypoxic-ischemia. The influx of neutrophils also indicates that the immature immune system is capable of responding to an inflammatory stimulus induced by global $\mathrm{HI}$. This concept is in line with recent literature challenging the dogma that the preterm immune system is naive [47-49]. However, the fact that neutrophils were predominantly observed in the perivascular zone following $\mathrm{HI}$, and to a lesser extent in the interstitium, indicated that the capacity of fetal neutrophils to transmigrate was immature [48].

We postulate that the cerebral neutrophils, as seen in our model, were derived from the spleen, since this organ is considered to be the predominant source of invading neutrophils following focal ischemia of the brain $[18,50,51]$. This concept is further supported by work of Ajmo et al. who showed in a rat model of focal cerebral ischemia that splenectomy reduced neutrophil influx and microglial activation, ultimately diminishing ischemic brain injury [17]. 
Notably, $\mathrm{HI}$-induced involution of the spleen may have clinical postnatal consequences since splenic involution has been associated with an increased risk of postnatal infectious complications such as early onset sepsis [21,53]. Splenectomy in our model of global $\mathrm{HI}$ is required to confirm the role of the spleen as a source of neutrophils.

Table 1. Estimated fixed and random effect parameters of the piecewise (mixed) regression model. Estimated fixed and random effect parameters of the piecewise (mixed) regression model (Outcome variable: mean IBI length, on the log scale. Covariance structure: diagonal). The fixed effect regression coefficients $B$ for the continuous time variables indicate average changes in mean IBI length per day. For nominal variables, 6 represent average changes in the highlighted category (in brackets) with respect to the reference group (omitted). ${ }^{*} P \leq 0.05, \#$ $P \leq 0.01, \neq P \leq 0.001$, NS, non-significant.

\begin{tabular}{ll}
\hline Parameters & $(95 \% \mathrm{CI})$ \\
\hline (fixed and random effects) & $\mathrm{n}=16$ \\
Intercept & $2.60(2.19,3.00) \ddagger$ \\
Group (Sham ) & $-7.14(-1.39,-0.03) *$ \\
Dummy Pre-post UCO (pre-time) & $-0.63(-0.95,-0.32) \ddagger$ \\
Group*pre-post dummy & $0.65(0.27,1.02) \ddagger$ \\
Pre-UCO time & $-0.01(-0.20,0.18) \mathrm{NS}$ \\
Post-UCO time & $0.29(0.12,0.46) \ddagger$ \\
Post-UCO time ${ }^{2}$ & $-0.12(-4.84,1.73) \ddagger$ \\
Post-UCO time & 3 \\
Residual variance & $0.01(0.00,0.02) \ddagger$ \\
Random intercept variance - pre-UCO time & $0.03(0.02,0.05) \ddagger$ \\
Random slope variance - pre-UCO time & $0.29(0.12,0.68) *$ \\
Random slope variance -post-UCO time HI & $0.03(0.01,0.10) *$ \\
\hline
\end{tabular}

The cerebral and systemic inflammatory changes observed in our study were accompanied by prolonged suppression of preterm brain function. The persistent reduction in brain activity as observed in our study is in line with previous studies in comparable ovine models of global $\mathrm{HI}[22,54]$. Clinical evidence showed that persistent suppression of EEG activity is associated with poor outcome, indicating the severity of the HI-insult applied in this study $[55,56]$. Furthermore, global $\mathrm{HI}$ induced severe brain atrophy in our study, which has previously been associated with neuronal injury [57, 58].

Our findings showed that $\mathrm{HI}$-induced cerebral inflammation was paralleled by region-specific preOL vulnerability. In the subcortical white matter (SCWM), loss of morphologically immature 04-positive preOLs was associated with hypomyelination, which is in concordance with previous results in a similar model of hypoxic-ischemic sheep $[22,54]$. In the periventricular white matter (PVWM), we observed loss of morphologically immature preOLs as well as increased numbers of morphologically mature preOLs 
following global $\mathrm{HI}$. These findings suggested that the preOL response following global $\mathrm{HI}$ varied from degeneration to proliferation and depended on the region and the morphological maturity of preOLs. This concept is supported by recent studies suggesting that myelination failure of the preterm brain following $\mathrm{HI}$ may be caused by a combination of preOL degeneration, regeneration and arrested maturation [59-61].

Table 2. Interpretation of model parameters

\begin{tabular}{|c|c|}
\hline Group (Sham ) & $\begin{array}{l}\text { Captures IBI length differences in means between SHAM } \\
\text { and } \mathrm{HI} \text { averaged over all time points }\end{array}$ \\
\hline $\begin{array}{l}\text { Dummy Pre-post UCO } \\
\text { (pre-time) }\end{array}$ & $\begin{array}{l}\text { Captures the (vertical) shift of mean IBI values, induced by } \\
\text { the interrupted treatment (UCO) }\end{array}$ \\
\hline Group*pre-post dummy & $\begin{array}{l}\text { Captures the differential shift of mean IBI length values } \\
\text { immediately after UCO - significant only for the HI group }\end{array}$ \\
\hline Pre-UCO time & $\begin{array}{l}\text { Captures a linear increase of mean IBI length over time } \\
\text { before UCO - Note: Non-significant }\end{array}$ \\
\hline \multicolumn{2}{|l|}{ Post-UCO time } \\
\hline Post-UCO time ${ }^{2}$ & $\begin{array}{l}\text { All } 3 \text { time associated parameters capture curve-linear } \\
\text { changes of mean IBI lengths over time after UCO }\end{array}$ \\
\hline \multicolumn{2}{|r|}{ 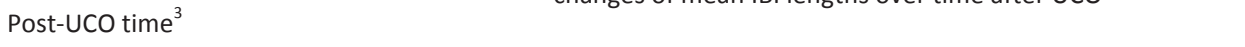 } \\
\hline Residual variance & Captures within subjects variability (noise) \\
\hline Random intercept variance - pre-UCO time & Captures between subject variability at the outset \\
\hline Random slope variance - pre-UCO time & $\begin{array}{l}\text { Captures between subject variability with respect to linear IBI } \\
\text { changes over time before UCO (each animal has its own } \\
\text { slope) }\end{array}$ \\
\hline Random slope variance -post-UCO time $\mathrm{HI}$ & $\begin{array}{l}\text { Captures heterogeneity of between subject variability with } \\
\text { respect to linear IBI changes over time after UCO - larger } \\
\text { variable responsiveness for the HI group }\end{array}$ \\
\hline
\end{tabular}

The observed white matter injury and functional impairments following global $\mathrm{HI}$ are typical findings in preterm infants with HIE underlining the translational character of the preterm sheep model.

In conclusion, this study provides evidence that cerebral inflammation and mobilization of the peripheral innate immune system are paralleled by injury and functional loss of the preterm brain following global HI. We postulate that the spleen plays a key role in preterm HIE by providing immune effector cells to the circulation and subsequently to the injured brain. Further studies should focus on the interplay between preterm brain inflammation and the activation of the peripheral immune system following global HI. Better understanding of the involvement of cerebral and systemic inflammation in the course of global $\mathrm{HI}$ will contribute to the development of future therapeutic interventions in preterm HIE. 


\section{References}

1. Volpe JJ: Neurology of the Newborn. 5th edn. Philadelphia: Elsevier-Saunders 2008.

2. Volpe JJ: Brain injury in premature infants: a complex amalgam of destructive and developmental disturbances. Lancet Neurol 2009, 8:110-124.

3. Abernethy LJ, Cooke RW, Foulder-Hughes L: Caudate and hippocampal volumes, intelligence, and motor impairment in 7-year-old children who were born preterm. Pediatr Res 2004, 55:884-893.

4. Isaacs EB, Lucas A, Chong WK, Wood SJ, Johnson CL, Marshall C, Vargha-Khadem F, Gadian DG: Hippocampal volume and everyday memory in children of very low birth weight. Pediatr Res 2000, 47:713-720.

5. Nosarti C, Al-Asady MH, Frangou S, Stewart AL, Rifkin L, Murray RM: Adolescents who were born very preterm have decreased brain volumes. Brain 2002, 125:1616-1623.

6. Reiss AL, Kesler SR, Vohr B, Duncan CC, Katz KH, Pajot S, Schneider KC, Makuch RW, Ment LR: Sex differences in cerebral volumes of 8-year-olds born preterm. J Pediatr 2004, 145:242-249.

7. Van Erp TG, Saleh PA, Rosso IM, Huttunen M, Lonnqvist J, Pirkola T, Salonen O, Valanne L, Poutanen VP, Standertskjold-Nordenstam CG, Cannon TD: Contributions of genetic risk and fetal hypoxia to hippocampal volume in patients with schizophrenia or schizoaffective disorder, their unaffected siblings, and healthy unrelated volunteers. Am J Psychiatry 2002, 159:1514-1520.

8. Edwards $A D$, Brocklehurst $P$, Gunn AJ, Halliday $H$, Juszczak $E$, Levene $M$, Strohm $B$, Thoresen $M$, Whitelaw A, Azzopardi D: Neurological outcomes at 18 months of age after moderate hypothermia for perinatal hypoxic ischaemic encephalopathy: synthesis and meta-analysis of trial data. BMJ 2010, 340:c363.

9. Jacobs S, Hunt R, Tarnow-Mordi W, Inder T, Davis P: Cooling for newborns with hypoxic ischaemic encephalopathy. Cochrane Database Syst Rev 2007, 4:CD003311.

10. Azzopardi DV, Strohm B, Edwards AD, Dyet L, Halliday HL, Juszczak E, Kapellou O, Levene M, Marlow N, Porter E, Thoresen M, Whitelaw A, Brocklehurst P: Moderate hypothermia to treat perinatal asphyxial encephalopathy. N Engl J Med 2009, 361:1349-1358.

11. Back SA, Han BH, Luo NL, Chricton CA, Xanthoudakis S, Tam J, Arvin KL, Holtzman DM: Selective vulnerability of late oligodendrocyte progenitors to hypoxia-ischemia. J Neurosci 2002, 22:455-463.

12. Back SA, Luo NL, Borenstein NS, Levine JM, Volpe JJ, Kinney HC: Late oligodendrocyte progenitors coincide with the developmental window of vulnerability for human perinatal white matter injury. $J$ Neurosci 2001, 21:1302-1312.

13. Volpe JJ, Kinney HC, Jensen FE, Rosenberg PA: The developing oligodendrocyte: key cellular target in brain injury in the premature infant. Int J Dev Neurosci 2011, 29:423-440.

14. Khwaja O, Volpe JJ: Pathogenesis of cerebral white matter injury of prematurity. Arch Dis Child Fetal Neonatal Ed 2008, 93:F153-161.

15. Saijo K, Glass CK: Microglial cell origin and phenotypes in health and disease. Nat Rev Immunol 2011, 11:775-787.

16. Hagberg H, Gressens P, Mallard C: Inflammation during fetal and neonatal life: implications for neurologic and neuropsychiatric disease in children and adults. Ann Neurol 2012, 71:444-457.

17. Ajmo CT, Jr., Vernon DO, Collier L, Hall AA, Garbuzova-Davis S, Willing A, Pennypacker KR: The spleen contributes to stroke-induced neurodegeneration. J Neurosci Res 2008, 86:2227-2234.

18. Offner H, Subramanian S, Parker SM, Afentoulis ME, Vandenbark AA, Hurn PD: Experimental stroke induces massive, rapid activation of the peripheral immune system. J Cereb Blood Flow Metab 2006, 26:654-665.

19. Gunn AJ, Bennet L: Fetal hypoxia insults and patterns of brain injury: insights from animal models. Clin Perinatol 2009, 36:579-593.

20. Hagberg H, Peebles D, Mallard C: Models of white matter injury: comparison of infectious, hypoxicischemic, and excitotoxic insults. Ment Retard Dev Disabil Res Rev 2002, 8:30-38. 


\section{Chapter 3}

21. Wolfs TG, Jellema RK, Turrisi G, Becucci E, Buonocore G, Kramer BW: Inflammation-induced immune suppression of the fetus: a potential link between chorioamnionitis and postnatal early onset sepsis. $J$ Matern Fetal Neonatal Med 2012, 25 Suppl 1:8-11.

22. Bennet L, Roelfsema V, George S, Dean JM, Emerald BS, Gunn AJ: The effect of cerebral hypothermia on white and grey matter injury induced by severe hypoxia in preterm fetal sheep. J Physiol 2007, 578:491506.

23. Jennekens W, Ruijs LS, Lommen CM, Niemarkt HJ, Pasman JW, van Kranen-Mastenbroek VH, Wijn PF, van Pul C, Andriessen P: Automatic burst detection for the EEG of the preterm infant. Physiol Meas 2011, 32:1623-1637.

24. Ito D, Imai Y, Ohsawa K, Nakajima K, Fukuuchi Y, Kohsaka S: Microglia-specific localisation of a novel calcium binding protein, Iba1. Brain Res Mol Brain Res 1998, 57:1-9.

25. Ito D, Tanaka K, Suzuki S, Dembo T, Fukuuchi Y: Enhanced expression of Iba1, ionized calcium-binding adapter molecule 1, after transient focal cerebral ischemia in rat brain. Stroke 2001, 32:1208-1215.

26. Matsumoto H, Kumon Y, Watanabe H, Ohnishi T, Shudou M, li C, Takahashi H, Imai Y, Tanaka J: Antibodies to CD11b, CD68, and lectin label neutrophils rather than microglia in traumatic and ischemic brain lesions. J Neurosci Res 2007, 85:994-1009.

27. Naumova EN, Must A, Laird NM: Tutorial in Biostatistics: Evaluating the impact of 'critical periods' in longitudinal studies of growth using piecewise mixed effects models. Int J Epidemiol 2001, 30:13321341.

28. Vannucci RC, Vannucci SJ: Perinatal hypoxic-ischemic brain damage: evolution of an animal model. Dev Neurosci 2005, 27:81-86.

29. Barone FC, Hillegass LM, Price WJ, White RF, Lee EV, Feuerstein GZ, Sarau HM, Clark RK, Griswold DE: Polymorphonuclear leukocyte infiltration into cerebral focal ischemic tissue: myeloperoxidase activity assay and histologic verification. J Neurosci Res 1991, 29:336-345.

30. Breckwoldt MO, Chen JW, Stangenberg L, Aikawa E, Rodriguez E, Qiu S, Moskowitz MA, Weissleder R: Tracking the inflammatory response in stroke in vivo by sensing the enzyme myeloperoxidase. Proc Natl Acad Sci U S A 2008, 105:18584-18589.

31. Campuzano O, Castillo-Ruiz MM, Acarin L, Gonzalez B, Castellano B: Decreased myeloperoxidase expressing cells in the aged rat brain after excitotoxic damage. Exp Gerontol 2011, 46:723-730.

32. Dean JM, Farrag D, Zahkouk SA, El Zawahry EY, Hagberg H, Kjellmer I, Mallard C: Cerebellar white matter injury following systemic endotoxemia in preterm fetal sheep. Neuroscience 2009, 160:606-615.

33. Dean JM, van de Looij Y, Sizonenko SV, Lodygensky GA, Lazeyras F, Bolouri H, Kjellmer I, Huppi PS, Hagberg H, Mallard C: Delayed cortical impairment following lipopolysaccharide exposure in preterm fetal sheep. Ann Neurol 2011.

34. Davalos D, Grutzendler J, Yang G, Kim JV, Zuo Y, Jung S, Littman DR, Dustin ML, Gan WB: ATP mediates rapid microglial response to local brain injury in vivo. Nat Neurosci 2005, 8:752-758.

35. Fetler L, Amigorena S: Neuroscience. Brain under surveillance: the microglia patrol. Science 2005, 309:392-393.

36. Gelderblom M, Leypoldt F, Steinbach K, Behrens D, Choe CU, Siler DA, Arumugam TV, Orthey E, Gerloff C, Tolosa E, Magnus T: Temporal and spatial dynamics of cerebral immune cell accumulation in stroke. Stroke 2009, 40:1849-1857.

37. Offner $\mathrm{H}$, Vandenbark AA, Hurn PD: Effect of experimental stroke on peripheral immunity: CNS ischemia induces profound immunosuppression. Neurosci 2009, 158:1098-1111.

38. Stevens SL, Bao J, Hollis J, Lessov NS, Clark WM, Stenzel-Poore MP: The use of flow cytometry to evaluate temporal changes in inflammatory cells following focal cerebral ischemia in mice. Brain Res 2002, 932:110-119.

39. Fassbender K, Bertsch T, Mielke O, Muhlhauser F, Hennerici M: Adhesion molecules in cerebrovascular diseases. Evidence for an inflammatory endothelial activation in cerebral large- and small-vessel disease. Stroke 1999, 30:1647-1650.

40. Garcia JH, Liu KF, Yoshida Y, Lian J, Chen S, del Zoppo GJ: Influx of leukocytes and platelets in an evolving brain infarct (Wistar rat). Am J Pathol 1994, 144:188-199. 
41. Kishimoto TK, Rothlein R: Integrins, ICAMs, and selectins: role and regulation of adhesion molecules in neutrophil recruitment to inflammatory sites. Adv Pharmacol 1994, 25:117-169.

42. Jin AY, Tuor UI, Rushforth D, Kaur J, Muller RN, Petterson JL, Boutry S, Barber PA: Reduced blood brain barrier breakdown in P-selectin deficient mice following transient ischemic stroke: a future therapeutic target for treatment of stroke. BMC Neurosci 2010, 11:12.

43. Kumar A, Mittal R, Khanna HD, Basu S: Free radical injury and blood-brain barrier permeability in hypoxic-ischemic encephalopathy. Pediatrics 2008, 122:e722-727.

44. Svedin P, Hagberg H, Savman K, Zhu C, Mallard C: Matrix metalloproteinase-9 gene knock-out protects the immature brain after cerebral hypoxia-ischemia. J Neurosci 2007, 27:1511-1518.

45. Tu YF, Tsai YS, Wang LW, Wu HC, Huang CC, Ho CJ: Overweight worsens apoptosis, neuroinflammation and blood-brain barrier damage after hypoxic ischemia in neonatal brain through JNK hyperactivation. $J$ Neuroinflammation 2011, 8:40.

46. Brochu ME, Girard S, Lavoie K, Sebire G: Developmental regulation of the neuroinflammatory responses to LPS and/or hypoxia-ischemia between preterm and term neonates: An experimental study. J Neuroinflammation 2011, 8:55.

47. Adkins B, Leclerc C, Marshall-Clarke S: Neonatal adaptive immunity comes of age. Nat Rev Immunol 2004, 4:553-564.

48. Levy O: Innate immunity of the newborn: basic mechanisms and clinical correlates. Nat Rev Immunol 2007, 7:379-390.

49. Luciano AA, Yu H, Jackson LW, Wolfe LA, Bernstein HB: Preterm labor and chorioamnionitis are associated with neonatal T cell activation. PLoS One 2011, 6:e16698.

50. Offner H, Subramanian S, Parker SM, Wang C, Afentoulis ME, Lewis A, Vandenbark AA, Hurn PD: Splenic atrophy in experimental stroke is accompanied by increased regulatory $T$ cells and circulating macrophages. J Immunol 2006, 176:6523-6531.

51. Vendrame M, Gemma C, Pennypacker KR, Bickford PC, Davis Sanberg C, Sanberg PR, Willing AE: Cord blood rescues stroke-induced changes in splenocyte phenotype and function. Exp Neurol 2006, 199:191-200.

52. Winerdal M, Winerdal ME, Kinn J, Urmaliya $V$, Winqvist O, Aden U: Long lasting local and systemic inflammation after cerebral hypoxic ischemia in newborn mice. PLoS One 2012, 7:e36422.

53. Toti P, De Felice C, Occhini R, Schuerfeld K, Stumpo M, Epistolato MC, Vatti R, Buonocore G: Spleen depletion in neonatal sepsis and chorioamnionitis. Am J Clin Pathol 2004, 122:765-771.

54. Dean JM, George SA, Wassink G, Gunn AJ, Bennet L: Suppression of post-hypoxic-ischemic EEG transients with dizocilpine is associated with partial striatal protection in the preterm fetal sheep. Neuropharmacology 2006, 50:491-503.

55. Pressler RM, Boylan GB, Morton M, Binnie CD, Rennie JM: Early serial EEG in hypoxic ischaemic encephalopathy. Clin Neurophysiol 2001, 112:31-37.

56. van Rooij LG, Toet MC, Osredkar D, van Huffelen AC, Groenendaal F, de Vries LS: Recovery of amplitude integrated electroencephalographic background patterns within 24 hours of perinatal asphyxia. Arch Dis Child Fetal Neonatal Ed 2005, 90:F245-251.

57. Inder TE, Huppi PS, Warfield S, Kikinis R, Zientara GP, Barnes PD, Jolesz F, Volpe JJ: Periventricular white matter injury in the premature infant is followed by reduced cerebral cortical gray matter volume at term. Ann Neurol 1999, 46:755-760.

58. Inder TE, Warfield SK, Wang H, Huppi PS, Volpe JJ: Abnormal cerebral structure is present at term in premature infants. Pediatrics 2005, 115:286-294.

59. Buser JR, Maire J, Riddle A, Gong X, Nguyen T, Nelson K, Luo NL, Ren J, Struve J, Sherman LS, Miller SP, Chau V, Hendson G, Ballabh P, Grafe MR, Back SA: Arrested preoligodendrocyte maturation contributes to myelination failure in premature infants. Ann Neurol 2012, 71:93-109.

60. Segovia KN, McClure M, Moravec M, Luo NL, Wan Y, Gong X, Riddle A, Craig A, Struve J, Sherman LS, Back SA: Arrested oligodendrocyte lineage maturation in chronic perinatal white matter injury. Ann Neurol 2008, 63:520-530. 


\section{Chapter 3}

61. Billiards SS, Haynes RL, Folkerth RD, Borenstein NS, Trachtenberg FL, Rowitch DH, Ligon KL, Volpe JJ, Kinney HC: Myelin abnormalities without oligodendrocyte loss in periventricular leukomalacia. Brain Pathol 2008, 18:153-163. 


\section{Chapter 4}

\section{Mesenchymal stem cells induce T-cell tolerance and protect the preterm brain after global hypoxia-ischemia}

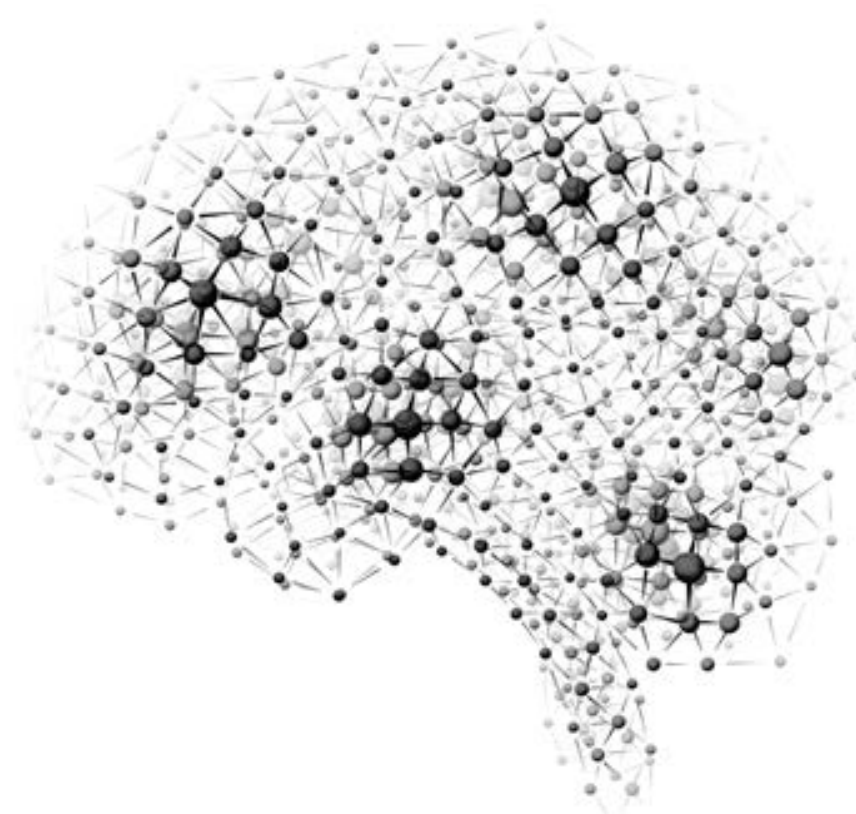

Published as: Jellema RK, Wolfs TG, Lima Passos V, Zwanenburg A, Ophelders DR, Kuypers E, Hopman AH, Dudink J, Steinbusch HW, Andriessen P, Germeraad WT, Vanderlocht J, Kramer BW: Mesenchymal stem cells induce T-cell tolerance and protect the preterm brain after global hypoxia-ischemia. PLoS ONE 2013, 8:e73031. 


\section{Abstract}

Hypoxic-ischemic encephalopathy (HIE) in preterm infants is a severe disease for which no curative treatment is available. Cerebral inflammation and invasion of activated peripheral immune cells have been shown to play a pivotal role in the etiology of white matter injury, which is the clinical hallmark of HIE in preterm infants. The objective of this study was to assess the neuroprotective and anti-inflammatory effects of intravenously delivered mesenchymal stem cells (MSC) in an ovine model of HIE. In this translational animal model, global hypoxia-ischemia (HI) was induced in instrumented preterm sheep by transient umbilical cord occlusion, which closely mimics the clinical insult.

Intravenous administration of $2 \times 10^{6} \mathrm{MSC} / \mathrm{kg}$ reduced microglial proliferation, diminished loss of oligodendrocytes and reduced demyelination, as determined by histology and Diffusion Tensor Imaging (DTI), in the preterm brain after global HI. These anti-inflammatory and neuroprotective effects of MSC were paralleled by reduced electrographic seizure activity in the ischemic preterm brain. Furthermore, we showed that MSC induced persistent peripheral T-cell tolerance in vivo and reduced invasion of T-cells into the preterm brain following global $\mathrm{HI}$.

These findings show in a preclinical animal model that intravenously administered MSC reduced cerebral inflammation, protected against white matter injury and established functional improvement in the preterm brain following global HI. Moreover, we provide evidence that induction of T-cell tolerance by MSC might play an important role in the neuroprotective effects of MSC in HIE. This is the first study to describe a marked neuroprotective effect of MSC in a translational animal model of HIE. 


\section{Introduction}

Preterm infants are prone to brain injury after a perinatal hypoxic-ischemic insult [1-3]. Hypoxic-ischemic encephalopathy (HIE) in preterm infants is predominantly characterized by white matter injury (i.e. periventricular leukomalacia) which is caused by damage to highly vulnerable immature oligodendrocytes $[1,2,4]$. HIE in preterm infants is associated with cognitive disorders in $25-50 \%$ of all cases and $5-10 \%$ suffer from severe motor deficits (i.e. cerebral palsy) [5]. However, therapeutic options to improve the neurodevelopmental outcome in preterm infants after HIE are unavailable.

There is mounting evidence that the inflammatory response following brain ischemia plays a crucial role in the pathophysiology of ischemic brain injury $[6,7]$. This concept is predominantly based on literature showing activation of the cerebral and peripheral immune system after focal ischemia (i.e. stroke; transient or permanent occlusion of cerebral perfusion) in adult $[8,9]$ and term neonatal [10] rodent models. Recently, we have demonstrated in a translational ovine model, that global hypoxiaischemia (HI), which was induced by transient umbilical cord occlusion, caused cerebral inflammation and activation of the peripheral immune system in a similar way as observed after focal ischemia [11]. More precisely, we showed in this model, which is representative for brain development of preterm infants, that global $\mathrm{HI}$ induced a profound microglial response followed by a second peripheral inflammatory response characterized by invasion of mobilized peripheral immune cells into the ischemic preterm ovine brain [11]. These inflammatory changes were associated with marked injury to pre-oligodendrocytes and hypomyelination of the preterm brain [11], which are well known indicators of white matter injury in the ischemic preterm brain $[1,2,12]$. Our findings indicated that the immature immune system is readily mobilized after global $\mathrm{HI}$ and is involved in the etiology of white matter injury, the clinical hallmark of hypoxicischemic preterm brain injury [11].

Since inflammation plays an important role in the etiology of neonatal brain injury, neuroprotective therapies should have strong anti-inflammatory and regenerative capacities if aimed at the repair of the hypoxic-ischemic neonatal brain. Mesenchymal stem cells (MSC) meet these criteria [13-16], and therefore several studies have been conducted to assess whether MSC therapy can protect the neonatal term brain after focal ischemia [17-22]. The objective of our study was to assess the neuroprotective and anti-inflammatory potential of MSC therapy in the preterm brain exposed to global hypoxic-ischemia. We hypothesized that intravenously administered human bonemarrow derived MSC would be neuroprotective in a translational animal model of preterm HIE. To test this hypothesis, preterm instrumented sheep were exposed to 25 minutes of umbilical cord occlusion at 0.7 gestation. At this time of gestation neurodevelopment of fetal sheep is equivalent to that of a preterm infant of 30-32 weeks [23, 24]. The neuroprotective effect of MSC treatment was studied by assessment of white 
matter injury and electrographic seizure activity. The anti-inflammatory effect of MSC treatment was studied by evaluation of the peripheral T-cell response.

\section{Materials \& methods}

\section{Ethics Statement}

The experimental protocol and design of the study were in line with the institutional guidelines for animal experiments and were approved by the institutional Animal Ethics Research committee of Maastricht University, The Netherlands.

\section{Animals and surgery}

Fetuses of time-mated Texel ewes were instrumented as previously described [11]. In short, all fetuses were instrumented with an arterial catheter for blood pressure measurements and blood sampling, a venous catheter for administration of MSC and ECG electrodes for heart rate monitoring. EEG electrodes were placed as previously described [11]. The anterior and posterior placed electrodes were considered C3-C4 channel and P3-P4 channel, respectively. An inflatable vascular occluder (OC16HD, $16 \mathrm{~mm}$, In Vivo Metric, Healdsburg, CA, USA) was placed around the umbilical cord to induce transient global HI. All fetal catheters and leads were exteriorized through a trocar hole in the flank of the ewe. The welfare of the animals was monitored daily by certified personnel.

\section{Randomization and blinding}

Prior to the entire series of experiments, animals were randomized by an independent researcher who was not involved in the animal experiments. The randomization resulted in four experimental groups (Fig 1). The investigator performing the (sham) umbilical cord occlusions was blinded for treatment allocation. Tissue sampling and the analyses of brain tissue and electrophysiological data were conducted in a blinded fashion.

\section{Experimental design}

Fetuses were instrumented at $101.5 \pm 1.0$ (mean \pm SD) days of gestation (experimental day -4). After surgery ewe and fetus were allowed to recover for four days. At gestational age $105.5 \pm 1.1$ (mean \pm SD) (experimental day 0 ) fetuses were subjected to 25 minutes of umbilical cord occlusion (Fig 2) by rapidly inflating the occluder. After umbilical cord occlusion a reperfusion period of $7 \mathrm{~d}$ followed. 


\section{Mesenchymal stem cells}

Human bone marrow-derived mesenchymal stem cells (Merck Millipore, Billerica MA, USA) isolated from a male healthy donor were expanded following the manufacturer's protocol. After four passages the cells were frozen in freezing medium containing $10 \%$ FCS and $10 \%$ DMSO and stored in liquid nitrogen. The expanded MSC were validated for their differentiation potential and cell surface molecules. MSC effectively differentiated into osteoblasts and adipocytes (data not shown). Expression of cell surface molecules on infused MSC was confirmed by flow cytometry analysis. MSC expressed CD44, HLA-I, CD49c, CD13, CD54, CD58, CD140b, CD105, CD90, CD73 dimly expressed CD117 and CD49d and did not express HLA-II, CD45, CD34, CD40, CD80, CD146, CD3, CD86 and CD19. MSC were thawed and washed twice with PBS one hour before administration. MSC were infused intravenously $1 \mathrm{~h}$ after (sham) umbilical cord occlusion. Fetuses received $3.5 \times 10^{6} \mathrm{MSC}$ (approximately $2.0 \times 10^{6} / \mathrm{kg} \mathrm{BW}$ ) resuspended in $1 \mathrm{~mL}$ PBS via the venous line.

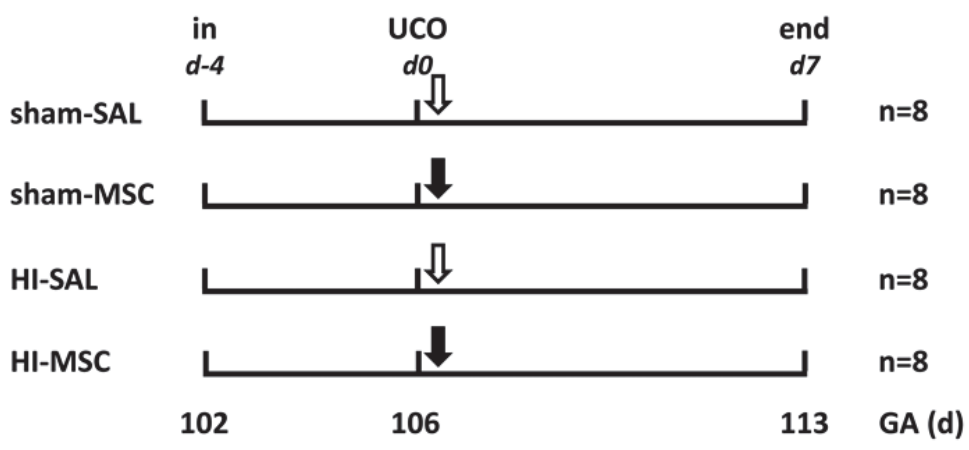

Figure 1. Study design. Fetuses were instrumented at a gestational age (GA) of $102 \mathrm{~d}$. After a recovery period of $4 \mathrm{~d}$ fetuses were subjected to $25 \mathrm{~min}$ of umbilical cord occlusion (UCO) or sham. One hour after UCO or sham, fetuses received either intravenous mesenchymal stem cells (2.0 million/ kg BW) (closed arrow) or saline 0,9\% (open arrow). After a $7 d$ reperfusion period brain tissue was collected. Abbreviations: in = instrumentation, $\mathrm{HI}=$ hypoxia-ischemia, $S A L=$ saline, $M S C=$ mesenchymal stem cells.

\section{Data acquisition}

Physiological data was acquired as described previously [11]. After filtering, the raw EEG signals of the central and posterior channels were converted into amplitudeintegrated EEG (aEEG) traces, using a Matlab ${ }^{\circledR}$ (R2011b; The Mathworks Inc., Natick, MA, USA) algorithm similar to the clinical EEG NicoletOneTM device (Viasys Healthcare, Conshohocken, PA, USA) [25]. The EEG processing included an asymmetric band-pass filter that strongly attenuates activity below $2 \mathrm{~Hz}$ and above $15 \mathrm{~Hz}$, semi-logarithmic amplitude compression and time compression [26]. The (a)EEG traces were used to 


\section{Chapter 4}

detect electrographic seizure activity, which in the aEEG usually is seen as an abrupt rise in the lower margin amplitude (LMA) and a simultaneous rise in the upper margin amplitude (UMA), often followed by a short period of decreased amplitude [27]. The raw EEG simultaneously shows gradual build-up and decline in amplitude of repetitive sharp-waves [28]. From $24 \mathrm{~h}$ before UCO to the end of the experiment, aEEG and EEG were displayed simultaneously. Electrographic seizure activity with a duration $\geq 10 \mathrm{~s}$ was annotated using both aEEG/EEG traces in $n=6$ animals per experimental group. Annotation was performed by a neonatologist, experienced in neonatal aEEG interpretation, who was blinded for treatment allocation.

A

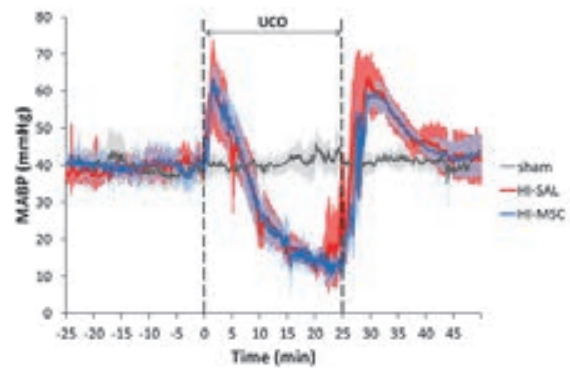

B

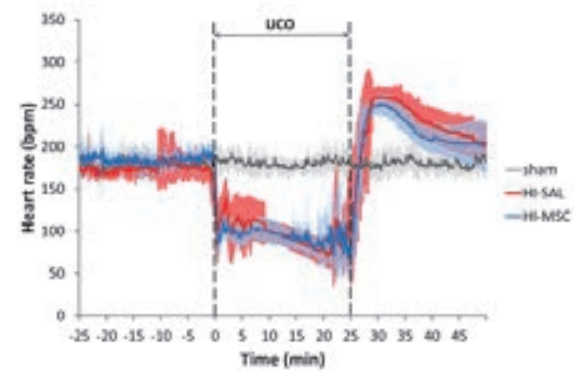

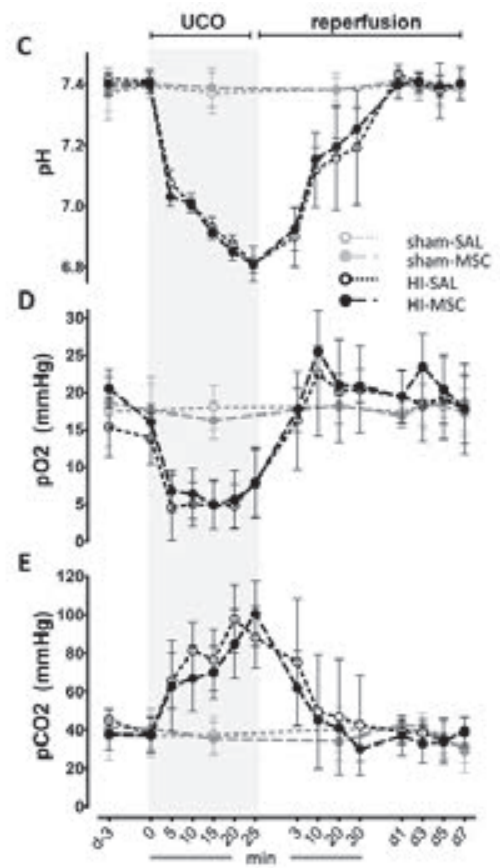

Figure 2. Reproducibility of 25 min umbilical cord occlusion (UCO). (A) Fetal mean arterial blood pressure (MABP) and (B) fetal heart rate (FHR) measurements indicated that all animals exposed to global $\mathrm{HI}$ experienced the same degree of hypotension and bradycardia, respectively, at the end of UCO; means (thick line) $\pm S D$ (shaded areas) of $n=8$ animals per experimental group are shown. MABP and FHR normalized within one hour after the end of UCO and were stable throughout the rest of the study period. All sham operated animals had similar MABP and FHR parameters during the entire duration of the study. For clarity reasons the sham-SAL and sham-MSC groups are depicted as one sham group. (C-E) Blood gas analysis indicated that twenty five minutes of umbilical cord occlusion induced comparable acidosis, hypoxemia and hypercarboxemia in all animals exposed to global $\mathrm{HI}$, as demonstrated by $(C)$ arterial $\mathrm{pH},(D)$ arterial partial oxygen pressure (pO2) and (E) arterial partial carbon dioxide pressure ( $p C O 2)$, respectively; means (lines) \pm $S D$ (error bars) of $n=8$ animals are depicted. Blood gas indices in animals exposed to global $\mathrm{HI}$ normalized within one hour after the end of UCO and stayed within the normal range throughout the rest of the study period. 


\section{MRI}

At the end of the experiment (day 7), the fetal brain was removed from the skull and weighed. The right hemisphere was submersion fixated in $4 \%$ paraformaldehyde (PFA) for 3 months and stored at 4 degrees Celsius. Forty eight hours prior to MRI imaging, the right hemisphere was washed with PBS and stored in PBS containing $1 \%$ sodiumazide at 4 degrees Celsius to wash out all PFA. After optimization, all DTI images were acquired using an echo planar imaging (EPI) sequence with diffusion gradients $\left(b=4000 \mathrm{~s} / \mathrm{mm}^{2}\right)$ applied in 66 non-collinear directions and 6 BO measurements. An average of 60 slices was recorded within 36 minutes using a repetition time $(T R)=500$ $\mathrm{ms}$ and echo time $(T E)=75 \mathrm{~ms}$. Isovolumetric voxel size was $0.5 \mathrm{~mm}^{3}$. The FOV was $30 \times 60 \times 60 \mathrm{~mm}$ and scan matrix size 60x120x60 mm.

DTI data was post processed using ExploreDTI software and fractional anisotropy (FA) maps maps were displayed [29]. White matter injury was assessed by measuring fractional anisotropy (FA), which has been previously shown to be unaffected by fixation [30]. Delineation of ROIs was performed by a neonatologist, experienced in DTI analysis, who was blinded for the treatment allocation. FA values within the delineated ROI in the SCWM and hippocampus were calculated with ExploreDTI [29].

\section{Immunohistochemistry brain}

Following MRI imaging the right hemisphere was embedded in gelatin and serial coronal sections $(50 \mu \mathrm{m})$ were cut on a Leica VT $1200 \mathrm{~S}$ vibrating microtome (Leica Biosystems, Nussloch, Germany). Free floating sections at the level of mid-thalamus and posterior hippocampus were stained with a rabbit anti-ionized calcium binding adaptor molecule 1 (IBA-1) antibody (Wako Pure Chemical Industries, Osaka, Japan), which is a highly specific marker for microglia, localizing resting and activated microglia [11]. A mouse anti-O4 antibody (Merck Millipore, Billerica, MA, USA) was used to detect preoligodendrocytes (preOLs) (oligodendrocyte progenitors and immature oligodendrocytes) and a rat anti-myelin basic protein (MBP) antibody (Merck Millipore, Billerica, MA, USA) was used to detect myelin sheaths and myelin producing (mature) oligodendrocytes. Endogenous peroxidase-activity was blocked by incubation with $0,3 \% \mathrm{H} 2 \mathrm{O} 2$ in Tris buffered saline (TBS, pH 7.6). Free floating sections were incubated overnight (antiIBA-1 and MBP) or during three days (anti-O4) at $4^{\circ} \mathrm{C}$ with the diluted primary antibody (1:1000 anti-IBA-1, 1:400 anti-O4 and 1:2000 MBP) followed by incubation with a secondary donkey-anti-rabbit (anti-IBA-1), donkey-anti-rat (MBP) or donkey-anti-mouse (anti-04) biotin labeled antibody.

The immunostaining was enhanced with Vectastain $A B C$ peroxidase Elite kit (PK6200, Vector Laboratories, Burlingame, CA, USA) followed by a nickel sulfatediaminobenzidine (NiDAB) staining. Sections were mounted on gelatin-coated glass slides, air-dried, dehydrated in ascending ethanol concentrations and coverslipped with PerTex. After cutting of free floating sections, the remainder of the tissue was 
embedded in paraffin and serial coronal sections $(4 \mu \mathrm{m})$ were cut. Sections at the level of mid-thalamus and posterior hippocampus were stained with CD3 (DAKO A0452, DAKO Denmark) for detection of T-cells.

Endogenous peroxidase was inactivated by incubation with $0,3 \% \mathrm{H} 2 \mathrm{O} 2$ that was dissolved in PBS. Antigen retrieval was performed by boiling in citrate buffer $\mathrm{pH}$ 6.0. Antigen aspecific binding was prevented by incubating the slides for 30 minutes with $5 \%$ bovine serum albumin (BSA). Slides were incubated overnight at $4^{\circ} \mathrm{C}$ with the diluted primary antibody (CD3 1:200) followed by incubation with the appropriate secondary biotin labeled antibody. Immunostaining was enhanced with Vectastain $A B C$ peroxidase Elite kit (PK-6200, Vector Laboratories) followed by a NiDAB staining. Sections were counterstained with $0.1 \%$ Nuclear Fast Red washed, dehydrated and coverslipped.

\section{Analysis of immunohistochemistry}

For the analysis of IBA-1 immunoreactivity, digital images of the subcortical white matter (SCWM) (100x magnification) and hippocampus (20x magnification) were acquired using an Olympus AX-70 microscope (Olympus, Tokyo, Japan) equipped with a black and white digital camera. For the analysis of IBA-1 immunoreactivity, $n=6$ for sham-SAL, $n=3$ for sham-MSC, $n=6$ for HI-SAL and $n=6$ for HI-MSC animals per group were analyzed. In each individual animal, IBA-1 immunoreactivity was assessed in six consecutive coronal sections (posterior hippocampus/ mid-thalamus level). In the hippocampus, area fraction of IBA-1 immunoreactivity was assessed in one 20x digital image per section by delineating the hippocampus and determining the areal fraction of IBA-1 immunoreactivity expressed as a percentage of total hippocampal area with a standard threshold using Leica Qwin Pro V 3.5.1 software (Leica, Rijswijk, the Netherlands). In the SCWM, the area fraction of IBA-1 immunoreactivity was determined in five adjacent 100x digital images obtained in standardized locations within the SCWM of each section (Fig $3 \mathrm{~A}$ ). The results of five images per section were averaged to obtain the areal fraction of IBA-1 immunoreactivity within the SCWM for each section. The digital images were obtained and analyzed by an independent observer who was blinded to the experimental conditions.

For the analysis of MBP immunoreactivity, digital images of the subcortical white matter (SCWM) (100x magnification) were acquired using the Olympus AX-70 microscope. For the analysis of MBP immunoreactivity, $n=6$ for sham-SAL, $n=3$ for sham-MSC, $n=6$ for HI-SAL and $n=6$ for HI-MSC animals per group were analyzed. In each individual animal, MBP immunoreactivity was assessed in six consecutive coronal sections (posterior hippocampus/ mid-thalamus level). In the SCWM, the MBP immunoreactivity was determined in five adjacent 100x digital images obtained in standardized locations within the SCWM of each section (Fig. 3A). Areal fraction of MBP-positive myelin sheaths was determined in each digital image with a standard lowpass intensity threshold set to detect all MBP immunoreactivity and a standard high- 
pass intensity threshold set to exclude the intense staining of the MBP-positive mature oligodendrocytes (Fig 4B) using Leica Qwin Pro V 3.5.1 software. By excluding the immunoreactivity of MBP-positive mature oligodendrocytes the measurements accurately represented white matter only. The results of five images per section were averaged to obtain the areal fraction of MBP immunoreactivity within the SCWM for each section. The digital images were obtained and analyzed by an independent observer who was blinded to the experimental conditions.

O4 immunoreactivity in the SCWM was assessed as previously described [11]. In short, a differential count was performed, discriminating between immature (ringshaped membrane staining, no processes), mature (ring-shaped membrane staining, extensively branched processes) and degenerative (fragmented membrane staining, fragmentation of processes, signs of cell death; nuclear condensation and apoptotic bodies) phenotype of the $\mathrm{O} 4$ positive cells. The sum of the differential count resulted in the total number of $\mathrm{O} 4$ positive cells. For the analysis of $\mathrm{O} 4$ positive cells in the SCWM, $\mathrm{n}=6$ for sham-SAL, $\mathrm{n}=3$ for sham-MSC, $\mathrm{n}=6$ for HI-SAL and $\mathrm{n}=6$ for HI-MSC animals per group were analyzed. In each individual animal, the number of $\mathrm{O} 4$ positive cells was assessed in six consecutive coronal sections (posterior hippocampus/ mid-thalamus level). In each section, $\mathrm{O} 4$ positive cells were counted in eight randomly chosen fields of view in the SCWM (within the regions as indicated in Fig $3 \mathrm{~A}$ ) with a $40 \mathrm{x}$ objective equipped with a counting grid $\left(0.0625 \mathrm{~mm}^{2}\right)$ using a Nikon Eclipse E400 microscope (Nikon, Amsterdam, the Netherlands). The results of the eight differential counts were averaged to obtain the differential count of $\mathrm{O} 4$ positive cells per section. The investigator who performed the differential count was blinded to the experimental conditions.

For the analysis of CD3 staining in the SCWM, three coronal sections per animal ( $n=4$ for sham-SAL, $n=4$ for sham-MSC, $n=4$ for HI-SAL and $n=4$ for HI-MSC) were studied at the posterior hippocampus/ mid-thalamus level. In each section, cells were counted in ten fields of view (focused on the cerebral vasculature) in the subcortical white matter with a 20x objective equipped with a counting grid $\left(0.25 \mathrm{~mm}^{2}\right)$ using a Nikon Eclipse E400 microscope (Nikon, Amsterdam, the Netherlands). The numbers of CD3positive cells were expressed as cells per field of view (FOV).

\section{Proliferation assay}

At the end of the experiment (day 7), the spleen was immediately harvested after sacrifice. Single-cell splenocyte suspensions were obtained by dissociating freshly sampled spleen tissues in gentleMACS ${ }^{\mathrm{T}}$ C-tubes (MiltEnyi, Leiden, the Netherlands) filled with Gibco $^{\circledR}$ Iscove's Modified Dulbecco's Medium (IMDM) (Life Technologies, Bleiswijk, the Netherlands) using the gentleMACS ${ }^{\mathrm{TM}}$ Dissociator (MiltEnyi, Leiden, the Netherlands). Subsequently, the cell suspensions were passed through a $70 \mu \mathrm{m}$ cell strainer (BD Biosciences, Erembodegem-Aalst, Belgium). Splenocytes were stored in 
nitrogen in freezing medium containing IMDM medium with $10 \%$ heat-inactivated FCS and $10 \%$ DMSO.

For the proliferation assay, splenocytes of all experimental groups (sham-SAL $n=4$, sham-MSC n=4, HI-SAL n=4, HI-MSC n=4) were thawed. Splenocytes were labeled with CFSE (Sigma-Aldrich, Zwijndrecht, The Netherlands) in a final concentration of $1 \mu \mathrm{M}$. CFSE-labeled splenocytes were plated at a concentration of 1.0 million cells/ $\mathrm{mL}$ in a round bottom 96-wells plate in DMEM (Gibco ${ }^{\circledR}$, Life Technologies, Bleiswijk, The Netherlands) culture medium containing 10\% FCS and 1\% Penicillin Streptomycin solution. CFSE-labeled splenocytes were stimulated by adding Phytohemagglutinin (PHA) (Lectin; Sigma-Aldrich, Zwijndrecht, The Netherlands) at a final concentration of 1 $\mu \mathrm{g} / \mathrm{mL}$ and human recombinant IL-2 (Proleukin ${ }^{\circledR}$; Aldesleukin (Chiron), Novartis, Basel, Switzerland) at a final concentration of $500 \mathrm{IU} / \mathrm{mL}$ to the culture medium. These final concentrations yielded optimal proliferation of fetal sheep splenocytes in pilot experiments (data not shown). Stimulated splenocytes were cultured during five days in an incubator set at $37^{\circ} \mathrm{C}$ and $5 \% \mathrm{CO} 2$. On day 5 the proliferated splenocytes were stained for detection of T-helper cells (mouse anti sheep CD4-AlexaFluor ${ }^{\circledR} 647$ (CD4A647); AbDSerotec, Düsseldorf, Germany), cytotoxic T-cells (mouse anti sheep CD8-R$\mathrm{PE}$ (CD8-PE); AbDSerotec, Düsseldorf, Germany) and viability (7-Aminoactinomycin D (7-AAD); BD Biosciences, Bleiswijk, the Netherlands) according to the manufacturer's protocol. Stained cells were acquired on a FACS Canto II flow cytometer (BD Biosciences, Bleiswijk, the Netherlands) equipped with FACS Diva software (BD Biosciencs, Bleiswijk, the Netherlands). Gating strategy is depicted in Fig S1A-C. The number of non-proliferating (high CFSE fluorescent intensity) CD4- and CD8-positive cells was expressed as a percentage of total viable splenocytes in the well.

Because of the lack of good flow cytometry antibodies cross-reacting with ovine lineage markers it was not possible to gate on CD3. However, it was possible to discriminate between ovine CD4-positive T-cells and CD8-positive T-cells (gating strategy; Fig S1). Cells being positive for both CD4 and CD8 are presumably monocytes or myeloid cells (with Fc receptor) and were not taken along in our analysis. The gate for the non-proliferating fraction was set based on the condition without mitogen (data not shown).

\section{Fluorescent In Situ Hybridization (FISH)}

The FISH probe for chromosomes Y (DYZ3, Sat. III) [31] was selected to identify intravenously administered human male MSC in the preterm ovine brain. The probe was labeled by standard nick translation with biotin (Bio). The labeled probe was applied at a concentration of $1 \mathrm{ng} / \mu \mathrm{l}$ in 60\% formamide, 2x SSC, 10\% dextran sulphate, and a 50x excess of carrier DNA (salmon sperm DNA). FISH was performed on $4 \mu \mathrm{m}$ thick formalin fixed and paraffin embedded tissue sections (at the posterior hippocampus/ midthalamus level) put on amino coated slides (superfrost plust). In brief, sections were heated at $80{ }^{\circ} \mathrm{C}$ for 15 minutes to improve cellular adhesion to the slides during 
the entire FISH procedure, dewaxed and hydrated followed by microwaving in $10 \mathrm{mM}$ Na-Citrate $\mathrm{pH}$ buffer $1 \times 10 \mathrm{~min}$ at $100{ }^{\circ} \mathrm{C}$ and $20 \mathrm{~min}$ at RT to cool down. Washed in demineralized water and rinsed in $0.01 \mathrm{M} \mathrm{HCl}$ and subsequently digested in $2.5 \mathrm{mg}$ pepsin in $0.01 \mathrm{~N} \mathrm{HCl}$. Afterwards the slides were washed in $1 \times 0.01 \mathrm{~N} \mathrm{HCl}, 1 \times \mathrm{PBS}$ and post fixed in $1 \%$ formaldehyde in PBS for $5 \mathrm{~min}$ at RT. Slides were washed with PBS, demineralized water and dehydrated in an alcohol series. The probe was applied under a coverslip, simultaneously denatured at $80{ }^{\circ} \mathrm{C}$ for $10 \mathrm{~min}$ and hybridized overnight at $37{ }^{\circ} \mathrm{C}$. After hybridization, the preparations were washed for $5 \mathrm{~min}$ in $2 \times \mathrm{SSC}, 0.05 \%$ tween-20 (Janssen Chimica, Beerse, Belgium) and $0.1 \times$ SSC $61{ }^{\circ} \mathrm{C}(2 \times 5 \mathrm{~min})$. The hybridized probe was detected in a triple layer detection method with FITC-conjugated avidin (Av-FITC, 1: 100 dilution; Vector Laboratories, CA, USA), biotinylated goat antiavidin (Bio-GaA, 1:100 dilution: Vector Laboratories) and Av-FITC. Finally, the slides were washed in PBS containing 0.05\% Tween-20, dehydrated in an ascending ethanol series, and mounted in Vectashield (Vector Laboratories) containing DAPI (Sigma: 0.5 $\mu \mathrm{g} / \mu \mathrm{l})$. Images were recorded with the Metasystems Image Pro System (black and white CCD camera; Sandhausen, Germany) mounted on top of a Leica DM-RE fluorescence microscope equipped with FITC and DAPI single band pass filters for single color analysis. Images were recorded using an automatic integration time allowing semi quantitative evaluation (using the full dynamic range of the camera without signal intensity saturation; TIF 8 bits image).

\section{PCR}

The distribution of MSC throughout the tissues was confirmed by PCR for humanspecific $\beta-2$ microglobulin as previously reported [32]. Genomic DNA that was used as template was extracted from snap frozen tissues including subcortical white matter and hippocampus of the left hemisphere, fetal lung (right middle lobe) and spleen using the Wizard Genomic Purification kit (Promega, Leiden, The Netherlands) according to the supplier's recommendations. The presence of amplifiable DNA was evaluated by PCR for $\beta$-actin. PCR reactions were performed in a total volume of $25 \mu \mathrm{l}$ with specific primers for $\beta$-actin or $\beta-2$ microglobulin using $1 \mu$ of genomic DNA. Next, a nested PCR was conducted for $\beta-2$ microglobulin using $2.5 \mu$ of the amplified product of the first reaction as a template. The amplified products were separated on ethidium bromidestained $2 \%$ agarose gels and captured using the Imagemaster ${ }^{\circledR}$ VDS equipped with a CCD camera (GE Healthcare Life Sciences (Pharmacia Biotech), Uppsala, Sweden). The amplified products were evaluated using the Big Dye termination sequencing kit (Perkin Elmer/Cetus, Emeryville, CA).

Primers for $\beta$-actin were 5'-CGGGACCTGACTGACTAC-3' (sense) and 5'GAAGGAAGGCTGGAAGAG-3' (antisense); primers used for the amplification of $\beta-2$ microglobulin were 5'- GTGTCTGGGTTTCATCAATC-3' (sense), 5'GGCAGGCATACTCATCTTTT-3' (antisense), 5'- TGGGTTTCATCAATCCGACAT-3' (nested sense) and 5'- CTCATCTTTTTCAGTGGGGGT-3' (nested antisense). 
PCR were performed in a total volume of $25 \mu \mathrm{l}$ in PCR buffer (Promega, Leiden, The Netherlands) in the presence of $0.2 \mathrm{mM}$ dNTP (Promega, Leiden, The Netherlands), $1 \mathrm{M}$ of each primer, $0.3 \mathrm{mM} \mathrm{MgCl}$, and $0.5 \mathrm{U}$ of Taq polymerase (Promega, Leiden, The Netherlands). PCR conditions for each primer couple were as follows: $\beta$-actin; $95^{\circ} \mathrm{C}$ for $30 \mathrm{~s}, 53^{\circ} \mathrm{C}$ for $45 \mathrm{~s}$ and $72^{\circ} \mathrm{C}$ for $30 \mathrm{~s}$ during 40 cycles: human-specific $\beta-2$ microglobulin; $95^{\circ} \mathrm{C}$ for $30 \mathrm{~s}, 53^{\circ} \mathrm{C}$ for $30 \mathrm{~s}$ and $72^{\circ} \mathrm{C}$ for $20 \mathrm{~s}$ during 45 cycles: human-specific $\beta-2$ microglobulin nested $95^{\circ} \mathrm{C}$ for $30 \mathrm{~s}, 50^{\circ} \mathrm{C}$ for $45 \mathrm{~s}$ and $72^{\circ} \mathrm{C}$ for $20 \mathrm{~s}$ during 45 cycles.

Table 1. Animal characteristics. Fetuses were subjected to umbilical cord occlusion at a comparable age. Fetal body weight did not differ between experimental groups. Global HI caused significant brain atrophy, which was prevented by intravenous MSC administration.

\begin{tabular}{lllll}
\hline & $\begin{array}{l}\text { sham-SAL }(\mathbf{n}=8) \\
\text { mean }(95 \% \mathrm{Cl})\end{array}$ & $\begin{array}{l}\text { sham-MSC }(\mathbf{n}=8) \\
\text { mean }(95 \% \mathrm{Cl})\end{array}$ & $\begin{array}{l}\text { HI-SAL }(\mathbf{n}=8) \\
\text { mean }(95 \% \mathrm{Cl})\end{array}$ & $\begin{array}{l}\text { HI-MSC }(\mathbf{n}=\mathbf{8}) \\
\text { mean }(95 \% \mathrm{Cl})\end{array}$ \\
\hline GA at UCO (d) & $105.5(104.9 ; 106.1)$ & $105.3(104.6 ; 106.1)$ & $105.3(104.7 ; 105.9)$ & $105.8(105.0 ; 106.7)$ \\
BW (g) & 1791.9 & 1783.0 & 1742.0 & 1829.7 \\
& $(1602.2 ; 1963.7)$ & $(1584.7 ; 1981.3)$ & $(1553.8 ; 1930.2)$ & $(1586.8 ; 2072.6)$ \\
brain (g) & $29.9(28.2 ; 31.5)$ & $29.0(27.3 ; 30.8)$ & $24.7(23.3 ; 26.2)$ & $27.5(25.5 ; 29.5)$ \\
\hline
\end{tabular}

\section{Statistics}

Summary statistics of animal characteristics and all outcome parameters are shown as means with $95 \% \mathrm{Cl}$. Groups' comparisons with respect to all outcome parameters (except seizure data) were drawn with analysis of variance (ANOVA) or with random intercept models in case of repeated measurements per animal (e.g. different sections per brain). Since these tests assume normal distribution of the data, variables, whose distributions were positively skewed, were log-transformed previous to statistical testing. To facilitate interpretation, averages on the log scale were back transformed to the original scale (antilog) and are presented as geometric means and corresponding $95 \% \mathrm{Cls}$, as previously reported [11]. Seizure data was zero-inflated (i.e. no seizures in sham animals), showing pronounced skewness that could not be remedied by log transformation. Hence, pair-wise groups' comparisons of seizure data were performed with nonparametric Mann-Whitney tests. Seizure data are presented as medians and corresponding interquartile range (IQR). For assessment of correlations, the Pearson or Spearman correlation coefficient was calculated, as appropriate. To avoid overestimation of treatment effects, a False Discovery Rate (FDR) of 5\% was used for multiple testing correction. Groups' differences with FDR corrected $\mathrm{P}<0.05$ were considered statistically significant. Statistical analysis was performed with IBM SPSS Statistics Version 20.0 (IBM Corp., Armonk, NY, USA). 


\section{Results}

\section{Animal characteristics and reproducibility of umbilical cord occlusion}

Fetal body weight and gestational age at the time of UCO did not differ significantly between the four experimental groups (Table 1). No differences were found in MABP, $\mathrm{FHR}, \mathrm{pH}$, arterial partial oxygen pressure or arterial partial carbon dioxide pressure between the HI-SAL and HI-MSC group, indicating that the physiological response to UCO and the degree of acidosis, hypoxemia and hypercarboxemia was similar in all animals exposed to global HI (Fig 2).

\section{MSC reduced microglial proliferation after global $\mathrm{HI}$}

Global $\mathrm{HI}$ resulted in a significant (sham-SAL vs. HI-SAL; $\mathrm{P}=0.002$ ) increase of IBA-1 immunoreactivity in the SCWM, indicating profound microglial proliferation in this region (Fig $3 \mathrm{~A}$ and $\mathrm{C}$ ). In line, significantly (sham-SAL vs. HI-SAL; $\mathrm{P}<0.001$ ) increased IBA-1 immunoreactivity was found in the hippocampus following global $\mathrm{HI}$ (Fig $3 \mathrm{~B}$ and D). Intravenous MSC significantly (HI-SAL vs. HI-MSC; $\mathrm{P}=0.020$ ) reduced IBA-1 immunoreactivity in the SCWM (Fig $3 \mathrm{~A}$ and $\mathrm{C}$ ). Intravenous MSC administration partially reduced IBA-1 immunoreactivity in the hippocampus, but the difference did not reach statistical significance (HI-SAL vs. HI-MSC; P=0.218) (Fig 3 B and D).

\section{MSC reduced white matter injury after global $\mathrm{HI}$}

The 04-positive preOLs observed in the SCWM were predominantly of immature phenotype (i.e. ring-shaped membrane staining, no processes) (Fig 4 A). The number of O4-positive cells was significantly (sham-SAL vs. HI-SAL; $\mathrm{P}<0.001$ ) decreased after global $\mathrm{HI}$ in the SCWM (Fig $4 \mathrm{~A}$ and $\mathrm{C}$ ), indicating $\mathrm{HI}$-induced loss of preOLs in this region. Intravenous MSC administration significantly (HI-SAL vs. HI-MSC; $\mathrm{P}=0.002$ ) increased the number of O4-positive preOLs with immature phenotype in the SCWM (Fig $4 \mathrm{~A}$ and C). The number of preOL was inversely related $(r=-.83, P<0.001)$ to IBA-1 immunoreactivity in the SCWM (Fig S2 A).

Global $\mathrm{HI}$ significantly (sham-SAL vs. HI-SAL; $\mathrm{P}<0.001$ ) reduced MBP immunoreactivity in the SCWM, indicating marked demyelination in this region (Fig $4 \mathrm{~B}$ and D). Accordingly, the number of MBP-positive mature oligodendrocytes clearly decreased following global $\mathrm{HI}$ (Fig $4 \mathrm{~B}$ ). Intravenous MSC administration significantly increased (HI-SAL vs. HI-MSC; P=0.007) myelination (Fig 4 B and D). In line, loss of MBPpositive mature oligodendrocytes was prevented by MSC treatment (Fig 4 B). MBP immunoreactivity was inversely related $(r=-.71, P=0.002)$ to IBA-1 immunoreactivity in the SCWM (Fig S2 B). 

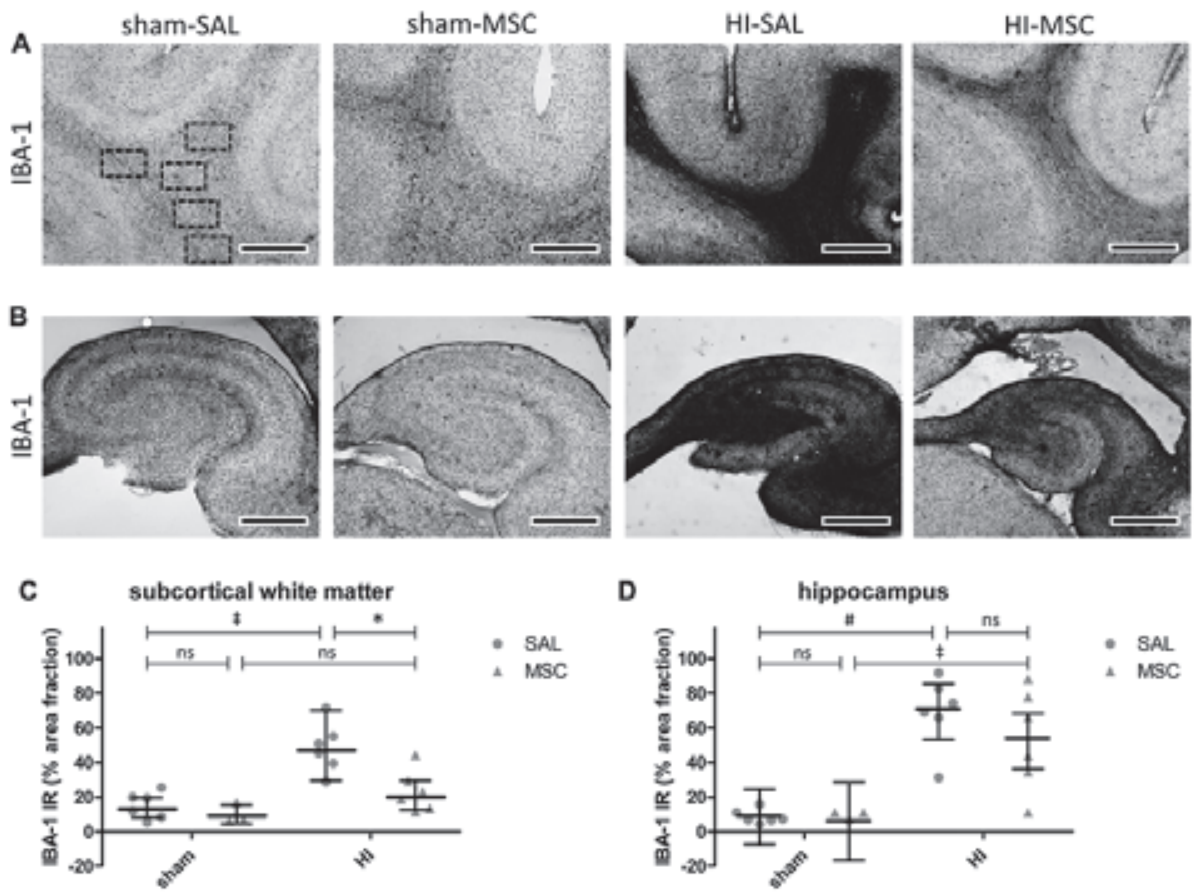

Figure 3. Intravenous MSC reduced proliferation of microglia after global HI. (A) Immunohistochemical IBA-1 staining in the SCWM of the four experimental groups with squares in the first panel indicating the regions where immunoreactivity was assessed. Global HI induced a profound increase of IBA-1 immunoreactivity, which was significantly reduced by intravenous MSC treatment. (B) Immunohistochemical IBA-1 staining in the hippocampus of the four experimental groups. Profound proliferation of microglia was observed in the hippocampus following global HI. MSC partially reduced the inflammatory response of microglia in the hippocampus after global HI. (C-D) Graphical presentation of area fraction of IBA-1 immunoreactivity in SCWM and hippocampus; (C) geometric means $\pm 95 \% \mathrm{Cl}$ and (D) means $\pm 95 \% \mathrm{Cl}$ and levels of significance are depicted, which were calculated by the random intercept model with all repeated measures (i.e. brain sections) per animal (sham-SAL $n=6$, sham-MSC $n=3$, HI-SAL $n=6, H I-M S C n=6)$. Dots show the averaged results of the repeated measures (i.e. brain sections) per animal. ${ }^{*} P \leq 0.05, \neq P \leq 0.01, \# P \leq 0.001$. IBA-1 $=$ ionized calcium binding adaptor molecule $1, H I=$ hypoxia-ischemia, $S A L=$ saline, $M S C=$ mesenchymal stem cells, IR = immunoreactivity. $(A-B)$ Scale bars represent $1 \mathrm{~mm}$.

FA values in the SCWM were significantly decreased (sham-SAL vs. HI-SAL; P=0.017) following global $\mathrm{HI}$ (Fig $5 \mathrm{~A}$ and $\mathrm{B}$ ), indicating disturbed organization of white matter tracts. Intravenous MSC administration significantly increased (HI-SAL vs. HI-MSC; $\mathrm{P}=0.028$ ) FA values in the SCWM following global HI (Fig $5 \mathrm{~B}$ ), indicating that intravenous MSC prevented disturbances in white matter tracts organization. In line with clinical findings [33], DTI did not show significant changes of FA values after global $\mathrm{HI}$ in the hippocampus (data not shown). 

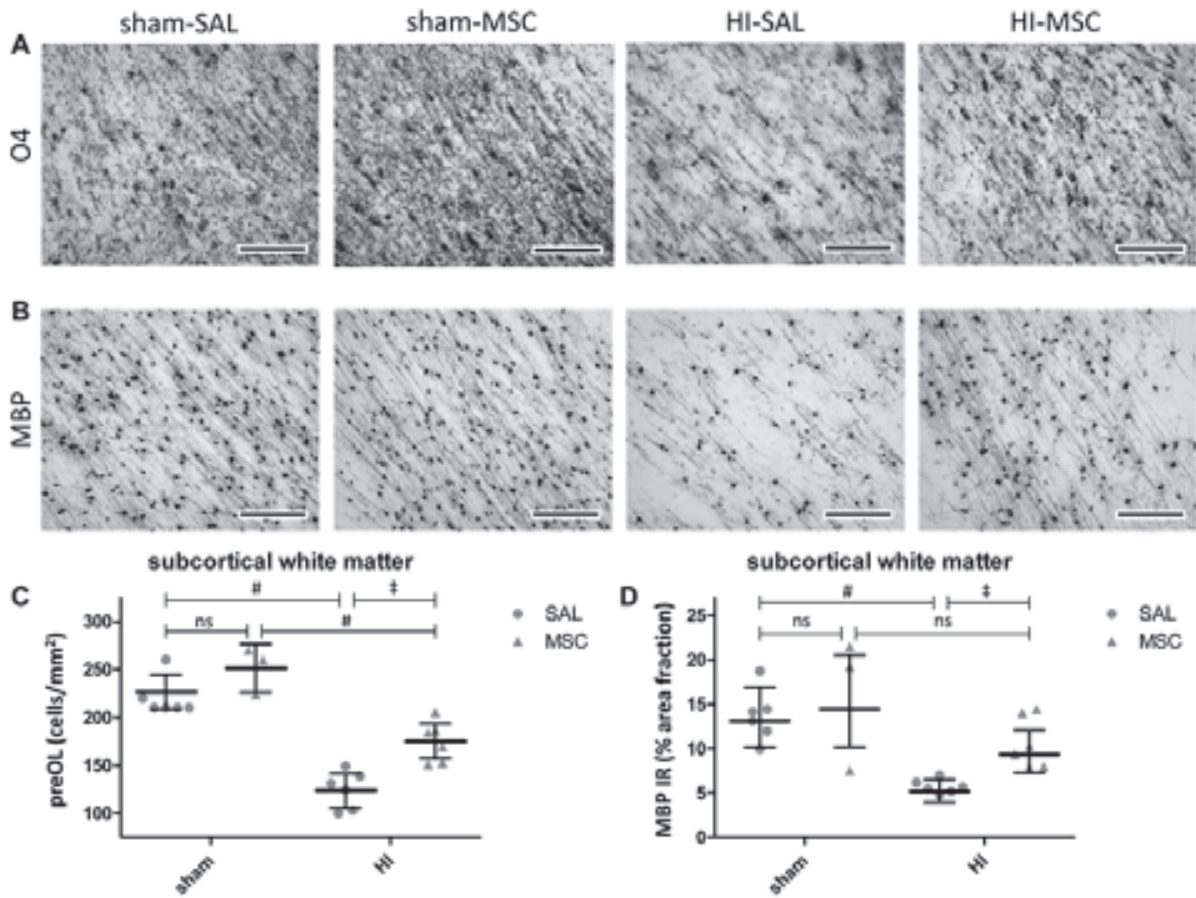

Figure 4. Intravenous MSC treatment reduced loss of pre-oligodendrocytes and demyelination after global $\mathrm{HI}$. (A) Immunohistochemical 04 staining in the subcortical white matter (SCWM) of all four experimental groups. The number of 04-positive cells was similar between sham operated animals treated with saline or MSC. Global HI induced marked loss of O4-positive cells. Intravenous MSC significantly increased the number of O4-positive cells after global HI. (B) Immunohistochemical MBP staining in the SCWM of all four experimental groups. The area fraction of MBP was similar between sham operated animals treated with saline or MSC. Marked hypomyelination was observed in the SCWM following global HI. Intravenous MSC significantly increased myelination of the preterm brain after global HI. (C-D) Graphical presentation of number of O4-positive cells and MBP immunoreactivity in SCWM; (C) means $\pm 95 \% \mathrm{Cl}(D)$ geometric means \pm 95\% $\mathrm{Cl}$ and levels of significance are depicted, which were calculated by the random intercept model with all repeated measures (i.e. brain sections) per animal (sham-SAL $n=6$, sham-MSC $n=3, H I-S A L n=6, H I-M S C n=6$ ). Dots show the averaged results of the repeated measures (i.e. brain sections) per animal. * $P \leq 0.05, \neq P \leq 0.01$, \# P $\leq 0.001$. PreOL = pre-oligodendrocytes, $H I=$ hypoxia-ischemia, $S A L=$ saline, $M S C=$ mesenchymal stem cells, $I R=$ immunoreactivity, log = natural logarithm. Scale bars: (A) $100 \mu \mathrm{m}$, (B) $200 \mu \mathrm{m}$.

\section{MSC reduced the electrographic seizure burden following global HI}

Global HI significantly increased (sham-SAL vs. HI-SAL $p=0.008$ ) the electrographic seizure activity following UCO (Fig 5 C-D). In line with clinical [34] and experimental [35] data, the seizure activity peaked in the first $24 \mathrm{~h}$ after UCO, followed by a second smaller peak in the period between 24 and $48 \mathrm{~h}$ after UCO (data not shown).

Intravenous MSC administration significantly reduced (HI-SAL vs. HI-MSC p=0.031) the number of electrographic seizures during the study period after global HI (Fig 5 D). 


\section{Chapter 4}

Seizure activity was very rarely detected in sham animals treated with saline or MSC (Fig 5 D). Neuronal injury was further demonstrated by significant (sham-SAL vs. HI-SAL; $\mathrm{P}<0.001$ ) brain atrophy following global $\mathrm{HI}$ (Table 1), which was diminished (HI-SAL vs. HI-MSC; $\mathrm{P}=0.058$ and sham-MSC vs. HI-MSC; $\mathrm{P}=0.381$ ) by intravenous MSC treatment (Table 1).

A

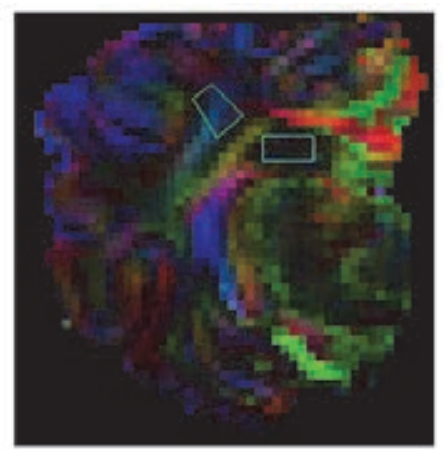

C

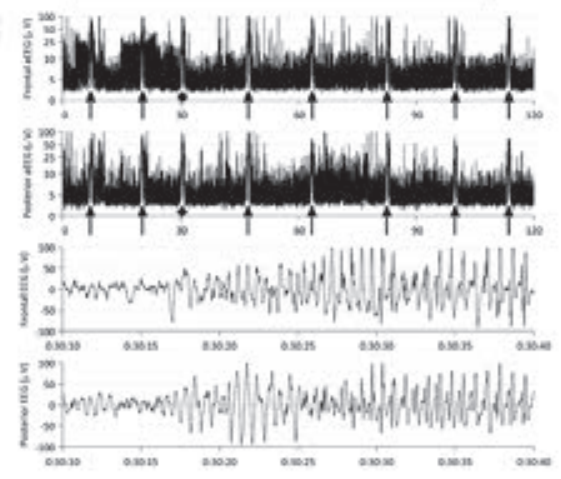

B

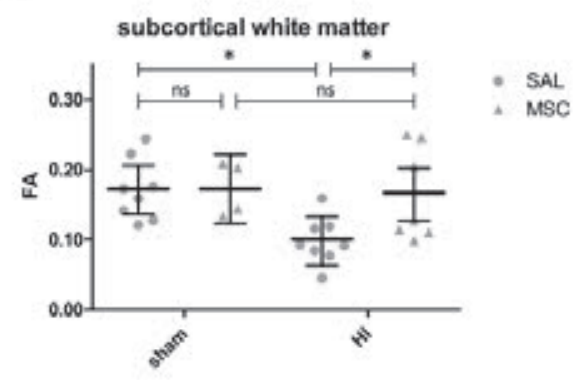

D

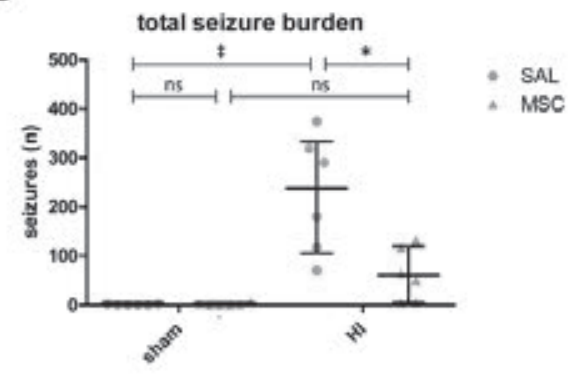

Figure 5. Intravenous MSC treatment prevented white matter injury and reduced electrographic seizure activity after global HI. (A) Regions of interest; SCWM and hippocampus in FA map. FA values in the hippocampus were not altered by global HI (data not shown). (B) Global HI caused a significant decrease in FA values in the SCWM, which was prevented by intravenous MSC administration; means $\pm 95 \% \mathrm{Cl}$ and levels of significance are depicted, which were calculated with ANOVA (sham-SAL $n=8$, sham-MSC $n=4, H I-S A L n=8$, HI-MSC $n=8$ ). Dots show each measurement (i.e. non-repeated measures) per animal. ${ }^{*} P \leq 0.05, \pm P \leq 0.01, \#$ $P \leq 0.001 . F A=$ fractional anisotropy,$S A L=$ saline,$M S C=$ mesenchymal stem cells, $H I=$ hypoxia-ischemia.$(C)$ Representative image of an aEEG trace from a HI-SAL animal. The two upper traces represent aEEG traces of the C3-C4 and P3-P4 channel, respectively. The aEEG signal is time-compressed, showing a 120-min period. The amplitude is displayed semi-logarithmic, indicating a LMA of approximately 4-3 $\mu V$ and UMA of approximately $10 \mu \mathrm{V}$. The arrows indicate seizure activity. The two lower traces depict the corresponding EEG signal (30 s) of one electrographic seizure activity indicated by the diamond. (D) Intravenous MSC administration significantly reduced electrographic seizure burden following global $\mathrm{Hl}$; medians \pm IQR are depicted (sham-SAL $n=6$, sham-MSC $n=6$, HI-SAL $n=6, H I-M S C n=6$ ). * $P \leq 0.05, \neq P \leq 0.01, \# P \leq 0.001$. SAL = saline, $M S C=$ mesenchymal stem cells, $H I=$ hypoxia-ischemia . 


\section{MSC induced sustained T-cell tolerance}

The percentage of non-proliferative (i.e. reduced CFSE dilution) CD4-positive splenocytes derived from HI-SAL animals was not significantly altered compared to those splenocytes from sham-SAL animals (Fig $6 \mathrm{~A}$ and $\mathrm{C}$ ), indicating that global $\mathrm{HI}$ did not alter the proliferative capacity of splenocytes.

Remarkably, the percentage of non-proliferative CD4-positive splenocytes derived from sham-MSC animals was significantly ( $P=0.012)$ increased compared to the shamSAL group (Fig $6 \mathrm{~A}$ and $\mathrm{C}$ ). In line, the percentage of non-proliferative CD4-positive splenocytes derived from HI-MSC animals was significantly $(P=0.020)$ increased compared to the HI-SAL group (Fig $6 \mathrm{~A}$ and C), indicating that intravenously administered MSC persistently suppressed the in vivo responsiveness of CD4-positive helper T cells in the spleen.

The proliferation capacity of CD8-positive splenocytes was not affected by global $\mathrm{HI}$ or MSC (data not shown). MSC-mediated suppression of helper T-cells in vivo was inversely related (Pearson $r=-.60, P=0.035$ ) to proliferation of microglia in the subcortical white matter (Fig S2 C).

\section{MSC reduced T-cell invasion after global HI}

In sham conditions, T-cells were predominantly detected in the intravascular space of the preterm brain (Fig 6 B). Global HI significantly increased (sham-SAL vs. HI-SAL; $\mathrm{P}<0.001$ ) the number T-cells in the SCWM (Fig $6 \mathrm{~B}$ and D). In the hypoxic-ischemic preterm brain, T-cells were primarily located in the perivascular and interstitial space, indicating $\mathrm{HI}$-induced invasion of T-cells into the preterm brain (Fig 6 B). Remarkably, intravenous MSC administration significantly reduced (HI-SAL vs. HI-MSC; P=0.028) the number of T-cells in the SCWM following global HI (Fig $6 \mathrm{~B}$ and D), indicating that intravenous MSC prevented invasion of T-cells into the preterm brain.

\section{Detection of MSC in the preterm brain seven days after administration}

Within the subcortical white matter of MSC treated animals, we localized 20-40 cells per section that stained positive for the human specific Y-chromosome probe (Fig $7 \mathrm{C}$ and D). MSC were detected in 4 of 5 studied animals that received MSC. The presence of MSC in the brain was confirmed by human-specific $\beta 2$-microglobulin PCR (Fig S3). The amplified PCR products contained the correct human $\beta 2$-microglobulin sequences as evaluated by sequencing. In addition, MSC were detected with PCR in SCWM, hippocampus, lung and spleen (data not shown). 


\section{Chapter 4}

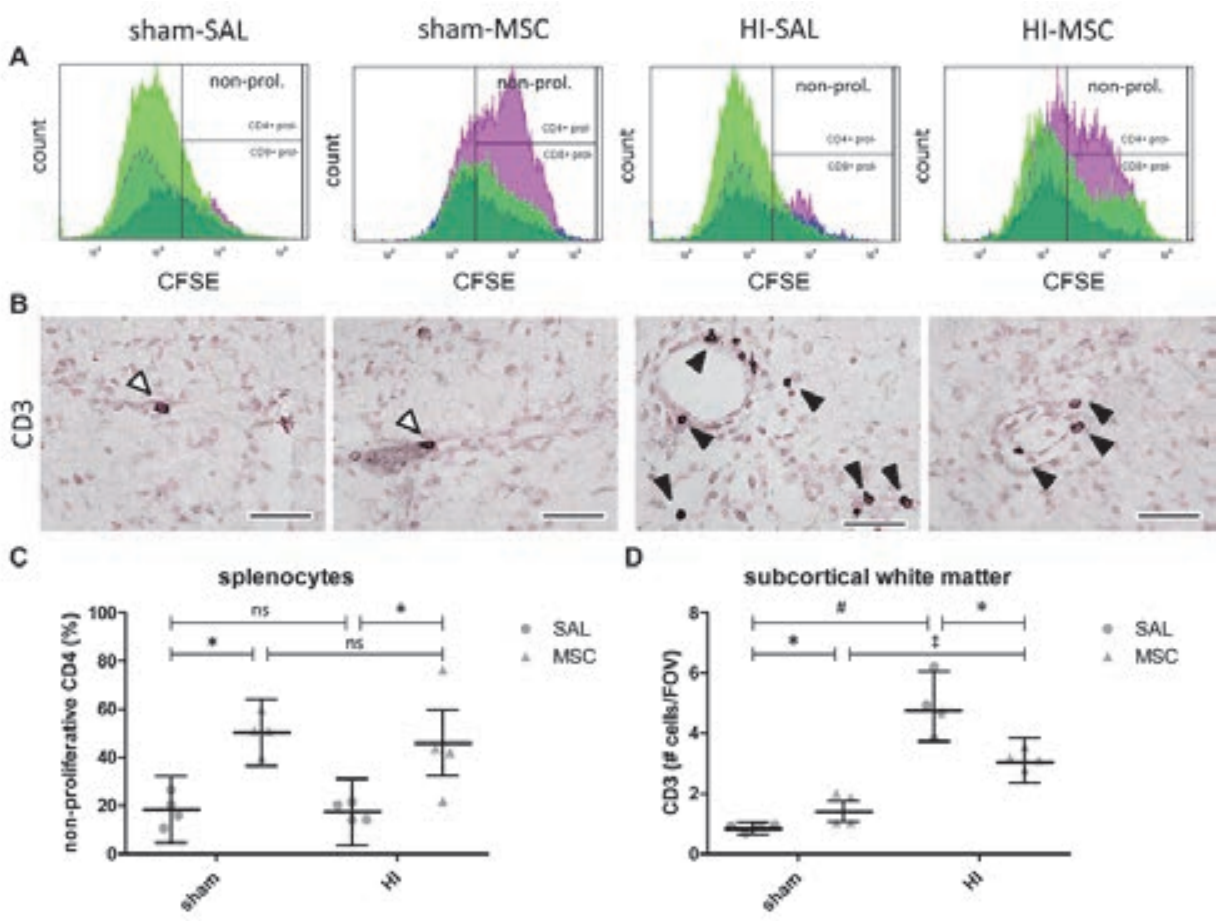

Figure 6. Intravenous MSC modulated the peripheral T-cell response after global HI. MSC persistently suppressed the proliferative capacity of CD4-positive splenocytes and reduced the number of invading T-cells into the preterm brain follow global $\mathrm{HI}$ and. (A) Representative flow cytometry histograms showing proliferation (increased CFSE dilution) of CD4-positive splenocytes (green) and CD8-positive splenocytes (blue) derived from the different experimental groups. Global $\mathrm{HI}$ did not alter the proliferative capacity of CD4positive splenocytes (HI-SAL versus sham-SAL). MSC significantly suppressed the proliferation of CD4-positive splenocytes in sham operated animals (sham-MSC versus sham-SAL) and in animals exposed to global $\mathrm{HI}$ (HIMSC versus HI-SAL). (B) Immunohistochemical CD3 (T-cell) staining in the subcortical white matter (SCWM) of all four experimental groups. In sham conditions, $T$-cells were primarily detected in the intravascular space (open arrows). Following global $\mathrm{HI}$, a significant increase in the number of perivascular and interstitial (black arrows) CD3-postive cells was observed. T-cell invasion after global HI was significantly reduced by MSC. (CD) Graphical presentation of (C) the percentage of non-proliferative CD4-positive splenocytes and (D) number of CD3-positive cells in SCWM; (C) means $\pm 95 \% \mathrm{Cl}$ and (D) geometric means $\pm 95 \% \mathrm{Cl}$ and levels of significance are depicted, which were calculated by ANOVA for CD4 proliferation (C) and the random intercept model with all repeated measures (i.e. brain sections) for CD3 counts (D). Dots show each measurement (i.e. non-repeated measures) per animal for CD4 proliferation (C) and the averaged results of the repeated measures (i.e. brain sections) per animal for $C D 3$ counts $(D)$. * $P \leq 0.05, \neq P \leq 0.01, \# P \leq 0.001$. SAL = saline,$M S C=$ mesenchymal stem cells, $H I=$ hypoxia-ischemia, $F O V=$ field of view. 


\section{Discussion}

Hypoxic-ischemic encephalopathy (HIE) in preterm infants is associated with cognitive and motor disorders, for which there is currently no therapeutic cure. The lack of feasible experimental models which are comparable to human neurodevelopment is one of the main hurdles that prevent the development of novel therapeutic strategies for hypoxic-ischemic injury in the preterm brain. We and others previously demonstrated that the fetal ovine model of global hypoxia-ischemia (HI) by umbilical cord occlusion (UCO) closely resembles the situation in human preterm infants in terms of neurodevelopment and white matter injury, which is the clinical hallmark of hypoxic-ischemic injury in the preterm brain $[1,11,12]$. In the current study, we use this translational animal model to provide evidence for the therapeutic potential of intravenous administration of MSC in the preterm brain after global $\mathrm{HI}$.

We first assessed the effects on the cerebral anti-inflammatory effects of MSC by studying the proliferative response of microglia, which are typically activated early after global $\mathrm{HI}[11,36]$. Our findings demonstrated that intravenous administration of MSC reduced the cerebral inflammatory response in the hypoxic-ischemic preterm brain after global HI. Secondly, we studied the protective effects of MSC on white matter injury. We showed that global $\mathrm{HI}$ induced a marked loss of preOLs, which was paralleled by hypomyelination of the preterm brain. In line with clinical evidence [37], FA values obtained with diffusion tensor imaging (DTI) were decreased following global HI indicating $\mathrm{HI}$-induced breakdown of white matter organization. Intravenous administration of MSC prevented the loss of preOLs after global $\mathrm{HI}$ and reduced histological white matter injury, which was confirmed with DTI. The third step was to study neuronal injury on a functional level by assessing electrographic seizure burden following global $\mathrm{HI}$ in amplitude-integrated electroencephalogram (aEEG). Our findings showed that intravenous MSC treatment decreased the electrographic seizure activity following global HI. Reducing seizure activity is clinically highly relevant, since several studies have shown that seizures in neonatal HIE are associated with adverse neurodevelopmental outcome [3840].

The preceding findings showed that intravenous MSC reduced the initial inflammatory response in the preterm brain mediated by microglia and provided protection against evolving white matter and neuronal injury after global HI. To further assess the mechanism underlying the therapeutic effects of MSCs, we studied modulation of the peripheral T-cell response and subsequent invasion of these cells into the ischemic preterm brain. We and others have previously shown that the initial cerebral inflammatory response after the hypoxic-ischemic insult is followed by a second peripheral inflammatory response characterized by mobilization and invasion of peripheral immune effector cells (i.e. neutrophils and T-cells) into the preterm brain [10, 11, 36, 41]. Previous in vitro studies have demonstrated that MSC suppressed helper T-cell proliferation and induced an anti-inflammatory, more tolerant, phenotype in these immune effector 
cells [42-44]. These findings were confirmed and extended by our study showing that MSC induced persistent tolerance of T-cells in vivo. Furthermore, we showed that the degree of peripheral T-cell tolerance was inversely related to cerebral inflammation. Moreover we found that MSC reduced T-cell invasion following global HI. Based on these findings, we hypothesize that sequestered MSC modulated peripheral helper Tcells to become unresponsive, making them less susceptible for activation and mobilization in response to brain-derived damage signals following global HI. This suppression of peripheral immune cells may decrease invasion of immune effector cells into the brain observed after global $\mathrm{HI}$, thereby reducing a second inflammatory hit to the ischemic preterm brain [11].
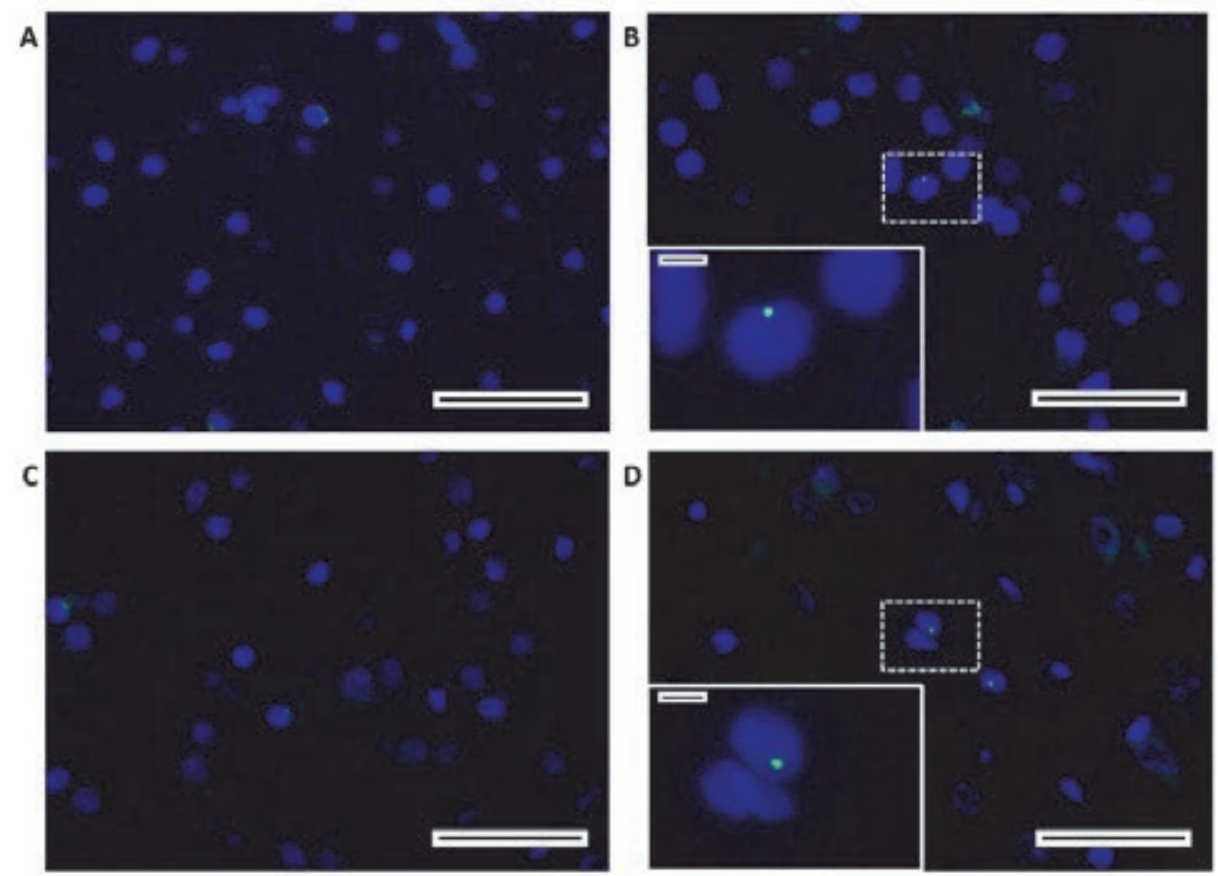

Figure 7. MSC were detected in the fetal ovine brain. A FISH probe specific for the human Y-chromosome detected the presence of systemically deliverd MSC in the ovine brain. (A-D) Representative fluorescent images of the SCWM in the different experimental groups; (A) sham-SAL, (B) sham-MSC, (C) HI-SAL and (D) HI-MSC. (A-B) In saline treated animals the FISH probe did not react with any nucleus. (C-D) The FISH probe was detected in MSC treated animals indicating that MSC were present in the preterm brain $7 d$ after intravenous administration. Scale bars: $(A-D) 50 \mu \mathrm{m}$, scale bars inserts: $(A-D) 5 \mu \mathrm{m}$.

The newly identified modulation of T-cell tolerance in vivo and reduction of T-cell invasion after intravenous MSC administration adds to the understanding of the antiinflammatory effects of MSC in the context of inflammation-driven organ injury. Be- 
sides the anti-inflammatory effects of MSC in our model, we speculate that the observed protective effects of MSC on white matter injury are based on additional mechanisms. First, the MSC-mediated reduction of cerebral inflammation potentially reduced injury to vulnerable preOLs in the preterm brain. This concept is supported by studies showing microglia-mediated injury to preOLs [45] and our findings that preOL density and myelination in the subcortical white matter were inversely related to proliferation of microglia. A second effect might be attributed to MSC-mediated regeneration of lost preOLs and diminished arrested oligodendrocyte maturation. The latter concept is supported by in vitro data showing that MSC stimulate neural progenitor cells to differentiate towards the oligodendrocyte lineage $[46,47]$ and in vivo data demonstrating remyelination after intracerebral delivery of MSC in a rat model of neonatal hypoxic-ischemic brain injury [48].

From the MSC that were administered intravenously, only a few cells $(<0.01 \%)$ were located within the preterm ovine brain at seven days after global HI. PCR and sequencing confirmed the presence of MSC in the brain and also confirmed that MSC were present in lung and spleen seven days after intravenous administration. In concordance with our findings, a study by Lee et al. showed that MSC were neuroprotective in a rat model of neonatal hypoxic-ischemic brain injury, while less than $0.01 \%$ of intravenously administered MSC were recovered in brain, lung and spleen tissue within $96 \mathrm{~h}$ after infusion [49]. Remarkably, also intracerebral injected MSC were shown to be neuroprotective, although they disappeared rapidly after injection [50]. These findings suggest that the neuroprotective effects of MSC last longer than their presence implying that MSC-mediated modulation of inflammation and repair of injury is initiated early after administration.

Several other studies using rodent models of neonatal hypoxic-ischemic brain injury have previously shown neuroprotective effects of MSC after intracerebral injection [18, 20, 48], intranasal [51] and intravenous administration [17, 21]. These rodent models however have several limitations that make them less suitable for clinical translation $[23,24,52]$. The strength of the instrumented preterm sheep model is that it closely resembles human preterm neurodevelopment and second, that the global $\mathrm{HI}$ insult induced by umbilical cord occlusion accurately mimics the common clinical etiology of HIE in preterm infants [24, 52].

We showed that xenotransplanted human MSC effectively modulated immune responses and stimulated neuronal repair in preterm sheep, without any signs of immunological rejection. These findings are in line with early work by Zanjani et al. showing that human xenotransplanted HSC were well tolerated by the permissive environment of preimmune fetal sheep [53] and even after establishment of the fetal immune system [32]. The latter findings indicated that MSC have unique immunological characteristics that allow them to persist in a xenogeneic environment [32].

The observed neuroprotective effects in our model were seen following severe hypoxic-ischemic brain injury suggesting that the MSC-mediated treatment effects will 


\section{Chapter 4}

be enhanced following milder episodes of ischemia in the preterm brain. Although the dosage of MSC administered in our model was consistent with completed $[21,54]$ and ongoing (ClinicalTrials.gov: NCT01501773, NCT01297413, NCT01678534) clinical trials of focal cerebral ischemia (i.e. stroke), dose escalation studies need to be conducted to determine the optimal dosing strategy in hypoxic-ischemic preterm brain injury. In addition, the magnitude of the treatment effect may depend on the timing of intervention; we infused MSC $1 \mathrm{~h}$ after the $\mathrm{HI}$ insult particularly aimed at intervening early with the detrimental inflammatory response following global HI. However, it is conceivable that repetitive dosing may especially enhance the regenerative effects of MSC. Furthermore, neuroprotective effects of MSC observed here may have been underestimated after a reperfusion period of one week. It is plausible that additional MSC-mediated repair of white matter and neuronal networks takes place beyond the period of one week after global HI. Whether the observed structural changes and reduction in electrographic seizures are associated with long term improvement of cognitive and motoric function needs to be addressed in future (clinical) studies [13].

In conclusion, we report for the first time that intravenously administered mesenchymal stem cells (MSC) were neuroprotective in a translational ovine model of preterm brain injury after global HI. We demonstrated that MSC protected the preterm brain against white matter injury and established functional improvement. We provide evidence that the neuroprotective effects of MSC may be mediated by modulation of the peripheral T-cell response after global HI. Further experimental research is needed to elucidate the anti-inflammatory and regenerative mechanisms of action of MSC and to evaluate the long-term therapeutic effect of MSC on motoric and cognitive function after global HI. Future clinical trials should focus on the optimization of timing and dosing of MSC therapy in preterm infants with hypoxic-ischemic brain injury. 


\section{Supplementary figures}

A

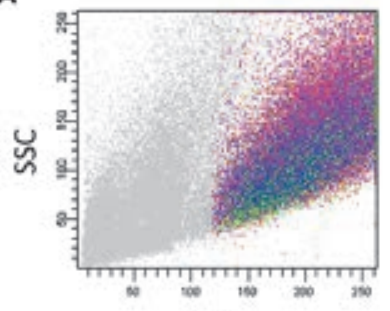

FSC
B

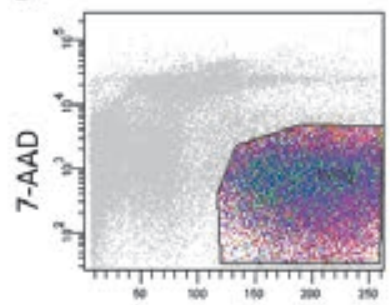

FSC

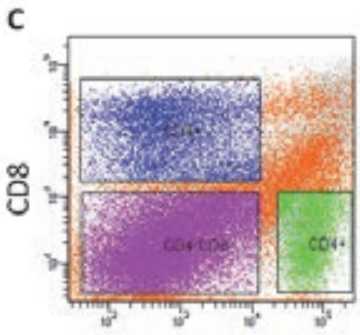

CD4

Figure S1. Gating strategy proliferation assay. (A-C) Dot plots illustrating gating strategy in the flow cytometry analysis of the proliferation assay. FSC = forward scatter, SSC = sideward scatter, 7-AAD = 7Aminoactinomycin D (viability stain).

A

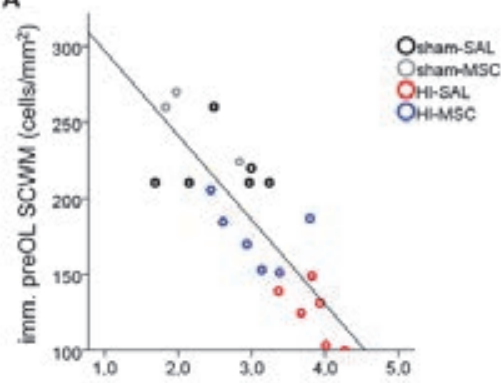

C

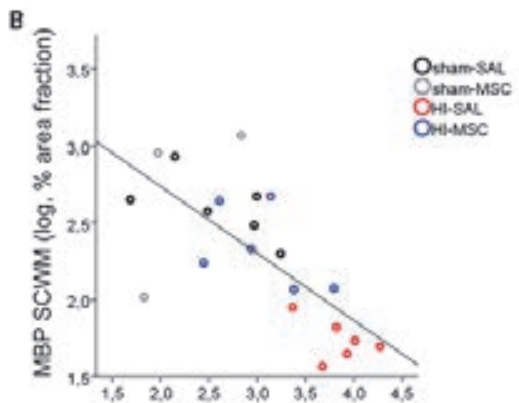

IBA-1 SCWM (log. \% area fraction)

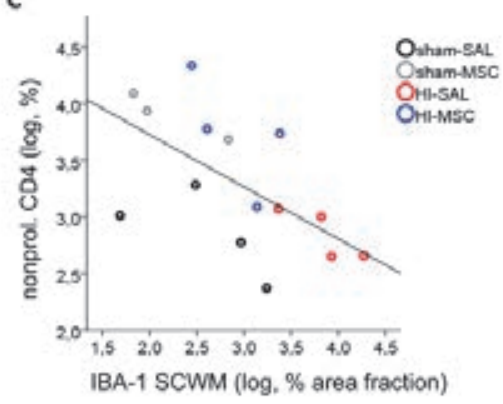

Figure S2. Correlation plots. (A) Density of immature preOLs was inversely related (Pearson $r=-.83$, $P<0.001)$ to IBA-1 immunoreactivity in the SCWM. (B) MBP immunoreactivity was inversely related (Pearson $r=-.71, P=0.002)$ to IBA-1 immunoreactivity in the SCWM. (C) The number of non-proliferating CD4-postive $T$ cells harvested from the spleen was inversely related (Pearson $r=-.60, P=0.035$ ) to IBA-1 immunoreactivity in the subcortical white matter. 


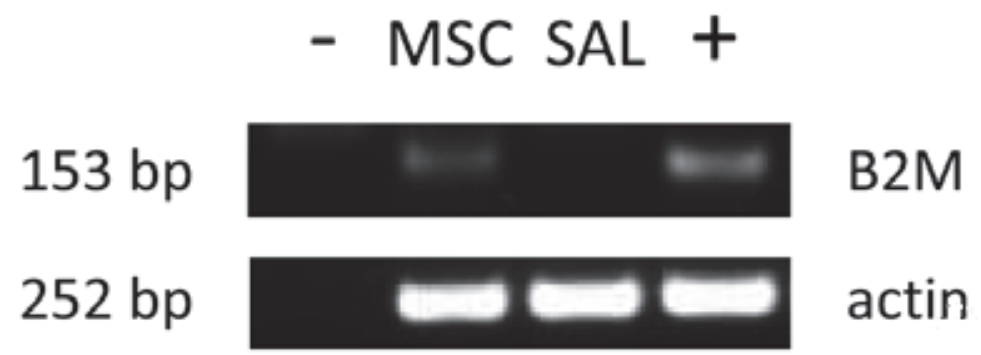

Figure S3. Detection of human specific B-2-microglobulin DNA sequences in preterm sheep brain. Genomic DNA was extracted from subcortical white matter of a MSC treated animal (MSC) and a saline treated animal (SAL) and analyzed by nested PCR for the presence of human B-2-microglobulin (B2M) DNA sequences. The presence of amplifiable DNA was evaluated by $P C R$ for B-actin (actin). - = water control, + = positive control; genomic DNA extracted from one million human MSC. 


\section{References}

1. Back SA, Luo NL, Borenstein NS, Levine JM, Volpe JJ, Kinney HC: Late oligodendrocyte progenitors coincide with the developmental window of vulnerability for human perinatal white matter injury. $J$ Neurosci 2001, 21:1302-1312.

2. Volpe JJ, Kinney HC, Jensen FE, Rosenberg PA: The developing oligodendrocyte: key cellular target in brain injury in the premature infant. Int J Dev Neurosci 2011, 29:423-440.

3. Volpe JJ: Neurology of the Newborn. 5th edn. Philadelphia: Elsevier-Saunders 2008.

4. Buser JR, Maire J, Riddle A, Gong X, Nguyen T, Nelson K, Luo NL, Ren J, Struve J, Sherman LS, Miller SP, Chau V, Hendson G, Ballabh P, Grafe MR, Back SA: Arrested preoligodendrocyte maturation contributes to myelination failure in premature infants. Ann Neurol 2012, 71:93-109.

5. Volpe JJ: Brain injury in premature infants: a complex amalgam of destructive and developmental disturbances. Lancet Neurol 2009, 8:110-124.

6. Brea D, Sobrino T, Ramos-Cabrer P, Castillo J: Inflammatory and neuroimmunomodulatory changes in acute cerebral ischemia. Cerebrovasc Dis 2009, 27 Suppl 1:48-64.

7. Offner $\mathrm{H}$, Vandenbark AA, Hurn PD: Effect of experimental stroke on peripheral immunity: CNS ischemia induces profound immunosuppression. Neurosci 2009, 158:1098-1111.

8. Offner H, Subramanian S, Parker SM, Afentoulis ME, Vandenbark AA, Hurn PD: Experimental stroke induces massive, rapid activation of the peripheral immune system. J Cereb Blood Flow Metab 2006, 26:654-665.

9. Ajmo CT, Jr., Vernon DO, Collier L, Hall AA, Garbuzova-Davis S, Willing A, Pennypacker KR: The spleen contributes to stroke-induced neurodegeneration. J Neurosci Res 2008, 86:2227-2234.

10. Winerdal M, Winerdal ME, Kinn J, Urmaliya V, Winqvist O, Aden U: Long lasting local and systemic inflammation after cerebral hypoxic ischemia in newborn mice. PLoS One 2012, 7:e36422.

11. Jellema RK, Lima Passos V, Zwanenburg A, Ophelders DR, De Munter S, Vanderlocht J, Germeraad WT, Kuypers E, Collins JJ, Cleutjens JP, Jennekens W, Gavilanes AW, Seehase M, Vles HJ, Steinbusch H, Andriessen P, Wolfs TG, Kramer BW: Cerebral inflammation and mobilization of the peripheral immune system following global hypoxia-ischemia in preterm sheep. J Neuroinflammation 2013, 10:13.

12. Bennet L, Roelfsema V, George S, Dean JM, Emerald BS, Gunn AJ: The effect of cerebral hypothermia on white and grey matter injury induced by severe hypoxia in preterm fetal sheep. J Physiol 2007, 578:491506.

13. Gortner L, Felderhoff-Muser U, Monz D, Bieback K, Kluter H, Jellema RK, Kramer BW, Keller M, Reiss I, Horn PA, Giebel B: Regenerative therapies in neonatology: clinical perspectives. Klin Padiatr 2012, 224:233-240.

14. Uccelli A, Moretta L, Pistoia V: Mesenchymal stem cells in health and disease. Nat Rev Immunol 2008, 8:726-736.

15. Bennet L, Tan S, Van den Heuij L, Derrick M, Groenendaal F, van Bel F, Juul S, Back SA, Northington F, Robertson NJ, Mallard C, Gunn AJ: Cell therapy for neonatal hypoxia-ischemia and cerebral palsy. Ann Neurol 2012, 71:589-600.

16. Salem HK, Thiemermann C: Mesenchymal stromal cells: current understanding and clinical status. Stem Cells 2010, 28:585-596.

17. Yasuhara T, Hara K, Maki M, Mays RW, Deans RJ, Hess DC, Carroll JE, Borlongan CV: Intravenous grafts recapitulate the neurorestoration afforded by intracerebrally delivered multipotent adult progenitor cells in neonatal hypoxic-ischemic rats. J Cereb Blood Flow Metab 2008, 28:1804-1810.

18. Yasuhara T, Matsukawa N, Yu G, Xu L, Mays RW, Kovach J, Deans RJ, Hess DC, Carroll JE, Borlongan CV: Behavioral and histological characterization of intrahippocampal grafts of human bone marrow-derived multipotent progenitor cells in neonatal rats with hypoxic-ischemic injury. Cell Transplant 2006, 15:231238.

19. van Velthoven CT, Kavelaars A, van Bel F, Heijnen CJ: Mesenchymal stem cell treatment after neonatal hypoxic-ischemic brain injury improves behavioral outcome and induces neuronal and oligodendrocyte regeneration. Brain Behav Immun 2010, 24:387-393. 


\section{Chapter 4}

20. van Velthoven CT, van de Looij Y, Kavelaars A, Zijlstra J, van Bel F, Huppi PS, Sizonenko S, Heijnen CJ: Mesenchymal stem cells restore cortical rewiring after neonatal ischemia in mice. Ann Neurol 2012, 71:785-796.

21. Lee JA, Kim BI, Jo CH, Choi CW, Kim EK, Kim HS, Yoon KS, Choi JH: Mesenchymal stem-cell transplantation for hypoxic-ischemic brain injury in neonatal rat model. Pediatr Res 2010, 67:42-46.

22. Perasso L, Cogo CE, Giunti D, Gandolfo C, Ruggeri P, Uccelli A, Balestrino M: Systemic administration of mesenchymal stem cells increases neuron survival after global cerebral ischemia in vivo (2VO). Neural Plast 2010, 2010:534925.

23. Wolfs TG, Jellema RK, Turrisi G, Becucci E, Buonocore G, Kramer BW: Inflammation-induced immune suppression of the fetus: a potential link between chorioamnionitis and postnatal early onset sepsis. $J$ Matern Fetal Neonatal Med 2012, 25 Suppl 1:8-11.

24. Hagberg H, Peebles D, Mallard C: Models of white matter injury: comparison of infectious, hypoxicischemic, and excitotoxic insults. Ment Retard Dev Disabil Res Rev 2002, 8:30-38.

25. Niemarkt HJ, Jennekens W, Maartens IA, Wassenberg T, van Aken M, Katgert T, Kramer BW, Gavilanes AW, Zimmermann LJ, Bambang Oetomo S, Andriessen P: Multi-channel amplitude-integrated EEG characteristics in preterm infants with a normal neurodevelopment at two years of corrected age. Early Hum Dev 2012, 88:209-216.

26. Maynard D, Prior PF, Scott DF: A continuous monitoring device for cerebral activity. Electroencephalogr Clin Neurophysiol 1969, 27:672-673.

27. Rosen I: The physiological basis for continuous electroencephalogram monitoring in the neonate. Clin Perinatol 2006, 33:593-611, v.

28. Davidson JO, Quaedackers JS, George SA, Gunn AJ, Bennet L: Maternal dexamethasone and EEG hyperactivity in preterm fetal sheep. J Physiol 2011, 589:3823-3835.

29. Leemans A, Jeurissen B, Sijbers J, Jones DK: ExploreDTI: a graphical toolbox for processing, analyzing, and visualizing diffusion MR data. In 17th Annual Meeting of Intl Soc Mag Reson Med; Hawaii, USA. 2009: 3537.

30. Riddle A, Dean J, Buser JR, Gong X, Maire J, Chen K, Ahmad T, Cai V, Nguyen T, Kroenke CD, Hohimer AR, Back SA: Histopathological correlates of magnetic resonance imaging-defined chronic perinatal white matter injury. Ann Neurol 2011, 70:493-507.

31. Jansen MP, Hopman AH, Bot FJ, Haesevoets A, Stevens-Kroef MJ, Arends JW, Jox A, Wolf J, Ramaekers FC, Schouten HC: Morphologically normal, CD30-negative B-lymphocytes with chromosome aberrations in classical Hodgkin's disease: the progenitor cell of the malignant clone? J Pathol 1999, 189:527-532.

32. Liechty KW, MacKenzie TC, Shaaban AF, Radu A, Moseley AM, Deans R, Marshak DR, Flake AW: Human mesenchymal stem cells engraft and demonstrate site-specific differentiation after in utero transplantation in sheep. Nat Med 2000, 6:1282-1286.

33. Alderliesten T, Nikkels PG, Benders MJ, de Vries LS, Groenendaal F: Antemortem cranial MRI compared with postmortem histopathologic examination of the brain in term infants with neonatal encephalopathy following perinatal asphyxia. Arch Dis Child Fetal Neonatal Ed 2013, 98:F304-309.

34. Lynch NE, Stevenson NJ, Livingstone V, Murphy BP, Rennie JM, Boylan GB: The temporal evolution of electrographic seizure burden in neonatal hypoxic ischemic encephalopathy. Epilepsia 2012, 53:549557.

35. Bennet L, Roelfsema V, Pathipati P, Quaedackers JS, Gunn AJ: Relationship between evolving epileptiform activity and delayed loss of mitochondrial activity after asphyxia measured by nearinfrared spectroscopy in preterm fetal sheep. J Physiol 2006, 572:141-154.

36. Gelderblom M, Leypoldt F, Steinbach K, Behrens D, Choe CU, Siler DA, Arumugam TV, Orthey E, Gerloff C, Tolosa E, Magnus T: Temporal and spatial dynamics of cerebral immune cell accumulation in stroke. Stroke 2009, 40:1849-1857.

37. Ward P, Counsell S, Allsop J, Cowan F, Shen Y, Edwards D, Rutherford M: Reduced fractional anisotropy on diffusion tensor magnetic resonance imaging after hypoxic-ischemic encephalopathy. Pediatrics 2006, 117:e619-630. 
38. Glass HC, Glidden D, Jeremy RJ, Barkovich AJ, Ferriero DM, Miller SP: Clinical Neonatal Seizures are Independently Associated with Outcome in Infants at Risk for Hypoxic-Ischemic Brain Injury. J Pediatr 2009, 155:318-323.

39. Gluckman PD, Wyatt JS, Azzopardi D, Ballard R, Edwards AD, Ferriero DM, Polin RA, Robertson CM, Thoresen M, Whitelaw A, Gunn AJ: Selective head cooling with mild systemic hypothermia after neonatal encephalopathy: multicentre randomised trial. Lancet 2005, 365:663-670.

40. Miller SP, Weiss J, Barnwell A, Ferriero DM, Latal-Hajnal B, Ferrer-Rogers A, Newton N, Partridge JC, Glidden DV, Vigneron DB, Barkovich AJ: Seizure-associated brain injury in term newborns with perinatal asphyxia. Neurology 2002, 58:542-548.

41. Shichita T, Sugiyama Y, Ooboshi H, Sugimori H, Nakagawa R, Takada I, Iwaki T, Okada Y, lida M, Cua DJ, Iwakura Y, Yoshimura A: Pivotal role of cerebral interleukin-17-producing gammadeltaT cells in the delayed phase of ischemic brain injury. Nat Med 2009, 15:946-950.

42. Aggarwal S, Pittenger MF: Human mesenchymal stem cells modulate allogeneic immune cell responses. Blood 2005, 105:1815-1822.

43. Di Nicola M, Carlo-Stella C, Magni M, Milanesi M, Longoni PD, Matteucci P, Grisanti S, Gianni AM: Human bone marrow stromal cells suppress T-lymphocyte proliferation induced by cellular or nonspecific mitogenic stimuli. Blood 2002, 99:3838-3843.

44. Selmani Z, Naji A, Zidi I, Favier B, Gaiffe E, Obert L, Borg C, Saas P, Tiberghien P, Rouas-Freiss N, Carosella ED, Deschaseaux F: Human leukocyte antigen-G5 secretion by human mesenchymal stem cells is required to suppress $T$ lymphocyte and natural killer function and to induce CD4+CD25highFOXP3+ regulatory T cells. Stem Cells 2008, 26:212-222.

45. Back SA, Luo NL, Mallinson RA, O'Malley JP, Wallen LD, Frei B, Morrow JD, Petito CK, Roberts CT, Jr., Murdoch GH, Montine TJ: Selective vulnerability of preterm white matter to oxidative damage defined by F2-isoprostanes. Ann Neurol 2005, 58:108-120.

46. Steffenhagen C, Dechant FX, Oberbauer E, Furtner T, Weidner N, Kury P, Aigner L, Rivera FJ: Mesenchymal stem cells prime proliferating adult neural progenitors toward an oligodendrocyte fate. Stem Cells Dev 2012, 21:1838-1851.

47. Rivera FJ, Couillard-Despres S, Pedre X, Ploetz S, Caioni M, Lois C, Bogdahn U, Aigner L: Mesenchymal stem cells instruct oligodendrogenic fate decision on adult neural stem cells. Stem Cells 2006, 24:22092219.

48. van Velthoven CT, Kavelaars A, van Bel F, Heijnen CJ: Repeated mesenchymal stem cell treatment after neonatal hypoxia-ischemia has distinct effects on formation and maturation of new neurons and oligodendrocytes leading to restoration of damage, corticospinal motor tract activity, and sensorimotor function. J Neurosci 2010, 30:9603-9611.

49. Lee RH, Pulin AA, Seo MJ, Kota DJ, Ylostalo J, Larson BL, Semprun-Prieto L, Delafontaine P, Prockop DJ: Intravenous hMSCs improve myocardial infarction in mice because cells embolized in lung are activated to secrete the anti-inflammatory protein TSG-6. Cell Stem Cell 2009, 5:54-63.

50. van Velthoven CT, Kavelaars A, van Bel F, Heijnen CJ: Mesenchymal stem cell transplantation changes the gene expression profile of the neonatal ischemic brain. Brain Behav Immun 2011.

51. Donega V, van Velthoven CT, Nijboer CH, van Bel F, Kas MJ, Kavelaars A, Heijnen CJ: Intranasal mesenchymal stem cell treatment for neonatal brain damage: long-term cognitive and sensorimotor improvement. PLoS One 2013, 8:e51253.

52. Back SA, Riddle A, Hohimer AR: Role of instrumented fetal sheep preparations in defining the pathogenesis of human periventricular white-matter injury. J Child Neurol 2006, 21:582-589.

53. Zanjani ED, Pallavicini MG, Ascensao JL, Flake AW, Langlois RG, Reitsma M, MacKintosh FR, Stutes D, Harrison MR, Tavassoli M: Engraftment and long-term expression of human fetal hemopoietic stem cells in sheep following transplantation in utero. J Clin Invest 1992, 89:1178-1188.

54. Bang OY, Lee JS, Lee PH, Lee G: Autologous mesenchymal stem cell transplantation in stroke patients. Ann Neurol 2005, 57:874-882. 



\section{Chapter 5}

\section{Systemic G-CSF attenuates cerebral inflammation and hypomyelination but does not reduce seizure burden in preterm sheep exposed to global hypoxia-ischemia}

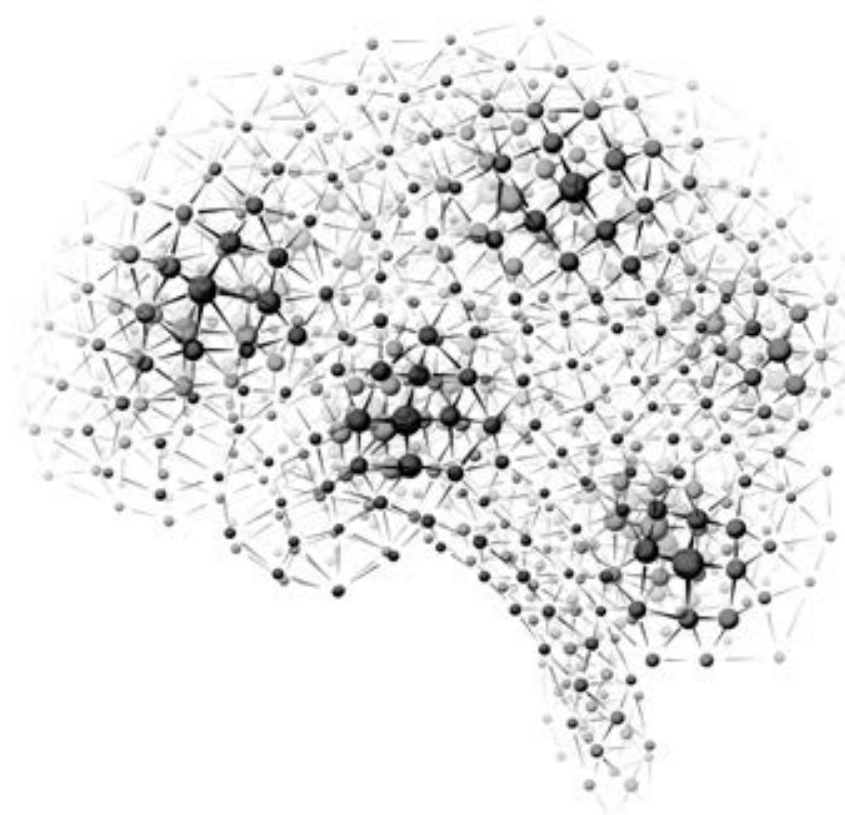

Published as: Jellema RK, Lima Passos V, Ophelders DR, Wolfs TG, Zwanenburg A, De Munter S, Nikiforou M, Collins JJ, Kuypers E, Bos GM, Steinbusch HW, Vanderlocht J, Andriessen P, Germeraad WT, Kramer BW: Systemic G-CSF attenuates cerebral inflammation and hypomyelination but does not reduce seizure burden in preterm sheep exposed to global hypoxia-ischemia. Exp Neurol 2013, 250C:293-303. 


\section{Abstract}

Hypoxic-ischemic encephalopathy (HIE) is common in preterm infants, but currently no curative therapy is available. Cell-based therapy has great potential in the treatment of hypoxic-ischemic preterm brain injury. Granulocyte-colony stimulating factor (G-CSF) is known to mobilize endogenous hematopoietic stem cells (HSC) and promotes proliferation of endogenous neural stem cells. On these grounds, we hypothesized that systemic G-CSF would be neuroprotective in a large translational animal model of hypoxicischemic injury in the preterm brain.

Global hypoxia-ischemia (HI) was induced by transient umbilical cord occlusion in instrumented preterm sheep. G-CSF treatment $(100 \mu \mathrm{g} / \mathrm{kg}$ intravenously, during five consecutive days) was started one day before the global $\mathrm{HI}$ insult to ascertain mobilization of endogenous stem cells within the acute phase after global HI. Mobilization of HSC and neutrophils was studied by flow cytometry. Brain sections were stained for microglia (IBA-1), myelin basic protein (MBP) and myeloperoxidase (MPO) to study microglial proliferation, white matter injury and neutrophil invasion respectively. Electrographic seizure activity was analyzed using amplitude-integrated electroencephalogram (aEEG).

G-CSF effectively mobilized CD34-positive HSC in the preterm sheep. In addition, GCSF caused marked mobilization of neutrophils, but did not influence enhanced invasion of neutrophils into the preterm brain after global HI. Microglial proliferation and hypomyelination following global HI were reduced as a result of G-CSF treatment. GCSF did not cause reduction of the electrographic seizure activity after global HI.

In conclusion, G-CSF induced mobilization of endogenous stem cells which was associated with modulation of the cerebral inflammatory response and reduced white matter injury in an ovine model of preterm brain injury after global HI. G-CSF treatment did not improve neuronal function as shown by seizure analysis. Our study shows that G-CSF treatment has neuroprotective potential following hypoxic-ischemic injury in the preterm brain. 


\section{Introduction}

Hypoxic-ischemic brain injury (i.e. hypoxic-ischemic encephalopathy; HIE) in preterm infants is associated with cognitive and motor disorders causing life-long neurological disability with a tremendous impact on the patient's life and his environment [1]. HIE in preterm infants is predominantly characterized by white matter injury, the clinical hallmark of HIE in prematurity [1-5]. Currently no therapeutic intervention is available for HIE in preterm infants. The regenerative potential of cell-based therapy may provide a good treatment option for this vulnerable patient group [6-8]. Recently, we showed in a translational animal model of HIE that exogenous administration of bone marrowderived mesenchymal stem cells (MSC) early after global hypoxia-ischemia (HI) established functional neuroprotection and dampened the cerebral and systemic inflammatory response [9]. These findings indicated that the therapeutic window of opportunity for modulation of the cerebral and peripheral inflammatory response and initiation of repair mechanisms after global HI corresponds to the first hours after the insult [9].

Although exogenous administration of stem cells seems beneficial for the preterm ischemic brain, the alternative of pharmacologically potentiating the endogenous regenerative capacity after injury remains appealing as biological risks, logistics and costs remain potential obstacles for exogenous stem cell therapy [6]. In preterm infants especially, the brain and other tissues possess high numbers of regenerative stem cells [7, $10,11]$. Pharmacological interventions aimed at mobilizing these stem cells after injury form a promising prospect in the preterm environment [6].

Granulocyte-colony stimulating factor (G-CSF) is a potent drug that has been shown to mobilize hematopoietic stem cells (HSC), which can be neuroprotective, and to stimulate proliferation of endogenous neural stem cells [12]. G-CSF is clinically approved in neonatal and pediatric medicine for the treatment and prevention of neutropenia [13-15]. The neuroprotective properties of G-CSF are currently tested in clinical trials with adult stroke patients [16-20]. Its protective role on the neonatal brain following hypoxia-ischemia however remains debated [21-26]. These previous neonatal studies have tested G-CSF therapy in rodent models of neonatal hypoxic-ischemic brain injury. Neurodevelopment in the rodent brain however follows a different time course then in the human brain [27-29]. In contrast to the human (and ovine) situation, white matter myelination in the rodent brain occurs in the postnatal period [27-29].

Therefore, we hypothesized that systemic G-CSF treatment would be neuroprotective in a large translational animal model (sheep) of hypoxic-ischemic preterm brain injury. To test this hypothesis, instrumented fetal sheep were exposed to 25 minutes of umbilical cord occlusion at 0.7 gestation, which is equivalent to $30-32$ gestational weeks of human neurodevelopment $[28,29]$. G-CSF treatment $(100 \mu \mathrm{g} / \mathrm{kg}$ intravenously daily, during five consecutive days) was started one day before the global $\mathrm{HI}$ insult to ascertain that mobilized endogenous stem cells were readily available within the therapeutic 
window of opportunity. We studied the effect of G-CSF treatment on the cerebral and systemic inflammatory response, white matter injury and seizure activity.

\section{Materials \& methods}

\section{Study approval}

The experimental protocol and study design were in line with the institutional guides for animal experiments and were approved by the institutional Animal Ethics Research committee of Maastricht University, the Netherlands.

\section{Randomization and blinding}

Prior to the entire series of experiments, animals were randomized by an independent researcher who was not involved in the animal experiments. Randomization resulted in four experimental groups: (1) sham umbilical cord occlusion, saline treatment (shamSAL; $n=8$ ), (2) sham umbilical cord occlusion, G-CSF treatment (sham-G-CSF; $n=8$ ), (3) umbilical cord occlusion, saline treatment (HI-SAL; $n=8$ ) and (4) umbilical cord occlusion, G-CSF treatment (HI-G-CSF; $n=8$ ) (Figure 1). The investigator performing the (sham) umbilical cord occlusions was blinded to treatment allocation. Tissue sampling and the analyses of brain tissue and electrophysiological data were conducted in a blinded fashion.

\section{Animals and surgery}

Singleton fetuses of time-mated Texel ewes were instrumented at $101.6 \pm 1.0$ (mean \pm SD) days of gestation as previously described [30]. In short, all fetuses were instrumented with an arterial catheter for blood pressure measurements and blood sampling, a venous catheter for administration of G-CSF and electrocardiogram (ECG) electrodes for heart rate monitoring. Two pairs of custom-made shielded silver-tipped electroencephalogram (EEG) electrodes (Cooner wire Co., Chatsworth, CA, USA) were placed bilaterally on the dura over the parasagittal parietal cortex $(5 \mathrm{~mm}$ and $15 \mathrm{~mm}$ anterior to point bregma and $10 \mathrm{~mm}$ lateral), with a subcutaneous silver reference electrode $(10 \mathrm{~mm})$ placed in the neck. The EEG electrodes were secured with cyanoacrylate glue and covered with fetal skin. The anterior and posterior placed electrodes were considered C3-C4 channel and P3-P4 channel, respectively. An inflatable vascular occluder (OC16HD, 16mm, In Vivo Metric, Healdsburg, CA, USA) was placed around the umbilical cord to induce transient global HI. The fetus was placed back in the uterus which was subsequently closed. All fetal catheters and leads were exteriorized through a trocar hole in the flank of the ewe. Catheters were continuously perfused with heparinized saline $(25 \mathrm{IU} / \mathrm{mL}, 0.2 \mathrm{~mL} / \mathrm{h}$ ). Surgical wounds were inspected daily and treated with chlortetracycline spray to prevent infection. Animals had ad 
libitum access to water and food. The welfare of the animals was monitored daily by certified personnel.

\section{Experimental design}

Fetuses were instrumented at $101.6 \pm 1.0$ (mean \pm SD) days of gestation (experimental day -4). After surgery, the ewe and her fetus were allowed to recover for three to four days. At gestational age $105.6 \pm 1.0$ (mean \pm SD) (experimental day 0) fetuses were subjected to 25 minutes of umbilical cord occlusion by rapidly inflating the occluder with sterile saline of a defined volume known to completely inflate the occluder. Complete occlusion was confirmed by a sudden drop in heart rate and subsequent arterial blood gas analysis indicating acidemia, hypoxemia and hypercarboxemia (Figure 2), which has previously been shown to induce global hypoxia-ischemia and subsequent cerebral hypoperfusion [31]. After umbilical cord occlusion a reperfusion period of 7 days followed. At the end of the experiment (experimental day 7), both ewe and fetus were euthanized by administration of pentobarbital $(200 \mathrm{mg} / \mathrm{kg})$.

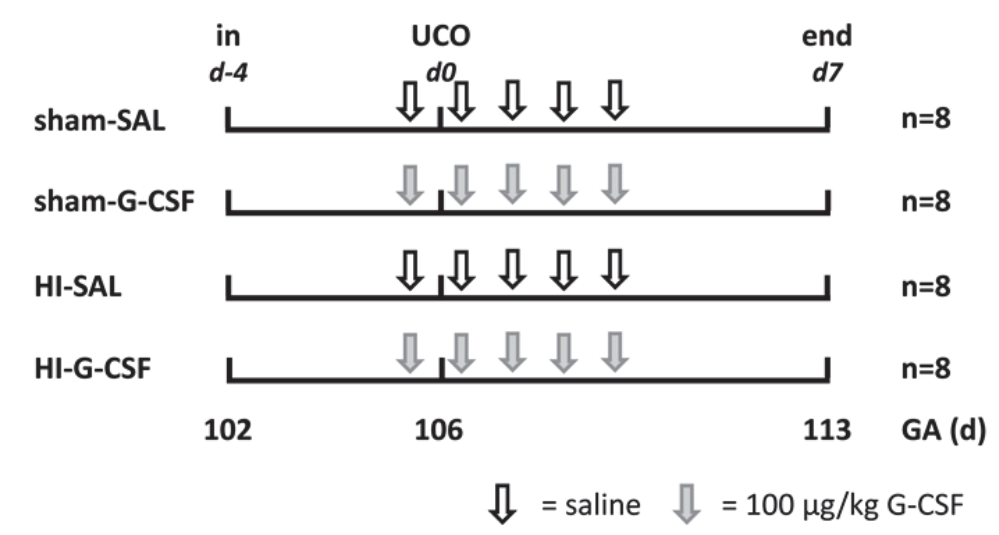

Figure 1. Study design. Fetuses were instrumented at a gestational age (GA) of $102 d$ (experimental day -4). After a recovery period of $4 d$, on experimental day 0 fetuses were subjected to 25 min of umbilical cord occlusion (UCO) or sham. One day before UCO or sham, fetuses received either intravenous G-CSF (100 $\mu \mathrm{g} /$ $\mathrm{kg} B W$ ) (grey arrow) or saline (open arrow). After a reperfusion period of 7 days brain tissue was collected. in = instrumentation, $\mathrm{HI}$ = hypoxia-ischemia, $S A L=$ saline, $\mathrm{G}-\mathrm{CSF}=$ granulocyte-colony stimulating factor .

\section{Granulocyte colony-stimulating factor administration}

One day before umbilical cord occlusion (experimental day -1), fetuses received 100 $\mu \mathrm{g} / \mathrm{kg}$ human recombinant G-CSF (Neupogen, Amgen Inc, Thousand Oaks, CA, USA) or saline daily through the venous catheter for five consecutive days (Figure 1). 
Human recombinant G-CSF (5 $\mathrm{\mu g} / \mathrm{kg}$ ) has been previously shown to mobilize sheep white blood cells [32]. In a pilot study we confirmed that human recombinant G-CSF (10 $\mu \mathrm{g} / \mathrm{kg}$ ) mobilized white blood cells in instrumented fetal sheep (data not shown).

G-CSF dosage in our experiments $(100 \mu \mathrm{g} / \mathrm{kg})$ was chosen based on a metaanalysis by Minnerup et al., which concluded that in most adult rodent studies $50 \mu \mathrm{g}$ /kg G-CSF was neuroprotective in focal cerebral ischemia (i.e. stroke) [33]. However, meta-regression analysis showed that higher doses were likely to have even stronger therapeutic effects [33]. In addition, neonatal rodent studies showed neuroprotection with G-CSF dosage varying between $50 \mu \mathrm{g} / \mathrm{kg}$ up to $200 \mu \mathrm{g} / \mathrm{kg}$ during five consecutive days $[22,23,25,26,34]$. Based on these findings, we performed a second pilot study which showed marked mobilization of ovine white blood cells and HSC after administration of $100 \mu \mathrm{g} / \mathrm{kg}$ human recombinant G-CSF during five consecutive days (data not shown). Ovine HSC were detectable 24 hours after the initial infusion of human recombinant G-CSF. Therefore, we started G-CSF treatment 24 hours before the global hypoxic-ischemic insult to ascertain mobilization of endogenous stem cells within the acute phase after global $\mathrm{HI}$.

\section{EEG and ECG data acquisition}

Physiological data was acquired as described previously [30]. In short, blood pressure, amniotic pressure EEG and ECG data were acquired and digitized by a custom-made MPAQ unit (Maastricht-Programmable AcQuisition system, Maastricht Instruments BV, Maastricht, the Netherlands) with IDEEQ software (Maastricht Instruments BV). EEG data were sampled at $1000 \mathrm{~Hz}$ and stored on hard-disk for off-line analysis. EEG data were filtered using a $0.5-30 \mathrm{~Hz} 4^{\text {th }}$ order Butterworth band-pass filter. EEG signal with an amplitude $>1000 \mu \mathrm{V}$ was considered an artifact and removed from analysis $(<1 \%$ of data). After filtering, the raw EEG signals of the central and posterior channels were converted into amplitude-integrated EEG (aEEG) traces, using an (Matlab based) algorithm similar to the clinical EEG NicoletOne ${ }^{T M}$ device (Viasys Healthcare, Conshohocken, PA, USA), as previously described [35-37]. The aEEG processing includes an asymmetric band pass filter that strongly attenuates activity below $2 \mathrm{~Hz}$ and above $15 \mathrm{~Hz}$, semilogarithmic amplitude compression, rectifying, smoothing and time compression. The bandwidth reflects variations in minimum and maximum EEG amplitude. The amplitude display is linear between 0 and $10 \mu \mathrm{V}$ and logarithmic from 10 to $100 \mu \mathrm{V}$. The semilogarithmic display enhances identification of changes in low-voltage activity and avoids overloading of the display at high amplitudes.

We previously showed that seizure activity in instrumented fetal sheep can be easily detected on aEEG as an abrupt rise in the lower margin amplitude and a simultaneous rise in the upper margin amplitude often followed by a short period of decreased amplitude [9]. When detected on aEEG, seizure activity was confirmed on the raw EEG by gradual build-up and then decline in frequency and amplitude of repetitive spikes or sharp-wave or activity with duration of at least $10 \mathrm{~s}$. 
EEG seizure activity was annotated manually using aEEG/EEG traces and the total number and length of seizures was subsequently calculated. Annotation was performed by a neonatologist, experienced in aEEG interpretation, who was blinded to treatment allocation. For the analysis of seizure burden, $n=6$ for sham-SAL, $n=4$ for sham-G-CSF, $n=6$ for HI-SAL and $\mathrm{n}=4$ for HI-G-CSF animals per group were available for analysis.
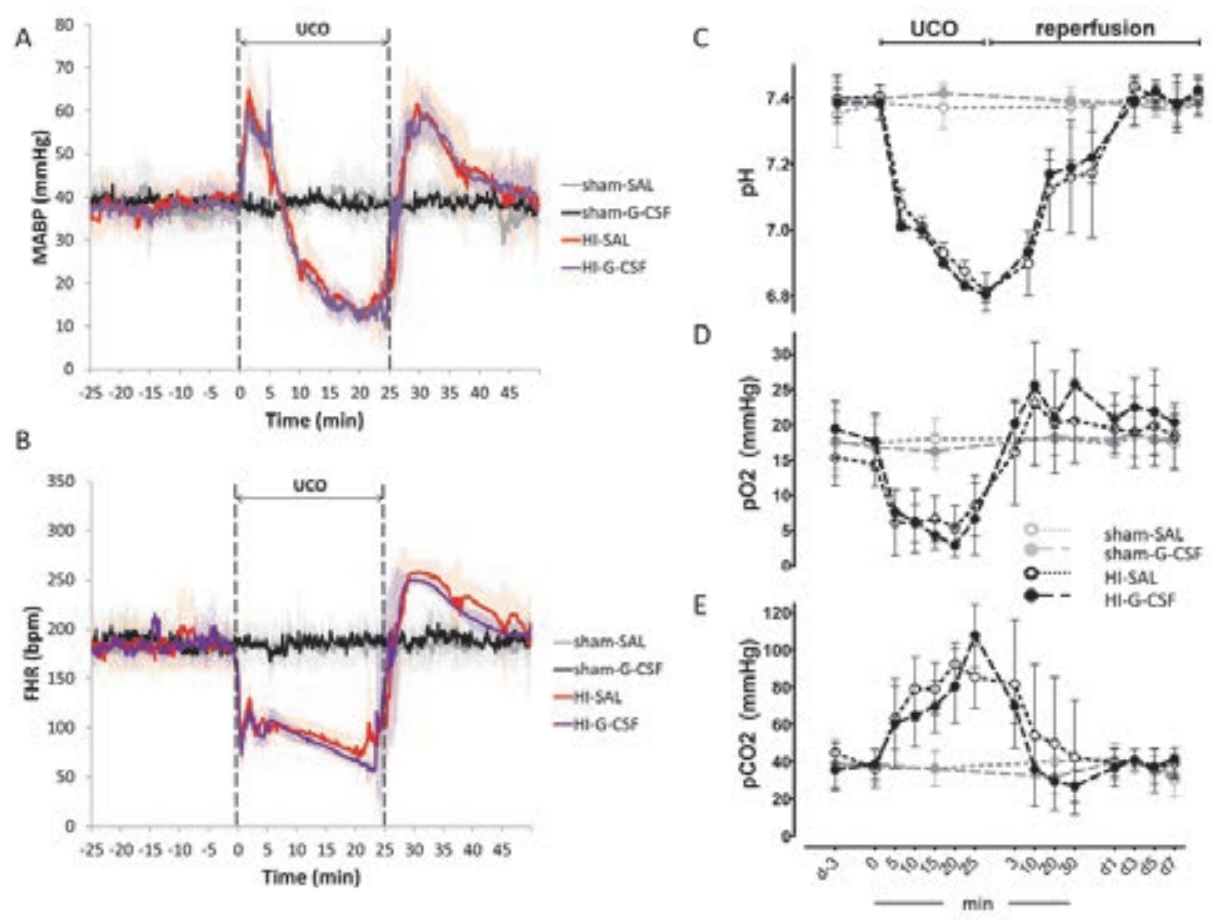

Figure 2. Reproducibility of 25 min umbilical cord occlusion (UCO) as evidenced by comparable vital parameters and blood gases in animals exposed to global HI. (A) Fetal mean arterial blood pressure (MABP) and $(B)$ fetal heart rate (FHR) measurements indicated that all animals exposed to global HI experienced the same degree of hypotension and bradycardia, respectively; means (thick line) $\pm S D$ (shaded areas) of $n=8$ animals per experimental group are shown. (C-E) Blood gas analysis indicated that 25 min of umbilical cord occlusion induced comparable acidosis, hypoxemia and hypercarboxemia in all animals exposed to global $\mathrm{HI}$, as demonstrated by $(C)$ arterial $\mathrm{pH},(\mathrm{D})$ arterial partial oxygen pressure ( $p O 2)$ and (E) arterial partial carbon dioxide pressure ( $p C \mathrm{CO}$ ), respectively; means (lines) $\pm S D$ (error bars) of $n=8$ animals are depicted. $\mathrm{HI}=$ hypoxia-ischemia, $S A L=$ saline, $G-C S F=$ granulocyte-colony stimulating factor, min = minutes.

\section{Brain immunohistochemistry}

After 3 months of submersion fixation in 4\% paraformaldehyde, the right cerebral hemisphere was embedded in gelatin and serial coronal sections $(50 \mu \mathrm{m})$ were cut on a Leica VT 1200 S vibrating microtome (Leica Biosystems, Nussloch, Germany). Free floating sections at the level of mid-thalamus and posterior hippocampus were stained with 
a rabbit anti-ionized calcium binding adaptor molecule 1 (IBA-1) antibody (Wako Pure Chemical Industries, Osaka, Japan) for microglia, a rabbit anti-myeloperoxidase (MPO) antibody (DAKO A0398, DAKO, Glostrup, Denmark) for neutrophils or a rat anti-myelin basic protein (MBP) antibody (Merck Millipore, Billerica, MA, USA) for myelin sheaths and myelin producing (mature) oligodendrocytes, as previously described [30].

\section{Analysis of immunohistochemistry}

For the analysis of IBA-1 immunoreactivity, digital images of the subcortical white matter (SCWM) (100x magnification) and hippocampus (20x magnification) were acquired using an Olympus AX-70 microscope (Olympus, Tokyo, Japan) equipped with a black and white digital camera. For the analysis of IBA- 1 immunoreactivity, $n=6$ for sham-SAL, $\mathrm{n}=3$ for sham-G-CSF, $\mathrm{n}=6$ for HI-SAL and $\mathrm{n}=6$ for HI-G-CSF animals per group were analyzed. In each individual animal, IBA-1 immunoreactivity was assessed in six consecutive coronal sections (posterior hippocampus/ mid-thalamus level). In the hippocampus, area fraction of IBA-1 immunoreactivity was assessed in one 20x digital image per section by delineating the hippocampus and determining the areal fraction of IBA-1 immunoreactivity expressed as a percentage of total hippocampal area with a standard threshold using Leica Qwin Pro V 3.5.1 software (Leica, Rijswijk, the Netherlands). In the SCWM, the area fraction of IBA-1 immunoreactivity was determined in five adjacent $100 x$ digital images obtained in standardized locations within the SCWM of each section. The results of five images per section were averaged to obtain the areal fraction of IBA-1 immunoreactivity within the SCWM for each section. The digital images were obtained and analyzed by an independent observer who was blinded to the experimental conditions.

For the analysis of MBP immunoreactivity, digital images of the subcortical white matter (SCWM) (100x magnification) were acquired using the Olympus AX-70 microscope. MBP immunoreactivity was analyzed in $n=6$ for sham-SAL, $n=3$ for sham-G-CSF, $\mathrm{n}=6$ for $\mathrm{HI}-\mathrm{SAL}$ and $\mathrm{n}=6$ for $\mathrm{HI}-\mathrm{G}-\mathrm{CSF}$ animals per group. In each individual animal, MBP immunoreactivity was assessed in six consecutive coronal sections (posterior hippocampus/ mid-thalamus level). In the SCWM, the MBP immunoreactivity was determined in five adjacent 100x digital images obtained in standardized locations within the SCWM of each section. Using Leica Qwin Pro V 3.5.1 software, areal fraction of MBPpositive myelin sheaths was determined in each digital image with a standard low-pass intensity threshold set to detect all MBP immunoreactivity and a standard high-pass intensity threshold set to exclude the intense staining of MBP-positive mature oligodendrocytes, to ensure measurements accurately represented white matter only. The results of five images per section were averaged to obtain the areal fraction of MBP immunoreactivity within the SCWM for each section. The digital images were obtained and analyzed by an independent observer who was blinded to the experimental conditions. 


\section{White blood cell counts}

Automated white blood cell counts were performed in heparinized arterial blood on experimental day $-3,0,1,3,5$ and 7 using a Sysmex XE-5000 hematology analyzer (Sysmex, Etten-Leur, the Netherlands).

\section{Spleen immunohistochemistry}

Spleens were removed immediately following sacrifice and subsequently weighed. Tissue blocks were snap frozen in liquid nitrogen. Frozen spleen sections $(4 \mu \mathrm{m})$ were stained for CD3 (DAKO A0452) for detection of T-cells and MPO (DAKO A0398) for detection of neutrophils, as previously described [30].

For the analysis of CD3 and MPO immunoreactivity, digital images of spleen sections were acquired at 100x magnification using a Leica DM200 microscope equipped with a Leica DFC295 digital camera (Leica Microsystems) and Leica Application Suite (LAS) software (Leica LAS V 3.7). Areal fraction of CD3 and MPO immunoreactivity was determined in five sections per animal (sham-SAL $n=6$, sham-G-CSF $n=6, H I-S A L n=6, H I-$ G-CSF $n=6$ ) with a standard threshold to determine positive staining using Leica Qwin software (Leica Qwin Pro V 3.5.1).

\section{Flow cytometry}

Fetal whole blood was stored in liquid nitrogen in freezing medium containing Iscove's modified Dulbecco's medium (IMDM) medium with $10 \%$ heat-inactivated fetal calf serum and $10 \%$ dimethylsulfoxide (DMSO). To study mobilization of hematopoietic stem cells, neutrophils and T-cells on experimental day 0, 1 and 3, fetal whole blood samples were stained for detection of lymphocytes (mouse anti sheep CD45-biotin; AbDSerotec, Düsseldorf, Germany / streptavidin-Horizon V450; BD Biosciences, Bleiswijk, the Netherlands), hematopoietic stem cells (mouse anti sheep CD34; a kind gift by Dr. Porada, University of Nevada, Reno, NV, USA [38], with secondary rat anti mouse- R-phycoerythrin (-PE); BD Biosciences), neutrophils (mouse anti-bovine CD11bFluorescein isothiocyanate (-FITC); AbDSerotec), T-helper cells (mouse anti sheep CD4AlexaFluor $^{\circledR} 647$ (-A647); AbDSerotec), cytotoxic T-cells (mouse anti sheep CD8-Rphycoerythrin (-PE); AbDSerotec) and a viability marker (7-Aminoactinomycin D (7$A A D) ; B D$ Biosciences) according to the manufacturer's protocol. Stained cells were acquired on a FACS Canto II flow cytometer (BD Biosciences) equipped with FACS Diva software (BD Biosciencs). The total number of CD34, CD11b, CD4 and CD8 positive cells was calculated by multiplying the percentage of living CD45-positive lymphocytes with the corresponding white blood cell count.

\section{Statistics}

Summary statistics of animal characteristics and all outcome variables are shown as means with 95\% Confidence Interval $(\mathrm{Cl})$. Groups' comparisons of all outcome parame- 
ters (except white blood cell mobilization and seizure data) were drawn with analysis of variance (ANOVA) or with random intercept models in case of repeated measurements per animal (e.g. different sections per brain). HI (sham vs. HI) and treatment (saline vs. G-CSF) were the fixed effects. For random intercept models, animals constituted additionally the random effect. Variables, whose distributions were positively skewed, were log-transformed previous to statistical testing. To facilitate interpretation, averages on the log scale were back transformed to the original scale (antilog) and are presented as geometric means and corresponding $95 \% \mathrm{Cls}$.

Mobilization (HSC and neutrophils) and seizure data, both of them measured over time, showed pronounced right-skewness that could not be remedied by log transformation. Hence, for these variables, pair-wise groups' comparisons of mobilization and seizure data were performed with nonparametric Mann-Whitney tests, per individual time-point. They are presented as medians and corresponding interquartile range (IQR). A False Discovery Rate (FDR) of 5\% was used for multiple testing correction. Groups' differences with FDR corrected $\mathrm{P}<0.05$ were considered statistically significant. Statistical analysis was performed with IBM SPSS Statistics Version 20.0 (IBM Corp., Armonk, NY, USA).

Table 1. Animal characteristics ( $n=8$ animals per experimental group). Fetuses were subjected to umbilical cord occlusion at a comparable age. Fetal body weight did not differ between experimental groups. Global HI caused significant atrophy of the brain and hippocampus, which was not prevented by G-CSF. * = significantly different compared to sham-SAL.

\begin{tabular}{lllll}
\hline & $\begin{array}{l}\text { sham-SAL } \\
\text { mean }(95 \% \mathrm{Cl})\end{array}$ & $\begin{array}{l}\text { sham-G-CSF } \\
\text { mean }(95 \% \mathrm{Cl})\end{array}$ & $\begin{array}{l}\text { HI-SAL } \\
\text { mean }(95 \% \mathrm{Cl})\end{array}$ & $\begin{array}{l}\text { HI-G-CSF } \\
\text { mean }(95 \% \mathrm{Cl})\end{array}$ \\
\hline GA at UCO (d) & 105.6 & 105.7 & 105.4 & 105.7 \\
& $(105.2 ; 106.1)$ & $(104.9 ; 106.4)$ & $(104.8 ; 105.9)$ & $(105.0 ; 106.4)$ \\
BW (g) & 1686.3 & 1819.7 & 1739.5 & 1764.3 \\
& $(1517.8 ; 1854.8)$ & $(1527.9 ; 2111.5)$ & $(1524.0 ; 1955.1)$ & $(1494.1 ; 2034.4)$ \\
brain (g/ kg BW) & 17.6 & 16.2 & $15.0 *$ & 14.8 \\
& $(16.2 ; 18.9)$ & $(14.0 ; 18.3)$ & $(13.4 ; 16.6)$ & $(12.9 ; 16.8)$ \\
hippocampus (mm2) & 8.7 & 8.5 & $4.9 *$ & 4.9 \\
& $(8.0 ; 9.4)$ & $(7.3 ; 9.6)$ & $(4.1 ; 5.6)$ & $(4.1 ; 5.7)$ \\
\hline
\end{tabular}

\section{Results}

\section{Animal characteristics}

To test the therapeutic potential of G-CSF, we randomized 32 preterm sheep fetuses in four different experimental groups (Figure 1). After instrumentation and a recovery period of four days, animals were subjected to $25 \mathrm{~min}$ of (sham) umbilical cord occlusion (UCO) to induce global hypoxia-ischemia (HI). G-CSF was administered during five consecutive days, starting one day before UCO (Figure 1). Fetal body weight and gesta- 
tional age at did not differ significantly between the four experimental groups (Table 1). We assessed mean arterial blood pressure (MABP), fetal heart rate (FHR) and blood gases during UCO to investigate the physiological response during (sham) global $\mathrm{HI}$ in the different experimental groups. MABP (Figure 2A), FHR (Figure 2B), pH (Figure 2C), arterial partial oxygen pressure (Figure 2D) and arterial partial carbon dioxide pressure (Figure 2E) were comparable between the HI-SAL and HI-G-CSF group, indicating that the degree of hypotension, bradycardia, acidosis, hypoxemia and hypercarboxemia was similar in all animals exposed to global HI.
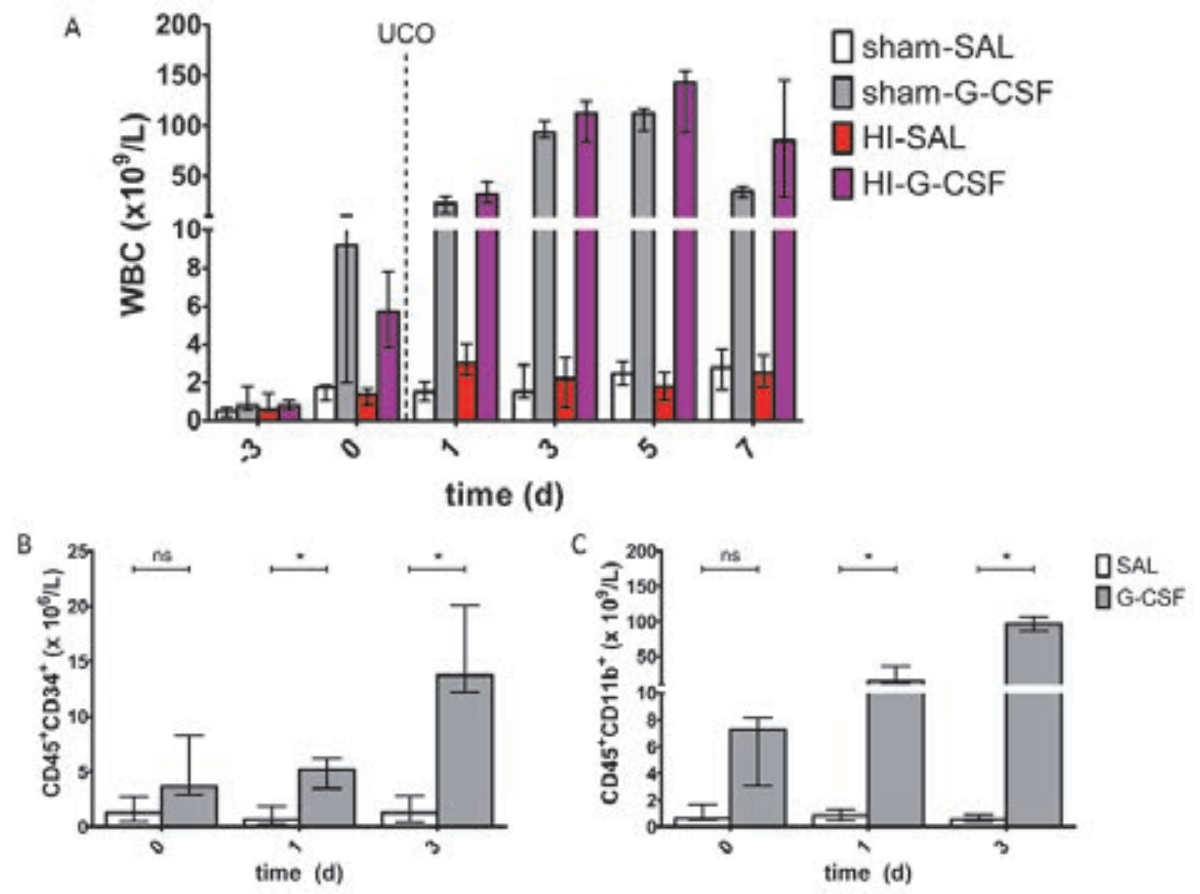

Figure 3. G-CSF induced mobilization of hematopoietic stem cells (HSC) within the therapeutic window of opportunity. (A) G-CSF induced marked mobilization of white blood cells (all treatment groups are shown. (B) G-CSF significantly increased the number of HSC (CD45/CD34 double positive) on experimental day 1 and 3. (C) G-CSF induced significant mobilization of neutrophils (CD45/CD11b double positive). (B-C) Saline treated animals (sham-SAL and HI-SAL) were compared with G-CSF treated animals (sham-G-CSF and HI-G-CSF), since white blood cell mobilization was altered by G-CSF treatment and not global HI. (A-C) medians \pm interquartile ranges (IQR) of $n=5$ animals are depicted. $* P \leq 0.05, \neq P \leq 0.01, \# P \leq 0.001$. SAL = saline, $G-C S F=$ granulocytecolony stimulating factor, $\mathrm{HI}=$ hypoxia-ischemia. 


\section{G-CSF mediated stem cell mobilization}

We assessed white blood cell (WBC) counts in arterial fetal blood to study G-CSF mediated mobilization of these cells. G-CSF induced marked mobilization of white blood cells (Figure 3A), which peaked around experimental day 3, after four doses of G-CSF.

We aimed to mobilize endogenous stem cells within the first hours after global HI, which was considered the therapeutic window of opportunity [9]. Flow cytometry analysis of fetal blood showed that G-CSF did not significantly increase numbers of CD45/CD34 double positive cells on experimental day 0 (SAL vs. G-CSF, P=0.091), but CD45/CD34 double positive cells were significantly increased on experimental day 1 (SAL vs. G-CSF, $\mathrm{P}=0.028$ ) and day 3 (SAL vs. G-CSF, $\mathrm{P}=0.028$ ) (Figure 3B).

These findings indicated that hematopoietic stem cells (HSC) were significantly mobilized 48 hours after the first dose of G-CSF. Since G-CSF therapy was initiated on experimental day -1 , HSC were mobilized within the first 24 hours following global $\mathrm{HI}$, which has previously been reported to correspond with the therapeutic window of opportunity [9]. In addition, flow cytometry demonstrated that G-CSF caused a profound mobilization of $\mathrm{CD} 11 \mathrm{~b}+$ neutrophils, which reached significance 48 hours after the first dose of G-CSF (Figure 3C). As expected, no changes were observed in the CD4+ and CD8+ T-cell subpopulations after G-CSF administration (data not shown).

To study placental transfer of G-CSF, we assessed mobilization of white blood cells in blood of the ewes. The numbers of white blood cells, neutrophils and HSC, were not altered in the maternal blood during the study period (data not shown), indicating that G-CSF, which was administered intravenously to the fetus, did not cross the placenta at sufficient levels to induce mobilization.

\section{G-CSF mediated effects on the spleen}

As previously reported [30], global $\mathrm{HI}$ induced splenic involution in saline treated animals (sham-SAL vs. HI-SAL, $\mathrm{P}=0.034$ ) (Figure $4 \mathrm{~A}$ ), indicating $\mathrm{HI}$-induced mobilization of splenocytes into the circulation. G-CSF significantly increased splenic weight (sham-SAL vs. sham-G-CSF, $\mathrm{P}<0.001$ ) (Figure $4 \mathrm{~A}$ ). Despite the G-CSF mediated increase in splenic weight, global $\mathrm{HI}$ still caused splenic involution in G-CSF treated animals (sham-G-CSF vs. HI-G-CSF, $\mathrm{P}=0.028$ ), indicating that global $\mathrm{HI}$ induced efflux of splenocytes in $\mathrm{G}-\mathrm{CSF}$ treated animals. Immunohistochemical staining of neutrophils in the spleen showed that the area fraction of MPO immunoreactivity was significantly increased after G-CSF administration (sham-SAL vs. sham-G-CSF, $P<0.010$ ) (Figure $4 B$ and $C$ ). The increased number of splenic neutrophils after G-CSF treatment may represent either increased mobilized neutrophils, which are present in the blood-filled red pulpa, or indicate increased myeloid hematopoietic activity, which can still be present in the preterm spleen. In line with observations in the circulation, G-CSF did not alter the number of splenic T-cells (data not shown). 


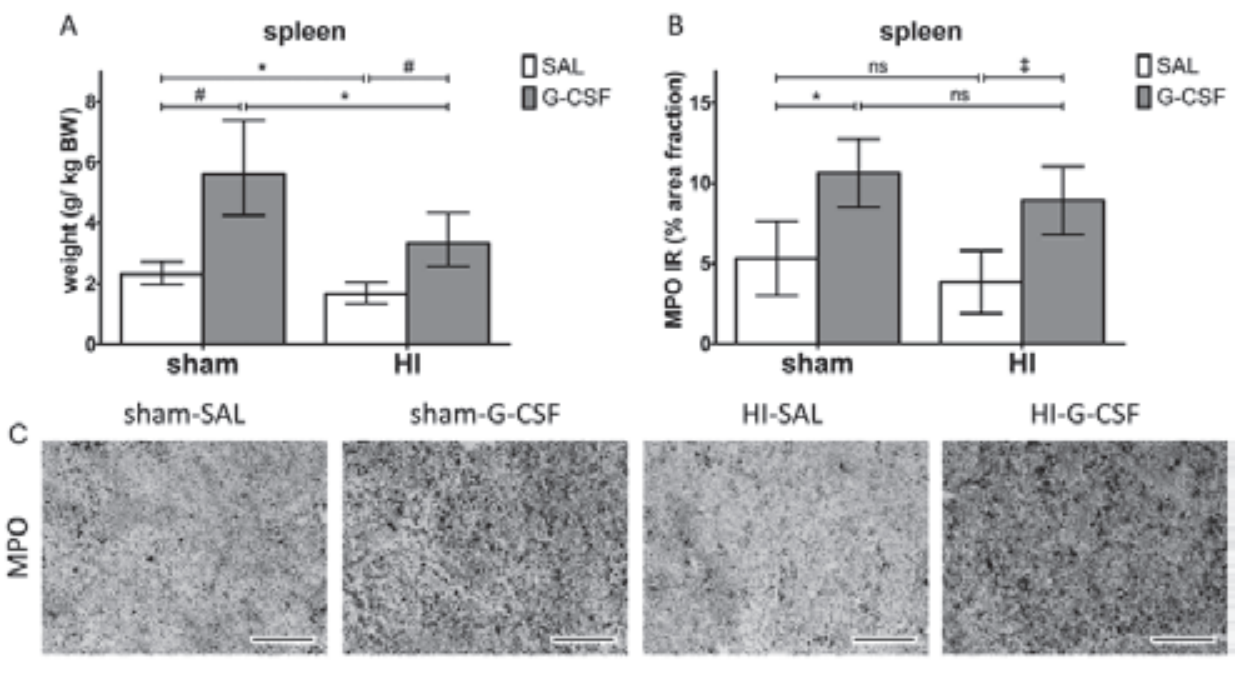

Figure 4. G-CSF increased splenic weight and number of splenic neutrophils. (A) G-CSF caused a significant increase in splenic weight in sham animals and animals exposed to global HI. Global HI induced significant splenic involution in both saline and G-CSF treated animals. Geometric means $\pm 95 \% \mathrm{Cl}$ and levels of significance are depicted, which were calculated with ANOVA (sham-SAL $n=8$, sham-G-CSF $n=8, H I-S A L n=8$, HI-G-CSF $n=8)(B-C)$ G-CSF significantly increased the number of neutrophils in the spleen in sham and $\mathrm{HI}$ conditions. Means $\pm 95 \% \mathrm{Cl}$ and levels of significance are depicted, which were calculated by the random intercept model with all repeated measures (i.e. spleen sections) per animal (sham-SAL $n=6$, sham-G-CSF $n=6$, HI-SAL $n=6, H I-G-C S F n=6) . * P \leq 0.05, \neq P \leq 0.01, \# P \leq 0.001$. SAL = saline, $G$-CSF = granulocyte-colony stimulating factor, $\mathrm{HI}=$ hypoxia-ischemia, $I R=$ immunoreactivity, MPO = myeloperoxidase. Scale bars: 200 $\mu \mathrm{m}$.

\section{G-CSF treatment reduced cerebral inflammation}

The cerebral inflammatory response after global $\mathrm{HI}$ was studied by assessing microglial proliferation using ionized calcium binding adaptor molecule 1 (IBA-1), which is a highly specific marker for resting and activated microglia in sheep [30]. We performed immunohistochemical IBA-1 staining in 6 coronal brain sections at the mid-thalamus/ posterior hippocampus level per animal. Area fraction of IBA-1 immunoreactivity was assessed in six animals per experimental group ( $n=3$ in the sham-G-CSF group). The response of microglia following global $\mathrm{HI}$ was assessed in the subcortical white matter (SCWM) and hippocampus, which are involved in motoric [1] and cognitive function, respectively [39]. 

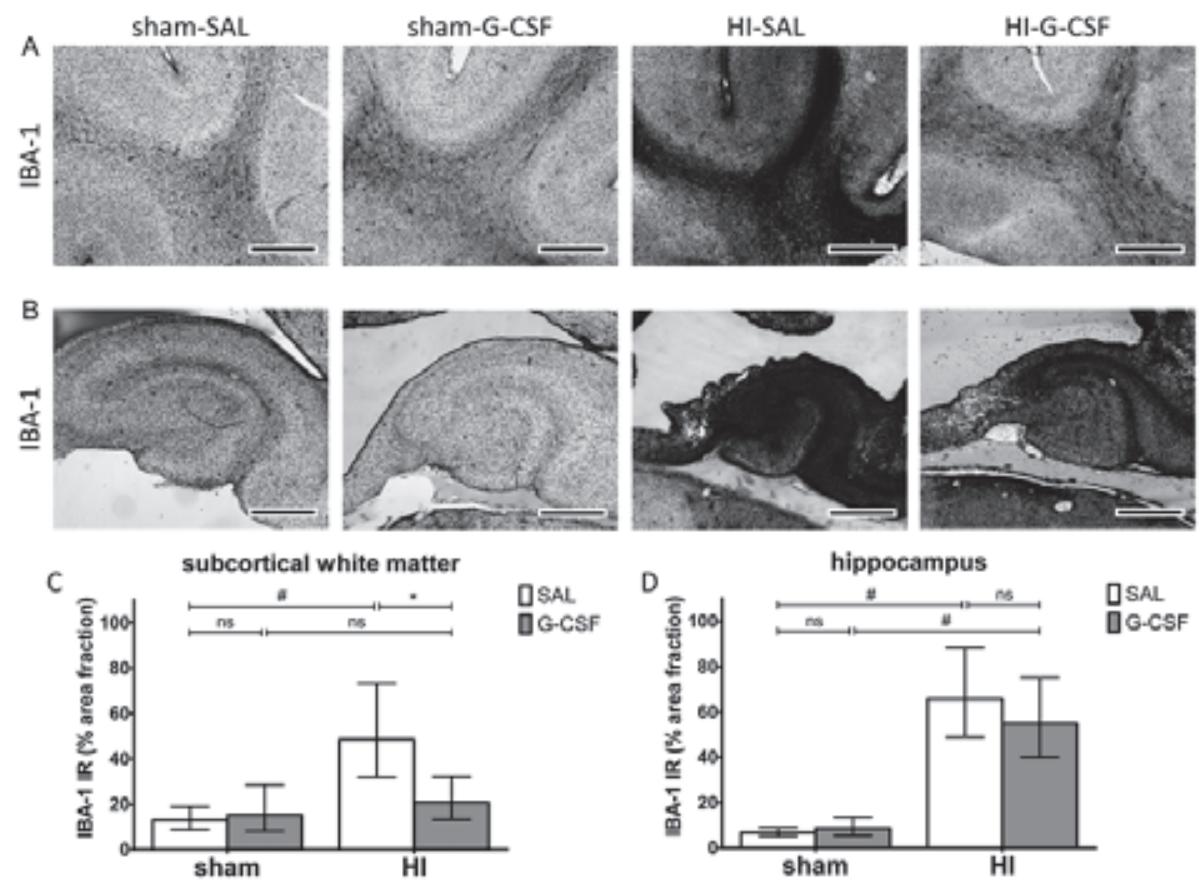

Figure 5. G-CSF reduced cerebral inflammation in the subcortical white matter (SCWM), but not in the hippocampus after global HI. (A) Immunohistochemical IBA-1 staining in the SCWM of the four experimental groups. Global HI induced a profound increase of IBA-1 immunoreactivity, which was significantly reduced by G-CSF. (B) Immunohistochemical IBA-1 staining in the hippocampus of the four experimental groups. Global $H$ l caused profound proliferation of microglia in the hippocampus. G-CSF did not reduce the inflammatory response of microglia in the hippocampus after global HI. (C-D) Area fraction of IBA-1 immunoreactivity in SCWM and hippocampus; geometric means $\pm 95 \% \mathrm{Cl}$ and levels of significance are depicted, which were calculated by the random intercept model with all repeated measures (i.e. brain sections) per animal (shamSAL $n=6$, sham-G-CSF $n=3$, HI-SAL $n=6, H I-G-C S F n=6)$. * $P \leq 0.05, \neq P \leq 0.01, \# P \leq 0.001$. IBA-1 = ionized calcium binding adaptor molecule $1, \mathrm{HI}=$ hypoxia-ischemia, $S A L=$ saline, $\mathrm{G}-\mathrm{CSF}=$ granulocyte-colony stimulating factor, $I R$ = immunoreactivity. Scale bars: $1 \mathrm{~mm}$.

In line with previous results [30], global $\mathrm{HI}$ resulted in a significant (sham-SAL vs. HI-SAL; $\mathrm{P}<0.001$ ) increase of IBA-1 immunoreactivity in the SCWM, indicating profound microglial proliferation in this region (Figure $5 \mathrm{~A}$ and $\mathrm{C}$ ). In accordance, significantly (sham-SAL vs. HI-SAL; $\mathrm{P}<0.001$ ) increased IBA-1 immunoreactivity was found in the hippocampus following global HI (Figure 5B and D). G-CSF significantly (HI-SAL vs. HI-G-CSF; P=0.028) reduced IBA-1 immunoreactivity in the SCWM (Figure 5A and C). G-CSF did not reduce IBA-1 immunoreactivity in the hippocampus (HI-SAL vs. HI-G-CSF; P=0.578) (Figure 5B and $D)$. No differences in IBA-1 immunoreactivity were observed between saline or GCSF treated sham operated animals in the SCWM and hippocampus. 


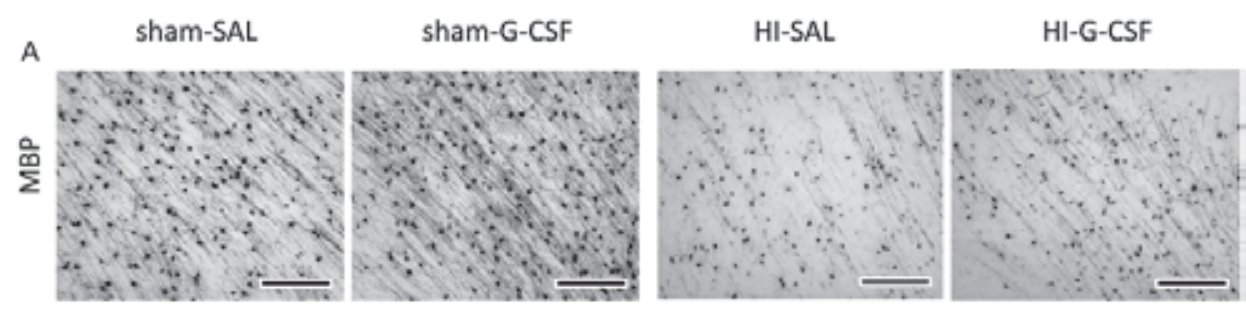

B

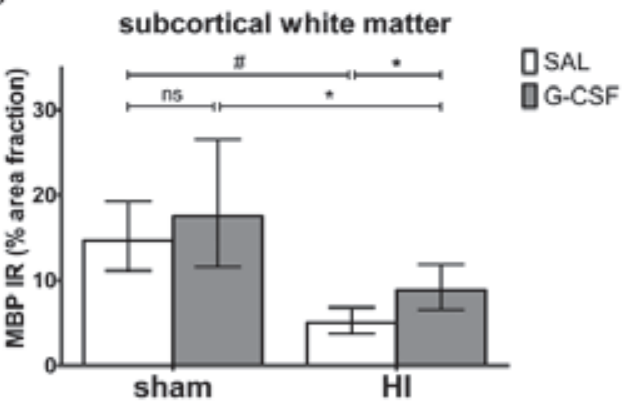

Figure 6. G-CSF reduced white matter injury. (A) Immunohistochemical MBP staining in the SCWM of the four experimental groups. The area fraction of MBP was similar between sham operated animals treated with saline or G-CSF. Global HI induced marked hypomyelination in the SCWM. G-CSF slightly increased myelination of the preterm brain after global HI (B) MBP immunoreactivity in SCWM; geometric means $\pm 95 \%$ $\mathrm{Cl}$ and levels of significance are depicted, which were calculated by the random intercept model with all repeated measures (i.e. brain sections) per animal (sham-SAL $n=6$, sham-G-CSF $n=3, H I-S A L n=6, H I-G-C S F$ $n=6)$. * $P \leq 0.05, \neq P \leq 0.01, \# P \leq 0.001$. MBP = myelin basic protein $1, H I=$ hypoxia-ischemia, $S A L=$ saline, $G-C S F$ = granulocyte-colony stimulating factor, $I R=$ immunoreactivity. Scale bars: $200 \mu \mathrm{m}$.

\section{G-CSF reduced white matter injury}

We studied histological white matter injury by assessing myelin binding protein (MBP) immunoreactivity in the SCWM. We performed immunohistochemical MBP staining in 6 coronal brain sections at the mid-thalamus/ posterior hippocampus level per animal. MBP immunoreactivity was assessed in six animals per experimental group ( $n=3$ in the sham-G-CSF group).

Global HI significantly (sham-SAL vs. HI-SAL; $\mathrm{P}<0.001$ ) reduced MBP immunoreactivity in the SCWM, indicating marked demyelination in this region (Figure 6A and B). GCSF treatment significantly increased MBP immunoreactivity (HI-SAL vs. HI-G-CSF; $\mathrm{P}=0.032$ ) No differences in MBP immunoreactivity in the SCWM were observed between sham operated animals treated with saline or G-CSF (Figure 6A and B). 


\section{G-CSF treatment did not reduce seizure burden following global HI}

Global HI caused high electrographical seizure activity in the first 72 hours following the hypoxic-ischemic insult. Analysis of the first 72 hours showed that global $\mathrm{HI}$ significantly increased seizure burden (sham-SAL vs. HI-SAL: day 0; $\mathrm{P}=0.010$, day $1 ; \mathrm{P}=0.028$, day 2; $\mathrm{P}=0.012$ ). However, G-CSF treatment did not reduce the seizure burden after global $\mathrm{HI}$ (HI-SAL vs. HI-G-CSF; day 0; $\mathrm{P}=0.955$, day $1 ; \mathrm{P}=0.955$, day $2 ; \mathrm{P}=0.164$ ). No differences in electrographical seizure activity were observed between sham operated animals treated with saline or G-CSF (Figure 7).

Furthermore, we studied neuronal injury by assessing brain weight and size of the hippocampus. Global HI induced profound atrophy of the brain (sham-SAL vs. HI-SAL; $\mathrm{P}=0.041$ ) and hippocampus (sham-SAL vs. HI-SAL; $\mathrm{P}<0.001$ ). G-CSF did not prevent global HI-induced atrophy in the brain (HI-SAL vs. HI-G-CSF; $\mathrm{P}=0.981$ ) or the hippocampus (HI-SAL vs. HI-G-CSF; P=0.983) (Table 1). Brain weight and hippocampal area were significantly related (Pearson $r=0.60, P=0.002$ ).
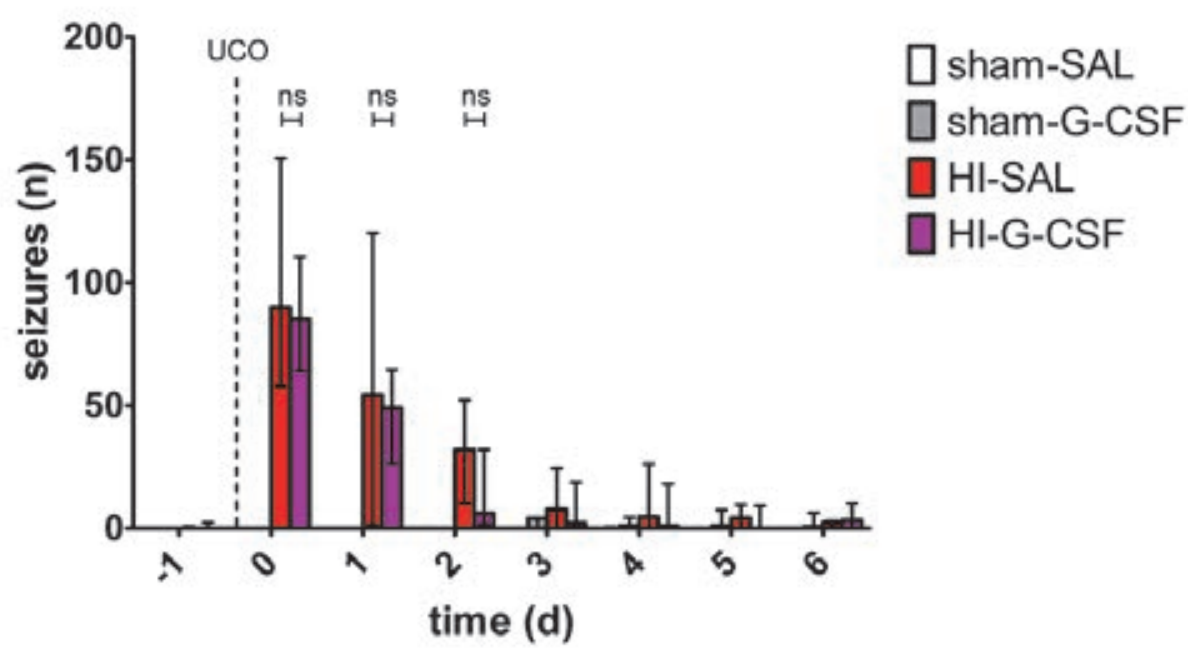

Figure 7. G-CSF did not reduce seizure burden after global HI. Global HI induced marked electrographic seizure activity, which peaked in the first 72 hours after the insult. G-CSF treatment did not reduce the number of seizures after global HI. Medians \pm interquartile ranges (IQR) and levels of significance are depicted, which were calculated by Mann-Whitney test (sham-SAL n=6, sham-G-CSF $n=4$, HI-SAL $n=6, H I-G$ -

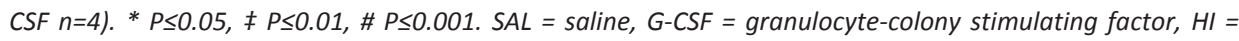
hypoxia-ischemia.

\section{Neutrophil invasion in the preterm brain after global HI was not enhanced by G-CSF}

To study whether the massive G-CSF mediated mobilization of neutrophils would cause a proportional influx of neutrophils in the brain, we qualitatively assessed brain sections for MPO-positive neutrophils. In the sham-G-CSF group, we observed a marked 
increase in intravascular MPO-positive cells. However, the intravascular neutrophils observed in sham-G-CSF animals did not extravasate (Figure 8), indicating that the BBB was not permeable for the abundantly available neutrophils in the non-ischemic preterm brain. In accordance with our previous findings, we observed an increase in perivascular and interstitial neutrophils after global $\mathrm{HI}$ in saline treated animals (Figure 8). In line with previous findings [40], G-CSF treatment did not enhance neutrophil invasion after global $\mathrm{HI}$, despite the high numbers of neutrophils present inside the cerebral vasculature (Figure 8).
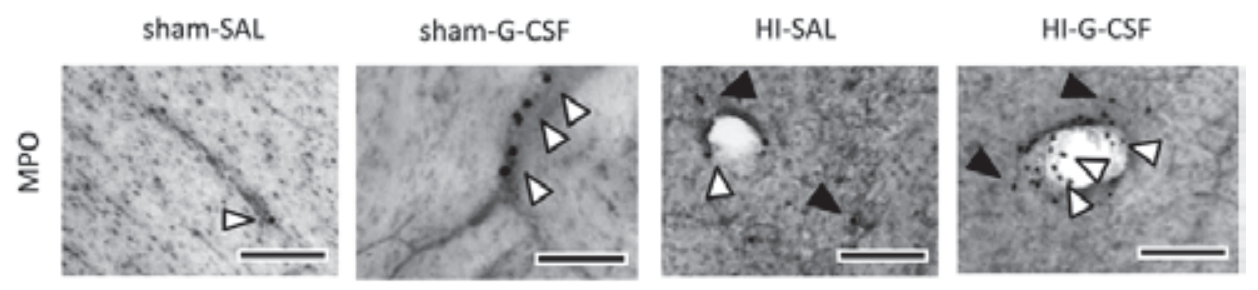

Figure 8. G-CSF did not enhance neutrophil invasion in the preterm brain after global HI. G-CSF increased the number of intravascular (open arrows) in animals exposed to sham and global HI. Global HI increased invasion of neutrophils (black arrows), which was not further enhanced by G-CSF. Scale bars: $100 \mu \mathrm{m}$. SAL = saline, G-CSF = granulocyte-colony stimulating factor, $\mathrm{HI}=$ hypoxia-ischemia .

\section{Discussion}

Preterm infants with hypoxic-ischemic encephalopathy (HIE) often experience severe disorders in motor and cognitive function, for which there is no effective cure [1]. Although granulocyte-colony stimulating factor (G-CSF) showed promising results in adult stroke $[16,33]$, there is conflicting data from rodent studies on the neuroprotective potential of G-CSF in neonatal brain after focal $\mathrm{HI}[22,23]$. In this study, we therefore assessed the neuroprotective potential of G-CSF treatment in the preterm brain in a translational ovine model of global hypoxic-ischemic injury. We aimed at mobilizing bone marrow-derived stem cells with G-CSF within the acute phase after global $\mathrm{HI}$ and therefore started G-CSF treatment 24 hours before the global hypoxic-ischemic insult.

We showed that human recombinant G-CSF effectively mobilized ovine hematopoietic stem cells (HSC) within the first 24 hours after global HI. These findings confirmed the presence of bone-marrow derived HSC in the systemic circulation in the acute phase following global $\mathrm{HI}$, which has previously been suggested to coincide with the therapeutic window of opportunity for the repair of hypoxic-ischemic preterm brain injury [9]. HSC, mobilized by G-CSF, have been shown to migrate to the ischemic brain [20]. Although differentiation of HSC into neurons most likely occurs rarely [41], HSC have been shown to support neuronal repair by secreting neurotrophic factors in the ischemic brain [42]. Furthermore, G-CSF has been reported to promote the transition of 
bone marrow-derived neural cells into the brain [12, 43]. Interestingly, the neuroprotective effect of G-CSF has been shown to be potentiated by additional treatment with stem cell factor (SCF) $[12,34]$. Since G-CSF and SCF act synergistically on mobilization and proliferation of bone marrow-derived stem cells [44-46], the potentiated neuroprotective effect was most likely explained by enhanced mobilization of hematopoietic stem cells and neural stem cells from the bone marrow. These findings underline that mobilization of endogenous bone-marrow derived stem cells is a feasible strategy to treat hypoxic-ischemic brain injury [12, 34, 43]

Despite effective mobilization of fetal HSC, administration of G-CSF to the fetus did not mobilize HSC in maternal blood, indicating that G-CSF did not pass the placenta at sufficient levels to induce mobilization. These findings indicate that a reversed administration route (mother to fetus) in the case of suspected intrauterine fetal asphyxia would most likely be ineffective in mobilizing neuroprotective fetal HSC.

We showed that the cerebral inflammatory response after global $\mathrm{HI}$, initiated by microglia, was attenuated by G-CSF treatment. Although the mechanisms of action of G-CSF are not fully understood, the anti-inflammatory effect of G-CSF may be attributed to several mechanisms. First of all, G-CSF has been shown to induce tolerance of Tcells [47-50], which have previously been reported to aggravate cerebral inflammation after invading the ischemic brain $[9,51-53]$. Furthermore, previous studies demonstrated that G-CSF treatment increased the number of regulatory T cells $[48,54,55]$, myeloid suppressor cells [54] and tolerogenic dendritic cells [50, 56]. These antiinflammatory effects of G-CSF on the peripheral immune system may dampen the peripheral inflammatory response after global $\mathrm{HI}$, consequently reducing the second inflammatory hit to the preterm brain characterized by invading immune effector cells. In line with this concept, we found that cerebral invasion of neutrophils after global $\mathrm{HI}$ was not enhanced by G-CSF, despite the marked G-CSF-mediated mobilization of these immune effector cells.

Furthermore, we studied white matter injury since this is the clinical hallmark of HIE in preterm infants. We demonstrated that G-CSF reduced hypomyelination after global HI, which may be secondary to the G-CSF-mediated reduction of microglial activation after global $\mathrm{HI}$, since it has been previously shown that activated microglia are injurious to pre-oligodendrocytes [57]. A second mechanism for increased myelination by G-CSF may be caused by G-CSF-mediated proliferation of intrinsic neural stem cells, which can replenish pre-oligodendrocytes $[12,58]$.

In the current study, G-CSF did not reduce the seizure burden after global $\mathrm{HI}$, indicating that neuronal function was not improved by this treatment. These findings are in line with the work of Schlager et al. showing that systemic G-CSF did not improve longterm motor and cognitive function in a rat model of neonatal hypoxic-ischemic brain injury [22]. In contrast, other experimental studies have reported that G-CSF improved function after cerebral ischemia [25] and protected against neuronal injury by activating the anti-apoptotic pathway [58-60] and stimulating angiogenesis [61-63]. 
G-CSF has been shown to be neuroprotective in rodents models of stroke [33, 58, 6368] and is currently being investigated in stroke patients [16-20]. Nevertheless, there is conflicting evidence on the neuroprotective potential of G-CSF in the neonatal brain exposed to focal hypoxia-ischemia [21-26, 69]. This discrepancy may be explained by distinct effects of G-CSF on the developing brain in comparison to the adult brain and underlines the need for an animal model that is closely similar to the human situation in terms of neurodevelopment and the mechanism of injury when studying G-CSF in the preterm brain. Despite the fact that our data showed effective mobilization of HSC in preterm sheep, it is conceivable that in the preterm environment expression of the GCSF receptor on precursor cells in the bone marrow and neural cells in the brain has not yet reached its mature state and therefore mobilization of HSC and neuroprotection are suboptimal. A limitation of the treatment protocol in our study was that G-CSF administration was started prior to injury. Although this regimen was deliberately chosen as a proof of principle to mobilize endogenous stem cells within the acute time period following global $\mathrm{HI}$, it did not allow assessment of the post injury treatment effect of GCSF, which would be clinically more relevant. Furthermore, we based the dosage of GCSF on previous studies that showed neuroprotective effects of G-CSF treatment in focal cerebral ischemia of the adult brain. The distinct causes of injury (global versus focal ischemia) and the different developmental stages of the adult versus the preterm brain may require different dosing strategies and therefore the dosage used in our study may be suboptimal.

In conclusion, we report that G-CSF treatment resulted in mobilization of endogenous stem cells, which was associated with decreased cerebral inflammation and reduced white matter injury after global HI. G-CSF treatment, however, did not protect against acute $\mathrm{HI}$-induced cerebral dysfunction as shown by seizure analysis. Our study shows that G-CSF treatment has the potential to attenuate structural injury in the preterm brain following global HI. Follow-up studies need to assess whether the observed structural improvements of the ischemic preterm brain mediated by G-CSF result in improved function on the long term, despite the fact that G-CSF did not reduce the initial seizure burden after global HI. Before any clinical translation, these studies should also address the mode of action of G-CSF in a developing environment similar to the human situation and optimize dosing and timing of administration. 


\section{Chapter 5}

\section{References}

1. Volpe JJ: Neurology of the Newborn. 5th edn. Philadelphia: Elsevier-Saunders 2008.

2. Buser JR, Maire J, Riddle A, Gong X, Nguyen T, Nelson K, Luo NL, Ren J, Struve J, Sherman LS, Miller SP, Chau V, Hendson G, Ballabh P, Grafe MR, Back SA: Arrested preoligodendrocyte maturation contributes to myelination failure in premature infants. Ann Neurol 2012, 71:93-109.

3. Volpe JJ, Kinney HC, Jensen FE, Rosenberg PA: The developing oligodendrocyte: key cellular target in brain injury in the premature infant. Int J Dev Neurosci 2011, 29:423-440.

4. Back SA, Luo NL, Borenstein NS, Levine JM, Volpe JJ, Kinney HC: Late oligodendrocyte progenitors coincide with the developmental window of vulnerability for human perinatal white matter injury. $J$ Neurosci 2001, 21:1302-1312.

5. Back SA, Han BH, Luo NL, Chricton CA, Xanthoudakis S, Tam J, Arvin KL, Holtzman DM: Selective vulnerability of late oligodendrocyte progenitors to hypoxia-ischemia. J Neurosci 2002, 22:455-463.

6. Gortner L, Felderhoff-Muser U, Monz D, Bieback K, Kluter H, Jellema RK, Kramer BW, Keller M, Reiss I, Horn PA, Giebel B: Regenerative therapies in neonatology: clinical perspectives. Klin Padiatr 2012, 224:233-240.

7. Bennet L, Tan S, Van den Heuij L, Derrick M, Groenendaal F, van Bel F, Juul S, Back SA, Northington F, Robertson NJ, Mallard C, Gunn AJ: Cell therapy for neonatal hypoxia-ischemia and cerebral palsy. Ann Neurol 2012, 71:589-600.

8. van Velthoven $\mathrm{CT}$, Kavelaars A, Heijnen $\mathrm{CJ}$ : Mesenchymal stem cells as a treatment for neonatal ischemic brain damage. Pediatr Res 2012, 71:474-481.

9. Jellema RK, Wolfs TG, Lima Passos V, Zwanenburg A, Ophelders DR, Kuypers E, Hopman AH, Dudink J, Steinbusch HW, Andriessen P, Germeraad WT, Vanderlocht J, Kramer BW: Mesenchymal stem cells induce T-cell tolerance and protect the preterm brain after global hypoxia-ischemia. PLoS One 2013, 8:e73031.

10. van Velthoven CTJ, Kavelaars A, van Bel F, Heijnen CJ: Regeneration of the ischemic brain by engineered stem cells: Fuelling endogenous repair processes. Brain Res Rev 2009, 61:1-13.

11. Titomanlio L, Kavelaars A, Dalous J, Mani S, El Ghouzzi V, Heijnen C, Baud O, Gressens P: Stem cell therapy for neonatal brain injury: Perspectives and Challenges. Ann Neurol 2011, 70:698-712.

12. Kawada H, Takizawa S, Takanashi T, Morita Y, Fujita J, Fukuda K, Takagi S, Okano H, Ando K, Hotta T: Administration of hematopoietic cytokines in the subacute phase after cerebral infarction is effective for functional recovery facilitating proliferation of intrinsic neural stem/progenitor cells and transition of bone marrow-derived neuronal cells. Circulation 2006, 113:701-710.

13. Carr R, Modi N, Dore C: G-CSF and GM-CSF for treating or preventing neonatal infections. Cochrane Database Syst Rev 2003:CD003066.

14. Donini M, Fontana S, Savoldi G, Vermi W, Tassone L, Gentili F, Zenaro E, Ferrari D, Notarangelo LD, Porta F, Facchetti F, Dusi S, Badolato R: G-CSF treatment of severe congenital neutropenia reverses neutropenia but does not correct the underlying functional deficiency of the neutrophil in defending against microorganisms. Blood 2007, 109:4716-4723.

15. Kuhn P, Messer J, Paupe A, Espagne S, Kacet N, Mouchnino G, Klosowski S, Krim G, Lescure S, Le Bouedec S, Meyer P, Astruc D: A multicenter, randomized, placebo-controlled trial of prophylactic recombinant granulocyte-colony stimulating factor in preterm neonates with neutropenia. $J$ Pediatr 2009, 155:324-330 e321.

16. Bath PM, Sprigg N: Colony stimulating factors (including erythropoietin, granulocyte colony stimulating factor and analogues) for stroke. Cochrane Database Syst Rev 2007:CD005207.

17. Schabitz WR, Schneider A: Developing granulocyte-colony stimulating factor for the treatment of stroke: current status of clinical trials. Stroke 2006, 37:1654; author reply 1655.

18. Shyu WC, Lin SZ, Lee CC, Liu DD, Li H: Granulocyte colony-stimulating factor for acute ischemic stroke: a randomized controlled trial. CMAJ 2006, 174:927-933. 
19. Sprigg N, Bath PM, Zhao L, Willmot MR, Gray L, Walker MF, Dennis MS, Russell N: Granulocyte-colonystimulating factor mobilizes bone marrow stem cells in patients with subacute ischemic stroke: the Stem cell Trial of recovery EnhanceMent after Stroke (STEMS) pilot randomized, controlled trial (ISRCTN 16784092). Stroke 2006, 37:2979-2983.

20. England TJ, Abaei M, Auer DP, Lowe J, Jones DR, Sare G, Walker M, Bath PM: Granulocyte-colony stimulating factor for mobilizing bone marrow stem cells in subacute stroke: the stem cell trial of recovery enhancement after stroke 2 randomized controlled trial. Stroke 2012, 43:405-411.

21. Keller M, Simbruner G, Gorna A, Urbanek M, Tinhofer I, Griesmaier E, Sarkozy G, Schwendimann L, Gressens P: Systemic application of granulocyte-colony stimulating factor and stem cell factor exacerbates excitotoxic brain injury in newborn mice. Pediatr Res 2006, 59:549-553.

22. Schlager GW, Griesmaier E, Wegleiter K, Neubauer V, Urbanek M, Kiechl-Kohlendorfer U, FelderhoffMueser U, Keller M: Systemic G-CSF treatment does not improve long-term outcomes after neonatal hypoxic-ischaemic brain injury. Exp Neurol 2011, 230:67-74.

23. Yata K, Matchett GA, Tsubokawa T, Tang J, Kanamaru K, Zhang JH: Granulocyte-colony stimulating factor inhibits apoptotic neuron loss after neonatal hypoxia-ischemia in rats. Brain Res 2007, 1145:227-238.

24. Kim BR, Shim JW, Sung DK, Kim SS, Jeon GW, Kim MJ, Chang YS, Park WS, Choi ES: Granulocyte stimulating factor attenuates hypoxic-ischemic brain injury by inhibiting apoptosis in neonatal rats. Yonsei Med J 2008, 49:836-842.

25. Fathali N, Lekic T, Zhang JH, Tang J: Long-term evaluation of granulocyte-colony stimulating factor on hypoxic-ischemic brain damage in infant rats. Intensive Care Med 2010, 36:1602-1608.

26. Chen WF, Hsu JH, Lin CS, Jong YJ, Yang CH, Huang LT, Yang SN: Granulocyte-colony stimulating factor alleviates perinatal hypoxia-induced decreases in hippocampal synaptic efficacy and neurogenesis in the neonatal rat brain. Pediatr Res 2011, 70:589-595.

27. Back SA, Riddle A, Hohimer AR: Role of instrumented fetal sheep preparations in defining the pathogenesis of human periventricular white-matter injury. J Child Neurol 2006, 21:582-589.

28. Hagberg H, Peebles D, Mallard C: Models of white matter injury: comparison of infectious, hypoxicischemic, and excitotoxic insults. Ment Retard Dev Disabil Res Rev 2002, 8:30-38.

29. Wolfs TG, Jellema RK, Turrisi G, Becucci E, Buonocore G, Kramer BW: Inflammation-induced immune suppression of the fetus: a potential link between chorioamnionitis and postnatal early onset sepsis. $J$ Matern Fetal Neonatal Med 2012, 25 Suppl 1:8-11.

30. Jellema RK, Lima Passos V, Zwanenburg A, Ophelders DR, De Munter S, Vanderlocht J, Germeraad WT, Kuypers E, Collins JJ, Cleutjens JP, Jennekens W, Gavilanes AW, Seehase M, Vles HJ, Steinbusch H, Andriessen P, Wolfs TG, Kramer BW: Cerebral inflammation and mobilization of the peripheral immune system following global hypoxia-ischemia in preterm sheep. J Neuroinflammation 2013, 10:13.

31. Gunn AJ, Bennet L: Fetal hypoxia insults and patterns of brain injury: insights from animal models. Clin Perinatol 2009, 36:579-593.

32. Almeida-Porada G, Porada C, Gupta N, Torabi A, Thain D, Zanjani ED: The human-sheep chimeras as a model for human stem cell mobilization and evaluation of hematopoietic grafts' potential. Exp Hematol 2007, 35:1594-1600.

33. Minnerup J, Heidrich J, Wellmann J, Rogalewski A, Schneider A, Schabitz WR: Meta-analysis of the efficacy of granulocyte-colony stimulating factor in animal models of focal cerebral ischemia. Stroke 2008, 39:1855-1861.

34. Doycheva D, Shih G, Chen H, Applegate R, Zhang JH, Tang J: Granulocyte-colony stimulating factor in combination with stem cell factor confers greater neuroprotection after hypoxic-ischemic brain damage in the neonatal rats than a solitary treatment. Trans/ Stroke Res 2013, 4:171-178.

35. Niemarkt HJ, Jennekens W, Maartens IA, Wassenberg T, van Aken M, Katgert T, Kramer BW, Gavilanes AW, Zimmermann $\amalg$, Bambang Oetomo S, Andriessen P: Multi-channel amplitude-integrated EEG characteristics in preterm infants with a normal neurodevelopment at two years of corrected age. Early Hum Dev 2012, 88:209-216. 


\section{Chapter 5}

36. Jennekens W, Ruijs LS, Lommen CM, Niemarkt HJ, Pasman JW, van Kranen-Mastenbroek VH, Wijn PF, van Pul C, Andriessen P: Automatic burst detection for the EEG of the preterm infant. Physiol Meas 2011, 32:1623-1637.

37. Niemarkt HJ, Andriessen P, Peters CH, Pasman JW, Zimmermann LJ, Bambang Oetomo S: Quantitative analysis of maturational changes in EEG background activity in very preterm infants with a normal neurodevelopment at 1 year of age. Early Hum Dev 2010, 86:219-224.

38. Porada CD, Harrison-Findik DD, Sanada C, Valiente V, Thain D, Simmons PJ, Almeida-Porada G, Zanjani ED: Development and characterization of a novel CD34 monoclonal antibody that identifies sheep hematopoietic stem/progenitor cells. Exp Hematol 2008, 36:1739-1749.

39. Abernethy $\amalg$, Cooke RW, Foulder-Hughes L: Caudate and hippocampal volumes, intelligence, and motor impairment in 7-year-old children who were born preterm. Pediatr Res 2004, 55:884-893.

40. Strecker JK, Sevimli S, Schilling M, Klocke R, Nikol S, Schneider A, Schabitz WR: Effects of G-CSF treatment on neutrophil mobilization and neurological outcome after transient focal ischemia. Exp Neurol 2010, 222:108-113.

41. Hess DC, Abe T, Hill WD, Studdard AM, Carothers J, Masuya M, Fleming PA, Drake CJ, Ogawa M: Hematopoietic origin of microglial and perivascular cells in brain. Exp Neurol 2004, 186:134-144.

42. Yanqing Z, Yu-Min L, Jian Q, Bao-Guo X, Chuan-Zhen L: Fibronectin and neuroprotective effect of granulocyte colony-stimulating factor in focal cerebral ischemia. Brain Res 2006, 1098:161-169.

43. Corti S, Locatelli F, Strazzer S, Salani S, Del Bo R, Soligo D, Bossolasco P, Bresolin N, Scarlato G, Comi GP: Modulated generation of neuronal cells from bone marrow by expansion and mobilization of circulating stem cells with in vivo cytokine treatment. Exp Neurol 2002, 177:443-452.

44. Gabrilove JL, White K, Rahman Z, Wilson EL: Stem cell factor and basic fibroblast growth factor are synergistic in augmenting committed myeloid progenitor cell growth. Blood 1994, 83:907-910.

45. McNiece IK, Langley KE, Zsebo KM: Recombinant human stem cell factor synergises with GM-CSF, GCSF, IL-3 and epo to stimulate human progenitor cells of the myeloid and erythroid lineages. Exp Hematol 1991, 19:226-231.

46. Hess DA, Levac KD, Karanu FN, Rosu-Myles M, White MJ, Gallacher L, Murdoch B, Keeney M, Ottowski P, Foley R, Chin-Yee I, Bhatia M: Functional analysis of human hematopoietic repopulating cells mobilized with granulocyte colony-stimulating factor alone versus granulocyte colony-stimulating factor in combination with stem cell factor. Blood 2002, 100:869-878.

47. Xiao BG, Lu CZ, Link H: Cell biology and clinical promise of G-CSF: immunomodulation and neuroprotection. J Cell Mol Med 2007, 11:1272-1290.

48. Rutella S, Pierelli L, Bonanno G, Sica S, Ameglio F, Capoluongo E, Mariotti A, Scambia G, d'Onofrio G, Leone $\mathrm{G}$ : Role for granulocyte colony-stimulating factor in the generation of human T regulatory type 1 cells. Blood 2002, 100:2562-2571.

49. Pan L, Delmonte J, Jr., Jalonen CK, Ferrara JL: Pretreatment of donor mice with granulocyte colonystimulating factor polarizes donor $\mathrm{T}$ lymphocytes toward type-2 cytokine production and reduces severity of experimental graft-versus-host disease. Blood 1995, 86:4422-4429.

50. Klangsinsirikul P, Russell NH: Peripheral blood stem cell harvests from G-CSF-stimulated donors contain a skewed Th2 CD4 phenotype and a predominance of type 2 dendritic cells. Exp Hematol 2002, 30:495501.

51. Gelderblom M, Leypoldt F, Steinbach K, Behrens D, Choe CU, Siler DA, Arumugam TV, Orthey E, Gerloff C, Tolosa E, Magnus T: Temporal and spatial dynamics of cerebral immune cell accumulation in stroke. Stroke 2009, 40:1849-1857.

52. Shichita T, Sugiyama Y, Ooboshi H, Sugimori H, Nakagawa R, Takada I, Iwaki T, Okada Y, lida M, Cua DJ, Iwakura Y, Yoshimura A: Pivotal role of cerebral interleukin-17-producing gammadeltaT cells in the delayed phase of ischemic brain injury. Nat Med 2009, 15:946-950.

53. Winerdal M, Winerdal ME, Kinn J, Urmaliya V, Winqvist O, Aden U: Long lasting local and systemic inflammation after cerebral hypoxic ischemia in newborn mice. PLoS One 2012, 7:e36422. 
54. Adeegbe D, Serafini P, Bronte V, Zoso A, Ricordi C, Inverardi L: In Vivo Induction of Myeloid Suppressor Cells and CD4(+)Foxp3(+) T Regulatory Cells Prolongs Skin Allograft Survival in Mice. Cell Transplant 2011, 20:941-954.

55. Zou L, Barnett B, Safah H, Larussa VF, Evdemon-Hogan M, Mottram P, Wei S, David O, Curiel TJ, Zou W: Bone marrow is a reservoir for CD4+CD25+ regulatory T cells that traffic through CXCL12/CXCR4 signals. Cancer Res 2004, 64:8451-8455.

56. Arpinati M, Green CL, Heimfeld S, Heuser JE, Anasetti C: Granulocyte-colony stimulating factor mobilizes Thelper 2-inducing dendritic cells. Blood 2000, 95:2484-2490.

57. Back SA, Luo NL, Mallinson RA, O'Malley JP, Wallen LD, Frei B, Morrow JD, Petito CK, Roberts CT, Jr., Murdoch GH, Montine TJ: Selective vulnerability of preterm white matter to oxidative damage defined by F2-isoprostanes. Ann Neurol 2005, 58:108-120.

58. Schneider A, Kruger C, Steigleder T, Weber D, Pitzer C, Laage R, Aronowski J, Maurer MH, Gassler N, Mier W, Hasselblatt M, Kollmar R, Schwab S, Sommer C, Bach A, Kuhn HG, Schabitz WR: The hematopoietic factor G-CSF is a neuronal ligand that counteracts programmed cell death and drives neurogenesis. J Clin Invest 2005, 115:2083-2098.

59. Harada M, Qin Y, Takano H, Minamino T, Zou Y, Toko H, Ohtsuka M, Matsuura K, Sano M, Nishi J, Iwanaga K, Akazawa H, Kunieda T, Zhu W, Hasegawa H, Kunisada K, Nagai T, Nakaya H, YamauchiTakihara K, Komuro I: G-CSF prevents cardiac remodeling after myocardial infarction by activating the Jak-Stat pathway in cardiomyocytes. Nat Med 2005, 11:305-311.

60. Shuai K: Modulation of STAT signaling by STAT-interacting proteins. Oncogene 2000, 19:2638-2644.

61. Hess DC, Hill WD, Martin-Studdard A, Carroll J, Brailer J, Carothers J: Bone marrow as a source of endothelial cells and NeuN-expressing cells After stroke. Stroke 2002, 33:1362-1368.

62. Ohki Y, Heissig B, Sato Y, Akiyama H, Zhu Z, Hicklin DJ, Shimada K, Ogawa H, Daida H, Hattori K, Ohsaka A: Granulocyte colony-stimulating factor promotes neovascularization by releasing vascular endothelial growth factor from neutrophils. Faseb J 2005, 19:2005-2007.

63. Lee ST, Chu K, Jung KH, Ko SY, Kim EH, Sinn DI, Lee YS, Lo EH, Kim M, Roh JK: Granulocyte colonystimulating factor enhances angiogenesis after focal cerebral ischemia. Brain Res 2005, 1058:120-128.

64. Gibson CL, Bath PM, Murphy SP: G-CSF reduces infarct volume and improves functional outcome after transient focal cerebral ischemia in mice. J Cereb Blood Flow Metab 2005, 25:431-439.

65. Gibson CL, Jones NC, Prior MJ, Bath PM, Murphy SP: G-CSF suppresses edema formation and reduces interleukin-1beta expression after cerebral ischemia in mice. J Neuropathol Exp Neurol 2005, 64:763769.

66. Schabitz WR, Kollmar R, Schwaninger M, Juettler E, Bardutzky J, Scholzke MN, Sommer C, Schwab S: Neuroprotective effect of granulocyte colony-stimulating factor after focal cerebral ischemia. Stroke 2003, 34:745-751.

67. Shyu WC, Lin SZ, Yang HI, Tzeng YS, Pang CY, Yen PS, Li H: Functional recovery of stroke rats induced by granulocyte colony-stimulating factor-stimulated stem cells. Circulation 2004, 110:1847-1854.

68. Six I, Gasan G, Mura E, Bordet R: Beneficial effect of pharmacological mobilization of bone marrow in experimental cerebral ischemia. Eur J Pharmacol 2003, 458:327-328.

69. Charles MS, Ostrowski RP, Manaenko A, Duris K, Zhang JH, Tang J: Role of the pituitary-adrenal axis in granulocyte-colony stimulating factor-induced neuroprotection against hypoxia-ischemia in neonatal rats. Neurobiol Dis 2012, 47:29-37. 

Chapter 6

\section{General discussion}

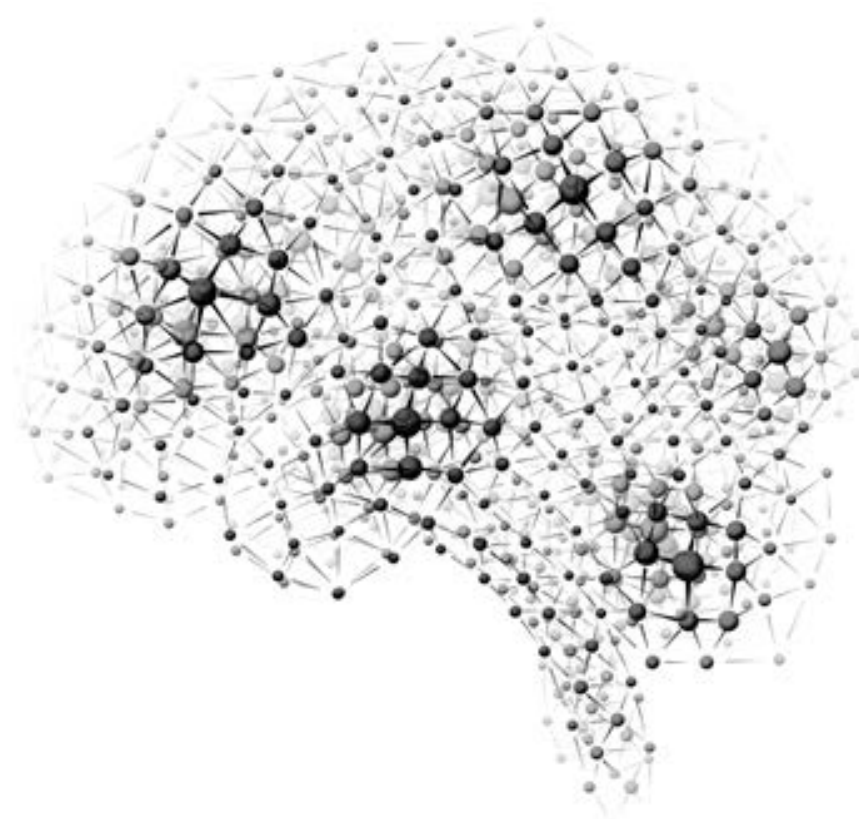


Hypoxic-ischemic encephalopathy (HIE) in preterm infants is associated with high morbidity, for which no therapeutic cure is available. Cell-based therapy is a promosing candidate to treat preterm infants suffering from hypoxic-ischemic brain injury. In this thesis the neuroprotective potential of cell-based therapy in the hypoxic-ischemic preterm brain was explored. For this purpose we established and validated a translational ovine model, which adequately mimicks the biology of the human preterm brain and the etiology of global hypoxia-ischemia.

\section{Impaired immature cerebrovascular regulatory system}

In chapter 2 we validated the translational model by assessing longitudinal function of the baroreceptor reflex in fetal sheep after 25 minutes of umbilical cord occlusion. The baroreflex is a vital part of the cerebrovascular autoregulatory system, which maintains adequate cerebral perfusion by adapting heart rate, myocardial contraction and vascular resistance when circulatory homeostasis is disturbed [1]. We hypothesized that adequate baroreflex function would be persistently disturbed by transient umbilical cord occlusion in fetal sheep. Our results confirmed our hypothesis. We showed that global hypoxia-ischemia disturbed optimal baroreflex function (i.e. heart rate mediated blood pressure control) as evidenced by an almost immediate and persistent decrease in heart rate variability following umbilical cord occlusion [2]. Disturbance of baroreflex sensitivity ( $\mathrm{ms} / \mathrm{mm} \mathrm{Hg}$ ) and increased delay between variations in heart rate and systolic blood pressure became evident 72 hours after transient umbilical cord occlusion and persisted until the end of the experiment (one week), suggesting that global hypoxiaischemia caused long term deregulation of the baroreceptor reflex arc [2]. Remarkably, impaired baroreflex function did not cause apparent changes in systolic blood pressure in our experiments. This observation may be explained by the fact that circulatory homeostasis was still maintained by adequate placental perfusion in the intra-uterine environment. It is conceivable that the damaged baroreflex function does not become clinically evident until after birth when circulatory homeostasis can no longer be sustained by maternal support and solely depends on endogenous regulatory systems.

The baroreflex arc consists of baroreceptors in the aortic arch and carotid arteries, afferent signaling pathways, the nucleus of the solitary tract in the brain stem and sympathetic and parasympathetic efferent signaling pathways. The observed functional disturbances in the baroreflex may thus be situated in various regions, since global hypoxia-ischemia may have affected all components of the baroreflex arc. We did neither assess histological injury of peripheral baroreceptors or nuclei in the brain stem, nor did we study function of signaling pathways. Nevertheless, based on previous studies showing brain stem injury after umbilical cord occlusion in association with short term disturbance of the baroreflex $[3,4]$, it seems plausible that central injury to the baroreflex arc plays a predominant role in the pathophysiology of impaired baroreflex function after global hypoxia-ischemia. 


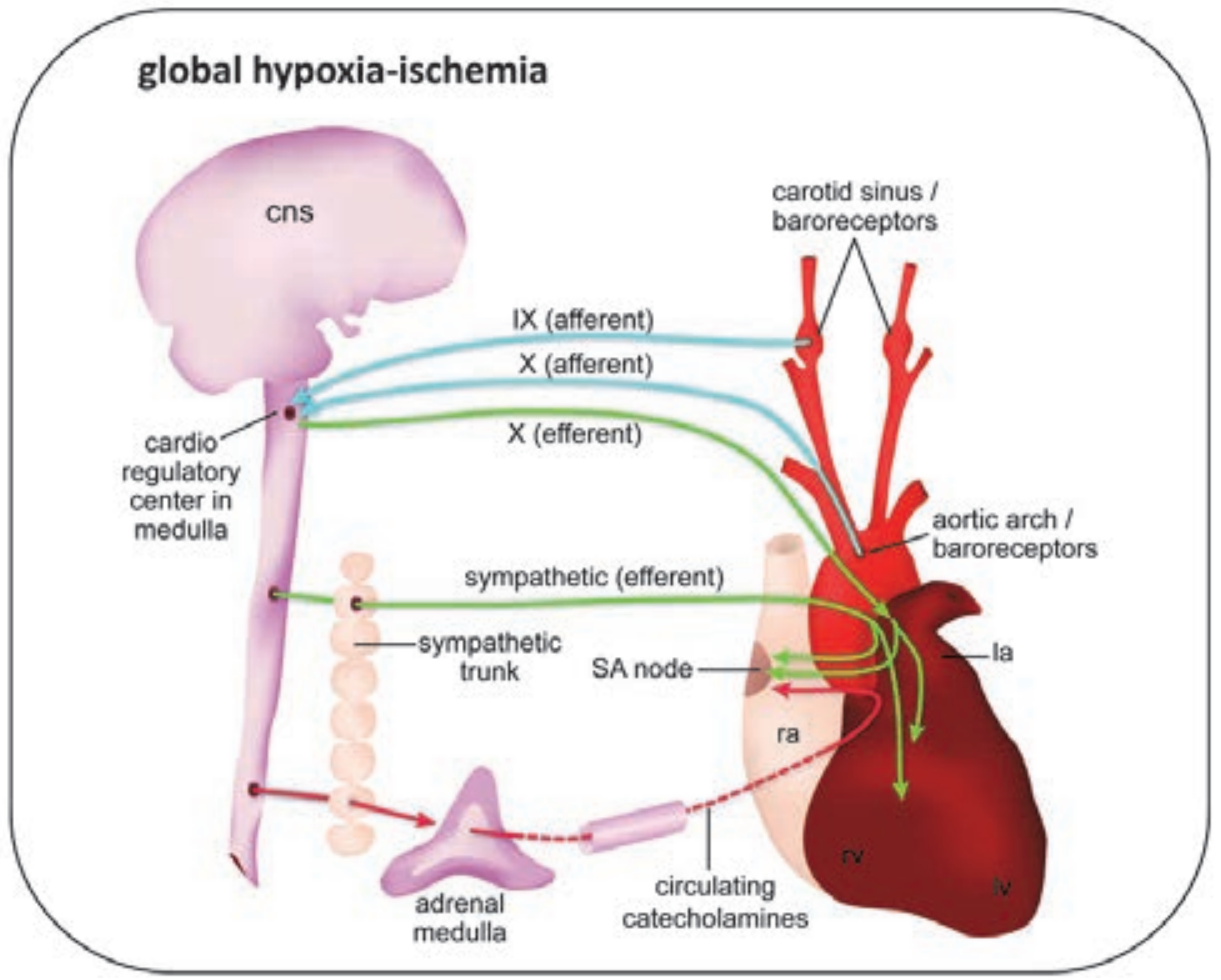

Figure 1: Global hypoxia-ischemia affected central and peripheral components involved in the baroreceptor reflex. CNS = central nervous system, la = left atrium, lv = left ventricle, $r a=$ right atrium, $r v=$ right ventricle, SA node = sinuatrial node. Adapted from McNeil, Neural Development 2010 [5].

Interestingly, our data showed that baroreflex sensitivity increased during the study period, indicating that baroreflex function matures during gestation [2]. This observation is of high clinical relevance since it demonstrates that preterm infants are born with an immature cerebrovascular autoregulatory system, making them highly vulnerable to blood pressure fluctuation and subsequent inadequate cerebral perfusion.

In conclusion, in chapter 2 we validated the translational ovine model of HIE by demonstrating that global hypoxia-ischemia disturbed normal development of the baroreflex causing long term impairment of the heart rate mediated blood pressure control. As a consequence, the preterm brain may be prone to blood pressure fluctuations impairing optimal cerebral perfusion which aggravates hypoxic-ischemic injury already caused by global hypoxia-ischemia. 


\section{Cerebral inflammation and the peripheral immune system}

In chapter 3, we hypothesized that global hypoxia-ischemia by transient umbilical cord occlusion would induce a cerebral and peripheral inflammatory response similar to the one seen after local cerebral ischemia. In addition, we hypothesized that cerebral inflammation would be associated with white matter injury and suppression of brain function. These hypotheses were confirmed by our study. We demonstrated that global hypoxia-ischemia induced profound cerebral inflammation as shown by marked activation and proliferation of microglia, which play a key role in the initiation of the cerebral inflammatory response after injury [6]. The microglial response typically arises within 24 hours after an ischemic insult [7-9]. Therefore, our data indicated that the first inflammatory hit to the preterm brain occurred early after global hypoxia-ischemia.

We showed for the first time that the peripheral immune system plays a pivotal role in the pathophysiology of HIE following global hypoxia-ischemia. Our findings demonstrated marked mobilization of white blood cells into the blood stream, which peaked within 24 hours after transient umbilical cord occlusion. Furthermore we observed an influx of neutrophils into the ischemic brain, facilitated by disruption of the blood-brain barrier, which is known to occur after hypoxia-ischemia [10-15]. Neutrophil invasion has previously been shown to typically occur within 48-72 hours after cerebral ischemia [7-9]. Therefore, we postulated that the influx of these immune effector cells was a second inflammatory hit to the ischemic preterm brain. Based on our observation of splenic involution after global hypoxia-ischemia, which could not be explained by increased apoptosis of splenocytes, we postulated that the neutrophils invading the ischemic brain originated from the spleen. This concept is in line with previous findings showing that the spleen was the predominant source of brain invading neutrophils after local cerebral ischemia [16-18] and that splenectomy reduced neutrophil influx and microglial activation in the ischemic hemisphere [19]. The ischemic brain may signal to the spleen directly by the release of DAMPs (intracellular proteins, DNA, RNA, nucleotides, heat shock proteins and extracellular matrix protein such as hyaluronic acid) and pro-inflammatory cytokines or indirectly by efferent neural signaling or increased activity of the hypothalamic-pituitary-adrenal (HPA) axis [20]. In utero splenic involution by depletion of immune cells may have important clinical consequences as this has been associated with an increased risk of postnatal infectious complications such as early onset sepsis [21, 22]. Furthermore, experimental evidence shows that antenatal inflammation leads to hyporesponsiveness of immune cells [23-28] which may also predispose to postnatal infection.

The cerebral and systemic inflammatory changes observed in our study were accompanied by marked white matter injury as evidenced by pre-oligodendrocyte injury and demyelination of the preterm brain. The pattern of white matter injury after transient umbilical cord occlusion was very similar to the pattern observed in clinical studies $[1,29]$, confirming the translational character of the animal model. Cerebral inflamma- 
tion and hypomyelination were associated with suppression of electrophysiological brain activity, a strong indicator of impaired brain function and poor clinical neurodevelopmental outcome $[30,31]$.

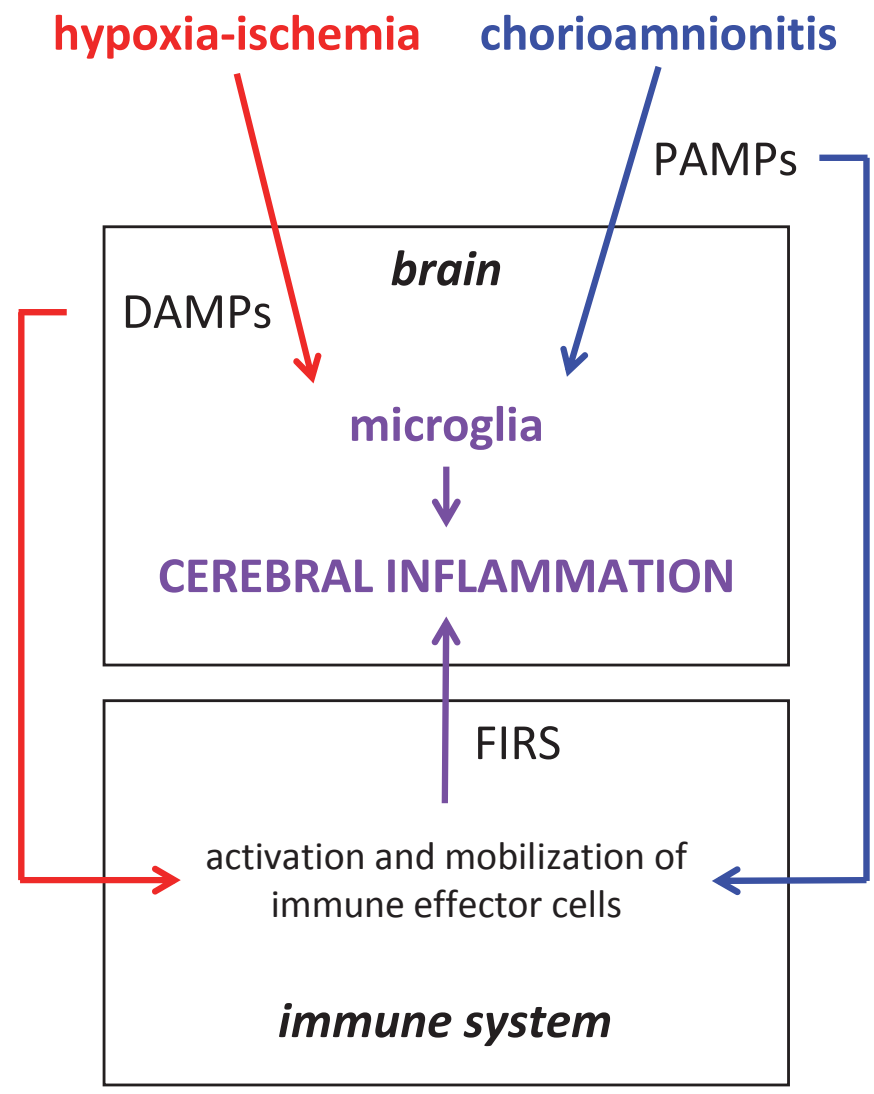

Figure 2. Hypoxia-ischemia and chorioamnionitis, two major upstream events causing brain injury, converge into a common inflammatory pathway. Global hypoxia-ischemia and chorioamnionitis are associated with release of brain-derived danger-associated molecular patterns (DAMPs) and pathogen-associated molecular patters (PAMPs), respectively. Upon detecting DAMPs and/or PAMPs microglia become activated causing a first inflammatory hit to the preterm brain. In addition, systemic DAMPs and PAMPs cause activation and mobilization of the peripheral immune system again converging into a common peripheral inflammatory response or fetal inflammatory response syndrome (FIRS) which forms a second hit to the preterm brain.

In conclusion, in chapter 3 we provided evidence for a two-stepped inflammatory response damaging the preterm brain after global hypoxia-ischemia; with an early inflammatory hit mediated by microglia and a second inflammatory hit mediated by spleen-derived immune effector cells invading the ischemic preterm brain. The cross- 
talk between the preterm brain and the peripheral immune system adds a new concept to the understanding of the pathophysiology of hypoxic-ischemic encephalopathy in prematurity and is in accordance with the current understanding that the immature immune system is capable of mounting an immune response in the face of high levels of danger, as is the case following profound global hypoxia-ischemia.

We postulate that the pathophysiology of global hypoxia-ischemia shares a common etiology with chorioamnionitis when considering the cerebral and peripheral inflammatory response (Figure 2). Chorioamnionitis similarly induces a cerebral inflammatory response $[32,33]$. However, in chorioamnionitis (or fetal sepsis) microglia are not activated by local release of DAMPs, but instead microglia may become activated after sensing pathogen-associated molecular patterns (PAMPs) associated with chorioamnionitis or sepsis [29,34]. Moreover, PAMPs have been shown to activate and mobilize the fetal immune system $[24,25,28,35,36]$ resulting in a peripheral immune response, referred to as the fetal inflammatory response syndrome (FIRS). As in the pathophysiology of global hypoxia-ischemia the peripheral immune response forms a second inflammatory hit to the preterm brain [33].

\section{Exogenous stem cells}

In chapter 4, we further elaborated on our findings that inflammation and cellular degeneration play a key role in the pathophysiology of hypoxic-ischemic encephalopathy (Figure 2) by addressing these pathogenic processes in an intervention study. We studied the neuroprotective potential of exogenous administration of MSCs to repair the ischemic preterm brain. We hypothesized that intravenously administered human bone-marrow derived MSCs would be neuroprotective by inhibiting the cerebral and peripheral inflammatory response and stimulate regeneration of injured cells after global hypoxia-ischemia (Figure 3). We tested this hypothesis in our translational animal model of hypoxic-ischemic preterm brain injury. MSCs were infused intravenously, to test effectiveness of MSC therapy using a clinically feasible administration route.

We found that MSCs reduced cerebral inflammation as evidenced by decreased activation and proliferation of microglia, which are typically activated early after global $\mathrm{HI}[7,37]$. Besides inhibition of microglial activation, we postulate that MSCs reduced cerebral inflammation by inducing a microglial type switch from a pro-inflammatory M1 phenotype to a $\mathrm{M} 2$ phenotype which has been shown to reduce cerebral inflammation $[38,39]$ and promote oligodendrocyte differentiation towards mature myelinproducing oligodendrocytes [40]. This concept is in line with previous work that showed increased $\mathrm{M} 2 / \mathrm{M} 1$ microglia ratio in the brain after transplantation of multipotent adult progenitor cells (MAPCs) [38], which can be considered as a subpopulation of MSCs with potent anti-inflammatory and regenerative capacities [38, 41-47].

In line with our previous findings in chapter 3, we showed that global hypoxiaischemia induced a marked loss of preOLs, which was paralleled by hypomyelination of 
the preterm brain. In chapter 4 we extended these findings using diffusion tensor imaging (DTI), a commonly used clinical diagnostic tool to assess white matter injury in the preterm brain [48-50]. DTI confirmed breakdown of white matter organization as evidenced by decreased fractional anisotropy (FA) values after global hypoxia-ischemia, which is in accordance with clinical evidence [50]. Remarkably, intravenous MSCs reduced histological white matter injury, which was confirmed with DTI.

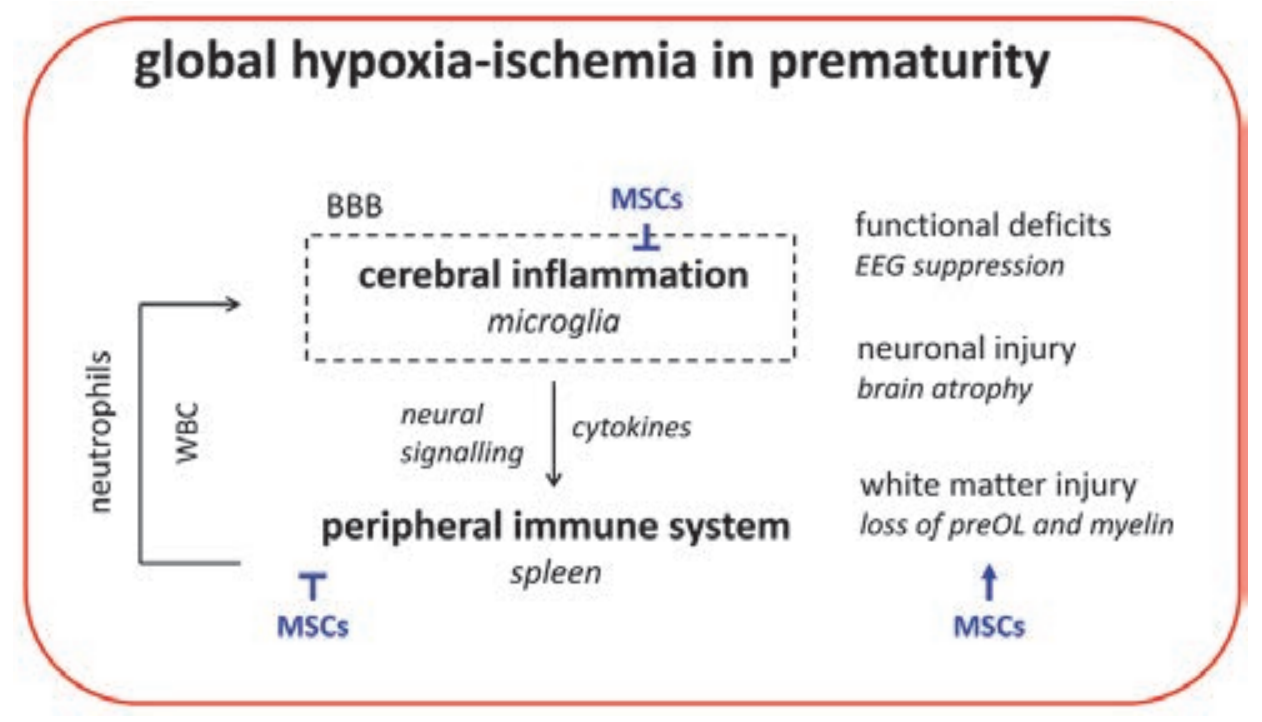

Figure 3. Hypothesis of MSC intervention study. MSCs dampen the microglia-mediated cerebral inflammation, which reduces signaling to the peripheral immune system. Secondly, MSCs inhibit activation of peripheral immune effector cells which prevents mobilization and invasion of these cells into the ischemic brain. Reducing the cerebral and peripheral inflammatory response will diminish brain injury. In addition, MSCs promote regeneration of oligodendrocytes and neurons, which improves myelination and functional outcome, respectively.

We postulate that the protective effects of MSCs on white matter were attributed to various mechanisms. First, MSCs reduced cerebral inflammation mediated by microglia, which have been shown to directly cause injury to preOLs [51]. Although we did not study these direct effects, preOL density and myelination in the subcortical white matter were inversely related to proliferation of microglia in our study. These results suggest that a reduction in microglial proliferation mediated by MSCs was associated with less injury to preOLs. Secondly, replenishment of preOLs by MSCs was considered to be attributed to regeneration of lost preOLs and re-activation of arrested oligodendrocyte maturation. This concept is supported by in vitro data showing that MSCs stimulate neural progenitor cells to differentiate towards the oligodendrocyte lineage $[52,53]$ and in vivo data demonstrating MSC-mediated remyelination of the ischemic brain [54]. 
Thirdly, MSCs may have induced remyelination indirectly by increasing the M2/M1 microglia ratio which has been shown to promote oligodendrocyte regeneration and differentiation [40].

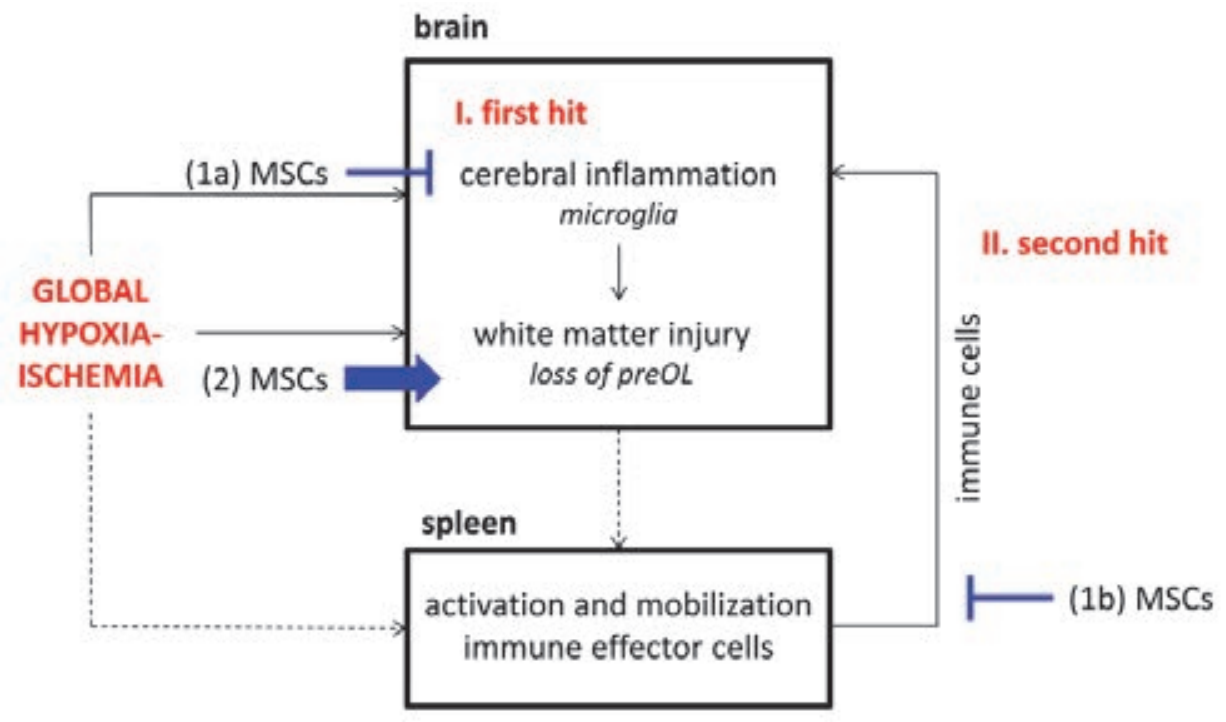

Figure 4. Dual effect of MSCs in two-stepped pathophysiology in hypoxic-ischemic encephalopathy of prematurity. I. Initial cerebral inflammatory response after global hypoxia-ischemia mediated by microglia. II. Second peripheral inflammatory response mediated by mobilized immune effector cells, which aggravate cerebral inflammation and concomitant brain injury after global hypoxia-ischemia. 1a. MSCs dampen the first inflammatory hit by reducing microglial activation, 1 b. MSCs dampen the second hit by inducing tolerance of immune effector cells, thereby reducing mobilization and invasion of these cells into the preterm brain. 2 . MSCs promote regeneration of pre-oligodendrocytes

We hypothesized that the anti-inflammatory effect of MSCs would not only consist of reducing the first inflammatory hit mediated by microglia, but that additionally MSCs would prevent the second inflammatory hit mediated by invasion of mobilized immune effector cells from the peripheral immune system. Therefore, we studied modulation of the peripheral T-cell response and subsequent invasion of these cells into the ischemic preterm brain. Our findings showed that proliferation capacity of splenic T-cells was inhibited in animals that had received MSCs, suggesting that MSCs induced persistent tolerance of T-cells in vivo. Furthermore invasion of T-cells into the ischemic brain was markedly reduced my MSCs. Based on these findings, we hypothesize that sequestered MSCs induced splenic helper T-cell tolerance. Unresponsive splenic T-cells were considered to be less receptive to danger signals (DAMPs, pro-inflammatory cytokines, neural signaling) from the ischemic preterm brain. As a consequence, tolerant T-cells are not mobilized, which prevents a second inflammatory hit mediated by invasion of these 
immune effector cells in the ischemic brain. Moreover, MSCs are considered to have an additional immunomodulating effect by inducing differentiation of naïve T-cells into regulatory T-cells (Tregs) $[55,56]$, which have been shown to play a key role in neuroprotective immunomodulation following cerebral ischemia $[17,57,58]$.

Our findings in chapter 3 suggested a central role for the spleen in the pathophysiology of preterm brain injury after global hypoxia-ischemia by providing immune cells that aggravate cerebral inflammation. Consistently, in chapter 4 we provided evidence that modulation of the splenic inflammatory response plays a pivotal role in the neuroprotective effect of MSCs after global hypoxia-ischemia. The concept of the spleen as a key mediator of neuroprotection by stem cell therapy is supported by previous findings indicating that MAPC-splenocyte contact was needed to modulate microglia activation [38]. Moreover, MAPC increased the number of splenic and systemic Tregs and concordantly induced a type switch of microglia towards an antiinflammatory phenotype [38].

To study engraftment of MSCs in the preterm brain after transplantation, we used a human specific Y-chromosome fluorescent in-situ hybridization (FISH) probe to detect male human MSCs in the ovine preterm brain. In line with findings from literature [59, 60], we detected very few MSCs in the brain one week after intravenous administration. At the end of the study period we observed marked neuroprotective effects of MSCs, while only a minor proportion of MSCs was detectable, indicated that the therapeutic effect of MSCs lasted longer than their presence. This phenomenon could be explained by several mechanisms. First of all, intravenously administered MSCs have been shown to engraft in the ischemic brain [61, 62]. MSCs are considered to transmigrate across the BBB either through the paracellular or transcellular pathways as in leukocyte diapedesis [61-64]. Although paracellular transmigration by MSCs in the preterm brain may be facilitated by immature tight junctions between endothelial cells of the cerebral vasculature, the efficiency of MSC transmigration across the BBB is still a matter of debate and therefore mandates further research [61,62]. Considering that MSCs are capable of reaching the ischemic brain, it is conceivable that in our study intravenously administered MSCs invaded the ischemic preterm brain but perished within a few days after they established sustained immunomodulation and regeneration. The second explanation for the observation that the therapeutic effect of MSCS lasted longer than their presence could be that MSC invasion into the ischemic preterm brain is actually marginal in the first place and MSCs rather exert their therapeutic effect in a long-distance fashion by secreting neuroprotective soluble factors while they are circulating, trapped in the lung or sequestrated in the spleen. This concept is supported by findings demonstrating that intravenously administered MSCs got trapped in the lung, but still mediated cardiac protection after myocardial infarction by secreting anti-inflammatory proteins [59]. In line, we detected the transplanted MSCs in lung and spleen tissue by PCR for human-specific $\beta-2$ microglobulin. 
In conclusion, in chapter 4 we demonstrated that intravenous administration of MSCs are neuroprotective for the preterm brain after severe global hypoxia-ischemia. Our findings indicated that the therapeutic effect was established (1) by dampening the cerebral and peripheral inflammatory response and (2) by establishing regeneration of oligodendrocytes. Importantly, we showed that the anti-inflammatory and proliferative effects of MSCs were associated with functional improvement in the preterm brain.

In summary of chapter 3 and 4, we provided evidence that MSCs established a dual effect (anti-inflammatory and regenerative) in the two-stepped (first hit, second hit) pathophysiology of global hypoxia-ischemia (Figure 4). The first hit after global hypoxia ischemia is attributed to microglial activation. The second hit is caused by the peripheral immune response. MSCs modulate inflammation by dampening the hit to the preterm brain by reducing microglial activation and by reducing mobilization of the immune effector cells that form the second inflammatory hit to the preterm brain. In addition MSCs induce regeneration of vulnerable pre-oligodendrocytes leading to restoration of white matter after injury.

\section{Endogenous stem cells}

In chapter 4, we showed that exogenous administration of MSCs established functional neuroprotection and dampened the cerebral and systemic inflammatory response. In chapter 5, we explored whether mobilization of endogenous stem cells by G-CSF would establish similar neuroprotection in the preterm brain after global hypoxia-ischemia. The growth-directed environment in preterm infants makes them excellent candidates for such an approach aimed at stimulating the endogenous regenerative potential, since in preterm infants the brain and other organs possess high numbers of stem cells [65-67]. A pharmacological intervention able to promote proliferation and mobilization of these stem cells after injury would have high therapeutic potential. Moreover, such a pharmacological therapy would circumvent biological risks, logistics and costs, which remain potential obstacles for exogenous stem cell therapy [68].

In chapter 4, we found that MSCs were neuroprotective when administered early after global hypoxia-ischemia [69]. These results indicated that the therapeutic window of opportunity for neuroprotection after global hypoxia-ischemia corresponded with the first hours after the insult. In the current study, we aimed at mobilizing endogenous stem cells by G-CSF within the same timeframe after global hypoxia-ischemia. Therefore, we started G-CSF treatment one day before global hypoxia-ischemia to ascertain that mobilized endogenous stem cells were readily available within the therapeutic window of opportunity. This study design was deliberately chosen as a proof-ofprinciple approach; we first wanted to proof the therapeutic effect of G-CSF with optimal timing of stem cell mobilization and future studies would need to assess effectiveness in a clinically more relevant post-injury treatment approach. G-CSF was chosen in this study for several reasons. G-CSF is a registered drug for the use in neonatal and 
pediatric patients with neutropenia [70-72], which has been shown to mobilize neuroprotective hematopoietic stem cells (HSCs) and stimulate proliferation of endogenous neural progenitor cells (NPCs) [73]. In addition, previous studies have shown that G-CSF also has direct neuroprotective effects [74-79].

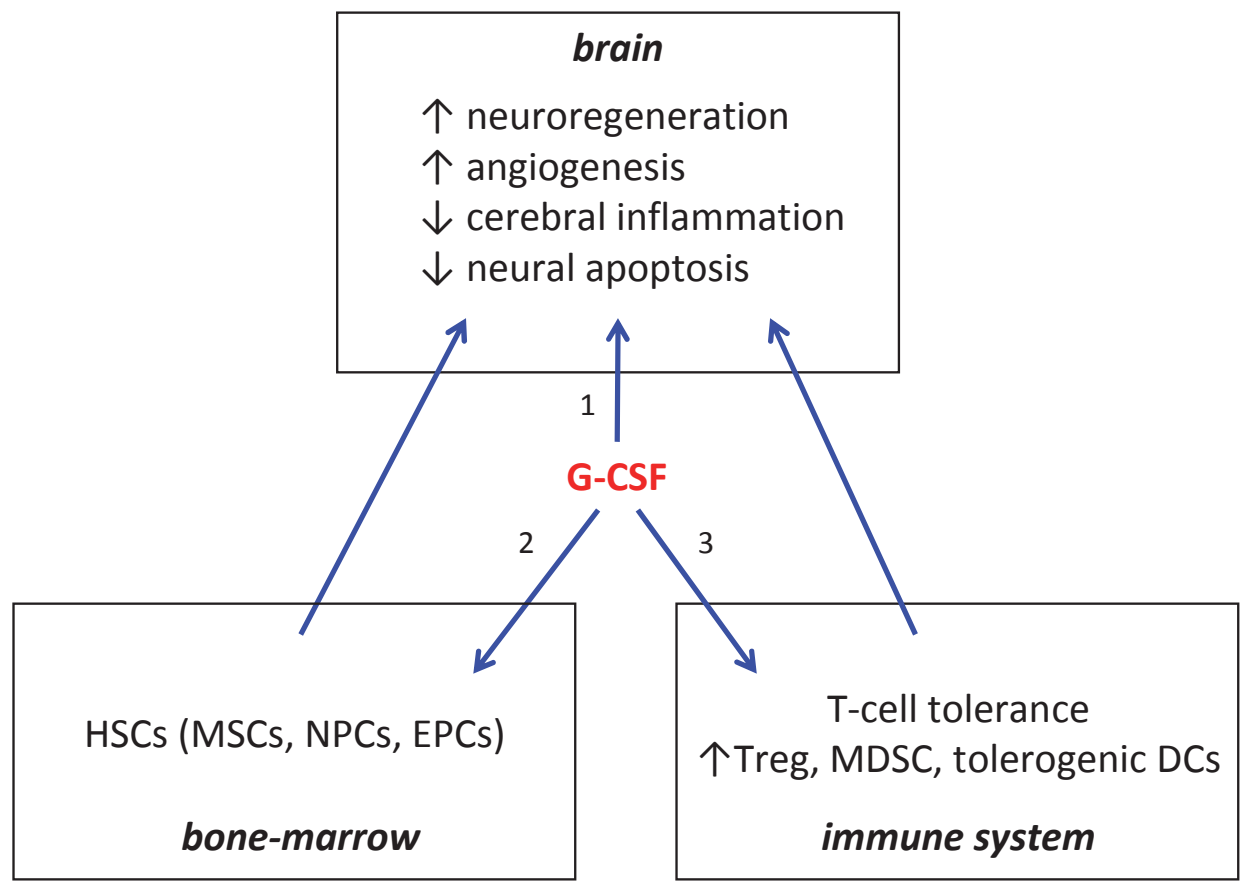

Figure 5. The postulated neuroprotective effects of G-CSF. (1) The direct neuroprotective effect of G-CSF involves reduction of neural apoptosis and stimulation of angiogenesis in the ischemic brain. The indirect neuroprotective effects of G-CSF consist of (2) mobilization of bone-marrow derived HSCs and other stem cells with regenerative, angiogenic and anti-inflammatory properties and (3) modulation of the peripheral immune response by inducing T-cell and DC tolerance and increasing the number of regulatory $T$-cells and myeloid suppressor cells (MDSC). G-CSF = granulocyte-colony stimulating factor, HSCs = hematopoietic stem cells, MSCs = mesenchymal stem cells, NPCs = neural progenitor cells, EPCs = endothelial progenitor cells

We hypothesized that systemic G-CSF treatment would reduce white matter injury and improve electrophysiological brain function in our translational sheep model of hypoxic-ischemic preterm brain injury. Our results showed that human recombinant G-CSF effectively mobilized ovine HSCs within the therapeutic window of opportunity, which coincides with the first 24 hours after global hypoxia-ischemia [69]. We had anticipated that G-CSF would be able to cross the placenta, which would have created an eligible chance to protect the preterm brain by a reversed administration route (mother to fetus) in the case of suspected intrauterine asphyxia. However, administration of G-CSF 
to the fetus did not mobilize HSCs in maternal blood, indicating that G-CSF did not pass the placenta at sufficient levels to induce mobilization [80].

Our findings showed that G-CSF attenuated white matter injury in the preterm brain following global hypoxia-ischemia as demonstrated by reduced loss of preoligodendrocytes and reduced hypomyelination [80]. We postulated that this neuroprotective effect could be attributed to the direct pharmacological effect of G-CSF in the ischemic brain and indirect effects via G-CSF mediated mobilization of stem cells from the bone-marrow and modulation of the peripheral immune system (Figure 5).

G-CSF can exert direct pharmacological effects in the brain since it is able to penetrate the blood-brain barrier (BBB) [75]. G-CSF directly activates the anti-apoptotic pathway through activation of various intracellular signaling cascades, including the activation of bcl-2 [74-76]. The anti-apoptotic effect of G-CSF may account for the reduced loss of pre-oligodendrocytes, which have been shown to become apoptotic after global hypoxia-ischemia [6]. G-CSF preferentially mobilizes HSCs from the bone-marrow [81-83]. Interestingly, previous reports have shown concomitant mobilization of MSCs $[84,85]$ and neural progenitor cells (NPCs) $[73,86]$, which could potentiate the neuroprotective effects of G-CSF. In addition, G-CSF has been shown to stimulate proliferation of intrinsic neural stem cells, which can replenish pre-oligodendrocytes [73, 75]. Mobilized HSCs have been shown to migrate to the ischemic brain [87], where these stem cells support neuronal repair by secreting neurotrophic factors in the ischemic brain [88] and adapt a neuronal phenotype [73, 86]. However, differentiation of HSCS into neurons is most likely a rare event [89] and therefore neuronal differentiation from mobilized HSCs is considered to reflect simultaneous mobilization of NPCs $[73,77,86]$ or transdifferentiation of concomitantly mobilized MSCs into a neural phenotype [9092]. Furthermore, G-CSF may additionally increase the availability of endothelial progenitor cells (EPCS), either by mobilization from the bone-marrow [77] or by differentiation of HSCs into EPCs [93]. EPCs could play an important role after cerebral hypoxiaischemia by contributing to neovascularization [93-97]. Remarkably, the neuroprotective effect of G-CSF has been shown to be potentiated by additional treatment with stem cell factor (SCF) $[73,98]$, which synergistically increased mobilization and proliferation of bone marrow-derived HSCs and NPCs [99-101].

We showed that G-CSF treatment attenuated the cerebral inflammatory response after global hypoxia-ischemia. We postulated that the anti-inflammatory effect of GCSF was attributed to direct inhibition of microglial activation (first hit) and indirect modulation of the peripheral immune response (second hit) after global hypoxiaischemia. Activated microglia are injurious to pre-oligodendrocytes [51] and therefore G-CSF mediated inhibition of microglial activation may contribute to reduction of hypomyelination. G-CSF has been shown to modulate T-cell immunity by polarizing proinflammatory Th1 cells to anti-inflammatory Th2 cells and induce tolerance of T-cells [102-105]. Furthermore, G-CSF has been shown to increase the number of regulatory $T$ cells $[103,106,107]$, myeloid suppressor cells [106] and tolerogenic dendritic cells [105, 
108]. These processes may modulate the peripheral immune system towards a tolerant state preventing recruitment of peripheral immune effector cells, which constitutes the second inflammatory hit when these cells invade the preterm brain $[6,7,69,109,110]$. In line with this concept, we found that invasion of immune effector cells into the ischemic brain was attenuated by G-CSF [80]. In experimental neonatal hypoxia-ischemia, G-CSF decreased the activity of the hypothalamic-pituitary-adrenal (HPA) axis [111], which is known to modulate peripheral immune responses [20].

Despite marked reduction of cerebral inflammation and decreased hypomyelination, G-CSF did not improve brain function as studied by seizure burden after global hypoxia-ischemia [80]. Since seizures predominantly occur in the acute phase following cerebral hypoxia-ischemia, increased seizure burden mainly indicated initial dysfunction of the brain. Seizure burden, however, is not a reliable measure for long-term functional performance, although seizures in neonatal HIE are associated with adverse neurodevelopmental outcome [112-114]. Therefore, follow-up studies need to assess whether the structural improvements that we observed in our study will actually result in improved function on the long term [80].

Since G-CSF showed such promising neuroprotection in rodent models of stroke $[75,79,115-120]$, several clinical studies have been initiated in stroke patients [87, 121124]. The first results of those randomized placebo-controlled clinical trials disappointingly showed that G-CSF failed to improve the degree of disability or dependence in the daily activities of stroke patients [125]. However, there was a trend for reduced infarct growth and a significant decrease of interleukin-1 in the G-CSF group [125]. These results should not discourage future clinical trials investigating the neuroprotective effect of G-CSF in the preterm neonate with HIE, since our findings have indicated in a translational animal model that the endogenous regenerative capacity in the preterm environment could be enhanced by G-CSF.

In conclusion, we reported in chapter 5 that G-CSF-mediated mobilization of endogenous stem cells attenuated cerebral inflammation and white matter injury in the preterm brain following global hypoxia-ischemia. However, seizure burden within the acute phase following ischemia was not reduced by G-CSF. Before clinical translation in preterm infants with HIE, future experimental studies should assess the effect of G-CSF on neurodevelopmental outcome in our translational model, which closely mimics the physiology of preterm infants and the etiology of HIE. 


\section{Future directions}

In this translational project, we transferred the clinical problem of preterm infants with HIE from bedside to bench. We developed an animal model, which mimicked the human situation as closely as possible and demonstrated that cell-based therapy has great potential to protect the preterm ischemic brain. Many questions, however, remain to be answered before cell-based therapy becomes an established treatment modality in neonatal medicine.

We have demonstrated that the peripheral immune system plays a pivotal role in the etiology of cerebral inflammation and white matter injury in the preterm brain after global hypoxia-ischemia. Future studies should further explore the temporal and spatial dynamics of the peripheral immune response. Our data indicated that the spleen may be the predominant source of mobilized immune effector cells that invade the brain and aggravate inflammation and injury. Splenectomy in our model could confirm this important cross-talk between the spleen and the preterm brain following global hypoxia-ischemia. Furthermore future experimental studies should further assess the cellular response in the peripheral immune system after global hypoxia-ischemia. In particular the role of T-cell immunity in global hypoxia-ischemia needs to be further explored.

We have shown neuroprotection by exogenous administration of MSCs within the acute phase after global hypoxia-ischemia. The regenerative effects of MSCs may be enhanced when a repetitive dose of MSCs is administered outside the acute window in which inflammation is initiated. This hypothesis needs to be tested in future studies. Dose-effect studies should be performed to optimize treatment effects of cell-based therapy for the ischemic preterm brain. Furthermore, we provided evidence that induction of T-cell tolerance by MSC might play an important role in the neuroprotective effects of MSCs in HIE. The exact mechanisms underlying the immunosuppressive effects of MSCs remain thus far largely unknown and therefore needs further exploration. Administration of labeled stem cells will give more insight in the distribution and migration of MSCs and will provide more detailed information on whether the antiinflammatory and regenerative effects of MSCs result from cell-cell contact, paracrine effects or a combination of both.

We have developed a translational model of ischemic preterm brain injury, which is a strong tool to test new therapies for preterm infants suffering from HIE. One important limitation of the current set-up of the model is the lack of long-term neurodevelopmental outcome assessment. For this purpose, instrumented lambs would need to be delivered at a viable age and receive supportive care until they can sustain themselves independently. Cognitive and motoric evaluation tools would need to be developed to consequently follow up neurodevelopmental outcome in these animals. Another important drawback of the sheep model is that the possibility of genetic manipulation and availability of sheep reactive antibodies is limited. 
Ahead of us lies the challenge to translate our findings of neuroprotective cell-based therapy for the ischemic preterm brain from bench to bedside. Efficacy, safety and feasibility of cell-based therapy needs to be demonstrated before such an innovative intervention strategy becomes standard of care in preterm infants suffering from HIE. Our findings confirmed the efficacy of cell-based therapy in a preclinical animal model of preterm HIE, which needs to be confirmed in clinical trials in preterm infants with HIE. A recent meta-analysis confirmed the safety of MSC therapy for the treatment of cardiovascular, neurological and oncological/ hematological disease in a mixed population of adult and pediatric patients and healthy volunteers [126]. Although these results are reaffirming concerning the safety of MSC therapy, more clinical data is required to confirm the safety of cell-based therapy in preterm infants. We consider allogeneic stem cell therapy as the most feasible cell-based therapy in perinatal medicine, since allogeneic cells can be used "off the shelf" in the acute setting of perinatal ischemic brain injury.

In conclusion, we showed in a translational animal model of HIE that cell-based therapy is partially effective in protecting the preterm brain against the detrimental cerebral and peripheral inflammatory response underlying white matter injury following global hypoxia-ischemia. Our findings form the basis of future preclinical work and followed by clinical trials testing the neuroprotective potential of cell-based therapy in preterm infants with HIE. These endeavors create an eligible chance to improve the life of many preterm infants that suffer from hypoxic-ischemic brain injury. 


\section{Chapter 6}

\section{References}

1. Volpe JJ: Neurology of the Newborn. 5th edn. Philadelphia: Elsevier-Saunders 2008

2. Zwanenburg A, Jellema RK, Jennekens W, Ophelders D, Vullings R, van Hunnik A, van Pul C, Bennet L, Delhaas T, Kramer BW, Andriessen P: Heart rate-mediated blood pressure control in preterm fetal sheep under normal and hypoxic-ischemic conditions. Pediatr Res 2013, 73:420-426.

3. George S, Gunn AJ, Westgate JA, Brabyn C, Guan J, Bennet L: Fetal heart rate variability and brain stem injury after asphyxia in preterm fetal sheep. Am J Physiol Regul Integr Comp Physiol 2004, 287:R925933.

4. Wassink G, Bennet L, Booth LC, Jensen EC, Wibbens B, Dean JM, Gunn AJ: The ontogeny of hemodynamic responses to prolonged umbilical cord occlusion in fetal sheep. J Appl Physiol 2007, 103:1311-1317.

5. McNeill EM, Roos KP, Moechars D, Clagett-Dame M: Nav2 is necessary for cranial nerve development and blood pressure regulation. Neural Dev 2010, 5:6.

6. Jellema RK, Lima Passos V, Zwanenburg A, Ophelders DR, De Munter S, Vanderlocht J, Germeraad WT, Kuypers E, Collins JJ, Cleutjens JP, Jennekens W, Gavilanes AW, Seehase M, Vles HJ, Steinbusch H, Andriessen P, Wolfs TG, Kramer BW: Cerebral inflammation and mobilization of the peripheral immune system following global hypoxia-ischemia in preterm sheep. J Neuroinflammation 2013, 10:13.

7. Gelderblom M, Leypoldt F, Steinbach K, Behrens D, Choe CU, Siler DA, Arumugam TV, Orthey E, Gerloff C, Tolosa E, Magnus T: Temporal and spatial dynamics of cerebral immune cell accumulation in stroke. Stroke 2009, 40:1849-1857.

8. Offner $\mathrm{H}$, Vandenbark AA, Hurn PD: Effect of experimental stroke on peripheral immunity: CNS ischemia induces profound immunosuppression. Neurosci 2009, 158:1098-1111.

9. Stevens SL, Bao J, Hollis J, Lessov NS, Clark WM, Stenzel-Poore MP: The use of flow cytometry to evaluate temporal changes in inflammatory cells following focal cerebral ischemia in mice. Brain Res 2002, 932:110-119.

10. Kishimoto TK, Rothlein R: Integrins, ICAMs, and selectins: role and regulation of adhesion molecules in neutrophil recruitment to inflammatory sites. Adv Pharmacol 1994, 25:117-169.

11. Jin AY, Tuor UI, Rushforth D, Kaur J, Muller RN, Petterson JL, Boutry S, Barber PA: Reduced blood brain barrier breakdown in P-selectin deficient mice following transient ischemic stroke: a future therapeutic target for treatment of stroke. BMC Neurosci 2010, 11:12.

12. Kumar A, Mittal R, Khanna HD, Basu S: Free radical injury and blood-brain barrier permeability in hypoxic-ischemic encephalopathy. Pediatrics 2008, 122:e722-727.

13. Svedin P, Hagberg H, Savman K, Zhu C, Mallard C: Matrix metalloproteinase-9 gene knock-out protects the immature brain after cerebral hypoxia-ischemia. J Neurosci 2007, 27:1511-1518.

14. Tu YF, Tsai YS, Wang LW, Wu HC, Huang CC, Ho CJ: Overweight worsens apoptosis, neuroinflammation and blood-brain barrier damage after hypoxic ischemia in neonatal brain through JNK hyperactivation. $J$ Neuroinflammation 2011, 8:40.

15. Brochu ME, Girard S, Lavoie K, Sebire G: Developmental regulation of the neuroinflammatory responses to LPS and/or hypoxia-ischemia between preterm and term neonates: An experimental study. J Neuroinflammation 2011, 8:55.

16. Offner H, Subramanian S, Parker SM, Afentoulis ME, Vandenbark AA, Hurn PD: Experimental stroke induces massive, rapid activation of the peripheral immune system. J Cereb Blood Flow Metab 2006, 26:654-665.

17. Offner H, Subramanian S, Parker SM, Wang C, Afentoulis ME, Lewis A, Vandenbark AA, Hurn PD: Splenic atrophy in experimental stroke is accompanied by increased regulatory $\mathrm{T}$ cells and circulating macrophages. 2006, 176:6523-6531.

18. Vendrame M, Gemma C, Pennypacker KR, Bickford PC, Davis Sanberg C, Sanberg PR, Willing AE: Cord blood rescues stroke-induced changes in splenocyte phenotype and function. Exp Neurol 2006, 199:191-200. 
19. Ajmo CT, Jr., Vernon DO, Collier L, Hall AA, Garbuzova-Davis S, Willing A, Pennypacker KR: The spleen contributes to stroke-induced neurodegeneration. J Neurosci Res 2008, 86:2227-2234.

20. Meisel C, Schwab JM, Prass K, Meisel A, Dirnagl U: Central nervous system injury-induced immune deficiency syndrome. Nat Rev Neurosci 2005, 6:775-786.

21. Toti P, De Felice C, Occhini R, Schuerfeld K, Stumpo M, Epistolato MC, Vatti R, Buonocore G: Spleen depletion in neonatal sepsis and chorioamnionitis. Am J Clin Pathol 2004, 122:765-771.

22. Wolfs TG, Jellema RK, Turrisi G, Becucci E, Buonocore G, Kramer BW: Inflammation-induced immune suppression of the fetus: a potential link between chorioamnionitis and postnatal early onset sepsis. $J$ Matern Fetal Neonatal Med 2012, 25 Suppl 1:8-11.

23. Kallapur SG, Jobe AH, Ball MK, Nitsos I, Moss TJM, Hillman NH, Newnham JP, Kramer BW: Pulmonary and systemic endotoxin tolerance in preterm fetal sheep exposed to chorioamnionitis. J Immunol 2007, 179:8491.

24. Kallapur SG, Nitsos I, Moss TJ, Polglase GR, Pillow JJ, Cheah FC, Kramer BW, Newnham JP, Ikegami M, Jobe $\mathrm{AH}$ : IL-1 mediates pulmonary and systemic inflammatory responses to chorioamnionitis induced by lipopolysaccharide. Am J Respir Crit Care Med 2009, 179:955-961.

25. Kramer BW, Ikegami M, Moss TJ, Nitsos I, Newnham JP, Jobe AH: Endotoxin-induced chorioamnionitis modulates innate immunity of monocytes in preterm sheep. Am J Respir Crit Care Med 2005, 171:7377.

26. Kramer BW, Jobe AH, Ikegami M: Monocyte function in preterm, term, and adult sheep. Pediatr Res 2003, 54:52-57.

27. Kramer BW, Joshi SN, Moss TJ, Newnham JP, Sindelar R, Jobe AH, Kallapur SG: Endotoxin-induced maturation of monocytes in preterm fetal sheep lung. Am J Physiol Lung Cell Mol Physiol 2007, 293:L345-353.

28. Kramer BW, Kallapur SG, Moss TJ, Nitsos I, Newnham JP, Jobe AH: Intra-amniotic LPS modulation of TLR signaling in lung and blood monocytes of fetal sheep. Innate Immun 2009, 15:101-107.

29. Volpe JJ: Brain injury in premature infants: a complex amalgam of destructive and developmental disturbances. Lancet Neurol 2009, 8:110-124.

30. Pressler RM, Boylan GB, Morton M, Binnie CD, Rennie JM: Early serial EEG in hypoxic ischaemic encephalopathy. Clin Neurophysiol 2001, 112:31-37.

31. van Rooij LG, Toet MC, Osredkar D, van Huffelen AC, Groenendaal F, de Vries LS: Recovery of amplitude integrated electroencephalographic background patterns within 24 hours of perinatal asphyxia. Arch Dis Child Fetal Neonatal Ed 2005, 90:F245-251.

32. Kuypers E, Jellema RK, Ophelders DR, Dudink J, Nikiforou M, Wolfs TG, Nitsos I, Pillow JJ, Polglase GR, Kemp MW, Saito M, Newnham JP, Jobe AH, Kallapur SG, Kramer BW: Effects of intra-amniotic lipopolysaccharide and maternal betamethasone on brain inflammation in fetal sheep. PLoS One 2013, 8:e81644.

33. Kuypers E, Ophelders D, Jellema RK, Kunzmann S, Gavilanes AW, Kramer BW: White matter injury following fetal inflammatory response syndrome induced by chorioamnionitis and fetal sepsis: lessons from experimental ovine models. Early Hum Dev 2012, 88:931-936.

34. Volpe JJ, Kinney HC, Jensen FE, Rosenberg PA: The developing oligodendrocyte: key cellular target in brain injury in the premature infant. Int J Dev Neurosci 2011, 29:423-440.

35. Wolfs TG, Buurman WA, Zoer B, Moonen RM, Derikx JP, Thuijls G, Villamor E, Gantert M, Garnier Y, Zimmermann LJ, Kramer BW: Endotoxin induced chorioamnionitis prevents intestinal development during gestation in fetal sheep. PLOS ONE 2009, 4:e5837.

36. Wolfs TG, Kallapur SG, Knox CL, Thuijls G, Nitsos I, Polglase GR, Collins JJ, Kroon E, Spierings J, Shroyer $\mathrm{NF}$, Newnham JP, Jobe AH, Kramer BW: Antenatal ureaplasma infection impairs development of the fetal ovine gut in an IL-1-dependent manner. Mucosal Immunol 2013, 6:547-556.

37. Jellema RK, Lima Passos V, Zwanenburg A, Ophelders DR, De Munter S, Vanderlocht J, Germeraad WT, Kuypers E, Collins JJ, Cleutjens JP, Jennekens W, Gavilanes AW, Seehase M, Vles HJ, Steinbusch H, Andriessen P, Wolfs TG, Kramer BW: Cerebral inflammation and mobilization of the peripheral immune system following global hypoxia-ischemia in preterm sheep. J Neuroinflammation 2013, 10:13. 


\section{Chapter 6}

38. Walker PA, Bedi S, Shah SK, Jimenez F, Xue H, Hamilton JA, Smith P, Thomas CP, Mays RW, Pati S, Cox CS: Intravenous multipotent adult progenitor cell therapy after traumatic brain injury: modulation of the resident microglia population. J Neuroinflammation 2012, 9:228.

39. van Velthoven CT, Kavelaars A, Heijnen CJ: Mesenchymal stem cells as a treatment for neonatal ischemic brain damage. Pediatr Res 2012, 71:474-481.

40. Miron VE, Boyd A, Zhao JW, Yuen TJ, Ruckh JM, Shadrach JL, van Wijngaarden P, Wagers AJ, Williams A, Franklin RJ, ffrench-Constant C: M2 microglia and macrophages drive oligodendrocyte differentiation during CNS remyelination. Nat Neurosci 2013, 16:1211-1218.

41. Boozer S, Lehman N, Lakshmipathy U, Love B, Raber A, Maitra A, Deans R, Rao MS, Ting AE: Global Characterization and Genomic Stability of Human MultiStem, A Multipotent Adult Progenitor Cell. J Stem Cells 2009, 4:17-28.

42. Kovacsovics-Bankowski M, Mauch K, Raber A, Streeter PR, Deans RJ, Maziarz RT, Van't Hof W: Preclinical safety testing supporting clinical use of allogeneic multipotent adult progenitor cells. Cytotherapy 2008, 10:730-742.

43. Reyes $M$, Verfaillie CM: Characterization of multipotent adult progenitor cells, a subpopulation of mesenchymal stem cells. Ann N Y Acad Sci 2001, 938:231-233; discussion 233-235.

44. Walker PA, Shah SK, Jimenez F, Gerber MH, Xue H, Cutrone R, Hamilton JA, Mays RW, Deans R, Pati S, Dash PK, Cox CS, Jr.: Intravenous multipotent adult progenitor cell therapy for traumatic brain injury: preserving the blood brain barrier via an interaction with splenocytes. Exp Neurol 2010, 225:341-352.

45. Yasuhara T, Hara K, Maki M, Mays RW, Deans RJ, Hess DC, Carroll JE, Borlongan CV: Intravenous grafts recapitulate the neurorestoration afforded by intracerebrally delivered multipotent adult progenitor cells in neonatal hypoxic-ischemic rats. J Cereb Blood Flow Metab 2008, 28:1804-1810.

46. Yasuhara T, Matsukawa N, Yu G, Xu L, Mays RW, Kovach J, Deans R, Hess DC, Carroll JE, Borlongan CV: Transplantation of cryopreserved human bone marrow-derived multipotent adult progenitor cells for neonatal hypoxic-ischemic injury: targeting the hippocampus. Rev Neurosci 2006, 17:215-225.

47. Yasuhara T, Matsukawa N, Yu G, Xu L, Mays RW, Kovach J, Deans RJ, Hess DC, Carroll JE, Borlongan CV: Behavioral and histological characterization of intrahippocampal grafts of human bone marrow-derived multipotent progenitor cells in neonatal rats with hypoxic-ischemic injury. Cell Transplant 2006, 15:231238.

48. Dudink J, Kerr JL, Paterson K, Counsell SJ: Connecting the developing preterm brain. Early Hum Dev 2008, 84:777-782.

49. Dudink J, Lequin M, van Pul C, Buijs J, Conneman N, van Goudoever J, Govaert P: Fractional anisotropy in white matter tracts of very-low-birth-weight infants. Pediatr Radiol 2007, 37:1216-1223.

50. Ward P, Counsell S, Allsop J, Cowan F, Shen Y, Edwards D, Rutherford M: Reduced fractional anisotropy on diffusion tensor magnetic resonance imaging after hypoxic-ischemic encephalopathy. Pediatrics 2006, 117:e619-630.

51. Back SA, Luo NL, Mallinson RA, O'Malley JP, Wallen LD, Frei B, Morrow JD, Petito CK, Roberts CT, Jr., Murdoch GH, Montine TJ: Selective vulnerability of preterm white matter to oxidative damage defined by F2-isoprostanes. Ann Neurol 2005, 58:108-120.

52. Steffenhagen C, Dechant FX, Oberbauer E, Furtner T, Weidner N, Kury P, Aigner L, Rivera FJ: Mesenchymal stem cells prime proliferating adult neural progenitors toward an oligodendrocyte fate. Stem Cells Dev 2012, 21:1838-1851.

53. Rivera FJ, Couillard-Despres S, Pedre X, Ploetz S, Caioni M, Lois C, Bogdahn U, Aigner L: Mesenchymal stem cells instruct oligodendrogenic fate decision on adult neural stem cells. Stem Cells 2006, 24:22092219.

54. van Velthoven CT, Kavelaars A, van Bel F, Heijnen CJ: Repeated mesenchymal stem cell treatment after neonatal hypoxia-ischemia has distinct effects on formation and maturation of new neurons and oligodendrocytes leading to restoration of damage, corticospinal motor tract activity, and sensorimotor function. J Neurosci 2010, 30:9603-9611.

55. Aggarwal S, Pittenger MF: Human mesenchymal stem cells modulate allogeneic immune cell responses. Blood 2005, 105:1815-1822. 
56. Selmani Z, Naji A, Zidi I, Favier B, Gaiffe E, Obert L, Borg C, Saas P, Tiberghien P, Rouas-Freiss N, Carosella ED, Deschaseaux F: Human leukocyte antigen-G5 secretion by human mesenchymal stem cells is required to suppress $T$ lymphocyte and natural killer function and to induce CD4+CD25highFOXP3+ regulatory T cells. Stem Cells 2008, 26:212-222.

57. Liesz A, Suri-Payer E, Veltkamp C, Doerr H, Sommer C, Rivest S, Giese T, Veltkamp R: Regulatory T cells are key cerebroprotective immunomodulators in acute experimental stroke. Nat Med 2009, 15:192199.

58. Planas AM, Chamorro A: Regulatory T cells protect the brain after stroke. 2009, 15:138-139.

59. Lee RH, Pulin AA, Seo MJ, Kota DJ, Ylostalo J, Larson BL, Semprun-Prieto L, Delafontaine P, Prockop DJ: Intravenous hMSCs improve myocardial infarction in mice because cells embolized in lung are activated to secrete the anti-inflammatory protein TSG-6. Cell Stem Cell 2009, 5:54-63.

60. van Velthoven CT, Kavelaars A, van Bel F, Heijnen CJ: Mesenchymal stem cell transplantation changes the gene expression profile of the neonatal ischemic brain. Brain Behav Immun 2011.

61. Karp JM, Leng Teo GS: Mesenchymal stem cell homing: the devil is in the details. Cell Stem Cell 2009, 4:206-216.

62. Liu L, Eckert MA, Riazifar H, Kang DK, Agalliu D, Zhao W: From blood to the brain: can systemically transplanted mesenchymal stem cells cross the blood-brain barrier? Stem Cells Int 2013, 2013:435093.

63. Dejana E: The transcellular railway: insights into leukocyte diapedesis. Nat Cell Biol 2006, 8:105-107.

64. Ley K, Laudanna C, Cybulsky MI, Nourshargh S: Getting to the site of inflammation: the leukocyte adhesion cascade updated. Nat Rev Immunol 2007, 7:678-689.

65. van Velthoven CTJ, Kavelaars A, van Bel F, Heijnen CJ: Regeneration of the ischemic brain by engineered stem cells: Fuelling endogenous repair processes. Brain Res Rev 2009, 61:1-13.

66. Bennet L, Tan S, Van den Heuij L, Derrick M, Groenendaal F, van Bel F, Juul S, Back SA, Northington F, Robertson NJ, Mallard C, Gunn AJ: Cell therapy for neonatal hypoxia-ischemia and cerebral palsy. Ann Neurol 2012, 71:589-600.

67. Titomanlio L, Kavelaars A, Dalous J, Mani S, El Ghouzzi V, Heijnen C, Baud O, Gressens P: Stem cell therapy for neonatal brain injury: Perspectives and Challenges. Ann Neurol 2011, 70:698-712.

68. Gortner L, Felderhoff-Muser U, Monz D, Bieback K, Kluter H, Jellema RK, Kramer BW, Keller M, Reiss I, Horn PA, Giebel B: Regenerative therapies in neonatology: clinical perspectives. Klin Padiatr 2012, 224:233-240.

69. Jellema RK, Wolfs TG, Lima Passos V, Zwanenburg A, Ophelders DR, Kuypers E, Hopman AH, Dudink J, Steinbusch HW, Andriessen P, Germeraad WT, Vanderlocht J, Kramer BW: Mesenchymal stem cells induce T-cell tolerance and protect the preterm brain after global hypoxia-ischemia. PLoS One 2013, 8:e73031.

70. Carr R, Modi N, Dore C: G-CSF and GM-CSF for treating or preventing neonatal infections. Cochrane Database Syst Rev 2003:CD003066.

71. Donini M, Fontana S, Savoldi G, Vermi W, Tassone L, Gentili F, Zenaro E, Ferrari D, Notarangelo LD, Porta F, Facchetti F, Dusi S, Badolato R: G-CSF treatment of severe congenital neutropenia reverses neutropenia but does not correct the underlying functional deficiency of the neutrophil in defending against microorganisms. Blood 2007, 109:4716-4723.

72. Kuhn P, Messer J, Paupe A, Espagne S, Kacet N, Mouchnino G, Klosowski S, Krim G, Lescure S, Le Bouedec S, Meyer P, Astruc D: A multicenter, randomized, placebo-controlled trial of prophylactic recombinant granulocyte-colony stimulating factor in preterm neonates with neutropenia. $J$ Pediatr 2009, 155:324-330 e321.

73. Kawada H, Takizawa S, Takanashi T, Morita Y, Fujita J, Fukuda K, Takagi S, Okano H, Ando K, Hotta T: Administration of hematopoietic cytokines in the subacute phase after cerebral infarction is effective for functional recovery facilitating proliferation of intrinsic neural stem/progenitor cells and transition of bone marrow-derived neuronal cells. Circulation 2006, 113:701-710. 


\section{Chapter 6}

74. Harada M, Qin Y, Takano H, Minamino T, Zou Y, Toko H, Ohtsuka M, Matsuura K, Sano M, Nishi J, Iwanaga K, Akazawa H, Kunieda T, Zhu W, Hasegawa H, Kunisada K, Nagai T, Nakaya H, YamauchiTakihara K, Komuro I: G-CSF prevents cardiac remodeling after myocardial infarction by activating the Jak-Stat pathway in cardiomyocytes. Nat Med 2005, 11:305-311.

75. Schneider A, Kruger C, Steigleder T, Weber D, Pitzer C, Laage R, Aronowski J, Maurer MH, Gassler N, Mier W, Hasselblatt M, Kollmar R, Schwab S, Sommer C, Bach A, Kuhn HG, Schabitz WR: The hematopoietic factor G-CSF is a neuronal ligand that counteracts programmed cell death and drives neurogenesis. J Clin Invest 2005, 115:2083-2098.

76. Shuai K: Modulation of STAT signaling by STAT-interacting proteins. Oncogene 2000, 19:2638-2644.

77. Hess DC, Hill WD, Martin-Studdard A, Carroll J, Brailer J, Carothers J: Bone marrow as a source of endothelial cells and NeuN-expressing cells After stroke. Stroke 2002, 33:1362-1368.

78. Ohki Y, Heissig B, Sato Y, Akiyama H, Zhu Z, Hicklin DJ, Shimada K, Ogawa H, Daida H, Hattori K, Ohsaka A: Granulocyte colony-stimulating factor promotes neovascularization by releasing vascular endothelial growth factor from neutrophils. Faseb J 2005, 19:2005-2007.

79. Lee ST, Chu K, Jung KH, Ko SY, Kim EH, Sinn DI, Lee YS, Lo EH, Kim M, Roh JK: Granulocyte colonystimulating factor enhances angiogenesis after focal cerebral ischemia. Brain Res 2005, 1058:120-128.

80. Jellema RK, Lima Passos V, Ophelders DR, Wolfs TG, Zwanenburg A, De Munter S, Nikiforou M, Collins JJ, Kuypers E, Bos GM, Steinbusch HW, Vanderlocht J, Andriessen P, Germeraad WT, Kramer BW: Systemic G-CSF attenuates cerebral inflammation and hypomyelination but does not reduce seizure burden in preterm sheep exposed to global hypoxia-ischemia. Exp Neurol 2013, 250C:293-303.

81. Liu F, Poursine-Laurent J, Link DC: The granulocyte colony-stimulating factor receptor is required for the mobilization of murine hematopoietic progenitors into peripheral blood by cyclophosphamide or interleukin-8 but not flt-3 ligand. Blood 1997, 90:2522-2528.

82. Petit I, Szyper-Kravitz M, Nagler A, Lahav M, Peled A, Habler L, Ponomaryov T, Taichman RS, ArenzanaSeisdedos F, Fujii N, Sandbank J, Zipori D, Lapidot T: G-CSF induces stem cell mobilization by decreasing bone marrow SDF-1 and up-regulating CXCR4. Nat Immunol 2002, 3:687-694.

83. Trumpp A, Essers M, Wilson A: Awakening dormant haematopoietic stem cells. Nat Rev Immunol 2010, 10:201-209.

84. Deng J, Zou ZM, Zhou TL, Su YP, Ai GP, Wang JP, Xu H, Dong SW: Bone marrow mesenchymal stem cells can be mobilized into peripheral blood by G-CSF in vivo and integrate into traumatically injured cerebral tissue. Neurol Sci 2011, 32:641-651.

85. Kassis I, Zangi L, Rivkin R, Levdansky L, Samuel S, Marx G, Gorodetsky R: Isolation of mesenchymal stem cells from G-CSF-mobilized human peripheral blood using fibrin microbeads. Bone Marrow Transplant 2006, 37:967-976.

86. Corti S, Locatelli F, Strazzer S, Salani S, Del Bo R, Soligo D, Bossolasco P, Bresolin N, Scarlato G, Comi GP: Modulated generation of neuronal cells from bone marrow by expansion and mobilization of circulating stem cells with in vivo cytokine treatment. Exp Neurol 2002, 177:443-452.

87. England TJ, Abaei M, Auer DP, Lowe J, Jones DR, Sare G, Walker M, Bath PM: Granulocyte-colony stimulating factor for mobilizing bone marrow stem cells in subacute stroke: the stem cell trial of recovery enhancement after stroke 2 randomized controlled trial. Stroke 2012, 43:405-411.

88. Yanqing Z, Yu-Min L, Jian Q, Bao-Guo X, Chuan-Zhen L: Fibronectin and neuroprotective effect of granulocyte colony-stimulating factor in focal cerebral ischemia. Brain Res 2006, 1098:161-169.

89. Hess DC, Abe T, Hill WD, Studdard AM, Carothers J, Masuya M, Fleming PA, Drake CJ, Ogawa M: Hematopoietic origin of microglial and perivascular cells in brain. Exp Neurol 2004, 186:134-144.

90. Brazelton TR, Rossi FM, Keshet GI, Blau HM: From marrow to brain: expression of neuronal phenotypes in adult mice. Science 2000, 290:1775-1779.

91. Mezey E, Chandross KJ, Harta G, Maki RA, McKercher SR: Turning blood into brain: cells bearing neuronal antigens generated in vivo from bone marrow. Science 2000, 290:1779-1782.

92. Tondreau T, Lagneaux L, Dejeneffe M, Massy M, Mortier C, Delforge A, Bron D: Bone marrow-derived mesenchymal stem cells already express specific neural proteins before any differentiation. Differentiation 2004, 72:319-326. 
93. Urbich C, Dimmeler S: Endothelial progenitor cells: characterization and role in vascular biology. Circ Res 2004, 95:343-353.

94. Yoon CH, Hur J, Park KW, Kim JH, Lee CS, Oh IY, Kim TY, Cho HJ, Kang HJ, Chae IH, Yang HK, Oh BH, Park YB, Kim HS: Synergistic neovascularization by mixed transplantation of early endothelial progenitor cells and late outgrowth endothelial cells: the role of angiogenic cytokines and matrix metalloproteinases. Circulation 2005, 112:1618-1627.

95. Murohara T, Ikeda H, Duan J, Shintani S, Sasaki K, Eguchi H, Onitsuka I, Matsui K, Imaizumi T: Transplanted cord blood-derived endothelial precursor cells augment postnatal neovascularization. J Clin Invest 2000, 105:1527-1536.

96. Asahara T, Murohara T, Sullivan A, Silver M, van der Zee R, Li T, Witzenbichler B, Schatteman G, Isner JM: Isolation of putative progenitor endothelial cells for angiogenesis. Science 1997, 275:964-967.

97. Tillman BW, Yazdani SK, Geary RL, Corriere MA, Atala A, Yoo JJ: Efficient recovery of endothelial progenitors for clinical translation. Tissue Eng Part C Methods 2009, 15:213-221.

98. Doycheva D, Shih G, Chen H, Applegate R, Zhang JH, Tang J: Granulocyte-colony stimulating factor in combination with stem cell factor confers greater neuroprotection after hypoxic-ischemic brain damage in the neonatal rats than a solitary treatment. Trans/ Stroke Res 2013, 4:171-178.

99. Gabrilove JL, White K, Rahman Z, Wilson EL: Stem cell factor and basic fibroblast growth factor are synergistic in augmenting committed myeloid progenitor cell growth. Blood 1994, 83:907-910.

100. McNiece IK, Langley KE, Zsebo KM: Recombinant human stem cell factor synergises with GM-CSF, GCSF, IL-3 and epo to stimulate human progenitor cells of the myeloid and erythroid lineages. Exp Hematol 1991, 19:226-231.

101. Hess DA, Levac KD, Karanu FN, Rosu-Myles M, White MJ, Gallacher L, Murdoch B, Keeney M, Ottowski P, Foley R, Chin-Yee I, Bhatia M: Functional analysis of human hematopoietic repopulating cells mobilized with granulocyte colony-stimulating factor alone versus granulocyte colony-stimulating factor in combination with stem cell factor. Blood 2002, 100:869-878.

102. Xiao BG, Lu CZ, Link H: Cell biology and clinical promise of G-CSF: immunomodulation and neuroprotection. J Cell Mol Med 2007, 11:1272-1290.

103. Rutella S, Pierelli L, Bonanno G, Sica S, Ameglio F, Capoluongo E, Mariotti A, Scambia G, d'Onofrio G, Leone G: Role for granulocyte colony-stimulating factor in the generation of human T regulatory type 1 cells. Blood 2002, 100:2562-2571.

104. Pan L, Delmonte J, Jr., Jalonen CK, Ferrara JL: Pretreatment of donor mice with granulocyte colonystimulating factor polarizes donor $\mathrm{T}$ lymphocytes toward type-2 cytokine production and reduces severity of experimental graft-versus-host disease. Blood 1995, 86:4422-4429.

105. Klangsinsirikul P, Russell NH: Peripheral blood stem cell harvests from G-CSF-stimulated donors contain a skewed Th2 CD4 phenotype and a predominance of type 2 dendritic cells. Exp Hematol 2002, 30:495501.

106. Adeegbe D, Serafini P, Bronte V, Zoso A, Ricordi C, Inverardi L: In Vivo Induction of Myeloid Suppressor Cells and CD4(+)Foxp3(+) T Regulatory Cells Prolongs Skin Allograft Survival in Mice. Cell Transplant 2011, 20:941-954.

107. Zou L, Barnett B, Safah H, Larussa VF, Evdemon-Hogan M, Mottram P, Wei S, David O, Curiel TJ, Zou W: Bone marrow is a reservoir for CD4+CD25+ regulatory $T$ cells that traffic through CXCL12/CXCR4 signals. Cancer Res 2004, 64:8451-8455.

108. Arpinati M, Green CL, Heimfeld S, Heuser JE, Anasetti C: Granulocyte-colony stimulating factor mobilizes Thelper 2-inducing dendritic cells. Blood 2000, 95:2484-2490.

109. Winerdal M, Winerdal ME, Kinn J, Urmaliya V, Winqvist O, Aden U: Long lasting local and systemic inflammation after cerebral hypoxic ischemia in newborn mice. PLoS One 2012, 7:e36422.

110. Shichita T, Sugiyama Y, Ooboshi H, Sugimori H, Nakagawa R, Takada I, Iwaki T, Okada Y, lida M, Cua DJ, Iwakura Y, Yoshimura A: Pivotal role of cerebral interleukin-17-producing gammadeltaT cells in the delayed phase of ischemic brain injury. Nat Med 2009, 15:946-950. 


\section{Chapter 6}

111. Charles MS, Ostrowski RP, Manaenko A, Duris K, Zhang JH, Tang J: Role of the pituitary-adrenal axis in granulocyte-colony stimulating factor-induced neuroprotection against hypoxia-ischemia in neonatal rats. Neurobiol Dis 2012, 47:29-37.

112. Glass HC, Glidden D, Jeremy RJ, Barkovich AJ, Ferriero DM, Miller SP: Clinical Neonatal Seizures are Independently Associated with Outcome in Infants at Risk for Hypoxic-Ischemic Brain Injury. J Pediatr 2009, 155:318-323.

113. Gluckman PD, Wyatt JS, Azzopardi D, Ballard R, Edwards AD, Ferriero DM, Polin RA, Robertson CM, Thoresen M, Whitelaw A, Gunn AJ: Selective head cooling with mild systemic hypothermia after neonatal encephalopathy: multicentre randomised trial. Lancet 2005, 365:663-670.

114. Miller SP, Weiss J, Barnwell A, Ferriero DM, Latal-Hajnal B, Ferrer-Rogers A, Newton N, Partridge JC, Glidden DV, Vigneron DB, Barkovich AJ: Seizure-associated brain injury in term newborns with perinatal asphyxia. Neurology 2002, 58:542-548.

115. Gibson CL, Bath PM, Murphy SP: G-CSF reduces infarct volume and improves functional outcome after transient focal cerebral ischemia in mice. J Cereb Blood Flow Metab 2005, 25:431-439.

116. Gibson CL, Jones NC, Prior MJ, Bath PM, Murphy SP: G-CSF suppresses edema formation and reduces interleukin-1beta expression after cerebral ischemia in mice. J Neuropathol Exp Neurol 2005, 64:763769.

117. Schabitz WR, Kollmar R, Schwaninger M, Juettler E, Bardutzky J, Scholzke MN, Sommer C, Schwab S: Neuroprotective effect of granulocyte colony-stimulating factor after focal cerebral ischemia. Stroke 2003, 34:745-751.

118. Shyu WC, Lin SZ, Yang HI, Tzeng YS, Pang CY, Yen PS, Li H: Functional recovery of stroke rats induced by granulocyte colony-stimulating factor-stimulated stem cells. Circulation 2004, 110:1847-1854.

119. Six I, Gasan G, Mura E, Bordet R: Beneficial effect of pharmacological mobilization of bone marrow in experimental cerebral ischemia. Eur J Pharmacol 2003, 458:327-328.

120. Minnerup J, Heidrich J, Wellmann J, Rogalewski A, Schneider A, Schabitz WR: Meta-analysis of the efficacy of granulocyte-colony stimulating factor in animal models of focal cerebral ischemia. Stroke 2008, 39:1855-1861.

121. Bath PM, Sprigg N: Colony stimulating factors (including erythropoietin, granulocyte colony stimulating factor and analogues) for stroke. Cochrane Database Syst Rev 2007:CD005207.

122. Schabitz WR, Schneider A: Developing granulocyte-colony stimulating factor for the treatment of stroke: current status of clinical trials. Stroke 2006, 37:1654; author reply 1655.

123. Shyu WC, Lin SZ, Lee CC, Liu DD, Li H: Granulocyte colony-stimulating factor for acute ischemic stroke: a randomized controlled trial. CMAJ 2006, 174:927-933.

124. Sprigg N, Bath PM, Zhao L, Willmot MR, Gray L, Walker MF, Dennis MS, Russell N: Granulocyte-colonystimulating factor mobilizes bone marrow stem cells in patients with subacute ischemic stroke: the Stem cell Trial of recovery EnhanceMent after Stroke (STEMS) pilot randomized, controlled trial (ISRCTN 16784092). Stroke 2006, 37:2979-2983.

125. Ringelstein EB, Thijs V, Norrving B, Chamorro A, Aichner F, Grond M, Saver J, Laage R, Schneider A, Rathgeb F, Vogt G, Charisse G, Fiebach JB, Schwab S, Schabitz WR, Kollmar R, Fisher M, Brozman M, Skoloudik D, Gruber F, Leal JS, Veltkamp R, Kohrmann M, Berrouschot J: Granulocyte ColonyStimulating Factor in Patients With Acute Ischemic Stroke: Results of the AX200 for Ischemic Stroke Trial. Stroke 2013, 44:2681-2687.

126. Lalu MM, McIntyre L, Pugliese C, Fergusson D, Winston BW, Marshall JC, Granton J, Stewart DJ: Safety of cell therapy with mesenchymal stromal cells (SafeCell): a systematic review and meta-analysis of clinical trials. PLoS One 2012, 7:e47559. 
Chapter 7

\section{Summary}

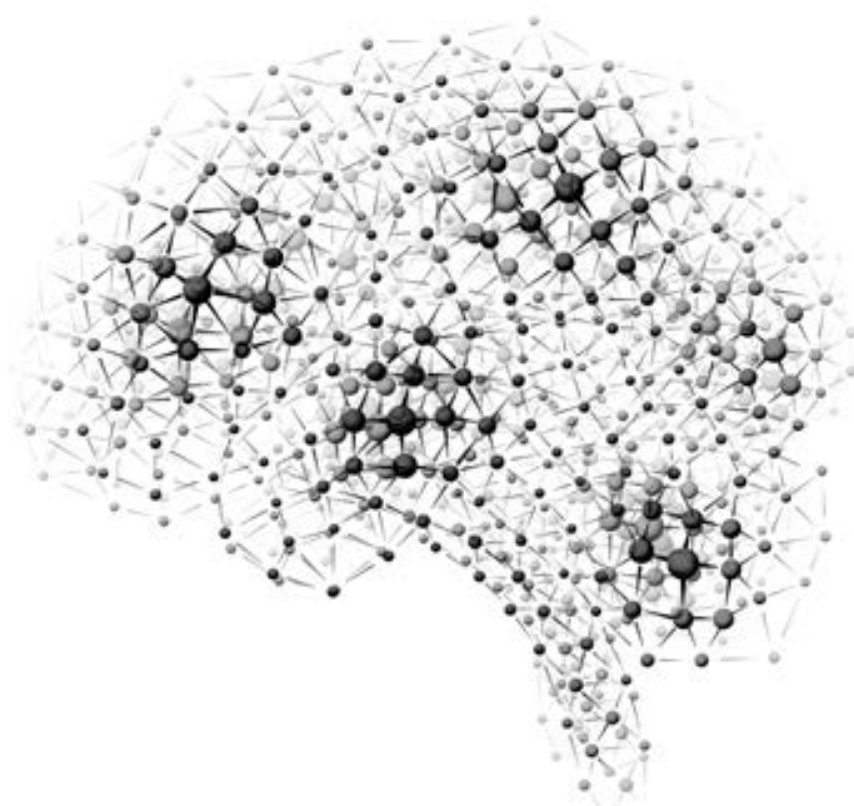




\section{Cell-based therapy for hypoxic-ischemic injury in the preterm brain}

\section{Introduction}

Preterm infants are prone to hypoxic-ischemic encephalopathy. Unfortunately, no therapy exists to treat this brain injury. The objective of this translational research project was (1) to study the role of the cerebral and peripheral inflammatory response in the etiology of preterm brain injury following global hypoxia-ischemia, and (2) to assess the neuroprotective effect of exogenous administration of stem cells and the mobilization of endogenous stem cells in the preterm brain after global hypoxia-ischemia.

\section{Methods}

Instrumented preterm sheep were subjected to global hypoxia-ischemia by 25 minutes of umbilical cord occlusion at a gestational age of 104 (term is 150 ) days ( \pm 32 weeks of human gestation). One hour after global hypoxia-ischemia animals were either treated with (1) exogenous mesenchymal stem cells (MSCs) or (2) mobilization of endogenous stem cells using granulocyte-colony stimulating factor (G-CSF). The study consisted of the treatmentgroups with appropriate controle groups. During a 7 day reperfusion period, all vital parameters, including (amplitude-integrated) electroencephalogram, were recorded. At the end of the experiment, the preterm brain was assessed using histology and diffusion tensor imaging (DTI). The effect of MSCs on the peripheral immune system was assessed in a splenocyte proliferation assay.

\section{Results}

Our findings showed that global hypoxia-ischemia induced marked activation and proliferation of microglia in the preterm brain. Furthermore, we observed mobilization of immune effector cells (T-cells and neutrophils), most likely originating from the spleen, that invaded the preterm brain. These pro-inflammatory changes were associated with loss of pre-oligodendrocytes and hypomyelination. Moreover, global hypoxia-ischemia caused persistent suppression of brain activity and a pronounced increase in the number of seizures.

Administration of exogenous mesenchymal stem cells (MSCs) reduced cerebral inflammation and white matter injury. MSCs induced T-cell tolerance, which was paralleled with diminished mobilization and invasion of these cells in the preterm brain. In addition, MSCs established functional improvement, as shown by decreased number of seizures after global hypoxia-ischemia.

Similarly, mobilization of endogenous stem cells using systemic granulocyte-colony stimulating factor (G-CSF) reduced cerebral inflammation and white matter injury. However, G-CSF did not reduce the number of seizures after global hypoxia-ischemia. 


\section{Conclusion}

We have shown in a translational animal model that cell-based therapy is effective in protecting the preterm brain against the cerebral and peripheral inflammatory responses that are involved in the etiology of white matter injury in the preterm brain after global hypoxia-ischemia. Our findings indicated that the administration of exogenous MSCs in particular is an effective method to reduce hypoxic-ischemic injury in the preterm brain. Our studies form the basis for future clinical trials, which will study feasibility of cell-based therapy in preterm infants with hypoxic-ischemic encephalopathy, creating an eligible chance to improve the life of many preterm infants that suffer from hypoxic-ischemic brain injury. 

Chapter 8

\section{Nederlandse samenvatting}

Summary in Dutch

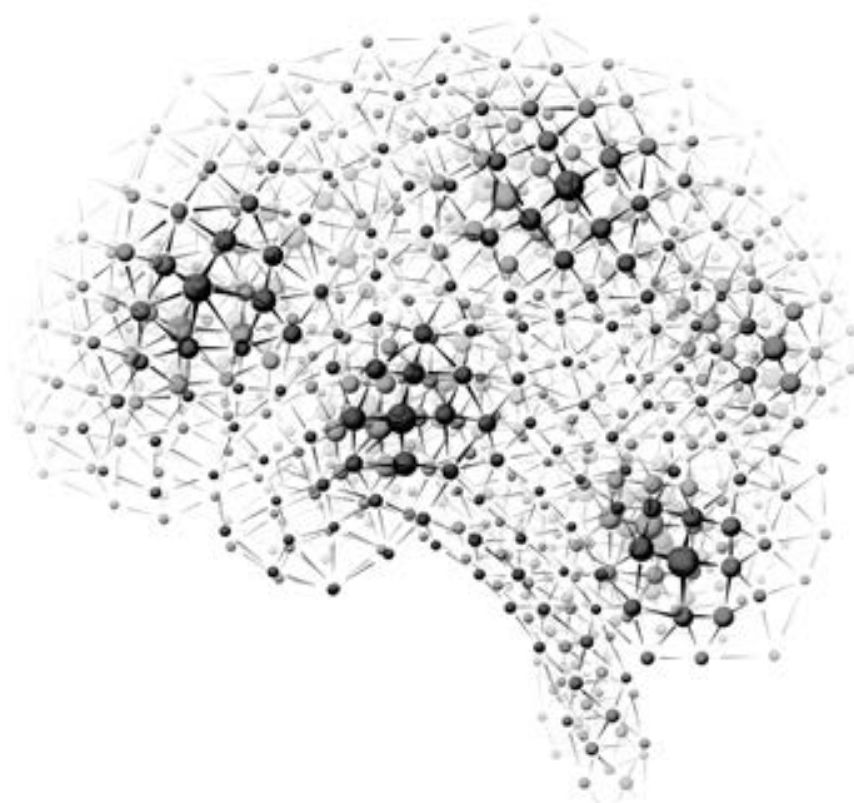




\section{Celtherapie voor schade door zuurstofgebrek in het premature brein}

\section{Introductie}

Hersenschade door zuurstofgebrek komt vaak voor bij premature pasgeborenen . Helaas bestaat er vooralsnog geen therapie om deze schade te behandelen. Het doel van dit translationele project was (1) het onderzoeken van de rol van de cerebrale en perifere ontstekingsresponse in het ontstaan van schade aan het premature brein na zuurstofgebrek en (2) het bestuderen van het beschermende effect van buitenaf toegediende stamcellen, dan wel mobilisatie van eigen stamcellen, op het premature brein na zuurstofgebrek.

\section{Methode}

Geinstrumenteerde premature schapen werden bij een draagtijd van 104 (à terme is 150 ) dagen ( \pm 32 weken humane zwangerschapsduur) in de baarmoeder blootgesteld aan zuurstofgebrek middels 25 minuten navelstrengcompressie. Kort na het zuurstofgebrek werden de dieren behandeld met (1) toediening van mesenchymale stamcellen (MSCs) of (2) met mobilisatie van lichaamseigen stamcellen middels granolocyte-colony stimulating factor (G-CSF). De studies bestonden uit de behandelgroepen en de geschikte controle groepen. Gedurende een reperfusieperiode van 7 dagen werden vervolgens alle vitale parameters, inclusief hersenfilmpje (EEG), opgenomen. Het premature brein werd aan het einde van de studie beoordeeld middels histologie en diffusion tensor imaging (DTI), een geavanceerde MRI techniek. Het effect van MSCs op het perifere immuunsysteem werd beoordeeld middels een kweek experiment waarin miltcellen uit alle studiegroepen werden gestimuleerd om te proliferen.

\section{Resultaten}

Onze resultaten lieten zien dat zuurstofgebrek uitgesproken activatie van microglia, de immuuncellen van het brein, teweeg bracht. Daarnaast zagen we mobilisatie van ontstekingscellen (T-cellen en neutrofiele granulocyten), waarschijnlijk afkomstig uit de milt, die het premature brein binnendrongen. Deze veranderingen gingen gepaard met verlies van pre-oligodendrocyten (witte stof producerende cellen) en verlies van witte stof in het premature brein. Bovendien veroorzaakte zuurstofgebrek blijvende onderdrukking van de hersenactiviteit en een evidente toename van het aantal epileptische insulten (convulsies).

Toediening van MSCs van buitenaf verminderde ontsteking in de hersenen en witte stofschade. MSCs zorgden er voor dat ontstekingscellen niet meer reageerden op prikkels, hetgeen gepaard ging met verminderde mobilisatie en invasie van deze cellen in het premature brein. Tevens brachten MSCs functioneel herstel teweeg, hetgeen werd aangetoond door verminderde convulsies na zuurstofgebrek. 
Mobilisatie van lichaamseigen stamcellen middels intraveneuze toediening van G-CSF reduceerde eveneens ontsteking in de hersenen en witte stofschade. Echter, G-CSF verminderde niet het aantal convulsies na zuurstofgebrek.

\section{Conclusie}

Wij hebben in een translationeel diermodel aangetoond dat celtherapie (toediening van MSCs en mobilisatie van lichaamseigen stamcellen middels G-CSF) in staat is het premature brein te beschermen tegen de ontstekingsrespons in het brein en de ontstekingsrespons van het perifere immuunsystem die beide ten grondslag liggen aan witte stof schade in het premature brein na zuurstofgebrek. Onze resultaten laten zien dat met name het toedienen van MSCs een effectieve methode is om hersenschade door zuurstofgebrek in het premature brein te verminderen. Onze studies vormen het fundament voor toekomstige klinische studies waarin de toepasbaarheid van celtherapie voor hersenschade bij premature pasgeborenen onderzocht gaat worden. Met deze inspanningen kunnen we in de toekomst mogelijk het leven van vele premature kinderen met hersenschade verbeteren. 

Chapter 9

\section{Valorization}

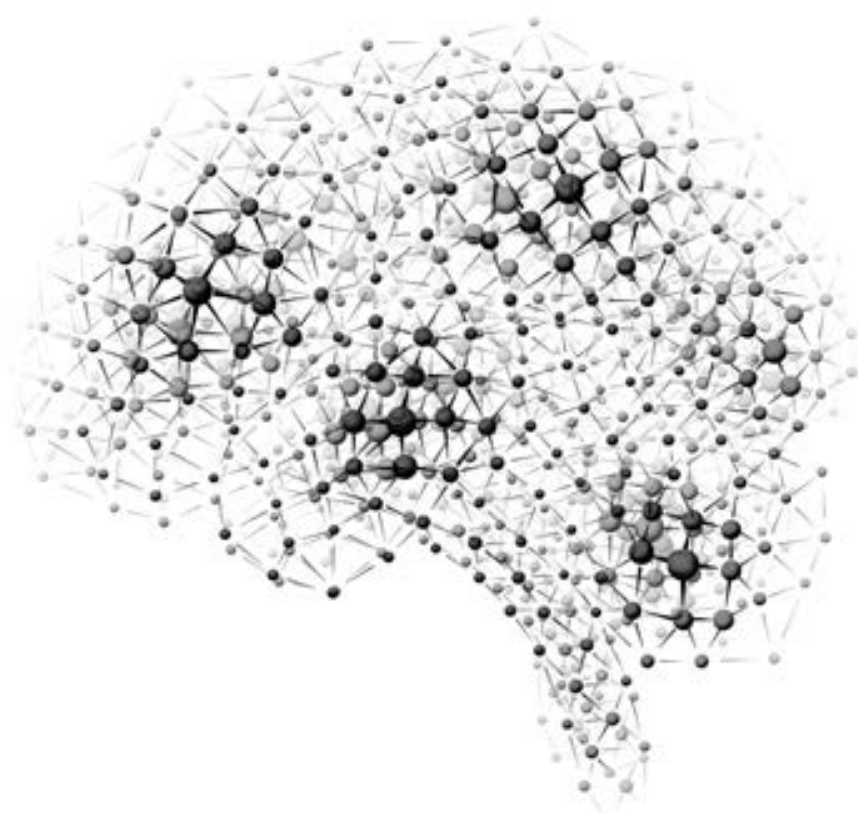




\section{Relevance}

This thesis addresses a huge health care problem. The project is aimed at developing a therapy for preterm babies with brain injury. Brain injury is the biggest contributor to perinatal mortality and long-term morbidity in preterm infants [1, 2]. The magnitude of the problem of prematurity and brain injury on a societal scale is illustrated by the large impact on the health care budget. Health care costs for preterm birth are inversely related with gestational age [3]. In Finland for example, health care costs of preterm birth in the first two years of life have been estimated to be around 100.000,- EUR for each surviving preterm infants (< $1000 \mathrm{~g}$ ) compared to 3.000,- EUR for normal birth weight children [4]. Two thirds of these costs consist of initial hospitalization costs [4]. Initial hospitalization costs can increase up to 250.000, - EUR in extremely preterm infants born around 25 weeks of gestation $[3,5]$. These extremely preterm infants are usually in hospital for a mean of one hundred days with an average of 45 days on intensive care or high care, which costs around 2.500,- EUR per infant per day [6]. Furthermore, initial hospitalization costs are related to the degree of surgical intervention and the intensity of assisted ventilation [3]. Inevitably, neonatal costs of surviving children are higher than for those infants who die [3]. Longer term economic costs of preterm birth after the neonatal period are associated with re-hospitalization, medical aids, outpatient visits, medical and non-medical therapy, special education and day care and have a great impact on the health care budget $[3,5]$. Brain injury and consecutive developmental disabilities are the most important contributors to economic life time costs of prematurity. A study by the Centers for Disease Control and Prevention in the United States calculated life time economic costs per infant of 1.000.000 USD for mental retardation, 920.000 USD for cerebral palsy, 420.000 USD for hearing loss and 570.000 USD for vision impairment [7]. A Danish study estimated the life time economic costs of cerebral palsy to be around 800.000 EUR per patient [8]

Besides a huge financial burden for society, preterm birth and brain injury pose an enormous financial burden on families of patients [3,5]. Parents of preterm infants are confronted with increasing out of pocket expenses which are not covered by their insurance. These expenses are predominantly caused by transportation, child care for siblings and accommodation during hospitalization [3]. In addition, parents of preterm infants often have to reduce their number of working hours which leaves them with significant wage losses [3-5].

It is evident that preterm birth is not merely a financial burden to society and families, it has a huge impact on the emotional well-being of patients, siblings and parents $[3,5,9]$. Mothers of preterm infants are at high risk to develop postpartum depression caused by stress and disappointment of the early birth, self-reproaches, the separation from their fragile child with only limited opportunities to interact, the ongoing medical crisis and the possibility of death or continued health and developmental problems of their child [9]. On the longer term parents of preterm 
infants are at higher risk to get divorced and loose friends and social activities, this risk significantly increases when the child is handicapped [10]. The enormous familial burden of preterm birth stresses the need for family centered care in perinatal medicine.

Fortunately, health care in perinatology has made huge steps in the last decades, which has improved outcome in preterm infants. As a consequence of enhanced perinatal care, the boundary of survival has shifted to earlier age. This shift comes at a cost, since chances of event-free survival are low in extreme prematurity. The most important disabling sequelae of prematurity are related to injury to the vulnerable immature brain. It can be expected that neurological outcome will be improved with ongoing reduction of risk factors for brain injury, such as prevention of preterm birth in the first place, growth retardation, infection, circulatory and ventilator disturbances by mechanical ventilation. Nevertheless a certain degree of brain injury reversely related to gestational age will always be associated with prematurity. The preceding emphasizes the strong need for neuroprotective therapy for preterm infants with brain injury.

\section{Therapeutic strategy}

Given the large impact on a societal and familial scale and the high incidence of neurodevelopmental complications, it is of utmost importance to accelerate the development of brain protective strategies for preterm infants. Therefore, the general objective of this thesis is to develop a therapy for preterm babies with brain injury, for whom currently there is no cure. In this thesis, we have studied the neuroprotective effects of cell-based therapy in the preterm brain. An innovative therapeutic strategy such as cell-based therapy for brain injury in the preterm brain must be first tested for efficacy and safety in an animal model before clinical application. We have established a reproducible translational animal model for white matter disease induced by global hypoxia-ischemia in fetal sheep. This animal model has important advantages over other potential species, since the developmental biology and the physiology of the fetal lamb closely resemble humans and the model allows complex fetal surgery. In this model we established clinical read-out parameters such as diffusion tensor imaging and amplitude integrated EEG. These elements provide a reliable clinical platform for the investigation of drugs for potential use in humans.

Our findings showed the reproducibility of our model and that global hypoxiaischemia induced marked activation and proliferation of microglia in the preterm brain $[11,12]$. Furthermore, we observed mobilization of immune effector cells (T-cells and neutrophils), most likely originating from the spleen, that invaded the preterm brain $[11,13]$. These pro-inflammatory changes, which are initiated within hours after the ischemic insult, were associated with loss of pre-oligodendrocytes and hypomyelination [11]. Moreover, global hypoxia-ischemia caused persistent suppression of brain activity 
and a pronounced increase in the number of seizures [11, 13, 14]. Administration of exogenous mesenchymal stem cells (MSCs) reduced cerebral inflammation and white matter injury. MSCs prevented severness of the inflammation and induced T-cell tolerance, which was paralleled with diminished mobilization and invasion of these cells in the preterm brain [13]. In addition, MSCs established functional improvement, as shown by decreased number of seizures after global hypoxia-ischemia [13]. Similarly, mobilization of endogenous stem cells using systemic granulocyte-colony stimulating factor (G-CSF) administration reduced cerebral inflammation and white matter injury [14]. However, G-CSF did not reduce the number of seizures after global hypoxiaischemia [14].

In conclusion, we have shown that cell-based therapy can be effective in protecting the preterm brain against the cerebral and peripheral inflammatory responses that are involved in the etiology of white matter injury. Our findings indicated that cell-based therapy may become an effective method to reduce white matter injury in the preterm brain.

\section{Target groups}

The patient group that we intend to target with this research primarily consists of preterm babies that suffer from brain injury caused by antepartum, peripartum or postpartum perinatal hypoxia-ischemia. In addition, term babies that suffer from brain injury may also benefit from the findings of this project. Although cooling therapy has been shown to improve neurodevelopmental outcome in mild to moderate cases of brain injury in term infants, cell-based therapy may enhance neuroprotection in these cases. In addition, severe cases of hypoxic-ischemic brain injury in term infants have been shown not to benefit from cooling. Cell-based therapy may provide neuroprotective potential in these term infants with severe brain damage.

The outcome of this innovative project is of high interest for a broad spectrum of clinicians, such as obstetricians, perinatologists, neonatologists, pediatric intensive care specialists, child neurologists and rehabilitation physicians, who focus on the neuroprotection of the developing brain and improving neurodevelopmental outcome for preterm infants suffering from white matter disease.

Basic scientists will benefit from the knowledge on the basic mechanisms of white matter disease in the preterm brain that has been acquired in our clinically relevant animal model. Neuroscientists can adopt the findings of our study and investigate the therapeutic effect of cell-based therapy into more detail. Additionally, in vitro or exvivo (co-)culture studies will further unravel the neuroprotective properties of MSCs and G-CSF. Furthermore, in our model, we have established an array of outcome parameters including brain histology, functional immunological cell-culture assays, diffusion tensor imaging techniques and brain activity monitoring by (amplitude- 
integrated) electroencephalogram. These outcome parameters can be adopted by other research groups for experimental purposes and to improve clinical practice.

Due to the close similarity with the human situation, the sheep model has a track record of translation of experimental findings into neonatal medicine, for example in neonatal neurology (e.g. cooling therapy in term infants) and neonatal respiratory care (e.g. ventilation strategies and surfactant administration). Therefore, translational neuroscientists and clinical trial scientists can use the preclinical data gained in our study as a template for the design of future clinical trials.

\section{Spin-off activities and products}

The potential spin-off of this innovative research project is considerable. Understanding the basic mechanisms of disease and the therapeutic mechanisms of cell based therapy creates new insights in disease processes and provides exciting opportunities for the development of therapies. The concept of cell-based therapy for hypoxic-ischemic injury in the preterm brain presented in this thesis can be further developed and commercialized by (spin-off) companies that provide the tools (i.e. the cells) and support the logistics of clinical implementation (i.e. initiating clinical trials).

Before clinical translation, a number of activities and products need to be developed. Stem cell products need to be manufactured in closed systems under Good Manufacturing Practice (GMP). Quality control and assurance need to be firmly embedded in the process of developing GMP stem cell products. This demands the setup of an infra-structure with clean rooms, closed culturing systems and GMP laboratory facilities. Standard operating procedures (SOP) have to be developed. The Investigational Medicinal Product Dossier (IMPD), which is the basis for approval of clinical trials in Europe, has to be written. Permission for a clinical trial needs to be obtained from the Central Committee on Research Involving Human Subjects (Centrale Commissie Mensgebonden Onderzoek; CCMO). Intellectual property or first to market principle may be claimed to protect the developed stem cell product. The commercialization of the stem cell product requires the writing of a business plan, market research and estimation of production costs and target earnings. Fund raising activities can be organized to raise awareness for prematurity and neurodevelopmental disability and to obtain sponsorship for further research.

The road to clinical translation of cell-based therapy for brain injury in preterm infants involves many steps for which our group has the adequate infrastructure in our institute supported by our cross-disciplinary network of international collaborators. As such, Maastricht University Medical Center could play a leading role as a center of excellence for neonatal cell-based therapy in the Benelux and the Euregion. 


\section{Innovation}

This thesis presents an innovative approach to develop a state-of-the-art therapy for preterm babies with brain injury. We adopted a translational strategy by first taking the clinical problem of brain injury in preterm infants from bedside to bench. First, we developed a translational animal model of brain injury induced by global hypoxiaischemia in preterm sheep, which closely mimics the human situation and used readout parameters which are common practice in daily clinical care. [11, 12]. Second, we studied the potential underlying mechanisms of brain injury in the preterm brain to identify targets for therapy. We identified the reduction of neuroinflammation and support of regeneration as two principal targets to prevent brain injury in the preterm brain [11]. Consistently, we explored the neuroprotective potential of different types of cell-based therapies in our ovine model and assessed whether their anti-inflammatory and regenerative properties improved the structural and functional outcome of the preterm brain $[13,14]$. Our findings indicated that cell-based therapy may become an effective method to reduce white matter injury in the preterm brain [13].

Now that we have shown the effectiveness of cell-based therapy in a highly relevant animal model of preterm brain injury, it is time to make the translational step from bench to bed and assess the neuroprotective potential of stem cell therapy in clinical trials. We aim to prevent the progression of brain injury as early as possible by reducing inflammation and stimulating regeneration early after the ischemic insult. This creates the opportunity to treat white matter disease in the earliest possible window of therapeutic opportunity. These endeavors create an eligible chance to improve the life of many preterm infants that suffer from brain injury thereby increasing disability-free lives.

\section{Scope}

The first steps towards clinical implementation of cell-based therapy for hypoxicischemic injury in the preterm brain have been taken. If clinical application reaffirms the experimental promises of regenerative medicine, it may still take a decade before this innovative therapy becomes standard of clinical care.

Translation from bench to bedside mandates proof of effect and safety in a clinical setting. We have shown in our translational animal model that stem cell therapy induces short-term improvement in structure and function of the preterm brain. The long-term therapeutic effects of cell-based therapy for hypoxic-ischemic injury in the preterm brain remain to be determined. Can we improve the motor skills of affected preterm infants? Can their school and social performance be improved? All these questions remain to be answered. Concerning the safety of stem cell therapy, several studies have shown the genetic stability of therapeutic stem cell products and the low risk of graft-induced malignancies [15]. Clinical trials in adult stroke patients show no 
side effects of allogeneic stem cell infusion [16]. However, the life-time risk of developing complications related to the cell-based therapy can be expected to be higher in preterm infants, whom may have a longer post-treatment life expectancy in comparison to older stroke patients.

In order to develop an optimal cell-based therapy for hypoxic-ischemic injury in the preterm brain timing is essential. In this thesis the optimal therapeutic window of opportunity was identified within the acute phase after the insult. The short time span between the insult and the optimal timing of therapy complicates the application of autologous stem cells (i.e. cord blood stem cells or induced pluripotent stem cells derived from fibroblasts), which take time to harvest and culture. Therefore, off-theshelf allogeneic stem cell products seem to be most feasible for cell-based therapy for hypoxic-ischemic injury in the preterm brain.

Further research is needed to determine whether the actual stem cells are needed for the therapeutic effect. There is evidence that the secretome of MSCs mediates similar anti-inflammatory and regenerative effects than the cells that secreted them $[15,17-19]$. This strategy avoids the potential risks involved with living allogeneic cell transplantation, i.e. graft versus host disease or tumour formation [15]. Thinking one step further, intensive stem cell research may lead to the identification of a single immunomodulatory or neurotrophic factor, which is primarily responsible for the therapeutic effect. The discovery of such a therapeutic agent may pave the way for its (recombinant) pharmaceutical manufacturing and clinical application as a drug.

In conclusion, this thesis presents the potential of cell-based therapy for hypoxicischemic injury in the preterm brain. Our studies may form the basis for future clinical trials, which will study feasibility of neuroprotective therapy in preterm infants with hypoxic-ischemic brain injury, creating an eligible chance to improve the life of many preterm infants by increasing disability-free lives. 


\section{Chapter 9}

\section{References}

1. Volpe JJ: Brain injury in premature infants: a complex amalgam of destructive and developmental disturbances. Lancet Neurol 2009, 8:110-124.

2. Saigal S, Doyle LW: An overview of mortality and sequelae of preterm birth from infancy to adulthood. Lancet 2008, 371:261-269.

3. Hodek JM, von der Schulenburg JM, Mittendorf T: Measuring economic consequences of preterm birth Methodological recommendations for the evaluation of personal burden on children and their caregivers. Health Econ Rev 2011, 1:6.

4. Tommiska V, Tuominen R, Fellman V: Economic costs of care in extremely low birthweight infants during the first 2 years of life. Pediatr Crit Care Med 2003, 4:157-163.

5. Institute of Medicine (Ed.). Preterm birth: Causes, Consequences and Prevention. Washington: The National Academies Press; 2007.

6. Gilbert WM, Nesbitt TS, Danielsen B: The cost of prematurity: quantification by gestational age and birth weight. Obstet Gynecol 2003, 102:488-492.

7. Economic costs associated with mental retardation, cerebral palsy, hearing loss, and vision impairment-United States, 2003. MMWR Morb Mortal Wkly Rep 2004, 53:57-59.

8. Kruse M, Michelsen SI, Flachs EM, Bronnum-Hansen H, Madsen M, Uldall P: Lifetime costs of cerebral palsy. Dev Med Child Neurol 2009, 51:622-628.

9. Davis L, Edwards $\mathrm{H}$, Mohay $\mathrm{H}$, Wollin J: The impact of very premature birth on the psychological health of mothers. Early Hum Dev 2003, 73:61-70.

10. Kusters CD, van der Pal SM, van Steenbrugge GJ, den Ouden LS, Kollee LA: [The impact of a premature birth on the family; consequences are experienced even after 19 years]. Ned Tijdschr Geneeskd 2013, 157:A5449.

11. Jellema RK, Lima Passos V, Zwanenburg A, Ophelders DR, De Munter S, Vanderlocht J, Germeraad WT, Kuypers E, Collins JJ, Cleutjens JP, Jennekens W, Gavilanes AW, Seehase M, Vles HJ, Steinbusch H, Andriessen P, Wolfs TG, Kramer BW: Cerebral inflammation and mobilization of the peripheral immune system following global hypoxia-ischemia in preterm sheep. J Neuroinflammation 2013, 10:13.

12. Zwanenburg A, Jellema RK, Jennekens W, Ophelders D, Vullings R, van Hunnik A, van Pul C, Bennet $L$, Delhaas T, Kramer BW, Andriessen P: Heart rate-mediated blood pressure control in preterm fetal sheep under normal and hypoxic-ischemic conditions. Pediatr Res 2013, 73:420-426.

13. Jellema RK, Wolfs TG, Lima Passos V, Zwanenburg A, Ophelders DR, Kuypers E, Hopman AH, Dudink J, Steinbusch HW, Andriessen P, Germeraad WT, Vanderlocht J, Kramer BW: Mesenchymal stem cells induce T-cell tolerance and protect the preterm brain after global hypoxia-ischemia. PLoS One 2013, 8:e73031.

14. Jellema RK, Lima Passos V, Ophelders DR, Wolfs TG, Zwanenburg A, De Munter S, Nikiforou M, Collins JJ, Kuypers E, Bos GM, Steinbusch HW, Vanderlocht J, Andriessen P, Germeraad WT, Kramer BW: Systemic G-CSF attenuates cerebral inflammation and hypomyelination but does not reduce seizure burden in preterm sheep exposed to global hypoxia-ischemia. Exp Neurol 2013, 250C:293-303.

15. Gortner L, Felderhoff-Muser U, Monz D, Bieback K, Kluter H, Jellema RK, Kramer BW, Keller M, Reiss I, Horn PA, Giebel B: Regenerative therapies in neonatology: clinical perspectives. Klin Padiatr 2012, 224:233-240.

16. Hess DC, Sila CA, Furlan AJ, Wechsler LR, Switzer JA, Mays RW: A double-blind placebo-controlled clinical evaluation of MultiStem for the treatment of ischemic stroke. Int J Stroke 2014, 9:381-386.

17. Biancone L, Bruno S, Deregibus MC, Tetta C, Camussi G: Therapeutic potential of mesenchymal stem cell-derived microvesicles. Nephrol Dial Transplant 2012, 27:3037-3042.

18. Katsuda T, Kosaka N, Takeshita F, Ochiya T: The therapeutic potential of mesenchymal stem cell-derived extracellular vesicles. Proteomics 2013, 13:1637-1653.

19. Lai RC, Arslan F, Lee MM, Sze NS, Choo A, Chen TS, Salto-Tellez M, Timmers L, Lee CN, El Oakley RM, Pasterkamp G, de Kleijn DP, Lim SK: Exosome secreted by MSC reduces myocardial ischemia/reperfusion injury. Stem Cell Res 2010, 4:214-222. 


\section{Dankwoord Acknowledgements}

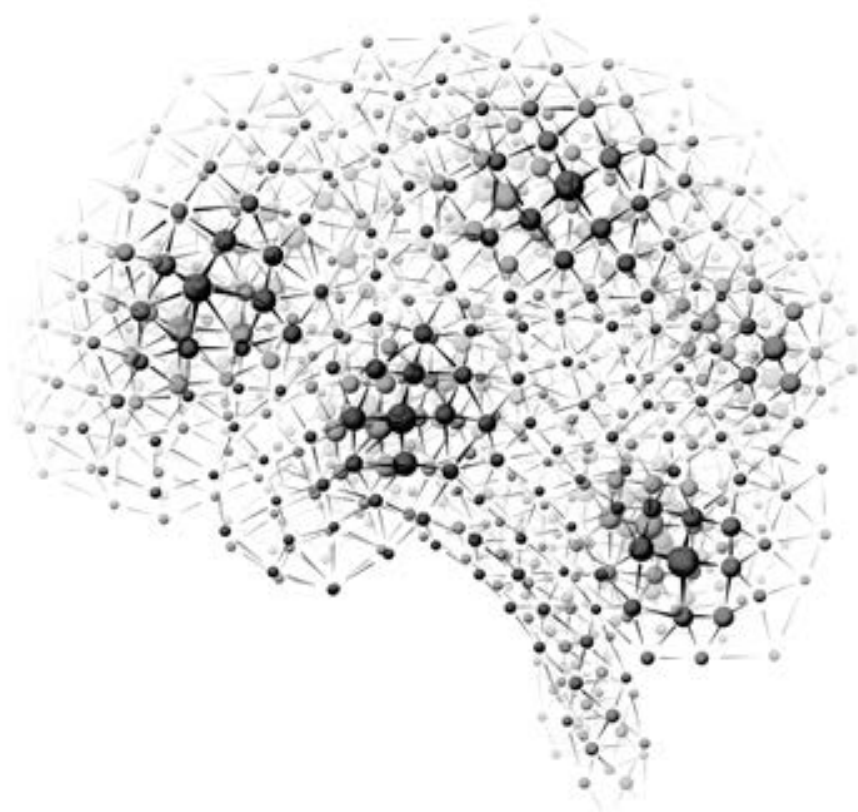


Dit omvangrijke promotieproject was niet tot stand gekomen zonder de hulp van veel collega's, familie en vrienden. Via deze weg wil ik al deze mensen heel hartelijk danken.

Allereerst wil ik het promotieteam bestaande uit Prof. Dr. Boris Kramer, Prof. Dr. Harry Steinbusch, Dr. Wilfred Germeraad en Dr. Peter Andriessen heel hartelijk danken. Beste Harry, bedankt voor het vertrouwen en het feit dat ik onder de paraplu van the School for Mental Health and Neuroscience en EURON de gelegenheid heb gekregen dit proefschrift aan te vangen en te voltooien door de "Maastricht/Aachen Rotationstelle" beurs. Beste Wilfred, ik wil jou hartelijk danken voor de ondersteuning op jouw lab van de Tumor Immunologie, maar bovenal wil ik je danken voor de inspirende discussies, de morele steun en de afleiding op de schaatsbaan. Beste Peter, ontzettend bedankt voor de onmisbare technische ondersteuning die dit project naar een hoger niveau heeft gebracht en het inspirerende voorbeeld dat je voor mij stelt als clinicus én wetenschapper. Beste Boris, ik kan me onze eerste ontmoeting en brainstorm nog herinneren als de dag van gisteren. We zaten meteen op één lijn en maakten een ambitieus plan. Jouw vertrouwen in mij en jouw onuitputtelijke inzet voor de wetenschap hebben de voorwaarden gecreëerd om alles uit me zelf en dit project te halen. Je drijft me af en toe tot het uiterste van mijn kunnen, maar je bent er ook altijd voor mij op moeilijke momenten. Ik hoop dat onze waardevolle samenwerking en vriendschap nog heel veel moois zal opleveren.

In de voltooiing van dit proefschrift en mijn wetenschappelijke vorming is de ondersteuning en vriendschap van Dr. Tim Wolfs en Dr. Joris Vanderlocht van onschatbare waarde geweest. Beste Tim, met jouw kritische blik en messcherpe feedback heb je mij op een cruciaal moment een belangrijke duw in de rug gegeven en ben je mijn voortgang blijven steunen. Daarnaast heb je als hoofd van het lab Kindergeneeskunde de technische ondersteuning van veel onderzoeksprojecten een impuls gegeven. Gelukkig was er altijd een hele gezonde balans tussen hard werken en heel veel plezier maken. We hebben regelmatig op de grond gelegen van het lachen met tranen in de ogen. Maatje bedankt!

Beste Joris, ik kan me nog heel goed herrineren dat Boris en ik voor het eerst bij jou en Wilfred op de kamer over ons project kwamen praten. Jullie waren direct enthousiast en La Chouffe werd de bindende factor van onze mooie samenwerking. Joris, je hebt mij wegwijs gemaakt in de wereld van immunologie en flow cytometrie. Onze vriendschap heeft je gelukkig er nooit van weerhouden om af en toe eens flink de poten onder mijn proefopzet of onderzoeksresultaten af te zagen. Dit waardeer ik enorm!

De leden van de leescommissie bestaande uit Prof. Dr. Luc Zimmermann (voorzitter), Prof. Dr. Frans Ramaekers, Prof. Dr. Marc de Baets, Prof. Dr. Arie Franx, Prof. Dr. Pierre 
Gressens en de leden van de corona wil ik hartelijk danken voor het lezen en beoordelen van mijn proefschrift.

Alle PhD studenten van het lab Kindergeneeskunde wil ik ontzettend bedanken voor de gezeligheid en samenwerking tijdens experimenten. Dr. Markus Gantert, bedankt voor jouw vriendschap en het aanleren van de chirurgische vaardigheden die ik nodig had bij de opzet van het diermodel. Daan Ophelders, ontzettend bedankt voor je onaflatende inzet en enthousiasme voor dit project Ik wens je heel veel succes met de voortzetting ervan. Dr. Jennifer Collins, Alex Zwanenburg, Dr. Elke Kuypers, Maria Nikiforou, Dr. med. Matthias Seehase, Dr. med. Matthias Hütten, Dr. Coen Willems, Monique Willems en Verena Lambermont, bedankt voor jullie inzet en ondersteuning bij mijn experimenten. Zonder jullie hulp was het onbegonnen werk geweest.

Ik heb altijd kunnen rekenen op de hulp en expertise van de laboranten van het lab Kindergeneeskunde. Zij hebben zich altijd keihard ingezet om de experimenten zo optimaal te laten verlopen. Leon Janssen, Dennis Kruk, Nico Kloosterboer en Lilian Kessels, bedankt voor jullie ondersteuning en de prettige samenwerking. Daarnaast wil ik de vele studenten die hebben geassisteerd bij de epxerimenten bedanken. Met name Stephanie De Munter, Yixuan Zhang en Sophie Kienhorst hebben een belangrijke bijdrage geleverd.

A special thanks to Prof. Dr. Laura Bennet. Dear Laura, thank you very much for your support in the initial phase of the project when I was setting up the animal model. Despite the twelve hour time difference between the Netherlands and New Zealand, our 'troubleshooting hotline' was of enormous help.

De medewerkers van het CPV en de DEC hebben een essentiele rol gespeeld bij de correcte uitvoering van de dierexperimenten. Dr. Barry Plooijer, Dr. Saskia Seeldraaijers, Joyce Suyk, Sanne Bout, Petra Dijkstra, Frans Slangen en Marianne Quaden bedankt voor jullie betrokkenheid en de prettige samenwerking.

Ook wil ik graag Arne van Hunnik van de vakgroep Fysiologie bedanken voor de onmisbare technische hulp bij het ontwerpen, installeren en toepassen van fysiologische meetapparatuur. De medewerkers van IDEE en Maastricht Instruments, met name Youri Curfs en Iwan de Jong, wil ik bedanken voor de ontwikkeling van de MPAQ meetsystemen en de bijbehorende software. Dr. Ward Jennekens en Dr. Rik Vullings, bedankt voor jullie 'tips and tricks' bij het uitvoeren en analyseren van de fysiologische metingen. Jack Cleutjens bedank ik voor het ontwerpen van software voor immunohistochemische analyses. 
De collega's van the School for Mental Health and Neuroscience, wil ik graag bedanken voor de goede samenwerking. Hellen Steinbusch, door jouw inzet zijn de breinanalyses naar een hoger niveau getild. Dr. Danilo Gavilanes, Prof. Dr. Hans Vles, Dr. Eveline Strackx en Dr. Evi Vlassaks wil ik graag danken voor de prettige samenwerking en de feedback tijdens besprekingen en op manuscripten.

De collega's van het Tumor Immunologie lab, Birgit Senden, Tammy Oth, Dr. Silvie Cloosen en Dr. Bob Meek wil ik ontzettend bedanken voor de labtechnische ondersteuning, het geduld bij het oplossen van technische problemen tijdens mijn FACS experimenten en bovenal de fijne samenwerking. Prof. Dr. Gerard Bos wil ik graag danken voor het faciliteren van mijn onderzoek. Gerard, bedankt dat je, na een kennismakingsgesprek met Boris en mij, ons aan jouw mensen van het lab Tumor Immunologie, Wilfed en Joris, hebt voorgesteld. Daarnaast bedankt voor het beschikbaar stellen van G-CSF voor de experimenten.

Dr. Valéria Lima Passos wil ik hartelijk danken voor de ondersteuning bij de statistiek. Beste Valéria, je hebt mij met heel veel geduld en betrokkenheid geleerd dat de juiste toepassing van statistiek onmisbaar is voor goede wetenschap en betekenisvolle interpretatie van resultaten. Jouw kritische houding en nauwgezette benadering hebben mijn manuscripten aanzienlijk verbeterd. Bovenal wil ik je bedanken voor het feit dat je me altijd met open armen hebt ontvangen en ontzettend veel morele steun hebt geboden.

De collega's van het Erasmus MC in Rotterdam, Dr. Jeroen Dudink en Dr. Anneriet Heemskerk, bedank ik voor de hulp bij de MRI metingen en analyses. Beste Jeroen, je hebt vanaf het begin een zeer belangrijke bijdrage geleverd aan dit project. Jouw aanstekelijke enthousiasme en de manier waarop jij kliniek en wetenschap combineert, is een inspiratiebron voor mij en ik hoop dan ook dat we onze mooie samenwerking lang voort zullen blijven zetten.

Dr. Walter Backes en Jos Slenter van de vakgroep Radiologie wil ik hartelijk danken voor de optimalisatie en nauwgezette uitvoering van de MRI metingen van de breintjes.

De collega's van het Universitätsklinikum in Aachen, Dr. Mark Schoberer, Dr. Jutta Arens en Prof. Dr. Orlikowsky bedank ik voor de inspirerende experimenten met de 'artifical placenta'.

Prof. Dr. Frans Ramaekers, Dr.Ton Hopman en Monique Ummelen wil ik bedanken voor de uitstekende hulp bij de FISH experimenten. 
Many thanks go to Dr. Robert W. Mays, Dr. Robert Deans and Dr. Jef Pinxteren of Athersys Inc. and ReGenesys who provided technical help with the stem cell differentiation assays described in this thesis. Dear Willie, Bob and Jef, we share the same concepts and ideas about regenerative medicine. On top of that we share our love for Belgium beer and a good glass of wine! All together this is an excellent basis for current and future collaboration!

Prof. Dr. Catherine Verfaillie en Dr. Valerie Roobrouck van het Stem Cell Institute Leuven (SCIL) wil ik graag bedanken voor het bijbrengen van de basisprincipes van stamcelkweken en stamceldifferentiatie.

Uiteraard wil ik ook mijn klinische collega's in Sittard, Veldhoven en Maastricht bedanken. Allereerst bedank ik hen voor de stimulans en tijd die ze mij hebben gegeven om mijn klinische horizon met wetenschap te verbreden. Maar vooral wil ik hen bedanken voor de dagelijkse input in mijn opleiding tot kinderarts.

De secretaresses en manager van de Kindergeneeskunde Natascha Vrijhoeven, Peggy van den Heuvel en Tamara Cauberg dank ik hartelijk voor alle administratieve ondersteuning en "trouble shooting" in het soms ondoorgankelijke oerwoud van academische administratie.

Mijn wetenschappelijke nestor en goede vriend is Dr. Peter Frederik. Beste Peter, het is allemaal begonnen tijdens mijn baantje als student-assistent op jouw lab, waar ik mijn maat van het eerste maastrichtse uur, Hilco Theeuwes, op mocht volgen. Samen met Paul Bomans, Prof. Dr. Matthijs Hesselink, Prof. Dr. Chris Reutelingsperger en Prof. Dr. Leo Hofstra bracht jij mij de beginselen van de wetenschap bij. Met name jouw devies "verkoop geen onzin" en "schrijven is de kunst van het weglaten" vormt nog steeds het vertrekpunt van mijn wetenschappelijke ondernemingen. Je hebt mijn nieuwsgierigheid en doorzettingsvermogen altijd beloont met onomwonden steun, bedankt.

Nooit was het mij gelukt om deze onderneming tot een goed einde te brengen zonder de liefdevolle steun van familie en vrienden. Daarom een ode aan hen:

Mijn vrienden dank ik hartelijk voor hun oprechte vriendschap en de mooie momenten van relativering en ontspanning. Arjen, Johannes, Jurjen en Cor, ofwel de Friesche Krentenbroden, ik ben trots op onze vriendschap die terug gaat naar het begin van de middelbare schooltijd toen we decor bouwden en voetbalden op het schoolplein. Ward, Martijn, Henri, Joep, Sjoerd en Bart, ofwel de Falstaff mannen, onze vriendschap gaat terug naar het begin van de studententijd toen we barmannen waren aan het mooiste pleintje van Maastricht. Inmiddels zijn we verspreid over de hele wereldbol, maar als we elkaar enige tijd niet gezien hebben, is het heel snel weer als vanouds. Ik 
hoop dat die trip naar Lapland er daadwerkelijk gaat komen! Femke en Jeroen, Sjoerd en Nora, bedankt voor de ontspannende diners, jullie luisterende oor, maar bovenal jullie liefdevolle aanmaningen om het af en toe een beetje rustiger aan te doen. Martijn en Godie, bedankt voor jullie morele steun op grote afstand, het is altijd bourgondisch gezellig als we elkaar weer zien. Sjoerd, 'grote broer', bedankt dat jij mijn paranimf wilt zijn.

Mijn schoonfamilie, Joris, Emmy, Esther en Ivo, bedankt voor jullie steun bij alle verbouwingen tijdens onze promotie en opleiding. Bovenal bedankt voor de heerlijk ontspannende momenten in Halsteren en Frankrijk.

Anna, Vincent, Roos en Linde, ik wil jullie graag bedanken voor de fijne momenten samen. Lieve Anna, bedankt dat je mijn paranimf wilt zijn. Het is een geruststellende gedachte te weten dat mijn zus, zoals altijd, achter me staat.

Lieve heit en mem, jullie hebben mij het vertrouwen en doorzettingsvermogen gegeven om mijn passie te volgen en alles er uit te halen wat er in zit. Bedankt voor jullie onvoorwaardelijke steun en betrokkenheid. Jullie zijn er altijd voor mij! Philippine, bedankt dat je altijd klaar staat met raad en daad en voor de heerlijke diners. Joop, bedankt voor je geduldig luisterend oor en relativerende adviezen.

Lieve Moos, ontzettend veel inspiratie voor dit proefschrif is ontsproten tijdens onze lange wandelingen op de Sint-Pietersberg. Veruit het belangrijkste deel heb ik geschreven met jou aan mijn voeten. Bedankt dat je ons leven zo verrijkt hebt!

Lieve Stephanie, jij als geen ander weet hoe zwaar het onderzoek af en toe was en desondanks bleef je altijd in mij en de goede afloop geloven. Zonder jouw geduld en liefde was dit proefschrift niet tot stand gekomen. Ik ben ontzettend trots dat jij mijn vrouw bent en dat we in blijde verwachting zijn. Met jou is het leven gewoon heel erg leuk! 


\section{Publications}

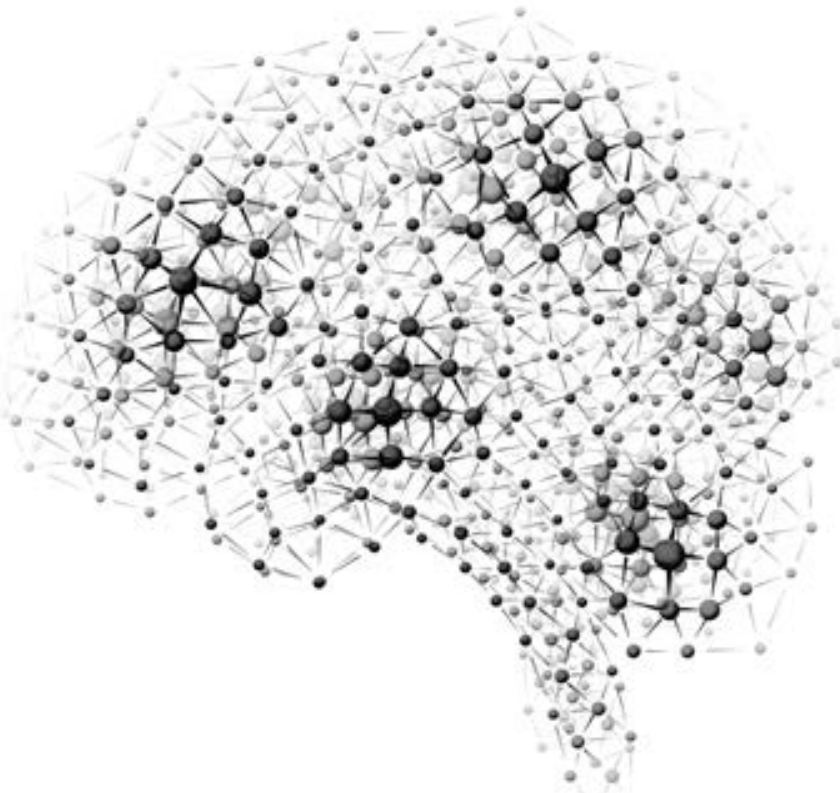




\section{THIS THESIS}

Jellema RK, Lima Passos V, Ophelders DR, Wolfs TG, Zwanenburg A, De Munter S, Nikiforou M, Collins JJ, Kuypers E, Bos GM, Steinbusch HW, Vanderlocht J, Andriessen P, Germeraad WT, Kramer BW: Systemic G-CSF attenuates cerebral inflammation and hypomyelination but does not reduce seizure burden in preterm sheep exposed to global hypoxia-ischemia. Exp Neurol 2013, 250C:293-303.

Jellema RK, Wolfs TG, Lima Passos V, Zwanenburg A, Ophelders DR, Kuypers E, Hopman AH, Dudink J, Steinbusch HW, Andriessen P, Germeraad WT, Vanderlocht J, Kramer BW: Mesenchymal stem cells induce T-cell tolerance and protect the preterm brain after global hypoxia-ischemia. PLoS One 2013, 8:e73031.

Jellema RK, Lima Passos V, Zwanenburg A, Ophelders DR, De Munter S, Vanderlocht J, Germeraad WT, Kuypers E, Collins JJ, Cleutjens JP, Jennekens W, Gavilanes AW, Seehase M, Vles HJ, Steinbusch H, Andriessen P, Wolfs TG, Kramer BW: Cerebral inflammation and mobilization of the peripheral immune system following global hypoxia-ischemia in preterm sheep. J Neuroinflammation 2013, 10:13.

*Zwanenburg A, *Jellema RK, Jennekens W, Ophelders D, Vullings R, van Hunnik A, van Pul C, Bennet L, Delhaas T, Kramer BW, Andriessen P: Heart rate-mediated blood pressure control in preterm fetal sheep under normal and hypoxic-ischemic conditions. Pediatr Res 2013, 73:420-426. *both authors contributed equally

\section{NOT INCLUDED IN THIS THESIS}

\section{REGENERATIVE MEDICINE}

Gortner L, Felderhoff-Muser U, Monz D, Bieback K, Kluter H, Jellema RK, Kramer BW, Keller M, Reiss I, Horn PA, Giebel B: Regenerative therapies in neonatology: clinical perspectives. Klin Paed 2012, 224:233-240.

\section{CHORIOAMNIONITIS STUDIES}

*Kuypers E, *Jellema RK, Ophelders DR, Dudink J, Nikiforou M, Wolfs TG, Nitsos I, Pillow JJ, Polglase GR, Kemp MW, Saito M, Newnham JP, Jobe AH, Kallapur SG, Kramer BW: Effects of intra-amniotic lipopolysaccharide and maternal betamethasone on brain inflammation in fetal sheep. PLoS ONE 2013, 8:e81644. *both authors contributed equally

*Gantert M, *Jellema RK, Heineman H, Gantert J, Collins JJ, Seehase M, Lambermont VA, Keck A, Garnier Y, Zimmermann L, Kadyrov M, Gavilanes AW, Kramer BW: 
Lipopolysaccharide-induced chorioamnionitis is confined to one amniotic compartment in twin pregnant sheep. Neonatology 2012, 102:81-88. *both authors contributed equally

Wolfs TG, Jellema RK, Turrisi G, Becucci E, Buonocore G, Kramer BW: Inflammationinduced immune suppression of the fetus: a potential link between chorioamnionitis and postnatal early onset sepsis. J Matern Fetal Neonatal Med 2012, 25 Suppl 1:8-11.

Kuypers E, Collins JJ, Jellema RK, Wolfs TG, Kemp MW, Nitsos I, Pillow JJ, Polglase GR, Newnham JP, Germeraad WT, Kallapur SG, Jobe AH, Kramer BW: Ovine fetal thymus response to lipopolysaccharide-induced chorioamnionitis and antenatal corticosteroids. PLoS ONE 2012, 7:e38257.

Kuypers E, Ophelders D, Jellema RK, Kunzmann S, Gavilanes AW, Kramer BW: White matter injury following fetal inflammatory response syndrome induced by chorioamnionitis and fetal sepsis: lessons from experimental ovine models. Early Hum Dev 2012, 88:931-936.

Kuypers E, Wolfs TG, Collins JJ, Jellema RK, Newnham JP, Kemp MW, Kallapur SG, Jobe $\mathrm{AH}$, Kramer BW: Intraamniotic lipopolysaccharide exposure changes cell populations and structure of the ovine fetal thymus. Reprod Sci 2013, 20:946-956.

Gantert M, Kreczmanski P, Kuypers E, Jellema RK, Strackx E, Bastian N, Gavilanes AW, Zimmermann LJ, Garnier Y, Schmitz C, Kramer BW: Effects of in utero endotoxemia on the ovine fetal brain: a model for schizophrenia? Front Biosci 2012, 4:2845-2853.

\section{PRETERM GUT STUDIES}

Reisinger KW, Elst M, Derikx JP, Nikkels PG, de Vries B, Adriaanse MP, Jellema RK, Kramer BW, Wolfs TG: Intestinal fatty acid binding protein (I-FABP): a possible marker for gut maturation. Pediatr Res 2014.

\section{ASPHYXIA AND RESUSCITATION STUDIES}

Seehase M, Houthuizen P, Jellema RK, Collins JJ, Bekers O, Breuer J, Kramer BW: Propofol administration to the fetal-maternal unit reduces cardiac injury in latepreterm lambs subjected to severe prenatal asphyxia and cardiac arrest. Pediatr Res 2013, 73:427-434. 
Smit AL, Seehase M, Stokroos RJ, Jellema RK, Felipe L, Chenault MN, Anteunis LJ, Kremer B, Kramer BW: Functional impairment of the auditory pathway after perinatal asphyxia and the short-term effect of perinatal propofol anesthesia in lambs. Pediatr Res 2013, 74:34-38.

\section{SURFACTANT AND VENTILATION STUDIES}

Seehase M, Collins JJ, Kuypers E, Jellema RK, Ophelders DR, Ospina OL, Perez-Gil J, Bianco F, Garzia R, Razzetti R, Kramer BW: New surfactant with SP-B and C analogs gives survival benefit after inactivation in preterm lambs. PLoS ONE 2012, 7:e47631.

\section{ARTIFICAL PLACENTA STUDIES}

Schoberer M, Arens J, Erben A, Ophelders D, Jellema RK, Kramer BW, Bruse JL, Brouwer $P$, Schmitz-Rode T, Steinseifer U, Orlikowsky T: Miniaturization: the clue to clinical application of the artificial placenta. Artif Organs 2014, 38:208-214.

Schoberer M, Arens J, Lohr A, Seehase M, Jellema RK, Collins JJ, Kramer BW, SchmitzRode T, Steinseifer U, Orlikowsky T: Fifty years of work on the artificial placenta: milestones in the history of extracorporeal support of the premature newborn. Artif Organs 2012, 36:512-516.

Arens J, Schoberer M, Lohr A, Orlikowsky T, Seehase M, Jellema RK, Collins JJ, Kramer BW, Schmitz-Rode T, Steinseifer U: NeonatOx: a pumpless extracorporeal lung support for premature neonates. Artif Organs 2011, 35:997-1001.

\section{OTHERS}

Jellema RK, Bomans P, Deckers N, Ungethum L, Reutelingsperger CP, Hofstra L, Frederik PM: Transfection efficiency of lipoplexes for site-directed delivery. J Liposome Res 2010, 20:258-267.

*Flinsenberg TWH, *Jellema RK, Engelberts AC, Rosias PPR, Heynens JH: Antibiotische profylaxe bij kinderen na een doorgemaakte urineweginfectie: zin of onzin? Tijdschr Kindergen 2010, 78:143-149. *both authors contributed equally

Voets IK, de Keizer A, Frederik PM, Jellema RK, Cohen Stuart MA: Environment-sensitive stabilisation of silver nanoparticles in aqueous solutions. J Colloid Interface Sci 2009, 339:317-324. 


\section{Curriculum vitae}

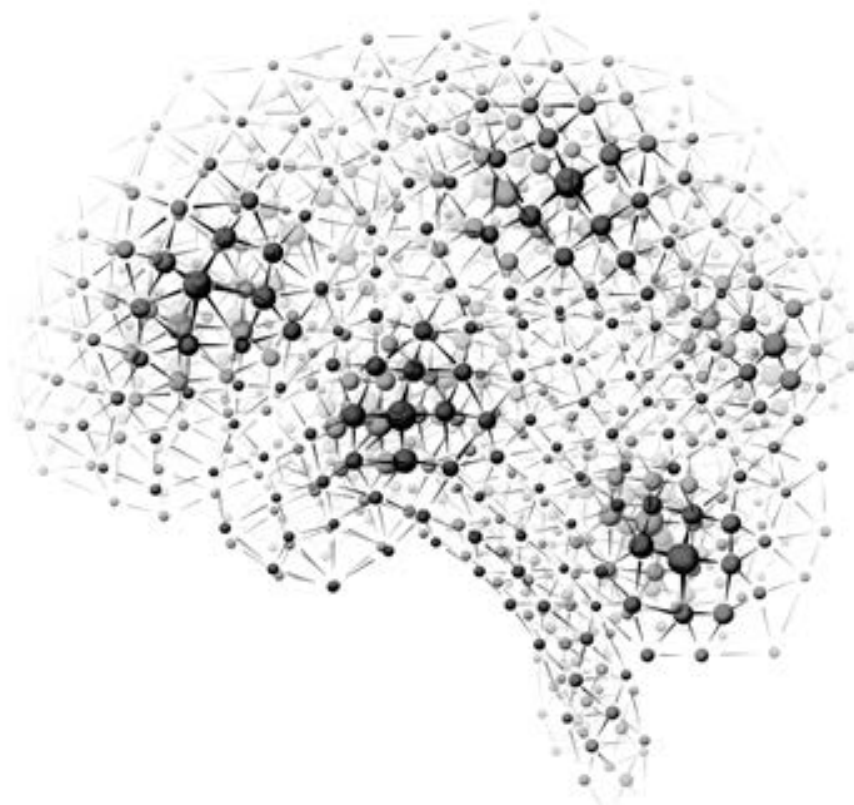


Reint Jellema werd op 4 mei 1981 geboren in Boornbergum (Friesland). Hij behaalde zijn Gymnasiumdiploma in 1999 aan het Drachtster Lyceum te Drachten. In hetzelfde jaar verhuisde hij naar Maastricht om Bewegingswetenschappen te studeren aan de Universiteit Maastricht, waar hij afstudeerde in 2005. Hij begon met de studie Geneeskunde in 2002 aan de Universiteit Maastricht. Hij behaalde zijn artsdiploma in 2008 en begon te werken als arts-assistent Kindergeneeskunde in het Orbis Medisch Centrum te Sittard. In 2009 begon hij zijn promotietraject aan de School for Mental Health and Neuroscience op de afdeling Kindergeneeskunde van de Universiteit Maastricht onder de supervisie van professor Boris Kramer en professor Harry Steinbusch. De resultaten van zijn onderzoek staan in dit proefschrift beschreven. In 2013 hervatte hij zijn klinische carrière als arts-assistent Kindergeneeskunde in het Máxima Medisch Centrum te Veldhoven. Vanaf 2014 is hij begonnen met de opleiding tot kinderarts in het Maastricht Universitair Medisch Centrum. Reint is getrouwd met Stephanie Knippenberg. Zij wonen samen in Maastricht.

Reint Jellema was born on May the 4th, 1981 in Boornbergum (Friesland, the Netherlands). In 1999, he graduated secondary school (Gymnasium) at the Drachtster Lyceum in Drachten. After that he moved to Maastricht to study Movement Sciences at Maastricht University (the Netherlands), where he graduated in 2005. In 2002 he started studying Medicine at Maastricht University (the Netherlands). He got his medical degree in 2008 and initiated his pediatric residency at Orbis Medical Centre in Sitard (the Netherlands). In 2009 he started his PhD-project at the School for Mental Health and Neuroscience and the department of Pediatrics under the supervision of Professor Boris Kramer and Professor Harry Steinbusch at Maastricht University (the Netherlands). The results of his research are presented in this thesis. In 2013 he resumed his clinical carreer as a resident in pediatrics at the Máxima Medical Center in Veldhoven (the Netherlands). From 2014 on he initiated his training to become a pediatrician at Maastricht Uinversity Medical Center (the Netherlands). Reint is married to Stephanie Knippenberg. They live together in Maastricht. 

